UNIVERSIDADE DE SÃO PAULO

FACULDADE DE ECONOMIA, ADMINISTRAÇÃO E CONTABILIDADE

DEPARTAMENTO DE ADMINISTRAÇÃO

PROGRAMA DE PÓS-GRADUAÇÃO EM ADMINISTRAÇÃO

GESTÃo ESTRATÉGICA dE PESSOAS E

CAPACIDADE DE INOVAÇÃO NO SETOR INDUSTRIAL

Alessandra Quishida

Orientador: Prof. Dr. Lindolfo Galvão de Albuquerque

SÃO PAULO 
Prof. Dr. Marco Antonio Zago Reitor da Universidade de São Paulo

Prof. Dr. Adalberto Américo Fischmann

Diretor da Faculdade de Economia, Administração e Contabilidade

Prof. Dr. Roberto Sbragia

Chefe do Departamento de Administração

Prof. Dr. Moacir de Miranda Oliveira Junior

Coordenador do Programa de Pós-Graduação em Administração 
ALESSANDRA QUISHIDA

\section{GESTÃO ESTRATÉGICA DE PESSOAS E CAPACIDADE DE INOVAÇÃO NO SETOR INDUSTRIAL}

Tese apresentada ao Programa de PósGraduação em Administração do Departamento de Administração da Faculdade de Economia, Administração e

Contabilidade da Universidade de São Paulo, como requisito parcial para obtenção do título de Doutora em Ciências.

Orientador: Prof. Dr. Lindolfo Galvão de Albuquerque

Versão Corrigida

São Paulo 


\section{FICHA CATALOGRÁFICA}

Elaborada pela Seção de Processamento Técnico do SBD/FEA/USP

Quishida, Alessandra

Gestão estratégica de pessoas e capacidade de inovação no setor industrial / Alessandra Quishida. -- São Paulo, 2015.

$171 \mathrm{p}$.

Tese (Doutorado) - Universidade de São Paulo, 2015.

Orientador: Lindolfo Galvão de Albuquerque.

1. Administração estratégica 2. Gestão estratégica de pessoas

3. Gestão de pessoas para inovação 4. Setor industrial I. Universidade de São Paulo. Faculdade de Economia, Administração e Contabilidade.

II. Título.

CDD -658.4012 
Dedico esta tese à minha mãe, Ruth Heiko Nagao, e ao meu pai, Roberto Toquihico Quishida: por terem se sacrificado e tornado possível meu sonho de estudar. 


\section{AGRADECIMENTOS}

Foram muitos os que contribuíram, cada um à sua maneira, para a realização desta tese. Mencionarei alguns, sem a pretensão de incluir todos os que me acompanharam nos últimos quatro anos, dos quais certamente sentirei saudades.

Primeiramente agradeço ao prof. Dr. Lindolfo Galvão de Albuquerque pelo importante papel que tem desempenhado em meu processo de desenvolvimento e pela orientação conduzida de maneira comprometida, assertiva e serena. Foi uma honra e um privilégio realizar minha tese de doutorado sob sua orientação.

Agradeço especialmente ao Prof. Dr. Adalberto Américo Fischmann e à prof. ${ }^{a}$ Dr. ${ }^{a}$ Liliana Vasconcellos Guedes pelo acolhimento e por terem cuidadosamente apontado oportunidades de melhoria no exame de qualificação.

Ao Prof. Dr. Roberto Sbragia, agradeço pelas contribuições precisas e valiosas, desde que apresentei meu pré-projeto de tese na disciplina Seminários de Elaboração de Estudos e Pesquisa em Administração.

Agradeço ao Grupo de Pesquisas em Gestão Estratégica de Pessoas da FEA/USP, onde encontrei um ambiente propício para apresentar e discutir o embrião desta tese. Agradeço principalmente ao Prof. Dr. Lindolfo Galvão da Albuquerque pela oportunidade de ingressar no Grupo em 2006 e por ter apostado em mim desde então. Agradeço também à prof. ${ }^{a}$ Dr. $^{a}$ Nildes Raimunda Pitombo Leite pelo constante estímulo e pelas recomendações sensatas; à prof. ${ }^{a}$ Dr, ${ }^{a}$ Ana Carolina de Aguiar Rodrigues e à prof. ${ }^{a}$ Dr. ${ }^{a}$ Eliane Maria Giavina Bianchi pelas dicas e sugestões de melhoria.

Agradeço ao prof. Dr. Martinho Isnard Ribeiro, que se responsabilizou por mim quando do ingresso no PPGA. Ao Prof. Dr. Isak Kruglianskas agradeço por ter me apresentado aos desafios práticos em gestão de pesquisa, desenvolvimento e inovação e ao Prof. Dr. André Luiz Fischer, agradeço pelas discussões estimulantes na disciplina de Tópicos Avançados em Gestão de Recursos Humanos. 
Aos colegas: Adalton Masalu Ozaki, Ana Maria Crepaldi, Angeli Kishore, Claudia Pavani, João Antônio Gomes Pereira, Georgia Tiepolo Smith Rogel, José Renato Kitahara, Luiz Antonio Bloem da Silveira Junior, Rosária Macri Segger Russo e Sonia Rosa Arbues Decoster, com quem pude contar nos momentos críticos.

Agradeço aos profissionais participantes da pesquisa, sem a colaboração dos quais esta tese não teria sido possível. Quanto às instituições que a apoiaram a pesquisa, alguns nomes merecem ser destacados: Sonia Regina Hierro Parolin, da Federação da Indústria do Estado do Paraná - FIEP; Rafael Pedro Pellicciotta e Ricardo Magnani, da Associação Nacional de Pesquisa e Desenvolvimento das Empresas Inovadoras - ANPEI; Daniel Dias, da Agência USP de Inovação; Iomar Cunha, Daniele dos Santos Colombari e Juciane Silva da Motta, da Federação da Indústria do Estado do Espírito Santo - FINDES.

Meus sinceros agradecimentos ao colega Marcelo Henrique de Araujo pelo apoio estatístico, ao Dr. Klaus Augusto Jenger pelos cuidados e à Cristiane Campos Costa Quishida pelas recomendações.

Agradeço ao CNPq por ter apoiado esta tese; ao SPG, PPGA e biblioteca da FEA/USP pela assistência e condições favoráveis de pesquisa.

Aos queridos Ruth Heiko Nagao, Carolina Quishida Salgado, André Luis Quishida, Roberto Toquihico Quishida - muito obrigada pela paciência e por terem me poupado, sobretudo na fase final de redação da tese.

Por fim, agradeço a Deus por ter iluminado meu caminho. 
viii

"A mente que se abre a uma nova ideia jamais voltará ao seu tamanho original."

Albert Einstein 


\section{RESUMO}

Este estudo versa sobre contribuições de fatores de estímulo para a capacidade de inovação e teve como problema de pesquisa "em que medida a gestão estratégica de pessoas pode contribuir para a capacidade de inovação no setor industrial?" Foram propostos três objetivos de investigação: identificar antecedentes da capacidade de inovação sob a perspectiva da gestão estratégica de pessoas; identificar indicadores de capacidade de inovação; e analisar as contribuições da gestão estratégica de pessoas para a capacidade de inovação. Foi realizada pesquisa bibliográfica nas literaturas de gestão estratégica de pessoas e gestão da inovação, por meio da qual foram obtidos sete antecedentes de capacidade de inovação, que consistem em características organizacionais. Quatro características foram selecionadas pela aderência às atividades de gestão estratégica de pessoas: filosofia, valores e normas; foco estratégico em inovação; liderança e gestão; e políticas e práticas de gestão de pessoas. Foi proposto um modelo conceitual inédito, tanto pelo design metodológico, quanto pela abrangência. Para investigar a relação de associação entre gestão estratégica de pessoas e capacidade de inovação foram utilizadas três variáveis intervenientes identificadas na literatura: porte da empresa, receita operacional bruta e tempo de operação no Brasil. Foi realizada uma pesquisa empírica descritiva, quantitativa, sob o processo dedutivo. A população consistiu em profissionais responsáveis pela gestão de projetos de pesquisa, desenvolvimento e inovação em organizações industriais de empresas com operações no Brasil. Foram feitos 1.034 contatos com profissionais com as características da população e obtidas 48 respostas completas na survey, sendo 39 válidas. Foi confirmada a hipótese geral do estudo, que gestão estratégica de pessoas está associada com capacidade de inovação. As características de gestão estratégica de pessoas que estiveram moderadamente ou altamente correlacionadas com os indicadores de capacidade de inovação foram: foco estratégico em inovação; liderança e gestão; e políticas e práticas de gestão de pessoas. A única característica que esteve pouco associada com os indicadores de capacidade de inovação sob a perspectiva dos participantes foi filosofia, valores e normas. Foram feitas sugestões de continuidade dessa pesquisa e de novos estudos relacionados ao tema.

Palavras-chave: gestão estratégica de pessoas; gestão de pessoas para inovação; administração estratégica. 


\begin{abstract}
This study focuses on stimulus factors' contributions for innovation management. Its research problem was "to what extent strategic human resource management can contribute to innovation capacity in the industrial sector?" The three objectives of this study were: identifying innovation capacity antecedents from the perspective of strategic human resource management; identifying innovation capacity indicators; and analyzing the contributions of strategic human resource management for innovation capacity. In order to identify innovation capacity antecedents, a bibliographical research in strategic human resources literature and in innovation management literature had been carried out. These antecedents consisted of seven organizational characteristics, four of which were chosen for being related to strategic human resource management: philosophy, values and norms; strategic innovative focus; leadership and management; and human resources policies and practices. An unprecedented conceptual model was developed in order to test the relationship between the independent and dependent variables: strategic human resource management and innovation capacity. In addition, three intervening variables were selected from the literature: organizational size, gross operating income and number of years operating in Brazil. An empirical, descriptive and quantitative research was carried out by means of deductive reasoning. The population of the study consisted of professionals responsible for research, development and innovation in industrial organizations operating in Brazil. From 1.034 professionals responsible for research, development and innovation were contacted, 48 of them participated in the survey and 39 provided complete answers. The general hypothesis of the study - that strategic human resource management is associated with innovation capacity - was confirmed. The strategic resource management characteristics that were moderately or highly correlated with innovation capacity were: strategic innovative focus; leadership and management; and human resources policies and practice. Philosophy, values and norms was the only characteristic that presented low correlation. Continuity of this research and new research topics were suggested.
\end{abstract}

Key words: strategic human resource management; people management for innovation; strategic management. 
1 PROBLEMA DE PESQUISA _ 9

1.1 Introdução _ 9

1.2 Definição da Situação-Problema _ 12

1.3 Objetivos e Justificativa _ 15

1.4 Pressupostos, Abrangência e Organização do Estudo__ 20

2 FUNDAMENTAÇÃO TEÓRICA _ 21

2.1 Capacidade Organizacional ___ 21

2.2 Gestão Estratégica de Pessoas _ 26

2.2.1 Gestão Estratégica de Pessoas no Contexto da Inovação ___ 33

2.3 Gestão da Inovação Organizacional _ـ 37

2.3.1 Capacidade de Inovação____ 43

2.3.1.1 Antecedentes de Capacidade de Inovação sob a Perspectiva da Gestão

Estratégica de Pessoas ___ 44

2.4 Consolidação da Fundamentação Teórica __ 54

2.4.1.1 Indicadores de Capacidade de Inovação ___ 56

3 METODOLOGIA DA PESQUISA__ 59

3.1 Natureza e Método _ 59

3.2 Modelo Conceitual e Variáveis___ 62

3.3 População e Amostra —

3.4 Hipóteses _ 71

3.5 Procedimentos _ 72

3.5.1 Delineamento da Pesquisa___ 72

3.5.2 Coleta de Dados ___ 76

3.6 Plano de Análise _ 82

3.7 Síntese e Considerações __ 84

4 APRESENTAÇÃO DOS DADOS E DISCUSSÃO DOS RESULTADOS _ 89

4.1 Tratamento dos Dados _ 89

4.2 Caracterização da Amostra _ 91

4.2.1 Caracterização das Empresas_____ 92

4.2.2 Caracterização dos Respondentes ___ _ 96

4.3 Análise Descritiva das Variáveis _ 100

4.3.1 Análise da Variável Independente Gestão Estratégica de Pessoas ___ 100

4.3.2 Análise da Variável Dependente Capacidade de Inovação ___ 109

4.3.3 Análise das Variáveis Intervenientes _________ 112 
4.4 Análise da Relação entre Gestão Estratégica de Pessoas e Capacidade de Inovação

4.4.1 Análise do Papel das Variáveis Intervenientes na Relação entre Gestão Estratégica de Pessoas e Capacidade de Inovação

4.4.1.1 Análise da Relação entre Gestão Estratégica de Pessoas e Capacidade de Inovação por Porte das Empresas Industriais

4.4.1.2 Análise da Relação entre Gestão Estratégica de Pessoas e Capacidade de Inovação por Receita Operacional Bruta das Empresas Industriais

4.4.2 Análise da Relação entre Gestão Estratégica de Pessoas e Capacidade de Inovação sob a Perspectiva do Tempo de Operação no Brasil das Empresas Industriais 129

4.5 Síntese Analítica 135

5 CONSIDERAÇÕES FINAIS 138

5.1 Síntese do Estudo 138

5.2 Contribuições do Estudo 140

5.3 Limitações da Pesquisa 141

5.4 Sugestões de Continuidade da Pesquisa 143

5.5 Sugestões de Novos Estudos em Temas Correlatos 146 REFERÊNCIAS 148

APÊEDICES 160

Apêndice 1 - Modelo de e-mail convite para participação na pesquisa 160

Apêndice 2 - Questionário 161

Apêndice 3 - Mapa das Variáveis 168

Apêndice 4 - Testes de Normalidade 171

Apêndice 5 - Matrizes de Correlação Adicionais 175

ANEXOS 179

Anexo 1 - Produto Interno Bruto e Participação das Grandes Regiões e Unidades da Federação 179

Anexo 2 - Critério para Classificação das Empresas por Porte, com Base na Receita Operacional Bruta 180

Anexo 3 - Caracterização de Empresas Industriais dos Estados do Paraná e Espírito Santo 181 


\section{LISTA DE ABREVIAÇÕES}

ANPEI - Associação Nacional de Pesquisa e Desenvolvimento das Empresas Inovadoras

CAPES - Coordenação de Aperfeiçoamento de Pessoal de Nível Superior

EnANPAD - Encontro da Associação Nacional de Pós-Graduação e Pesquisa em Administração

FEA/USP - Faculdade de Economia e Administração da Universidade de São Paulo

FEI - Foco estratégico em inovação

FIEP - Federação da Indústria do Estado do Paraná

FIESP - Federação da Indústria do Estado de São Paulo

FINDES - Federação da Indústria do Estado do Espírito Santo

FVN - Filosofia, valores e normas

GEP - Gestão Estratégica de Pessoas

LG - Liderança e gestão

OECD - Organisation for Economic Co-operation and Development

PIB - Produto Interno Bruto

PINTEC - Pesquisa Industrial de Inovação Tecnológica

PPGA FEA/USP - Programa de Pós-Graduação em Administração da Faculdade de Economia, Administração e Contabilidade da Universidade de São Paulo

PPGP - Políticas e práticas de gestão de pessoas

P\&D - Pesquisa e Desenvolvimento

P\&D\&I - Pesquisa e Desenvolvimento e Inovação

RH - Recursos Humanos

SSCI - Social Sciences Citation Index

SEMEAD - Seminários em Administração da FEA/USP

VBR - Visão da Firma Baseada em Recursos 


\section{LISTA DE QUADROS}

Quadro 1 - Configurações de estratégias orientadas para capacidades ................. 26

Quadro 2 - Níveis de contribuição da gestão de pessoas para inovação .............. 34

Quadro 3 - Periódicos pesquisados ............................................................... 36

Quadro 4 - Características da inovação organizacional ...................................... 39

Quadro 5 - Fatores e subfatores que influenciam a habilidade de gerenciar a inovação ................................................................................ 42

Quadro 6 - Fatores de estímulo à inovação e itens ............................................... 48

Quadro 7 - $\quad$ Dimensões da capacidade de inovação ............................................... 57

Quadro 8 - Escolhas metodológicas sob o enfoque quantitativo .......................... 61

Quadro 9 - Indicadores da variável independente gestão estratégica de pessoas . 66

Quadro 10 - Fontes de indicadores de gestão estratégica de pessoas ...................... 68

Quadro 11 - Indicadores da variável dependente capacidade de inovação ........... 69

Quadro 12 - Indicadores das variáveis intervenientes ........................................... 69

Quadro 13 - Breve caracterização das instituições parceiras da pesquisa .............. 78

Quadro 14 - Contatos efetuados por fontes de respondentes ................................. $\quad 80$

Quadro 15 - Síntese da metodologia ................................................................ $\quad 85$

Quadro 16 - Classificação do estudo quanto aos objetivos e formas de Investigação ............................................................................. 86

Quadro 17 - Alinhamento entre objetivo, hipóteses e formas de análise ................ 86

Quadro 18 - Interpretação do coeficiente de alfa de cronbach .............................. $\quad 90$

Quadro 19 - Operacionalização da variável dependente ...................................... 109

Quadro 20 - Categorias das variáveis intervenientes ........................................ 117

Quadro 21 - Faixas de tempo de operação no Brasil .............................................. 118 


\section{LISTA DE TABELAS}

Tabela 1 - Força de associação ...................................................................... 84

Tabela 2 - Resultados do coeficiente de alfa de cronbach ................................. 90

Tabela 3 - $\quad$ Origem do capital ....................................................................... 92

Tabela 4 - $\quad$ Receita operacional bruta (R\$ano) .................................................. 92

Tabela 5 - $\quad$ Porte das empresas ......................................................................... 93

Tabela 6 - $\quad$ Tipo de inovação praticada 2 ....................................................... 94

Tabela 7 - Tipo de inovação praticada 3 ........................................................ 94

Tabela 8 - Inovação organizacional .............................................................. 94

Tabela 9 - $\quad$ Tempo de operação no Brasil (anos completos) ................................ 95

Tabela 10 - Número de funcionários da empresa ................................................ 95

Tabela 11 - Número de funcionários alocados em P\&D\&I (estimativa) ................. 96

Tabela 12 - Número total de graduados, mestres e doutores alocados em P\&D\&I (estimativa) ............................................................................... 96

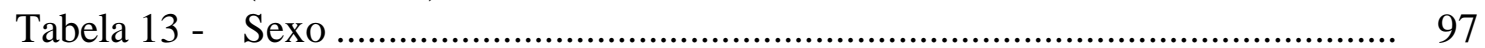

Tabela 14 - Faixa etária (anos completos) .......................................................... 97

Tabela 15 - Formação acadêmica (nível máximo obtido) …................................... 97

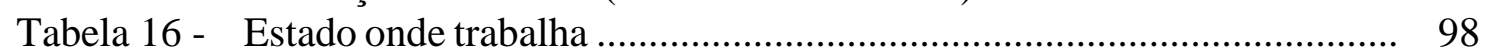

Tabela 17 - Classificação dos projetos que gerencia quanto ao tipo de pesquisa

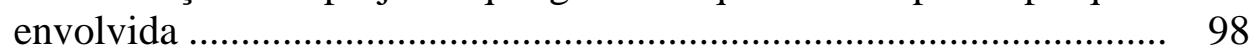

Tabela 18 - Tempo de experiência profissional nesta empresa em P\&D\&I (anos

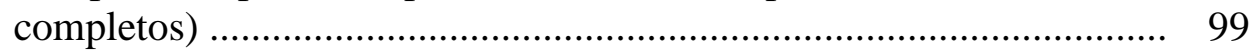

Tabela 19 - Número de funcionários sob sua responsabilidade ............................ 99

Tabela 20 - Operacionalização da variável independente ...................................... 100

Tabela 21 - Índice da soma das variáveis de cada característica de gestão estratégica de pessoas .................................................................... 101

Tabela 22 - Índice da soma das variáveis que representaram características de gestão estratégica de pessoas ........................................................ 102

Tabela 23 - Estatística descritiva dos índices de gestão estratégica de pessoas ...... 102

Tabela 24 - Filosofia, valores e normas (percentual e medidas descritivas) ............. 105

Tabela 25 - Foco estratégico em inovação (percentual e medidas descritivas) ........ 106

Tabela 26 - Liderança e gestão (percentual e medidas descritivas) .......................... 107

Tabela 27 Políticas e práticas de gestão de pessoas (percentual e medidas descritivas) ............................................................................ 108

Tabela 28 - Capacidade de inovação (percentual de e medidas descritivas) .......... 111

Tabela 29 - Porte das empresas ............................................................................ 112

Tabela 30 - Receita operacional bruta das empresas ............................................ 112

Tabela 31 - Tempo de operação das empresas no Brasil ....................................... 113

Tabela 32 - Correlação de Spearman entre "Gestão Estratégicas de Pessoas" e "Capacidade de Inovação" .............................................................. 115

Tabela 33 - Correlação entre "Gestão Estratégica de Pessoas" e "Capacidade de Inovação" (Micro e Pequenas Empresas) .......................................... 120

Tabela 34 - Correlação entre "Gestão Estratégica de Pessoas" e "Capacidade de Inovação" (Médias Empresas) ............................................................ 121

Tabela 35 - Correlação entre "Gestão Estratégica de Pessoas" e "Capacidade de Inovação" (Grandes Empresas) ........................................................... 122

Tabela 36 - Teste de Kruskal-Wallis: "Gestão Estratégica de Pessoas" e "Porte" ... 123 
Tabela 37 - Correlação entre "Gestão Estratégica de Pessoas" e "Capacidade de Inovação" (Receita Operacional Bruta de até R\$ 16 milhões) ...........

Tabela 38 - Correlação entre "Gestão Estratégica de Pessoas" e "Capacidade de Inovação" (Receita Operacional Bruta acima de R\$ 16 milhões e menor ou igual a $\mathrm{R} \$ 300$ milhões)

Tabela 39 - Correlação entre "Gestão Estratégica de Pessoas" e "Capacidade e Inovação" (Receita Operacional Bruta acima de R\$ 300 milhões) ....... 127

Tabela 40 - Teste de Kruskal-Wallis: "Gestão Estratégica de Pessoas" e "Receita Operacional Bruta"

Tabela 41 - Correlação entre "Gestão Estratégica de Pessoas" e "Capacidade de Inovação" (Tempo de Operação no Brasil: inferior a 12 anos)

Tabela 42 - Correlação entre "Gestão Estratégica de Pessoas" e "Capacidade de Inovação" (Tempo de Operação no Brasil: de 12 a 45 anos)

Tabela 43 - Correlação entre "Gestão Estratégica de Pessoas" e "Capacidade de Inovação" (Tempo de Operação no Brasil: de 46 a 70 anos) ................. 132

Tabela 44 - Correlação entre "Gestão Estratégica de Pessoas" e "Capacidade de Inovação" (Tempo de Operação no Brasil: acima de 70 anos) .............. 133

Tabela 45 - Teste de Kruskal-Wallis: "Gestão Estratégica de Pessoas" e "Tempo de Operação no Brasil”" 


\section{LISTA DE GRÁFICOS}

Gráfico 1 - Evolução da quantidade de artigos sobre gestão estratégica de

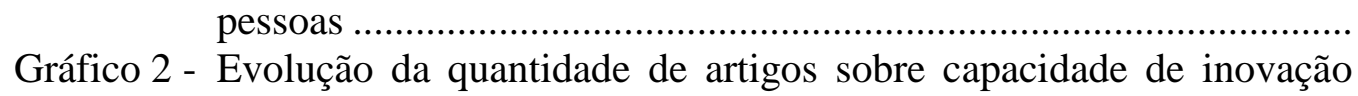
19

Gráfico 3 - Distribuição das respostas ............................................................ 81 


\section{LISTA DE FIGURAS}

Figura 1 - Modelo integrado de inovação e gestão de recursos humanos.................. 35

Figura 2 - Modelo de capacidade de inovação ...................................................... 46

Figura 3 - Modelo integrado de gestão da inovação ............................................... 47

Figura 4 - O processo de construção de teoria ...................................................... 60

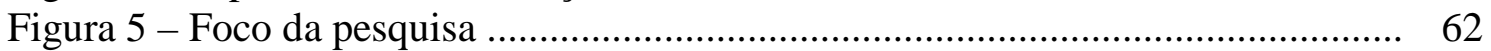

Figura 6 - Modelo conceitual da pesquisa ......................................................... 64

Figura 7 - Escala para observação e mensuração das variáveis independentes ........ 76

Figura 8 - Escala para observação e mensuração das variáveis dependentes ............ 76 


\section{$1 \quad$ PROBLEMA DE PESQUISA}

\subsection{Introdução}

A inovação tem sido considerada uma importante fonte de desenvolvimento dos países e de progresso da sociedade (SCHWAB, 2013). Há indícios de que a inovação esteja se disseminando e se dispersando geograficamente, para além dos países desenvolvidos. Dentre os países apontados com boas perspectivas de melhora no Índice Global de Inovação está o Brasil, que melhorou três pontos nesse índice, alcançando a $61^{a}$ posição em 2014 (DUTTA; LANVIN, 2013; DUTTA; LANVIN; WUNSCH-VINCENT, 2014).

No Brasil, a importância da inovação é evidenciada pelo marco legal que visa, dentre outros aspectos, estabelecer condições favoráveis para o desenvolvimento científico, tecnológico e para o incentivo à inovação na empresa (MCTI, 2013). A Lei da Inovação (Lei $n^{\circ} 10.973$ de 02 de dezembro de 2004) tem estimulado a inovação pela concessão de incentivos, a exemplo de benefícios fiscais para as empresas que investirem em pesquisa e desenvolvimento e em inovação tecnológica.

A inovação é uma importante fonte de vantagem competitiva. Sem foco em inovação, a organização não consegue continuamente criar produtos e serviços necessários para assegurar a prosperidade de seu negócio, sobretudo em ambientes competitivos e de contínua mudança (CROSSAN; APAYDIN, 2010; TIDD; BESSANT; PAVITT, 2008; HART; MILSTEIN, 2003).

No nível da empresa, a inovação pode ser considerada tanto um processo, quanto um resultado (CROSSAN; APAYDIN, 2010). Nesta tese foi considerada a visão processual, segundo a qual a inovação consiste em um meio para o alcance de resultados. Considerouse também que inovação consiste em uma atividade que pode ser gerenciada e que depende da existência de um contexto organizacional que a sustente (TIDD; BESSANT; PAVITT, 2008).

A gestão estratégica é parte importante desse contexto, posto que fornece subsídios para que as inovações de processo e de produto sejam bem-sucedidas. Organizações que almejam competir com base em inovação demandam alta capacidade estratégica, que 
consiste na habilidade de desenvolver e implementar estratégias para o alcance de vantagem competitiva sustentável (ARMSTRONG, 2011).

A gestão estratégica diz respeito à complexidade que deriva de situações ambíguas e não rotineiras, com implicações para toda a organização. Trata-se de um processo amplo e sistemático que não pode ser dissociado da estrutura, do comportamento, da cultura organizacional e que abrange a visão, a formulação, a implementação, o feedback contínuo e a avaliação de resultados visando orientar e empreender ações organizacionais de natureza estratégica, tática e operacional (BARNEY; HESTERLY, 2011; JOHNSON; SCHOLES; WHITTINGTON, 2007; MINTZBERG; AHLSTRAND; LAMPEL, 2007; ALBUQUERQUE, 2002).

Desde a década de 1980 a gestão de pessoas tem constado entre os problemas potencialmente mais frequentes na implementação de estratégias organizacionais (FISCHMANN, 1987) que aparentemente não foram solucionados e se estendem às estratégias de inovação (OKE; WALUMBWA; MYERS, 2012).

Por consolidar uma linguagem comum e integrada da estratégia nas organizações, a abordagem estratégica de gestão de pessoas tem sido chamada a contribuir para a etapa de implementação da estratégia.

Gestão estratégica de pessoas pode ser definida como "[...] um conjunto integrado de práticas, políticas e estratégias por meio das quais as organizações gerenciam seu capital humano, que influenciam e são influenciadas pela estratégia do negócio, pelo contexto organizacional e pelo contexto socioeconômico." (MARTÍN-ALCÁZAR; ROMEROFERNÁNDEZ; SÁNCHEZ-GARDEY, 2007, p. 651).

Descrita como linha de pesquisa que articula gestão estratégica e gestão de pessoas, ela envolve amplas questões de interesse da organização relativas a mudanças na estrutura, cultura, efetividade organizacional e desempenho, adequação de recursos a necessidades futuras, desenvolvimento de capacidades distintivas, gestão do conhecimento e gestão da mudança (ARMSTRONG, 2011).

A gestão estratégica de pessoas pode atuar como veículo de comunicação da estratégia (COUTINHO; KALLÁS, 2005), disseminando-a intensivamente em diferentes áreas funcionais e níveis hierárquicos para alcançar diferentes públicos em diferentes situações, 
de modo que cada indivíduo se sinta instigado a participar e fornecer sua contribuição genuína. A comunicação é essencial para a implementação de estratégias organizacionais no contexto da inovação. Afinal, uma estratégia bem formulada pode não ser devidamente implementada se as pessoas não conseguirem compreender seu papel na execução da estratégia (antes que ela se torne obsoleta).

A importância das pessoas para a inovação tem sido mundialmente enfatizada. Como exemplo, cita-se o Índice Global da Inovação, que dedicou a edição de 2014 exclusivamente à importância das pessoas para inovação. Conforme seus autores (DUTTA; LANVIN; WUNSCH-VINCENT, 2014), o fator humano explora o papel que os indivíduos e equipes desempenham no processo de inovação.

Capturar estatisticamente essa contribuição humana é um enorme desafio. Mais complexo ainda são os desafios enfrentados por aqueles que tentam apropriadamente fomentar o fator humano em inovação [...] Situá-lo no ambiente que irá devidamente fomentar, promover e capacitar o fator humano que está por trás da inovação organizacional e social é uma tarefa complexa, porém crítica. (DUTTA; LANVIN; WUNSCH-VINCENT, 2014, p. v).

Como são diversas as maneiras pelas quais a gestão estratégica de pessoas pode contribuir para o desempenho organizacional, optou-se por estabelecer um recorte. Esta tese se voltou para o setor industrial que, de acordo com pesquisa realizada pela EUROSTAT (2004), reúne a maior proporção de empresas que associam a atividade de inovação ao impacto significativo no negócio.

O dinamismo da indústria tem sido associado ao alto nível de imprevisibilidade e de mudanças incertas. Existe a necessidade de, continuamente, desenvolver capacidades organizacionais difíceis de serem imitadas e que diferenciam a firma de seus concorrentes (ZHANG; GARRETT-JONES; SZETO, 2013; STALK Jr.; EVANS; SHULMAN, 2000).

Esse dinamismo remete à capacidade da empresa de inovar que, para Papaconstantinou (1997) depende de múltiplos fatores, não obstante os esforços para criar novos produtos, melhorar processos produtivos, as habilidades de sua força de trabalho, a habilidade em aprender e o ambiente em que elas operam. Essa capacidade não deve ser tratada isoladamente, pois é composta por processos e práticas da empresa que atuam como um mecanismo-chave de estímulo, mensuração e reforço da inovação (LAWSON; SAMSON, 2001). 
Capacidade de inovação foi definida por Burgelman e Maidique (2004, p. 36) como “[...] um conjunto abrangente de características de uma organização que apoia e facilita suas estratégias de inovação." Sob o entendimento de Neely et al (2001, p. 117): “A capacidade de inovação de uma firma pode ser definida como o potencial daquela firma de gerar resultados em inovação. Para tanto, ela depende de recursos e capacidades que a firma possui, já que elas permitem explorar e desfrutar de oportunidades."

A capacidade de inovação se insere em um processo, que tem fatores antecedentes e consequentes. De acordo com Prajogo e Ahmed (2006, p. 503), os consequentes consistem em medidas de desempenho inovador e os antecedentes consistem em "[...] 'ações ${ }^{1}$ ou fatores de estímulo." Entre os fatores que atuam como estímulos contextuais internos destacam-se: liderança, cultura organizacional corporativa e práticas gerenciais.

Diante das evidências encontradas em estudos internacionais citados anteriormente e de estudos nacionais recentes como o que foi desenvolvido por Valladares, Brito e Vasconcellos (2012), que identificou a gestão de pessoas entre os fatores determinantes da capacidade de inovar, é possível supor que existem fatores de gestão estratégica de pessoas atuando como estímulos à capacidade de inovação.

Optou-se, portanto, por investigar a contribuição dos fatores de estímulo para a capacidade de inovação sob a perspectiva da gestão estratégica de pessoas em empresas do setor industrial.

\subsection{Definição da Situação-Problema}

Partiu-se do entendimento de que um estudo sobre a contribuição de fatores de estímulo para a capacidade de inovação sob a perspectiva da gestão estratégica de pessoas deveria se pautar em uma premissa orientadora. Para Martín-Alcázar, Romero-Fernández e Sánchez-Gardney (2007, p. 644), por exemplo: “A premissa de que existe uma positiva e significativa relação entre gestão do fator humano e desempenho organizacional é um argumento básico para a Gestão Estratégica de Pessoas." A reflexão sobre essa premissa suscita questionamentos como: seria tamanha a intensidade e abrangência da relação

\footnotetext{
${ }^{1}$ Marcação feita pelo autor.
} 
entre gestão do fator humano e desempenho organizacional, a ponto de ser generalizada e tratada como uma premissa? Tal questionamento, assim como os que seguirão ao longo desta tese, serão resgatados e discutidas no capítulo 4 que versa sobre a apresentação dos dados e discussão dos resultados.

A relação entre gestão do fator humano e desempenho organizacional enunciada por Martín-Alcázar, Romero-Fernández e Sánchez-Gardney (2007) tem sido investigada sob o enfoque de contribuições de estratégias, políticas e práticas de recursos humanos para o desempenho organizacional (COOKE; SAINI, 2010; AGARWALA, 2003; SOM, 2003; TANNEMBAUM; DUPUEE-BRUNO, 1994). Contudo, não se sabe sobre a existência de variáveis que possivelmente intermedeiam a referida relação no contexto da inovação, sobretudo no setor industrial.

Para investigar essa relação têm sido utilizadas diversas formas de alinhamento, como o interno e externo (LEPAK; SHAW, 2008). Porém, há de se considerar que o alinhamento pode ser contraproducente quando as organizações precisam lidar com objetivos competitivos conflitantes em ambientes complexos e de contínua mudança (WRIGHT; McMAHAN 1992). Um forte alinhamento de gestão de pessoas e estratégia pode inibir a habilidade da organização de se manter flexível o suficiente para se adaptar às mudanças (ALLEN; WRIGHT, 2007).

Esse parece ser o caso de organizações do setor industrial, que atuam em contextos dinâmicos e incertos. "Mudanças ocorrem a todo o momento: as inovações incrementais de hoje podem ser baseadas em inovações radicais de ontem, e estas podem ocorrer rapidamente.” (DOGSON; GANN; PHILLIPS, 2014, p. 6). Diante disso, questiona-se: seria o alinhamento organizacional suficiente para explicar as contribuições estratégicas de gestão de pessoas no contexto da inovação no setor industrial?

A visão da firma baseada em recursos tem sido utilizada como alternativa para a abordagem de alinhamento (GANNON; DOHERTY; HOPE, 2012), ao preconizar que as pessoas, consideradas recursos humanos da firma, podem ser aqueles que a tornam capaz de alcançar vantagem competitiva sustentável. Entretanto, essa abordagem esbarra no argumento de que a gestão de pessoas em organizações tem alterado seu foco de atenção, “[...] de gestão de recursos humanos para o desenvolvimento e manutenção da efetividade organizacional.” (ROEHLING et al, 2005, p. 208). Este trecho, entre vários outros 
presentes nas literaturas internacional e nacional, acena para mudança de um comportamento passivo dos recursos humanos da firma (no sentido de ator coadjuvante) para um comportamento mais ativo, com liberdade para agir e interferir na gestão do negócio. Seguindo essa linha de raciocínio, argumenta-se que além do alinhamento estratégico seja considerada a integração estratégica.

Ao considerar o alinhamento, no sentido de estar em conformidade, bem como a integração, no sentido de completar, de formar um todo, argumenta-se que as contribuições de gestão estratégica de pessoas podem ser melhor representadas. $\mathrm{O}$ fato de não terem sido encontrados resultados de pesquisas e modelos conceituais que traduzissem a integração estratégica - no sentido que está sendo utilizada neste estudo foi interpretado como lacuna teórica e, ao mesmo tempo, como uma oportunidade de investigação. Sendo assim, questiona-se: como representar a gestão estratégica de pessoas de maneira integrada, no contexto da inovação?

Outra importante lacuna consiste na necessidade apontada por Roehling et al (2005) de estudos que investiguem como a gestão de pessoas afeta o desenvolvimento e manutenção de capacidades de inovação. Após uma década, essa lacuna permanece uma demanda latente em gestão estratégica de pessoas. Provavelmente porque antes de compreender como a gestão de pessoas afeta o desenvolvimento e a manutenção de capacidades de inovação não seria necessário verificar quais são as características organizacionais que, sob a abordagem estratégica de gestão de pessoas, podem contribuir para a capacidade de inovação?

Indícios da contribuição da gestão estratégica de pessoas para as capacidades organizacionais já haviam sido identificados entre as décadas de 1990 e 2000, a exemplo da pesquisa bibliográfica realizada por Saá-Pérez e García-Falcón (2011), que se voltou para a contribuição de políticas e práticas de gestão de pessoas para o desenvolvimento de capacidades organizacionais. Não obstante a importância dessa pesquisa, não se sabe que outras características de gestão estratégica de pessoas contribuem para o desenvolvimento de capacidades organizacionais.

Sob a perspectiva da gestão de pessoas, foram poucos os estudos que investigaram suas possíveis contribuições para a capacidade de inovação. Os poucos estudos existentes se concentraram em políticas e práticas de gestão de pessoas. Por outro lado, sob a 
perspectiva da gestão da inovação, faltam estudos que analisem os antecedentes de forma mais integrada (PRAJOGO; AHMED, 2006).

Diante disso, sob a perspectiva epistemológica do fenômeno da contribuição da gestão estratégica de pessoas para a capacidade de inovação, foi formulado o seguinte problema de pesquisa: Em que medida a gestão estratégica de pessoas pode contribuir para a capacidade de inovação no setor industrial?

Neste estudo, gestão estratégica de pessoas (antecedente) foi representada por um conjunto de características organizacionais que abrangeram: filosofia, valores e normas; foco estratégico em inovação; liderança e gestão; e políticas e práticas de gestão de pessoas. Cada característica foi desdobrada em indicadores para operacionalizar a pesquisa empírica. Capacidade de inovação (consequente) também foi desdobrada em indicadores. Tanto o antecedente quanto o consequente serão explorados nos capítulos seguintes deste trabalho.

\subsection{Objetivos e Justificativa}

A contribuição da gestão estratégica de pessoas para capacidade de inovação é um fenômeno que tem sido pouco investigado e este estudo representa um passo na direção de sua compreensão.

Foram definidos os seguintes objetivos de investigação:

- identificar antecedentes da capacidade de inovação sob a perspectiva da gestão estratégica de pessoas;

- identificar indicadores de capacidade de inovação;

- analisar as contribuições da gestão estratégica de pessoas para a capacidade de inovação.

Para alcançar o primeiro objetivo, partiu-se de estudos anteriores realizados por Albuquerque (1999; 2002) e por Medeiros (2003). Esses autores propuseram amplas características organizacionais que atuam como referências para a gestão, aplicáveis à gestão de pessoas. Para alcançar o segundo objetivo, partiu-se do conceito de capacidade 
de inovação proposto por Burgelman e Maidique (2004). Com base nesses autores foi feita a pesquisa bibliográfica em gestão estratégica de pessoas e em capacidade de inovação. Para alcançar o terceiro objetivo, que dependeu do alcance dos objetivos anteriormente mencionados, foi mensurada a suposta relação de associação entre gestão estratégica de pessoas (antecedente) e capacidade de inovação (consequente) pelos valores dos coeficientes de correlação obtidos.

Este estudo se justifica pela importância nas duas áreas da Administração envolvidas nesta tese: gestão de pessoas e gestão da inovação conforme explicação fornecida nos parágrafos a seguir.

A origem da gestão de pessoas nos registros acadêmicos remete ao final da década de 1970 - início da década de 1980. Embora o termo gestão de recursos humanos tenha se mantido internacionalmente, no Brasil passou-se a utilizar também o termo gestão de pessoas (ALBUQUERQUE, 2002; FISCHER, 2002) - seja como sinônimo de gestão de recursos humanos, seja para ressaltar o caráter da ação (gestão), seja para ressaltar seu foco de atenção (pessoas). Nesta tese optou-se pela utilização do termo gestão de pessoas. Os termos recursos humanos e gestão de recursos humanos foram utilizados no contexto da visão da firma baseada em recursos.

A gestão estratégica de pessoas é uma importante linha de pesquisa que surgiu na década de 1980, cresceu e se consolidou nas décadas seguintes (LENGNICK-HALL et al, 2009). Essa visão é respaldada pela evolução da quantidade de artigos publicados em periódicos acadêmicos internacionais (Gráfico 1).

Para a elaboração do Gráfico 1, recorreu-se à base de dados ISI Web of Knowledge (2015), pelo índice de citações Social Sciences Citation Index (SSCI). Foi utilizado o termo de busca strategic human resource management no período de 1981 a 2014, utilizando a classificação por tópico, para que também fossem levadas em consideração combinações de palavras do termo de busca. As categorias de pesquisa utilizadas foram management e business, e o tipo de documento selecionado foi artigo.

De acordo com esse procedimento foram obtidos 1.059 artigos. Optou-se pela classificação dos artigos por ano de publicação e pela exibição da quantidade máxima de contagem de registros, que equivaleu aos 500 primeiros no período considerado. Os 
registros foram agrupados pela pesquisadora por décadas para facilitar a interpretação dos resultados.

Os resultados exibidos no Gráfico 1 revelaram que, desde a década de 1980, a quantidade de publicações acadêmicas sobre gestão estratégica de pessoas em periódicos internacionais indexados tem crescido substancialmente, passando de 12 na década de 1980 para 139 na década de 1990 e para 484 na década de 2000. É possível que a tendência de aumento da quantidade de artigos se mantenha na década de 2010, posto que em 2014 - antes da metade da década de 2010 - já haviam sido publicados 424 artigos sobre gestão estratégica de pessoas. Caso essa tendência se confirme, ao final dos próximos seis anos a quantidade de publicações ultrapassará a quantidade máxima obtida até então, de 424 artigos.

Gráfico 1 - Evolução da quantidade de artigos de gestão estratégica de pessoas

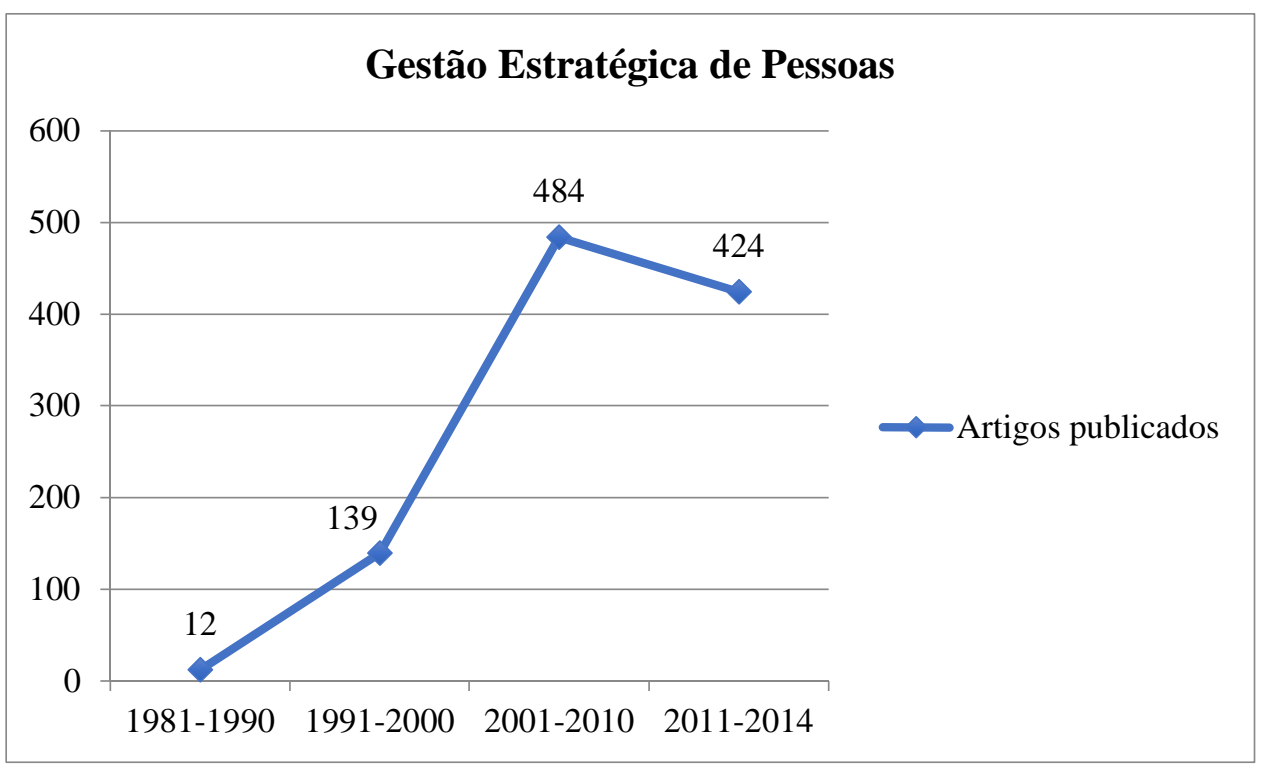

FONTE: ISI WEB OF KNOWLEDGE, 2015.

Os resultados reforçam a crescente importância da linha de pesquisa de gestão estratégica de pessoas no mundo. As sete vertentes temáticas desenvolvidas nessa linha de pesquisa apresentadas na seção 2.2 - Gestão Estratégica de Pessoas - ajudam a compreender os desafios e as oportunidades de investigação futuras.

Foram utilizados os mesmos procedimentos de busca para verificar a evolução da quantidade de artigos publicados sobre capacidade de inovação. Antes de detalhar esses 
procedimentos e apresentar os resultados da busca por artigos publicados nas últimas décadas, faz-se necessário discorrer brevemente sobre a inovação e sobre capacidade.

Inovação é um tema amplo e caracterizado na literatura acadêmica pela interdisciplinaridade. Para autores como Fagerberg (2006) não existe uma única disciplina que lide com todos os aspectos da inovação. Embora inovação seja tão antiga quanto a história da humanidade, no sentido de que existe algo de humano na tendência de pensar sobre novas e melhores maneiras de fazer as coisas e colocá-las em prática, ela surgiu como uma linha de pesquisa na década de 1960 e se proliferou recentemente nas publicações de ciências sociais (FAGERBERG, 2006).

Capacidade em inglês remete a duas palavras: capacity e capability. Em definições constitutivas ou "de dicionário", segundo Kerlinger (1979, p. 46), a primeira pode ser entendida como a habilidade de entender ou fazer algo; e a segunda, como a habilidade ou as qualidades necessárias para fazer algo (OXFORD, 2015). Depreende-se dessas definições que ambas as palavras podem ser utilizadas no sentido de habilidade. Todavia, enquanto capacity é estritamente direcionada a ações (entender ou fazer), capability é mais ampla no sentido de estar direcionada tanto a ações quanto a qualidades. Para poderem ser utilizadas como sinônimos nesta tese, não foram utilizadas as publicações em que capability foi utilizada no sentido de qualidades ou atributos.

Para pesquisar sobre capacidade de inovação na base de dados ISI Web of Knowledge (2015), pelo índice de citações Social Sciences Citation Index (SSCI), foram utilizados os termos de busca innovation capacity e innovation capability. Embora tenham sido considerados artigos publicados desde a década de 1960, quando foram identificados autores seminais em gestão de inovação, apenas os 500 primeiros registros no período considerado - de 1961 a 2014 - foram considerados. O limite máximo de 500 registros, pode, portanto, ser considerado uma limitação do processo de busca pela base de dados utilizada. Acrescenta-se que as categorias de pesquisa utilizadas foram management e business, e o tipo de documento selecionado foi artigo.

De acordo com esse procedimento foram obtidos 5.088 artigos, sendo 1.809 sobre innovation capacity e 3.279 sobre innovation capability. Optou-se pela classificação dos artigos por ano de publicação, posteriormente agrupados pela pesquisadora por décadas. 
Constatou-se que, desde a década de 1960, a quantidade de artigos publicados em periódicos internacionais indexados aumentou nas décadas de 1960 a 2000 com base nos procedimentos de busca utilizados.

Observa-se no Gráfico 2 que, nas décadas de 1970 e 1980, capacidade de inovação era um assunto pouco estudado, respondendo por 2 e 3 artigos, respectivamente. Na década de 1990, assistiu-se a um substancial aumento na quantidade de publicações, alcançando a marca de 367 . Na década de 2000, confirmou-se a tendência de aumento e assistiu-se a um expressivo aumento que correspondeu a 2.297 artigos publicados. Verificou-se, ainda, que nos quatro primeiros anos da década de 2010 a quantidade de artigos publicada (2.419) já havia superado a marca alcançada na década anterior.

Gráfico 2 - Evolução da quantidade de artigos sobre capacidade de inovação

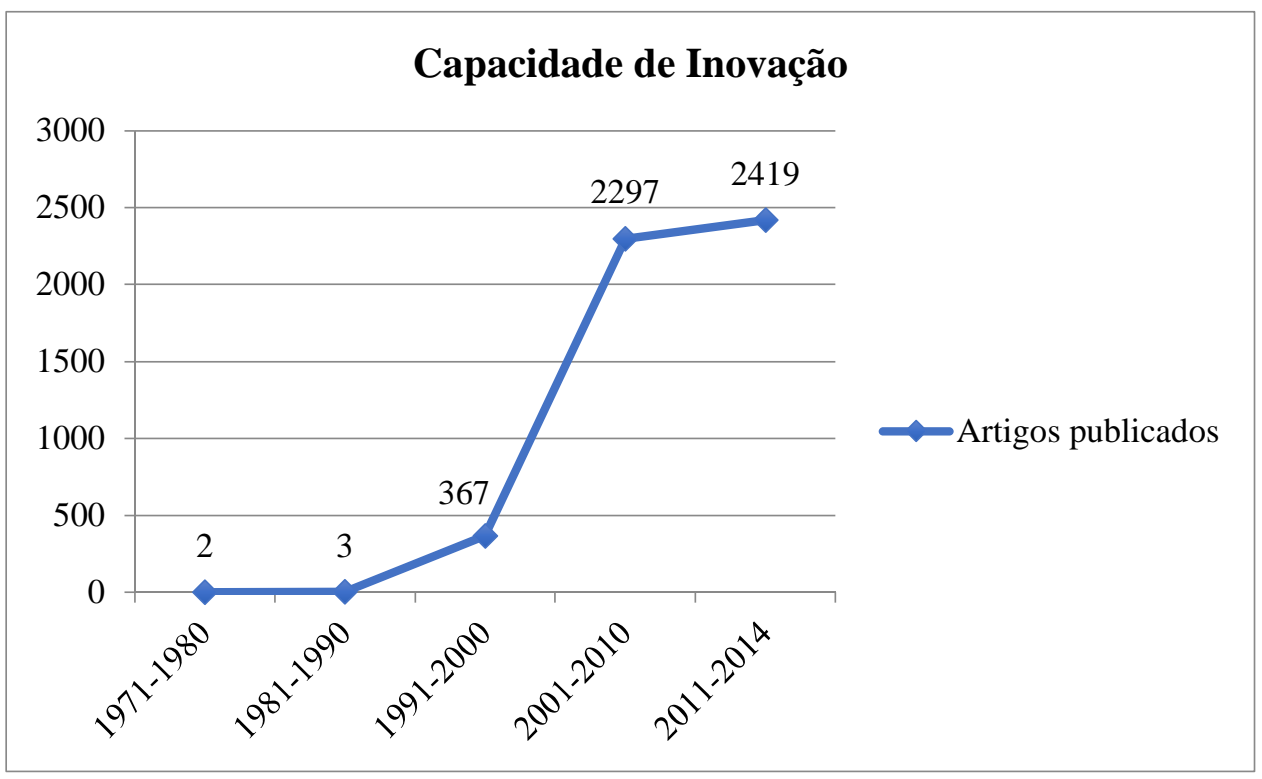

FONTE: ISI WEB OF KNOWLEDGE, 2015.

A análise dos resultados exibidos nos Gráficos 1 e 2 reforçam a relevância e a contemporaneidade dos temas gestão estratégica de pessoas e capacidade de inovação no meio acadêmico internacional. A diferença na quantidade de publicações de capacidade de inovação no período considerado - 5.088 artigos frente aos 1.059 de gestão estratégica de pessoas - pode ser atribuída à maior tradição e permeabilidade do tema nas diferentes áreas da Administração.

Dentre as contribuições deste estudo, destacam-se: a proposição de um modelo conceitual sobre gestão estratégica de pessoas e capacidade de inovação; a criação de um 
instrumento para mensuração das contribuições de gestão estratégica de pessoas para a capacidade de inovação, sob o enfoque da possível relação de associação entre ambos; bem como a proposição de uma agenda para pesquisas futuras envolvendo tanto a continuidade deste estudo, quanto a sugestão de pesquisas correlatas.

\subsection{Pressupostos, Abrangência e Organização do Estudo}

Parte-se dos seguintes pressupostos: inovação faz sentido para as empresas industriais, em maior ou menor intensidade; e gestão estratégica de pessoas pode ser identificada em todas as áreas funcionais das empresas, sejam elas de negócio ou de apoio.

Para definir a abrangência e os limites deste estudo, considerou-se que:

- embora a tecnologia tenha sido apontada como um fator determinante da inovação, nem todas as inovações são baseadas em tecnologia. Neste estudo as inovações foram tratadas de maneira ampla;

- embora tanto a capacidade de inovação quanto a gestão estratégica de pessoas possam ser retratadas sob diferentes níveis de análise, neste estudo focalizou-se apenas o nível organizacional;

- foram consideradas fora do escopo da pesquisa a estratégia organizacional e a estratégia de inovação, bem como seu processo implementação;

- também foram consideradas fora do escopo as medidas de resultados da atividade inovadora, tais como desempenho e resultado em inovação.

Este documento foi organizado em cinco capítulos, incluindo este de apresentação do problema de pesquisa. No segundo capítulo são apresentadas as abordagens, conceitos e vertentes temáticas. No terceiro capítulo é explicada a metodologia utilizada na pesquisa; no quarto capítulo são apresentados e analisados os resultados. No quinto capítulo são apresentadas as considerações finais, sugestões de continuidade da pesquisa e ideias para novas pesquisas. Por fim, são apresentadas as referências, os apêndices e os anexos. 


\section{FUNDAMENTAÇÃO TEÓRICA}

Neste capítulo são apresentadas as abordagens e os conceitos que embasaram esta tese ambos definidos à luz do problema de pesquisa com base em trabalhos seminais, clássicos e recentes ${ }^{2}$. Por fim, é feita a consolidação do conteúdo e feitas considerações que nortearão os capítulos subsequentes.

As publicações utilizadas nesta seção derivaram de um processo de busca nas bases de dados EBSCO (2014) e ISI Web of Knowledge (2014) no período de 2010 a 2014. Como as referências das obras consultadas remeteram a outras mais antigas, porém condizentes com este estudo, não se ateve às publicações recentes.

Para efetuar a busca de artigos foram feitas combinações utilizando principalmente os termos utilizados nas buscas foram: inovati*, factors, determinants, capacity, strategic human resource management, SHRM, HRM. Também foram considerados artigos publicados em anais de congressos como o Academy of Management e de eventos nacionais como o EnANPAD e o SEMEAD.

\subsection{Capacidade Organizacional}

Esta seção tem por objetivo apresentar a diretriz teórica deste estudo - capacidade organizacional - e explicá-la considerando sua diferença e relação termos e abordagens teóricas correlatas.

De acordo com a Visão da Firma Baseada em Recursos (VBR), a organização pode ser considerada um portfólio de recursos que a permite implementar estratégias diferenciadas.

Os recursos da firma incluem todos os ativos, capacidades, processos organizacionais, características organizacionais, informações, conhecimentos, etc. controlados pela firma que a permite conceber e implementar estratégias que melhorem sua eficiência e efetividade. $\mathrm{Na}$ linguagem da análise estratégica tradicional, os recursos são forças que as firmas podem utilizar para conceber e implementar suas estratégias. (BARNEY, 1991, p. 101).

\footnotetext{
${ }^{2}$ Foram consideradas recentes as publicações realizadas nos últimos cinco anos, que corresponderam ao período de 2010 a 2014.
} 
Considera-se a classificação de recursos da firma proposta por Barney (1991): recursos físicos incluem a tecnologia física, equipamentos, fábrica, localização geográfica, acesso a matéria-prima; recursos financeiros incluem todos os tipos de capital que a organização dispõe; recursos humanos incluem a experiência, treinamento, relacionamentos, julgamentos de indivíduos em uma organização; recursos organizacionais incluem a estrutura, sistemas formais e informais de planejamento, controle e coordenação e relações informais.

Recursos também podem ser classificados como tangíveis (podem ser vistos e quantificados) e intangíveis (ativos que normalmente estão profundamente enraizados no histórico da empresa e foram acumulados com o tempo. Por estarem embutidos em padrões exclusivos de rotinas, eles são relativamente difíceis de serem apreendidos e imitados pelos concorrentes).

Para ser estratégico, um recurso precisa atender às seguintes condições: ser valioso, na medida em que permite explorar oportunidades e/ou neutralizar ameaças do ambiente da firma; ser raro entre os concorrentes atuais e potenciais; ser imperfeitamente imitável; e não haver substitutos estratégicos equivalentes. Observadas essas condições, é possível que os recursos humanos contribuam para a implementação de estratégias do negócio e de inovação.

A ideia que a VBR poderia ser utilizada no contexto da gestão de pessoas tem sido defendida desde a década de 1990. Por intermédio das condições de validade, raridade, difícil imitação e não substituição, explica-se como os recursos humanos podem ser utilizados para criar e sustentar vantagem competitiva. Sustenta-se que a gestão de pessoas pode criar valor pelo decréscimo de custos ou pelo aumento de receitas e que recursos humanos com características de difícil imitação também podem ser adquiridos (WRIGHT; McMAHAN, 1992; BARNEY; WRIGHT, 1998).

A origem, evolução e consolidação da VBR podem ser representadas pelos seguintes marcos:

- identificação da importância dos recursos no contexto da firma no final da década de 1950 (PENROSE, 2006); 
- emergência da RBV como teoria a partir da década de 1980; crescimento na década de 1990;

- análise de suas implicações "para outros importantes campos, como gestão de RH” (BARNEY; KETCHEN Jr.; WRIGHT, 2011) na década de 2000;

- maturidade a partir de 2011, ao considerar a interface dessa teoria com temas emergentes a exemplo da sustentabilidade e com o aprofundamento de questões metodológicas (BARNEY; KETCHEN Jr.; WRIGHT, 2011).

Se por um lado, a VBR consiste em uma abordagem teórica condizente com este estudo por se referir ao ambiente organizacional interno, por outro, ela não se aplica por estreitar os limites de atuação da gestão de pessoas (no sentido que pessoas são consideradas recursos da firma). A adoção da VBR como diretriz teórica deste estudo entraria em conflito com sob a abordagem estratégica da gestão de pessoas retratada na seção 1.1 Introdução (página 10). Por esse motivo e pelo conteúdo exposto nas páginas anteriores, optou-se pela utilização de capacidade organizacional como diretriz teórica deste estudo.

De acordo com Ritala, Armila e Blomqvist (2009), a discussão sobre capacidades em nível organizacional tem suas origens na economia evolucionária (NELSON; WINTER, 1982; TEECE; PISANO; SHUEN, 1997) e na teoria da visão da firma baseada em recursos (BARNEY, 1991).

Capacidades se voltam para a análise de aspectos internos das organizações e se referem à habilidade de desenvolver recursos, geralmente de maneira combinada, utilizando processos organizacionais para alcançar um propósito desejado (AMIT; SCHOEMAKER, 1993).

Essas capacidades podem ser definidas como a habilidade da organização de integrar, construir e reconfigurar rotinas ou padrões de atividades adotados pela firma que são incorporados às organizacionais, seja por coordenação e integração, seja por reconfiguração e transformação de recursos (TALLMAN, 2003). O autor acrescenta que:

Capacidades representam maneiras sistemáticas de organizar recursos, sejam eles tangíveis, humanos ou rotinas de pequenos grupos. Tipicamente desenvolvidas na prática, assim como as rotinas, as capacidades são altamente dependentes de processos históricos e são únicas para a firma individualmente. Além de serem consideráveis fontes potenciais de vantagem competitiva, as capacidades são inerentemente dinâmicas, que em sistemas complexos de comportamento apresentam constante variação de aplicação e mudam sempre que novos conceitos organizacionais se apresentam diante da firma. (TALLMAN, 2003, p. 383) 
Observa-se que a palavra recursos foi utilizada para explicar capacidades. Existe uma certa sobreposição entre eles. Recursos e capacidades envolvem relacionamentos interpessoais, confiança, cultura, ambiente favorável entre outros aspectos difíceis de serem replicados, sobretudo em um curto espaço de tempo. Ambos são utilizados por organizações visando o alcance de vantagens competitivas (BARNEY; HESTERLY, 2011).

Recursos consistem em estoques de fatores disponíveis, adquiridos ou controlados pela firma. Eles são convertidos em produtos finais ou serviços utilizando uma ampla gama de outros ativos e mecanismos acessíveis (AMIT; SCHOEMAKER, 1993). Consistem também em ativos tangíveis e intangíveis que a organização detém e podem ser utilizados para criar e implementar estratégias. Capacidades, por sua vez, representam um subconjunto dos recursos e são definidas como os ativos tangíveis e intangíveis que permitem a organização aproveitar por completo outros recursos que ela detém. (BARNEY; HESTERLY, 2011).

Dado o exposto, recupera-se a visão de Tallman (2003), para quem capacidades organizacionais estão atreladas a aspectos comportamentais e culturais, e podem se modificar ao longo do tempo devido ao seu caráter inerentemente dinâmico. Essa visão foi adotada como norteadora do presente estudo.

Nós definimos capacidades dinâmicas como a habilidade da firma de integrar, construir e reconfigurar competências internas e externas para sobreviver em um ambiente de rápidas mudanças. Capacidades dinâmicas, portanto refletem a habilidade da organização de atingir novas e inovadoras formas de vantagem competitiva [...] (TEECE; PISANO; SHUEN, 1997 p. 516).

O caráter dinâmico das capacidades também está atrelado ao momento histórico: “Quando a economia era relativamente estática, a estratégia podia se manter estática [...] Nesse ambiente mais dinâmico, a estratégia tem de se tornar proporcionalmente mais dinâmica." (STALK Jr.; EVANS; SHULMAN, 2000, p. 84). Assim, fatores que tornaram as organizações capazes de competir e serem bem-sucedidas atualmente podem não ser os mesmos requisitados no futuro.

Além dos recursos, há outro termo que tem sido associado às capacidades organizacionais. Tratam-se das competências essenciais, que possuem um enfoque diferente de capacidades organizacionais, embora ambos estejam relacionados. 
Competências essenciais são utilizadas para descrever habilidades organizacionais únicas que podem ser compartilhadas entre as divisões/áreas da empresa para ofertar produtos que gerem vantagem competitiva no mercado (PRAHALAD; HAMEL, 2000). Capacidades, por sua vez, dizem respeito à habilidade do negócio de estabelecer estrutura e processos internos que influenciem seus membros a criar competências específicas e a tornar o negócio capaz de se adaptar às necessidades de mudanças dos clientes e estratégicas (ULRICH; LAKE, 1990).

Capacidades também se diferenciam pela maior perenidade em relação às competências essenciais, conforme o trecho a seguir.

\begin{abstract}
Algumas capacidades podem ser únicas, apesar de não serem diretamente valorizadas pelos clientes. Porém, quando combinadas com outras capacidades e recursos elas se tornam competências da firma - os recursos característicos e processos que distinguem uma firma de seus concorrentes. Portanto, competências essenciais, chave ou distintivas estão atreladas ao mercado - sob a perspectiva dos clientes - não apenas sob a perspectiva interna, dos que trabalham na firma. Diante disso, as competências são vulneráveis às mudanças de mercado [...] Essa é a armadilha das competências, quando uma série de capacidades que se tornaram competências essenciais, quando desenvolvidas sob a perspectiva interna, tornam-se irrelevantes para o mercado. (TALLMAN, 2003, p. 383).
\end{abstract}

No ambiente competitivo atual, visa-se a identificação e o desenvolvimento de capacidades organizacionais difíceis de serem imitadas e que diferenciam a firma de seus concorrentes sob a perspectiva dos clientes, gerando e sustentando vantagens competitivas. Segundo Tallman (2003) existem dois aspectos-chave envolvidos em configurações de estratégias orientadas para capacidades: criação e exploração.

A exploração ou alavancagem de capacidades remete a organizações direcionadas para eficiência e controle de custos. Essas organizações geralmente apresentam forte hierarquia, papeis bem definidos, comunicação formal e orientação para o alcance de objetivos econômicos.

A criação ou construção de capacidades, por outro lado, manifesta-se em contextos menos restritivos e está presente em organizações criativas, orientadas para projetos e se caracterizam pela prevalência de relacionamentos e papeis informais. Caracterizam-se também pela ampla comunicação, orientação para o alcance de múltiplos objetivos e forte pressão para explorar diferentes interesses e capacidades. De acordo com Tallman (2003), a configuração estratégica de criação de capacidades predomina em organizações inovadoras. 
Quadro 1 - Configurações de estratégias orientadas para capacidades

\begin{tabular}{|c|c|}
\hline Exploração de capacidades & Criação de capacidades \\
\hline - Foco em controle de custos & - Mentalidade de projetos \\
\hline - Forte hierarquia & - Relacionamentos e papeis informais \\
\hline - Papeis claramente definidos & - Ampla comunicação \\
\hline - Comunicação formal & - Múltiplos papeis \\
\hline $\begin{array}{l}\text { - Orientação para o alcance de objetivos } \\
\text { econômicos e homogeneidade. }\end{array}$ & $\begin{array}{l}\text { - Orientada para definir e explorar } \\
\text { diferentes interesses e capacidades. }\end{array}$ \\
\hline
\end{tabular}

FONTE: TALLMAN, 2003, p. 391.

Observa-se no Quadro 1 que as configurações de estratégias orientadas para criação e exploração de capacidades abordam questões relativas aos ambientes interno e externo. No que tange ao ambiente externo, elas podem ser associadas às estratégias organizacionais genéricas que visam o alcance de vantagem competitiva sustentável (PORTER, 1989). Nesse contexto a exploração de capacidades pode ser associada à estratégia genérica de baixo custo, enquanto a criação de capacidades pode ser associada à estratégica genérica de diferenciação.

Por integrarem o escopo desta tese, os aspectos internos serão retomados nos capítulos 3, 4 e 5 desta tese - respectivamente: Metodologia da Pesquisa; Apresentação dos Dados e Discussão dos Resultados; e Considerações Finais.

\subsection{Gestão Estratégica de Pessoas}

A origem da gestão estratégica de pessoas remonta à década de 1980, mais especificamente de teorias de ciências comportamentais, capital humano e relações industriais (ARMSTRONG, 2011).

A partir do processo natural de evolução da Administração, a gestão de recursos humanos foi sendo incorporada à literatura de gestão estratégica em países desenvolvidos, tomando como base os estudos sobre planejamento estratégico (ALBUQUERQUE, 1987). 
O debate sobre a importância e necessidade de pensar em recursos humanos em nível estratégico no Brasil foi desenvolvido por Albuquerque (1987) que, em sua tese de livredocência apresentada à FEA/USP em 1987, já caracterizava a gestão de recursos humanos como: “[...] uma função relegada a um segundo plano, e não considerada entre as preocupações estratégicas das empresas.” (ALBUQUERQUE, 1987, p. vi).

Os argumentos em prol da gestão estratégica de pessoas se fortaleceram na década de 1990 sob o discurso de autores como Ulrich (1998), para quem a gestão de pessoas deveria atuar como parceira do negócio. Legge (1995, p. 75) corroborou essa visão ao afirmar que "[...] em teoria, a gestão de recursos humanos é essencialmente uma atribuição de gestão estratégica mais central do que a gestão de pessoal ${ }^{3}$, já que é exercida pelos gestores $[\ldots] "$.

O termo em teoria foi utilizado no parágrafo anterior para se referir a uma retórica incompatível com a prática da gestão de recursos humanos em organizações. Parecia haver um conflito entre a gestão de recursos humanos considerada ideal e real. Na obra que a consagrou como uma das expoentes da visão crítica da gestão de recursos humanos, Legge (1995) dedicou um capítulo inteiro para tratar da: “integração 'estratégica' da gestão de pessoas com as políticas do negócio" (LEGGE, 1995, p. 96).

Em resposta às críticas e questionamentos que marcaram a década de 1990, assistiu-se a uma série de avanços teóricos e empíricos que delinearam a gestão estratégica de pessoas como linha de pesquisa em gestão de pessoas.

A década de 2000 se destacou pela ampliação de pesquisas em assuntos previamente identificados nas décadas anteriores e caracterizou-se pelo nível design metodológico das pesquisas, que segundo autores como Lengnick-Hall et al (2009) passaram a considerar relações de causalidade.

Um argumento que reforça a opção pela palavra pessoas é que “[...] quando se toma o indivíduo como recurso/objeto, a estratégia da empresa será sempre algo exterior a ele. Portanto, será algo que não lhe pertence de maneira genuína e para a qual ele contribuirá a partir de seu papel de objeto e não de sujeito da história." (COUTINHO; KALLÁS, 2005, p. 94).

\footnotetext{
${ }^{3}$ No sentido de departamento pessoal.
} 
Mascarenhas (2008, p. XVI) acrescenta um importante ponto ao afirmar que: “[...] Os debates em torno da gestão estratégica de pessoas refutam a tradicional visão do RH como gestor de funções administrativas para pensar no fator humano como fonte de vantagem competitiva."

Na década de 2000 a gestão estratégica de pessoas já era reconhecida como uma importante linha de pesquisa em gestão de pessoas. Boxall, Purcell e Wright (2007) corroboram esse entendimento ao classificarem-na de acordo com seu nível de agregação: micro, estratégico e internacional.

O nível micro se concentra nos desdobramentos de políticas de gestão de pessoas em processos e práticas. O nível estratégico focaliza as estratégias e políticas de gestão de pessoas adotadas pelas unidades de negócio/organizações e a mensuração de seus efeitos no desempenho organizacional. O nível internacional diz respeito à gestão de pessoas em organizações que possuem operações além das fronteiras nacionais.

Esses três níveis de agregação parecem permear os sete principais temas que, segundo Lengnick-Hall et al (2009), influenciaram substancialmente o desenvolvimento da gestão estratégica de pessoas como linha de pesquisa. Os temas derivaram de uma revisão sistemática da literatura calcada em artigos publicados nas décadas de 1980, 1990 e 2000 (até 2005). Cada tema é listado e explicado a seguir:

1) Perspectiva contingencial e alinhamento - focaliza relacionamentos contingenciais e maneiras de alinhar atividades de gestão de pessoas aos resultados estratégicos desejados; parte-se do entendimento de que determinadas práticas contribuem para o melhor desempenho organizacional desde que combinadas com objetivos específicos, condições e interesses estratégicos.

2) Criação de contribuições estratégicas - focaliza as contribuições do capital humano, as capacidades estratégicas e o desempenho competitivo da organização.

3) Componentes e estrutura do sistema de RH - visa desmembrar o sistema de RH em elementos passíveis de serem examinados de maneira detalhada; esses elementos podem ser combinados gerando configurações únicas, bem como a visualização de atividades de RH a partir de sistemas integrados. 
4) Expansão do escopo do RH estratégico - volta-se para o desenvolvimento de capacidades estratégicas e contribuições competitivas além da unidade de negócio, da firma ou das partes interessadas.

5) Implementação e execução de práticas de RH - versa sobre a habilidade da firma de executar as práticas pretendidas e alcançar resultados estratégicos de RH.

6) Mensuração de resultados em RH - volta-se para a determinação de medidas válidas e representativas das atividades de RH.

7) Questões metodológicas - versa sobre modelos conceituais e pressupostos teóricos em gestão estratégica de pessoas.

Para verificar a distribuição desses temas em publicações contemporâneas, Quishida e Andrade (2014) fizeram uma pesquisa bibliométrica em 114 artigos obtidos em periódicos e anais de eventos de administração geral e de gestão de pessoas. Foram consideradas as publicações realizadas tanto em âmbito nacional quanto internacional, no horizonte temporal de 2001 a 2011.

A produção nacional utilizada foi definida com base em periódicos classificados pelo índice WebQualis da Coordenação de Aperfeiçoamento de Pessoal de Nível Superior de 2011 (CAPES, 2012). A partir dessa classificação, optou-se pelos periódicos que atendessem a dois critérios, simultaneamente: constar entre os estratos A1, A2, B1 e B2 da área que reúne a produção de Administração/Contábeis e Turismo da plataforma WebQualis da CAPES; e apresentar citação do periódico na metodologia de trabalhos de revisão de literatura no Brasil no campo da Administração. Para a produção internacional foi adotado o índice Journal Citation Reports - JCR da ISI Web of Knowledge (JCR, 2012). Optou-se pela seleção dos periódicos com maior fator de impacto.

A pesquisa revelou que criação de contribuições estratégicas foi o tema que se destacou pela maior incidência de artigos. Trata-se do único tema que apresentou publicações em todos os anos, respondendo por mais da metade (52\%) dos 114 artigos analisados no período considerado. Esse resultado ratificou a importância de investigar o que seriam essas contribuições e como seria sua natureza. 


\section{Conceitos e Propriedades de Gestão Estratégica de Pessoas}

Tendo explicado sucintamente sua origem, desenvolvimento e consolidação, a gestão estratégica de pessoas será conceituada e caracterizada à luz do problema de pesquisa.

Partiu-se das visões de gestão de pessoas propostas por Legge (2005) para identificar os conceitos relevantes para este estudo. As visões da gestão de pessoas segundo essa autora são: descritiva comportamental, que tem como objeto de estudo o comportamento humano no trabalho; descritiva funcional, que abrange políticas, processos e práticas; normativa, que visa o alcance de resultados por meio das pessoas; e crítica, que se volta para a exploração da força de trabalho. Para os fins deste estudo foi adotada a visão normativa, frisando que sua predominância não implicou a anulação das demais.

Sob a visão normativa, gestão estratégica de pessoas pode ser conceituada como: “[...] um padrão de atividades planejadas e implementações intencionalmente realizadas de recursos humanos destinados a capacitar uma organização a alcançar seus objetivos." (WRIGHT; McMAHAN, 1992, p. 298).

Outro conceito relevante para este estudo - também sob a visão normativa - é o que trata a gestão estratégica de pessoas como: “[...] uma abordagem para gerenciar pessoas que lida com as maneiras pelas quais os objetivos organizacionais são alcançados por seus recursos humanos, por intermédio de estratégias, políticas e práticas integradas de RH.” (ARMSTRONG, 2011, p. 48).

Esses dois conceitos de gestão estratégica de pessoas foram utilizados nesta tese por considerarem tanto a abordagem de capacidade organizacional (primeiro conceito), quanto a integração de elementos componentes da gestão de RH (segundo conceito).

O que parece diferenciar um conceito do outro é a perspectiva sob a qual se considera a gestão do fator humano. No primeiro conceito, recursos humanos é retratado em nível macro, extensivo a toda a empresa. No segundo conceito esse mesmo termo é utilizado de maneira mais restrita, delineada em função de estratégias, políticas e práticas integradas de RH. Nesse sentido, questiona-se sobre o segundo conceito: seriam estratégias, políticas e práticas integradas de $R H$ suficientes para traduzir a complexidade da gestão estratégica de pessoas em organizações? 
Além de frisar a diferenciação entre os conceitos, faz-se necessário questionar sua aplicação. Quanto ao primeiro conceito, especificamente: até que ponto a gestão estratégica de pessoas, explicada por Wright e McMahan (1992) como um padrão de atividades planejadas e intencionalmente realizadas de gestão de pessoas, se insere em contextos organizacionais dinâmicos como o da inovação? A relevância desse questionamento estimulou a criação uma seção específica da tese, denominada: 2.2.1 Gestão Estratégica de Pessoas no Contexto da Inovação.

Boxall e Purcell (2003) sustentam que a gestão estratégica de pessoas diz respeito a todos os grupos de trabalho, envolve os gestores de diferentes áreas funcionais, incorpora uma série de estilos gerenciais; diz respeito à gestão do trabalho e de pessoas (individual e coletivamente) e se insere no contexto de indústrias e sociedades.

Segundo Armstrong (2011), Boxall e Purcell (2003), a gestão estratégica de pessoas possui dois objetivos centrais. O primeiro objetivo é o alinhamento das estratégias de gestão de pessoas com as estratégias do negócio (alinhamento vertical) e das estratégias de gestão de pessoas entre si (alinhamento interno ou coerência entre estratégias, políticas e práticas de $\mathrm{RH})$. O segundo objetivo consiste no desenvolvimento e implementação de políticas e programas práticos de gestão de pessoas para promover um senso de direção em um ambiente turbulento, bem como para satisfazer as necessidades organizacionais, individuais e coletivas dos profissionais.

Os conceitos de gestão estratégica de pessoas apresentados em parágrafos anteriores aparentemente convergem para o primeiro objetivo, de alinhamento. Porém, conforme explicado no capítulo introdutório desta tese, a maximização do alinhamento pode ser contraproducente quando a organização se deparar com a necessidade de gerir mudanças e lidar com objetivos conflitantes, sobretudo em ambientes complexos (WRIGHT; McMAHAN, 1992). O alinhamento estratégico, portanto, é um objetivo que precisa ser tratado com parcimônia.

O segundo objetivo, que diz respeito às contribuições da gestão de pessoas para promover um senso de direção em um ambiente turbulento não foi claramente retratado nos conceitos. Ele norteou a formulação da situação-problema desta tese e será retomado nos capítulos finais desta tese. 
Para Lepak e Shaw (2008) a gestão estratégica de pessoas se diferencia de outras linhas de pesquisas por apresentar pesquisas conduzidas em nível de análise macro, tais como unidades de negócio e organizações. Ela abrange uma ampla gama de atividades, tais como: gestão do capital humano, gestão do conhecimento, estruturação e desenvolvimento organizacional, gestão do quadro de funcionários (planejamento, recrutamento, seleção e gestão de talentos), gestão do desempenho humano, aprendizagem, gestão de recompensas, relações de trabalho e gestão do bem-estar dos profissionais (ARMSTRONG, 2011).

Martín-Alcázar, Romero-Fernández e Sánchez-Gardney (2007, p. 651) definem gestão estratégica de pessoas como "“...] um conjunto integrado de práticas, políticas e estratégias por meio das quais as organizações gerenciam seu capital humano, que influenciam e são influenciadas pela estratégia do negócio, pelo contexto organizacional e pelo contexto socioeconômico."

De maneira geral, ela se refere às questões que afetam ou são afetadas pelos planos estratégicos da organização e é condicionada pelos seguintes elementos do ambiente organizacional interno (ARMSTRONG, 2011, p. 20):

- o tipo de negócio da organização - privada, pública ou do terceiro setor, manufatura ou serviço;

- o tamanho da organização;

- o tempo de operação ou a maturidade da organização;

- a tecnologia ou as atividades chave do negócio;

- o perfil dos profissionais (equipe de apoio, trabalhadores do conhecimento, técnicos, administradores, trabalhadores de produção, vendas e atendimento ao cliente);

- as circunstâncias financeiras da organização, especialmente diante de crises econômicas;

- a cultura organizacional (padrões estabelecidos de valores, normas, crenças, atitudes e premissas que modelam as maneiras que as pessoas se comportam e realizam seu trabalho);

- o clima político e social na organização. 
Além desses elementos que condicionam a gestão estratégica de pessoas em organizações, há de se considerar seus elementos componentes. Sob a visão de Armstrong (2011) os elementos componentes são: estratégias, políticas e práticas integradas de recursos humanos.

Albuquerque (1999; 2002) propôs duas estratégias básicas de gestão de pessoas: controle e comprometimento com os objetivos organizacionais. Elas consistem em filosofias de Administração que dão origem a estratégias e a estruturas diferenciadas. Sob a perspectiva da estratégia de controle, os funcionários são considerados fator de produção, números e custos que precisam ser comandados e controlados para desempenharem bem suas funções. Sob a perspectiva da estratégia de comprometimento, os funcionários são considerados parceiros no trabalho. Espera-se que a organização invista nesses funcionários para que eles se comprometam, obtenham um bom desempenho e melhorem os resultados organizacionais. Embora em suas origens tais estratégias se contraponham, nas organizações elas podem ser observadas em continuum.

A estratégia de gestão de pessoas pode ser desdobrada em políticas e práticas. Embora ambas estejam relacionadas, não podem ser tratadas como sinônimos. Enquanto as políticas dizem respeito às intenções declaradas sobre programas, processos e técnicas, as práticas se referem aos programas, processos e técnicas reais, observadas e vivenciadas pelos funcionários (WRIGHT; BOSWELL, 2002). Devido à importância de políticas e práticas de gestão de pessoas para o presente estudo, esse assunto será retomado e aprofundado em seção específica: 2.3.1.1 - Antecedentes da Capacidade de Inovação sob a Perspectiva da Gestão Estratégica de Pessoas.

\subsubsection{Gestão Estratégica de Pessoas no Contexto da Inovação}

Evidências de que a gestão de pessoas poderia contribuir verticalmente para a inovação organizacional (alinhamento externo) já haviam sido identificadas na década de 1980 por Schuler e Jackson (1987). Para esses autores, quando a gestão de pessoas visa a inovação, determinadas características comportamentais são necessárias, tais como: alto nível de criatividade, foco no longo prazo, alto nível de cooperação e interdependência, preocupação moderada com a quantidade e qualidade, foco equilibrado em processo e 
em resultado, alto grau de propensão ao risco e alto grau de tolerância quanto à ambiguidade e imprevisibilidade. Essas características comportamentais foram definidas, na época, sob o nível de análise individual.

Dentre os estudos realizados nas últimas décadas sob o nível de análise organizacional, destaca-se o que foi realizado por Leede e Looise (2005). Para esses autores há dois níveis de contribuição da gestão de pessoas para inovação, sendo o primeiro nível a organização e o segundo nível os estágios de inovação, atividades ou projetos.

\section{Quadro 2 - Níveis de contribuição da gestão de pessoas para inovação}

\begin{tabular}{|c|c|}
\hline Nível de Inovação & Contribuições \\
\hline $\begin{array}{l}\text { PRIMEIRO NÍVEL: } \\
\text { Organização }\end{array}$ & $\begin{array}{l}\text { - atentar para a necessidade de uma visão compartilhada e do } \\
\text { envolvimento da liderança; } \\
\text { - prover treinamento e desenvolvimento de indivíduos-chave; } \\
\text { - estimular alto envolvimento e trabalho em equipe; } \\
\text { - zelar pelo clima organizacional propício para a inovação. }\end{array}$ \\
\hline $\begin{array}{l}\text { SEGUNDO NÍVEL: } \\
\text { Estágios da inovação, } \\
\text { atividades ou projetos }\end{array}$ & $\begin{array}{l}\text { - atentar para a importância da liderança; } \\
\text { - esclarecer/reforçar o papel da média gerência na inovação; } \\
\text { - esclarecer/reforçar peculiaridades envolvendo o trabalho em projetos e } \\
\text { equipes; } \\
\text { - estimular a criatividade nos funcionários }\end{array}$ \\
\hline
\end{tabular}

FONTE: Elaborado com base em LEEDE; LOOISE, 2005.

Os autores recomendam que os dois níveis (organização e estágios da inovação, atividades ou projetos) sejam considerados. Recomenda-se também que cada nível seja combinado com práticas de gestão de pessoas apropriadas, assegurando que as práticas do segundo nível estejam relacionadas com as do primeiro nível.

Esses mesmos autores desenvolveram um modelo que representou um importante passo rumo à integração entre inovação e gestão de pessoas. O modelo revelou que a gestão de pessoas deriva da estratégia empresarial, como também fornece subsídios para ajustá-la (Figura 1). 
Figura 1 - Modelo integrado de inovação e gestão de recursos humanos

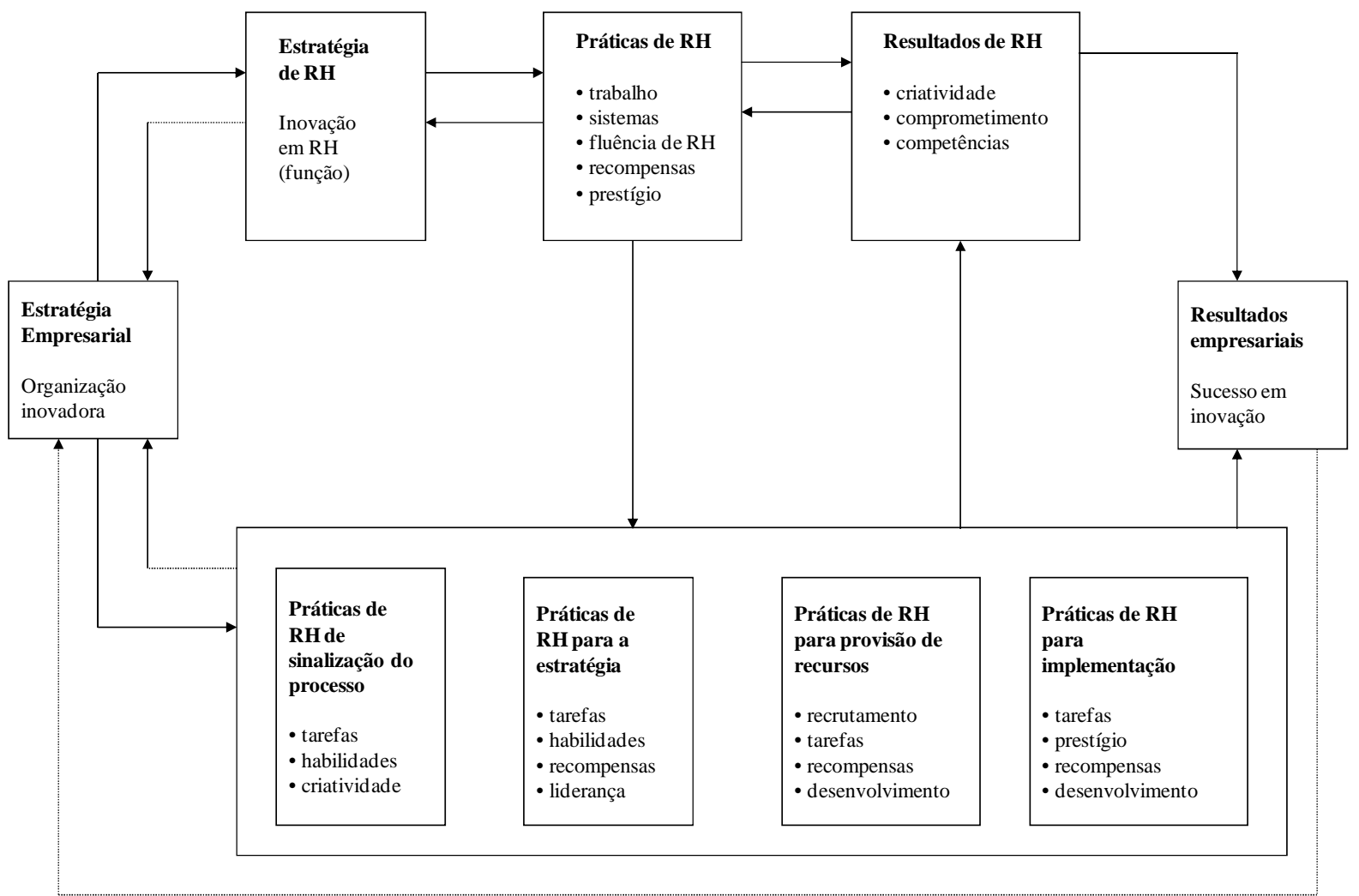

FONTE: LEEDE; LOOISE, 2005, p. 11.

O modelo pode ser interpretado da seguinte forma: a estratégia de recursos humanos é materializada nas práticas, que por sua vez geram potenciais resultados no contexto da inovação. As práticas de RH são subsidiadas e fomentam a estratégia e resultados empresariais direcionados para inovação.

Além da estratégia e práticas de $\mathrm{RH}$, outros aspectos relativos à gestão de pessoas têm se destacado no contexto da inovação, tais como: comportamento orientado à inovação, clima/ambiente favorável, atmosfera criativa, valores básicos compartilhados que sustentam a inovação, normas para inovação e práticas gerenciais centradas nas pessoas. A criatividade, comunicação, colaboração, atitude frente ao risco e atitude para inovar também envolvem gestão de pessoas e têm sido apontados como elementos que influenciam a habilidade da organização para gerenciar a inovação (PALLAS et al, 2013; HERZOG, 2010; SMITH et al, 2008; DOBNI, 2008; TIDD; BESSANT; PAVITT, 2008; LAWSON; SAMSON, 2001).

Dentre os resultados de pesquisas empíricas realizadas em países em desenvolvimento, cabe mencionar o que foi desenvolvido na Índia por Cooke e Saini (2010). Remuneração 
e avaliação de desempenho foram apontadas como práticas de gestão de pessoas mais utilizadas para subsidiar a implementação de estratégia orientada para inovação.

Os relatos de entrevistas realizadas com gestores das cinquenta e quatro organizações pesquisadas revelaram que houve ineficiência de iniciativas de gestão de recursos humanos voltadas para inovação, atribuída, principalmente, a maneira como foram implementadas. As iniciativas foram adotadas em resposta a modismos, sem a real compreensão sobre o que eram, como deveriam ser implementadas e se, de fato, beneficiariam os empregados. Trata-se de um ponto de atenção para pesquisadores e profissionais de organizações empresariais.

Recentemente foi feita uma revisão sistemática da literatura com o objetivo de levantar características da produção acadêmica internacional em gestão estratégica de pessoas para inovação no período de 2011 a 2014. Os trinta e dois periódicos pesquisados foram selecionados com base nos critérios descritos por Quishida e Andrade (2014), conforme o Quadro 3.

Quadro 3 - Periódicos pesquisados

\begin{tabular}{|l|l|}
\hline & $\begin{array}{l}\text { Academy of Management Review; Journal of Management; } \\
\text { Academy of Management Journal; Administration Science Quarterly; } \\
\text { Academy of Management Annals; Asia Pacific Journal of Management; }\end{array}$ \\
$\begin{array}{l}\text { Pdministração } \\
\text { Geral (15) }\end{array}$ & $\begin{array}{l}\text { Journal of Management Studies; Management Decision; Long Range } \\
\text { Planning; Strategic Management Journal; Organization Science; } \\
\text { International Journal of Management Review; Academy of Management } \\
\text { Perspective; Journal of International Business Studies; Omega } \\
\text { International Journal of Management Science. }\end{array}$ \\
\hline $\begin{array}{l}\text { Periódicos específicos } \\
\text { sobre } \\
\text { Gestão de } \\
\text { Pessoas (10) }\end{array}$ & $\begin{array}{l}\text { Journal of Organizational Behavior; Research in Organizational } \\
\text { Behavior; Human Resource Management Journal; Human Relations; } \\
\text { Human Resource Management Review; Journal of Human Resources; } \\
\text { Organizational Behavior Human Decision; International Journal of } \\
\text { Human Resource Management; Human Resource Development } \\
\text { Quarterly; Asia Pacific Journal of Human Resources. }\end{array}$ \\
\hline $\begin{array}{l}\text { Periódicos específicos } \\
\text { sobre Gestão da } \\
\text { Inovação (7) }\end{array}$ & $\begin{array}{l}\text { Technovation; R\&D Management; Journal of Product Innovation } \\
\text { Management; Creativity and Innovation Management; Industry and } \\
\text { Innovation; Innovation Management Policy and Practice; Asian Journal } \\
\text { of Technology Innovation. }\end{array}$ \\
\hline
\end{tabular}

Destacaram-se entre os tópicos mais abordados nos 72 artigos: práticas de gestão e de RH no contexto da inovação, desempenho organizacional, comportamento organizacional, desempenho inovador, cultura para inovação, estratégia de inovação e criatividade. 
Constatou-se que quanto aos objetivos teóricos, a maioria dos artigos se voltou para a descrição e explicação do fenômeno (respectivamente, 32 e 29 artigos), sugerindo um estágio embrionário de investigação. Foram identificados apenas 11 artigos que se voltaram para a explicação do referido fenômeno, sugerindo que se trata de um campo com boas perspectivas de crescimento.

\subsection{Gestão da Inovação Organizacional}

Esta seção será iniciada com conceitos e tipologias de inovação organizacional. Em seguida serão explicados os fatores que podem interferir na habilidade das empresas de gerenciar a inovação.

Inovação é uma palavra ampla que permite diferentes interpretações. Embora a ideia de novidade e de mudança permeie as diversas definições, não parece existir uma orientação única sobre o que pode ser considerado novo. Ela envolve um processo dinâmico, contínuo e de difícil de ser mensuração (TIDD; BESSANT; PAVITT, 2008; OECD, 1997).

Em publicações recentes, inovação foi conceituada da seguinte forma no contexto organizacional:

Inovação é: produção ou adoção, assimilação e exploração de uma novidade de valor agregado nas esferas econômica e social; renovação e ampliação de produtos, serviços e mercados; desenvolvimento de novos métodos de produção; e estabelecimento de novos sistemas gerenciais. É tanto um processo quanto um resultado. (CROSSAN; APAYDIN, 2010, p. 1155).

Para os propósitos da Community Innovation Survey uma inovação é definida como a introdução no mercado de um produto (bem ou serviço) novo ou significativamente melhorado ou de um processo novo ou significativamente melhorado, assim como as inovações organizacionais e de marketing incluindo logística ou métodos de distribuição. (EUROSTAT, 2012, p. 591)

Essas definições revelam a abrangência e a complexidade da inovação. Elas sugerem que inovação implica algo de novo, que pode envolver melhoria, renovação e ampliação, assim como novos enfoques para processos, produtos e serviços. Trata-se de uma atividade de gestão que pode envolver diferentes áreas funcionais da empresa como pesquisa e desenvolvimento (P\&D), marketing, produção, logística e organização. 
Embora a inovação tenha historicamente sido associada à função de P\&D (FORSMAN, 2011; KIRNER; KINKEL; JAEGER, 2009), obras datadas da década de 1980, como a que foi realizada pela OECD (1981) sinalizaram que o escopo de P\&D poderia ser ampliado.

Inovação consiste em todas as atividades científicas, técnicas, comerciais e financeiras necessárias para o desenvolvimento bem-sucedido e para o marketing de novos ou melhorados produtos manufaturados, o uso comercial de novos ou melhorados processos, equipamentos ou a introdução de nova forma de prestar um serviço. P\&D é apenas uma dessas atividades. (OECD, 1981, p. 15-16).

Essa visão se fortaleceu, a julgar pelo Manual de Oslo, publicado na década seguinte.

Inovação compreende várias atividades que não se inserem em $\mathrm{P} \& \mathrm{D}$, como as últimas fases do desenvolvimento para pré-produção, produção e distribuição, atividades de desenvolvimento com grau menor de novidade, atividades de suporte como treinamento e preparação de mercado, e atividades de desenvolvimento e implementação para inovações [....] as atividades de inovação podem também incluir a aquisição de conhecimentos externos ou bens de capital que não são parte de P\&D (OECD, 1997, p. 25).

A compreensão parcial da atividade de inovação tem acarretado problemas de gestão. Por exemplo: quando inovação é considerada um assunto de profissionais especialistas em $\mathrm{P} \& \mathrm{D}$, pode haver falta de comprometimento por parte de outros profissionais envolvidos, ainda que indiretamente, com atividades e projetos de inovação.

A inovação em nível organizacional requer a consideração de uma série de características: a incerteza, que torna mais difícil seu gerenciamento; elementos intangíveis (Quadro 4), tais como o conhecimento; demanda investimento financeiro; falta de clareza sobre os atores envolvidos que se beneficiarão da inovação; associação com capacidade de inovação, desempenho da organização, ganho e manutenção de vantagem competitiva no(s) mercado(s) em que atua. 
Quadro 4 - Características da inovação organizacional

\begin{tabular}{|c|c|}
\hline Características & Descrição \\
\hline $\begin{array}{l}\text { A inovação está associada à incerteza sobre } \\
\text { os resultados das atividades inovadoras. }\end{array}$ & $\begin{array}{l}\text { Não se sabe de antemão qual será o resultado das } \\
\text { atividades de inovação ou quão bem-sucedidas essas } \\
\text { atividades serão. }\end{array}$ \\
\hline A inovação envolve investimento. & $\begin{array}{l}\text { O investimento relevante pode incluir a aquisição de } \\
\text { ativos fixos ou intangíveis, assim como outras } \\
\text { atividades que podem render retornos potenciais no } \\
\text { futuro. }\end{array}$ \\
\hline $\begin{array}{l}\text { A inovação é o substrato dos } \\
\text { "transbordamentos". }\end{array}$ & $\begin{array}{l}\text { Os benefícios da inovação criadora raramente são } \\
\text { apropriados por completo pela empresa inventora. As } \\
\text { empresas que inovam por meio da adoção de uma } \\
\text { inovação podem se beneficiar dos "transbordamentos" } \\
\text { de conhecimentos ou do uso da inovação original. Para } \\
\text { algumas atividades de inovação os custos da imitação } \\
\text { são substancialmente menores que os custos de } \\
\text { desenvolvimento; por isso, faz-se necessário um } \\
\text { mecanismo efetivo de apropriação que ofereça um } \\
\text { incentivo para inovar. }\end{array}$ \\
\hline $\begin{array}{l}\text { A inovação requer a utilização de } \\
\text { conhecimento novo ou combinação para o } \\
\text { conhecimento existente. }\end{array}$ & $\begin{array}{l}\text { O conhecimento novo pode ser gerado pela empresa } \\
\text { inovadora no curso de suas atividades. O uso de } \\
\text { conhecimento novo ou a combinação do conhecimento } \\
\text { existente requer esforços inovadores que podem ser } \\
\text { distinguidos das rotinas padronizadas. }\end{array}$ \\
\hline $\begin{array}{l}\text { A inovação visa melhorar o desempenho de } \\
\text { uma empresa com o ganho ou manutenção } \\
\text { de vantagem competitiva. }\end{array}$ & $\begin{array}{l}\text { O ganho ou manutenção de vantagem competitiva } \\
\text { ocorre por meio de mudança da curva de demanda dos } \\
\text { produtos, mudança da curva de custos e aprimoramento } \\
\text { da capacidade de inovação da empresa. }\end{array}$ \\
\hline
\end{tabular}

FONTE: OECD, 1997, p. 43.

O setor tem sido apontado como um fator condicionante à inovação (IBGE, 2005; OECD, 2002; OECD, 1997). Em pesquisa específica sobre setores inovadores, a Science, Technology and Industry Scoreboard (OECD, 2011) revelou a importância de considerar as fontes não tecnológicas de inovação, além dos tradicionais gastos com P\&D. Essa posição se justifica pelos resultados da pesquisa, que revelaram a existência de setores com baixa intensidade de gastos com $\mathrm{P} \& \mathrm{D}$, porém que apresentam alta pontuação em outros índices como: inovação de produto e de mercado e no índice de intensidade de inovação.

A Pesquisa Industrial de Inovação Tecnológica (PINTEC) considera atividades de inovação todas as etapas científicas, tecnológicas, organizacionais e comerciais que conduzem, ou que pretendem conduzir à implementação de inovações. Algumas dessas 
atividades podem ser inovadoras por natureza, enquanto outras não são novas, porém necessárias para a implementação de inovações. De maneira geral, tratam-se de todas as atividades requeridas no desenvolvimento e implantação de produtos e processos tecnologicamente novos ou aperfeiçoados, podendo ser desenvolvidas dentro e/ou fora da empresa (IBGE, 2005).

De acordo com o Manual de Oslo (OECD, 1997), uma empresa ativamente inovadora é aquela que realizou atividades de inovação durante o período de análise, incluindo as atividades em andamento e as que foram abandonadas. Isso significa que a empresa é considerada inovadora independentemente de suas atividades terem resultado na implementação de uma ou mais inovações de produto/processo.

Embora a literatura reconheça vários tipos de inovação em nível organizacional, a maioria das pesquisas empíricas tem utilizado a tipologia de produtos e processos segundo Delgado-Verde et al (2011). Essa constatação é corroborada por autores como Frishammar et al (2012). Eles afirmam que, especialmente em empresas de manufatura, existe uma relação próxima entre inovação de produto e de processo. Esses autores argumentam que a maioria dos novos produtos não podem ser desenvolvidos e manufaturados sem inovação em ambos - produtos e processos - quando se propõe obter e sustentar vantagem competitiva.

Ressalta-se que as inovações de produtos não necessariamente precisam ser novas para o mercado e que as inovações em serviços não precisam ter sido as pioneiras na prestação desse serviço no mercado. Contudo, não podem se restringir à comercialização de inovações inteiramente produzidas por outras empresas, nem devem se restringir à introdução no mercado de mudanças meramente estéticas em produtos (EUROSTAT, 2012).

Embora sejam muitas as classificações de inovação - além de produto e processo - são listados outros tipos comumente encontrados em publicações de gestão da inovação: produto e serviço, incremental e radical; tecnológica e não baseada em tecnologia. (DELGADO-VERDE; CASTRO; NAVAS-LÓPEZ, 2011; TIDD; BESSANT; PAVITT, 2008; MATTHEWS, 2002).

Enquanto diferentes termos como inovação organizacional, administrativa, gerencial têm sido utilizados, Damanpour e Aravind (2011) explicam que as definições utilizadas para 
esses termos se sobrepõem significativamente, apesar de se distinguirem de outros tipos como inovação de produto, serviço e tecnológica.

A julgar pelos conceitos e tipos de inovação, ratifica-se o entendimento de Tidd, Bessant e Pavitt (2008) de que a inovação consiste em um processo central da organizacional que pode ser gerenciado. Segundo esses mesmos autores, o processo de gestão da inovação é considerado sob duas perspectivas: operacional e estratégica.

Sob a perspectiva operacional, a inovação pode ser compreendida como um fluxo que inicia com a geração de ideias, passa pela seleção, desenvolvimento de projetos e disseminação de inovações (TIDD; BESSANT; PAVITT, 2008). Sob a perspectiva estratégica, que consiste no foco da tese, ela diz respeito aos aspectos corporativos e de estratégias de inovação da organização e como elas impactam a gestão da inovação (SMITH et al, 2008).

Ainda no que tange à perspectiva estratégica, Smith et al (2008) identificaram os principais fatores que, segundo eles, influenciam a habilidade de gerenciar a inovação em organizações. Obtidos por revisão sistemática da literatura, os fatores são: tecnologia, processo de inovação, estratégia corporativa, estrutura organizacional, cultura organizacional, empregados, recursos, gestão do conhecimento, estilo de gestão e liderança. Os autores ressaltaram que os fatores não são independentes uns dos outros e que podem estar inter-relacionados nas organizações.

Cada fator foi desdobrado em subfatores, conforme representado no Quadro 5. 
Quadro 5 - Fatores e subfatores que influenciam a habilidade de gerenciar a inovação

\begin{tabular}{|c|c|}
\hline Fator & Subfator \\
\hline Tecnologia & $\begin{array}{l}\text { - Utilização da tecnologia } \\
\text { - Habilidades tecnológicas e educação } \\
\text { - } \quad \text { Estratégia tecnológica }\end{array}$ \\
\hline Processo de inovação & $\begin{array}{l}\text { - } \text { Geração de ideias } \\
\text { - Seleção e avaliação de técnicas } \\
\text { - } \quad \text { Mecanismos de implementação }\end{array}$ \\
\hline Estratégia corporativa & $\begin{array}{l}\text { - Estratégia organizacional } \\
\text { - Estratégia de inovação } \\
\text { - Visão e objetivos da organização } \\
\text { - Tomada de decisão estratégica } \\
\end{array}$ \\
\hline Estrutura organizacional & $\begin{array}{ll}\text { - } & \text { Diferenciação } \\
\text { - } & \text { Centralização } \\
\text { - } & \text { Formalização } \\
\end{array}$ \\
\hline Cultura organizacional & $\begin{array}{ll}\text { - } & \text { Comunicação } \\
\text { - } & \text { Colaboração } \\
\text { - } & \text { Atitude frente ao risco } \\
\text { - } & \text { Atitude para inovação } \\
\end{array}$ \\
\hline Empregados & $\begin{array}{ll}\text { - } & \text { Motivação para inovar } \\
\text { - Habilidade e educação dos empregados } \\
\text { - Personalidade dos empregados } \\
\text { - Treinamento } \\
\end{array}$ \\
\hline Recursos & $\begin{array}{l}\text { - Utilização de recursos escassos } \\
\text { - Planejamento e gerenciamento de recursos } \\
\text { - Recursos do conhecimento } \\
\text { - Recursos tecnológicos } \\
\text { - Recursos financeiros }\end{array}$ \\
\hline Gestão do conhecimento & $\begin{array}{l}\text { - Aprendizagem organizacional } \\
\text { - Conhecimento do ambiente externo } \\
\text { - Utilização de repositórios de conhecimentos }\end{array}$ \\
\hline Estilo de gestão e liderança & $\begin{array}{ll}\text { - } & \text { Gestão de pessoas } \\
\text { - } & \text { Estilo de gestão } \\
\text { - } & \text { Motivação dos empregados }\end{array}$ \\
\hline
\end{tabular}

FONTE: SMITH et al, 2008, p. 660.

Nota-se que dois dos fatores listados se relacionam diretamente com gestão estratégica de pessoas em nível organizacional de análise. O primeiro, cultura organizacional, “[...] está relacionada com os valores e crenças da organização e como eles impactam a habilidade de gerir a inovação na organização.”; e o segundo, estilo de gestão e liderança, "[...] refere-se aos empregados que têm responsabilidade de gestão na organização." (SMITH et al, 2008, p. 661). Os demais fatores podem ser considerados indiretamente relacionados com a gestão estratégica de pessoas conforme os conceitos apresentados na seção 2.2.1 - Gestão Estratégica de Pessoas e conforme os propósitos desta tese. 


\subsubsection{Capacidade de Inovação}

Nesta seção são apresentados os antecedentes da capacidade de inovação com a finalidade de identificar características organizacionais de gestão estratégica de pessoas.

Embora capacidade de inovação tenha despertado bastante interesse em pesquisas sobre inovação, Zhang et el (2013), alegam que não há uma definição amplamente aceita na literatura. Sendo assim, para fins deste estudo foram utilizados os critérios de busca estabelecidos no início deste capítulo para identificar uma definição condizente com o problema de pesquisa.

Foi adotada a definição de capacidade de inovação proposta por Burgelman e Maidique (2004, p. 36) como "[...] um conjunto abrangente de características de uma organização que apoia e facilita suas estratégias de inovação."

As estratégias de inovação foram consideradas de maneira ampla, no contexto da configuração estratégia de criação de capacidades, que segundo Tallman (2003) é mais condizente com inovação organizacional (seção 2.1 - Capacidades Organizacionais). Tratar as estratégias de maneira ampla, como configurações, é justificada pelo fato de que estratégias de inovação estão relacionadas, porém não fazem parte do problema de pesquisa.

Capacidade de inovação pode ser compreendida sob a visão da firma baseada em recursos, no sentido que a vantagem competitiva sustentável e desempenho superior da firma resultam de recursos e capacidades internas que sejam valiosas, raras, de difícil imitação e substituição. Essa visão oferece, segundo Zhang et al (2013, p. 5), uma maneira de compreender a dinâmica do processo de inovação: "A perspectiva de recursos e capacidades de inovação sugere que a inovação é um processo complexo e dinâmico, no qual a empresa continuamente identifica e desenvolve novos recursos e capacidades requeridos ou explora novas combinações de recursos."

De acordo com Dutta, Narassimhan e Rajiv (2005): capacidades são concebidas como a eficiência com que a firma emprega um determinado conjunto de recursos (insumos) disponíveis para alcançar determinados objetivos (resultados). Os autores preconizam que os objetivos podem variar, considerando as especificidades da firma. Considerando a definição de capacidade de inovação utilizada neste estudo, um possível objetivo seu seria 
o desempenho inovador e, em última instância, a implementação da estratégia de inovação. Como os objetivos da atividade inovadora não integraram o escopo deste estudo, eles serão abordados no capítulo de considerações finais, onde serão apresentadas sugestões de estudos futuros.

\subsubsection{Antecedentes de Capacidade de Inovação sob a Perspectiva da Gestão Estratégica de Pessoas}

Segundo Hult, Hurley e Knight (2004), existe concordância na literatura de que a inovação contribui para o desempenho do negócio. Entretanto, pouco se sabe sobre os antecedentes da capacidade de inovação e como esses antecedentes atuam coletivamente para influenciar o desempenho.

A inovatividade foi definida por Ahmed (1998) como um antecedente e como principal determinante da inovação. Ela foi definida por Hult, Hurley e Knight (2004) como a capacidade da firma de se engajar na inovação. A utilização da palavra engajamento para explicar a inovatividade condiz com a perspectiva cultural e estratégica da inovatividade (PALLAS et al, 2013), que consiste na abertura da firma para inovação e se manifesta em um comportamento organizacional ativo e orientado para inovação.

Em pesquisa realizada na Alemanha, Pallas et al (2013), entrevistaram executivos de empresas inovadoras e especialistas tanto do meio acadêmico e profissional. Da análise das entrevistas emergiram quatro dimensões de inovatividade em nível organizacional: foco estratégico em inovação, abertura na comunicação, sistema de motivação extrínseca e sistema de encorajamento. Como essas dimensões se relacionam com a abordagem estratégica da gestão de pessoas, elas serão sinteticamente apresentadas, buscando preservar o sentido atribuído pelos autores.

- Foco estratégico em inovação - parte do entendimento de que a firma continuamente inova se a alta gestão tiver uma visão de como a firma alcançará os objetivos traçados e de como conduzi-la ao alcance desses mesmos objetivos. A gestão, portanto, deve primeiramente ter uma atitude positiva em relação à 
inovação e se comportar adequadamente para assegurar seu foco estratégico em inovação e a capacidade da firma de se engajar na inovação.

- $\quad$ Abertura na comunicação - diz respeito a como organização enfatiza seu foco em inovação para todas as partes interessadas (stakeholders). Os autores se referem à comunicação estratégica, que consiste em uma atribuição da gestão estratégica de pessoas. Para tanto, fornecem o exemplo da missão da organização - que pode encorajar os empregados a ativamente buscar a inovação

- Sistema de motivação extrínseca - inclui tanto as recompensas financeiras quanto as não financeiras como aumento no reconhecimento, aceleração de promoção, mais autonomia e programas de premiação para aumentar o comportamento orientado para inovação dos empregados.

- Encorajamento da gestão - esta dimensão é baseada no argumento de que a alta gestão precisa encorajar os empregados a divulgarem suas ideias inovadoras. Isso implica conceder a eles oportunidades para inovar e estabelecer canais de comunicação adequados, fornecendo condições para que eles formal e informalmente possam comunicar suas ideias para a alta gestão.

Os autores preconizam que as quatro dimensões de inovatividade sob a perspectiva cultural e estratégica representam diferentes aspectos da inovatividade organizacional que, embora possam ser considerados isoladamente, se inter-relacionam formando um construto mais amplo (PALLAS et al, 2013).

A literatura de gestão da inovação contém vários modelos de capacidade de inovação baseados na auditoria de inovações, processo de desenvolvimento de novos produtos, gestão de $\mathrm{P} \& \mathrm{D}$ e processo de aquisição de tecnologia, bem como na implementação de inovação na produção. Todavia, Lawson e Samson (2001) alegaram a escassez de publicações que se voltassem para a construção de modelos sob a abordagem dinâmica de capacidades.

Então, com base na literatura de gestão da inovação, os mesmos autores desenvolveram um modelo de capacidade de inovação assumindo que determinada organização é orientada para inovação e que o desempenho inovador é um elemento primordial de sua estratégia competitiva. 
O modelo de capacidade estratégica representado na Figura 2 apresenta sete antecedentes de capacidade de inovação: visão e estratégia, competências, inteligência organizacional, criatividade e gestão de ideias, estrutura organizacional e sistemas, cultura e clima, e gestão da tecnologia.

Figura 2 - Modelo de capacidade de inovação

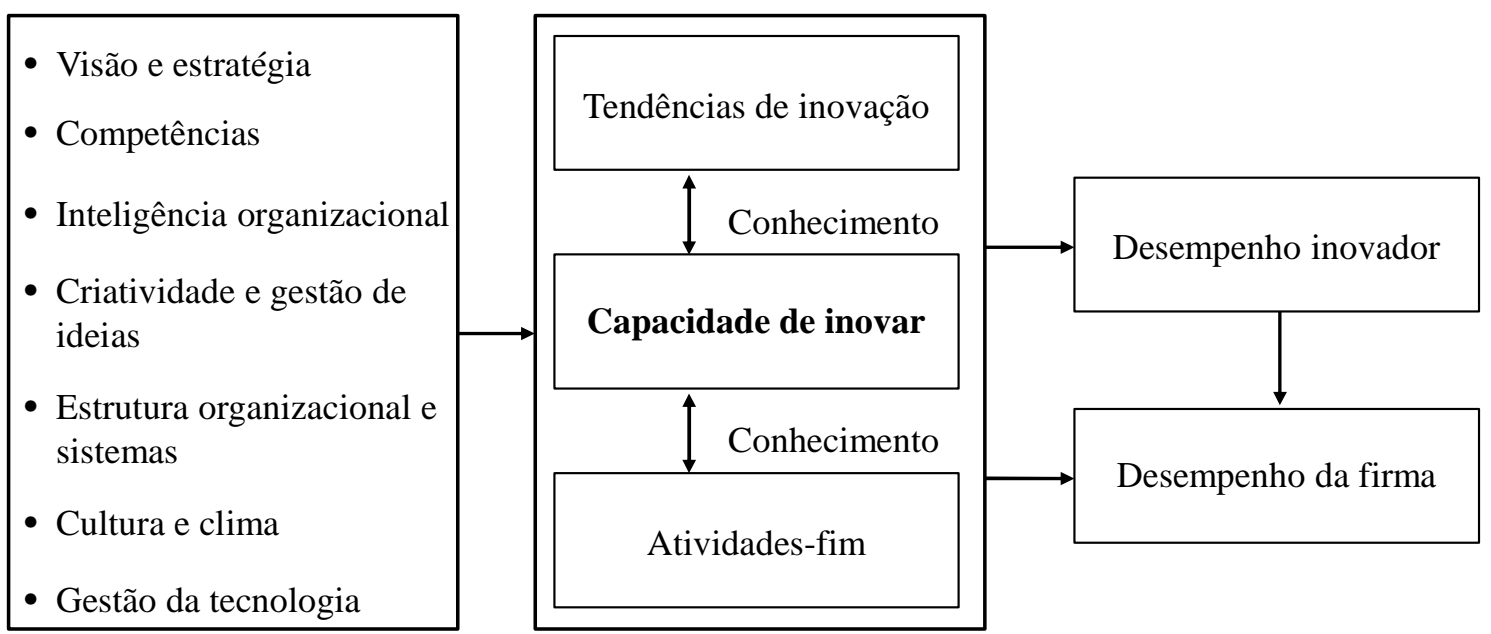

FONTE: LAWSON; SAMSON, 2001, p. 388.

Esse modelo apresenta coerência com as atividades de gestão estratégica de pessoas, que envolvem questões de interesse da organização relativas a mudanças na estrutura, cultura, efetividade organizacional e desempenho e apoia o desenvolvimento de capacidades organizacionais (ARMSTRONG, 2011), como a de inovar.

A capacidade de inovar de uma empresa afeta sua abertura para inovação em termos de produtos e processos de inovação, bem como na inovação da organização, em sentido amplo (NEELY et al, 2001).

Segundo Neely et al (2001), um estudo conduzido pela Confederação da Indústria Britânica e pelo Departamento de Comércio e Indústria revelou a existência de três fatores-chave que determinam a capacidade da firma de inovar e se inter-relacionam de maneira sinérgica. São eles: cultura organizacional, seus processos internos e suas relações interorganizacionais. Os fatores determinantes da capacidade de inovação se interrelacionam de maneira sinérgica, fortalecendo o argumento que a gestão estratégica de pessoas pode contribuir para a capacidade de inovação. 
A seguir serão apresentados modelos conceituais e resultados de pesquisas realizadas que apontaram características de gestão estratégica de pessoas como antecedentes da capacidade de inovação no período de 2004 a 2014.

Prajogo e Ahmed (2006) pesquisaram a relação existente entre estímulo à inovação, capacidade de inovação e desempenho em inovação com 194 gestores de organizações australianas. Eles defendiam a ideia de que o efeito da capacidade de inovação era determinado por quatro fatores de estímulo: liderança, gestão de pessoas, gestão do conhecimento e gestão da criatividade (Figura 3).

Figura 3 - Modelo integrado de gestão da inovação

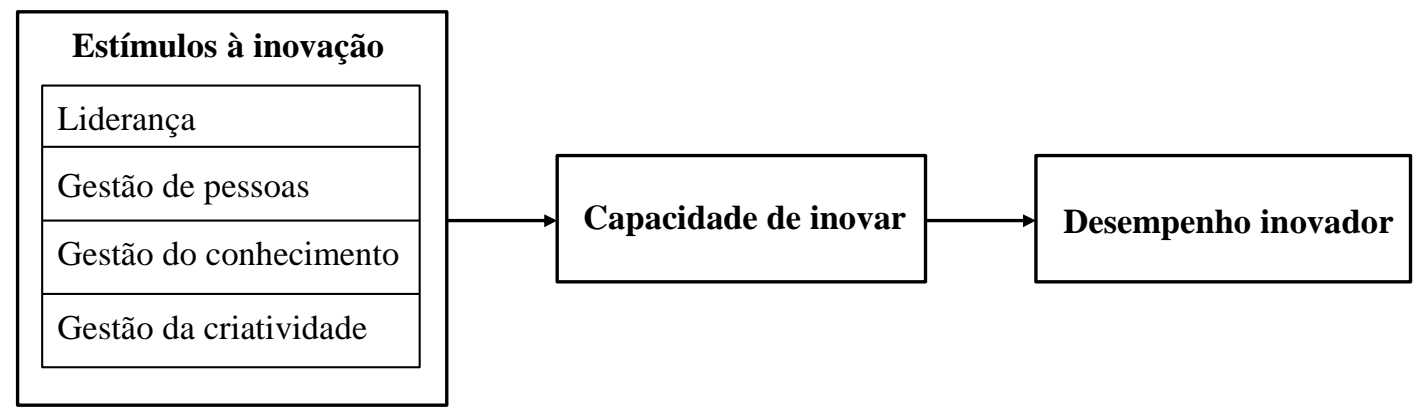

Fonte: Adaptado de PRAJOGO; AHMED, 2006.

Os autores constataram que tanto a relação entre estímulo à inovação e capacidade de inovação, quanto a relação entre capacidade de inovação e desempenho inovador foram significativas e fortes. Os resultados revelaram também que, o estímulo à inovação não apresentou efeito direto sobre o desempenho inovador, sendo seu efeito mediado pela capacidade de inovação.

No modelo conceitual desenvolvido pelos mesmos autores foram consideradas quatro fatores de estímulos à inovação identificados na literatura: liderança, gestão de pessoas, gestão do conhecimento e gestão da criatividade (Quadro 6) - fatores que podem ser abordadas direta ou indiretamente sob a perspectiva da gestão estratégica de pessoas. 
Quadro 6 - Fatores de estímulo à inovação e itens

\begin{tabular}{|c|c|}
\hline $\begin{array}{c}\text { Fatores de } \\
\text { estímulo }\end{array}$ & Itens \\
\hline Liderança & $\begin{array}{l}\text { - Compartilhamento de crenças similares } \\
\text { - Encorajamento de melhorias e aprendizagem } \\
\text { - Oportunidade de compartilhamento } \\
\text { - Alto grau de unidade de propósito }\end{array}$ \\
\hline $\begin{array}{l}\text { Gestão de } \\
\text { pessoas }\end{array}$ & $\begin{array}{l}\text { - Processo de treinamento e desenvolvimento } \\
\text { - Processo de comunicação } \\
\text { - Mensuração da satisfação dos empregados } \\
\text { - Flexibilidade e múltiplas habilidades dos empregados } \\
\text { - Qualidade do ambiente de trabalho }\end{array}$ \\
\hline $\begin{array}{l}\text { Gestão do } \\
\text { conhecimento }\end{array}$ & $\begin{array}{l}\text { - Desenvolvimento do capital intelectual } \\
\text { - Melhoria nos conhecimentos e habilidades dos empregados } \\
\text { - Compartilhamento e disseminação de informações } \\
\text { - Gestão de ativos intelectuais }\end{array}$ \\
\hline $\begin{array}{l}\text { Gestão da } \\
\text { criatividade }\end{array}$ & $\begin{array}{l}\text { - Tempo e recursos para geração de ideias } \\
\text { - Diversidade das habilidades dos grupos de trabalho } \\
\text { - Trabalho não-rotineiro e desafiador } \\
\text { - Recompensas e reconhecimento pela criatividade }\end{array}$ \\
\hline
\end{tabular}

FONTE: Adaptado de PRAJOGO; AHMED, 2006.

Verifica-se que os itens que descrevem cada fator de estímulo à inovação foram desdobrados em itens. Foi obtida significância estatística superior a $70 \%$ nos testes realizados.

Com base no conteúdo exposto nesta seção, nas visões e conceitos de gestão estratégica de pessoas apresentados em seções anteriores (1.1 - Introdução e 2.2 - Gestão Estratégica de Pessoas) alinhados com o primeiro objetivo de investigação desta tese, a seguir serão definidos e caracterizados os antecedentes de capacidade de inovação sob a perspectiva da gestão estratégica de pessoas.

$\underline{\text { Antecedentes de Capacidade de Inovação sob a Perspectiva da Gestão Estratégica de }}$ $\underline{\text { Pessoas }}$

Nesta seção serão apresentadas definições relativas aos antecedentes de capacidade de inovação sob a perspectiva da gestão estratégica de pessoas encontrados na literatura de gestão de pessoas e na de gestão de inovação. São eles: filosofia, valores e normas, foco estratégico em inovação, liderança e gestão e políticas e práticas de gestão de pessoas. 
Tais características organizacionais foram elaboradas, principalmente, com base nas revisões sistemáticas da literatura realizada por Quishida e Albuquerque (2014) e em estudos anteriores realizado por Albuquerque (1999; 2002) e Medeiros (2003).

\section{Filosofia, Valores e Normas (FVN)}

A filosofia de uma organização representa suas crenças, convicções e premissas básicas, não questionáveis e arraigadas na ação. Segundo Schein (1984), à medida que determinados processos cognitivos e motivacionais são repetidos e continuam a funcionar na organização, eles se tornam inconscientes. Filosofia, de acordo com esse autor, pode ser compreendida como o relacionamento com o ambiente, a natureza de realidade, tempo e espaço, a natureza da natureza humana, a natureza da atividade humana e a natureza das relações humanas.

Por valores entende-se "[...] um modo específico de conduta ou de condição de existência é individual ou socialmente preferível ao modo contrário ou oposto de conduta ou de existência." (ROKEACH, 1973, p. 5). Valores organizacionais são explícitos, compartilhados e orientam o comportamento das pessoas, além de possuírem um elemento de julgamento baseado no que se acredita ser correto, bom ou desejável (SCHEIN, 1984; ROBBINS; JUDGE; SOBRAL, 2011).

Valores são frequentemente associados aos estudos de cultura organizacional, definida por Schein (2010) como um padrão de premissas básicas compartilhadas, aprendidas e utilizadas por um grupo na solução de problemas de adaptação externa e de integração interna que funcionou bem o suficiente para ser considerada válida e, portanto, pode ser ensinada aos novos membros como modo correto de perceber, pensar e sentir em relação a tais problemas.

Na pesquisa realizada por Vasconcellos-Guedes et al (2012) foi investigada a presença de traços culturais que embasaram a inovação em uma empresa reconhecidamente inovativa do setor farmacêutico. Dentre os achados da pesquisa foram identificadas diferenças em traços culturais entre áreas funcionais da empresa. Acrescenta-se, ainda, que a inovação foi considerada um valor mais intenso na área de $\mathrm{P} \& \mathrm{D}$ em comparação com as demais áreas funcionais. Trata-se do público-alvo da pesquisa realizada nesta tese, que será descrito no capítulo de metodologia da pesquisa. 
A pesquisa bibliográfica realizada pelos mesmos autores mencionados no parágrafo anterior enfatizou alguns traços culturais relevantes no contexto da inovação, como: a mentalidade para inovação, medidas tangíveis de desempenho e incentivos, bem como o apoio e encorajamento e uso de inteligência inovativa por indivíduos e equipes.

Para Herzog e Leker (2010), cultura de inovação foi definida como:

- valores organizacionais básicos amplamente compartilhados que suportam a inovação;

- amplas normas organizacionais para inovação;

- práticas perceptíveis orientadas para inovação.

Dado o exposto, para a pesquisa realizada nesta tese, a característica FVN foi composta pelos seguintes elementos: crenças, convicções e premissas básicas, valores e normas organizacionais orientadas para inovação. As práticas perceptíveis orientadas para inovação foram consideradas sob a perspectiva da gestão de pessoas, na característica PPGP que será explicada adiante.

\section{Foco Estratégico em Inovação (FEI)}

Para que a abordagem estratégica da gestão de pessoas no contexto da inovação pudesse ser considerada na pesquisa, foi necessário incluir entre os antecedentes de capacidade de inovação sob a perspectiva da gestão estratégica de pessoas a característica FEI.

Essa inclusão se justifica, sobretudo, pela definição de gestão estratégica de pessoas apresentada em seção anterior (2.2 - Gestão Estratégica de Pessoas): “[...] um conjunto integrado de práticas, políticas e estratégias por meio das quais as organizações gerenciam seu capital humano, que influenciam e são influenciadas pela estratégia do negócio, pelo contexto organizacional e pelo contexto socioeconômico." (MARTÍN-ALCÁZAR; ROMERO-FERNÁNDEZ; SÁNCHEZ-GARDEY, 2007, p. 651).

Foco estratégico inovativo, segundo Pallas (2013) parte do entendimento de que a firma continuamente inova se a alta gestão tiver uma visão de como a firma alcançará os objetivos traçados e de como conduzi-la ao alcance desses mesmos objetivos. Para tanto, a gestão deve ter uma atitude positiva em relação à inovação e se comportar 
adequadamente para assegurar seu foco estratégico em inovação e a capacidade da firma de se engajar na inovação.

Para a pesquisa realizada nesta tese, a característica FEI foi composta pelos seguintes elementos: orientação da empresa para inovação, disseminação de informações sobre inovação, divulgação de resultados obtidos em inovação e extensão em que a gerência de P\&D\&I é envolvida na tomada de decisões estratégicas. Esses elementos serão detalhados na seção 2.4 - Consolidação da Fundamentação Teórica, com vistas à operacionalização da pesquisa empírica.

\section{Liderança e Gestão (LG)}

Liderança é definida por Robbins, Judge e Sobral (2011, p. 359) como: “[...] a capacidade de influenciar um conjunto de pessoas para alcançar metas e objetivos."

Destaca-se entre as correntes contemporâneas de pesquisas sobre liderança a do tipo transformacional (ROBBINS; JUDGE; SOBRAL, 2011), que se caracteriza principalmente por:

- influência idealizada - oferece uma visão e o sentido de missão, estimula o orgulho, obtém respeito e confiança;

- motivação inspiracional - comunica suas altas expectativas, utiliza símbolos para focar os esforços, expressa propósitos de maneira simples;

- estímulo intelectual - promove a inteligência, a racionalidade, a cuidadosa resolução de problemas;

- consideração individualizada - dá atenção personalizada, trata cada funcionário pessoalmente, aconselha, orienta.

Jung, Chow e Wu (2003) investigaram o papel da liderança transformacional na inovação organizacional em empresas de telecomunicações/eletrônicas. Eles identificaram a existência de uma relação positiva e direta entre o estilo transformacional e inovação, denotando que a alta gestão pode influenciar positivamente, tanto direta quanto indiretamente, criando uma cultura em que os empregados se sentem encorajados para discutir livremente, bem como experimentar ideias inovativas e oportunidades. 
A esses resultados de pesquisa, acrescenta-se a revisão sistemática na literatura feita por Denti e Hemsley (2012) sobre estudos em liderança e inovação organizacional. A análise das publicações indicou que liderança transformacional estimula o comportamento inovador de indivíduos e grupos (DENTI; HEMLIN, 2012).

É possível que outros estilos de liderança - além do transformacional - estejam associados à inovação organizacional. Entretanto, como estilos de liderança é um assunto que está fora do escopo desta tese, ele será retomado no capítulo 5 - Considerações Finais, na seção que versa sobre sugestões de estudos futuros.

Um importante atributo da liderança, a confiança, é definida como um estado psicológico: "Expectativa positiva de que o outro não agirá de maneira oportuna." (ROBBINS; JUDGE; SOBRAL, 2011, p. 378). Ademais, confiança não está relacionada apenas ao líder, como também às características dos liderados.

Ao trazer confiança para o contex to deste estudo, questiona-se: até que ponto a confiança na liderança propicia a capacidade de inovação? Uma forma de abordar essa questão passa pela análise das consequências da confiança, a exemplo do encorajamento para assumir riscos e facilitação do compartilhamento de informações (ROBBINS; JUDGE; SOBRAL, 2011) - comportamento e pratica relacionados com a inovação (TIDD; BESSANT; PAVITT, 2008).

Dado o exposto, para a pesquisa realizada nesta tese, a característica LG foi composta pelos seguintes elementos: liderança confiança, estilo de gestão e comportamentos de gerentes de projetos de $\mathrm{P} \& D \& I$ que, de acordo com a literatura, estão associados à inovação.

\section{Políticas e Práticas de Gestão de Pessoas (PPGP)}

Conforme explicação fornecida anteriormente na seção 2.2 - Gestão Estratégica de Pessoas, a estratégia de gestão de pessoas pode ser desdobrada em políticas e práticas, que embora estejam articuladas entre si, não podem ser tratadas como sinônimos. Enquanto as políticas dizem respeito às intenções declaradas sobre programas, processos e técnicas, as práticas se referem aos programas, processos e técnicas de reais, observadas e vivenciadas pelos funcionários (WRIGHT; BOSWELL, 2002). Sendo 
assim, práticas se diferenciam de políticas, embora estejam relacionadas no sentido que o primeiro elemento citado abrange o segundo.

No Brasil, as políticas de gestão de pessoas se destacaram pela ênfase em treinamento e desenvolvimento e saúde e segurança no trabalho (FIUZA et al, 2010). Esse achado de pesquisa se baseou na análise de trinta artigos publicados no período de 2004 a 2008, em sete periódicos científicos de classificação igual ou superior ao estrato B2 pelo índice WebQualis da Coordenação de Aperfeiçoamento de Pessoal de Nível Superior de 2011 (CAPES, 2012).

Em âmbito internacional, as políticas se destacam pela maior diversidade e abrangência expressas em suas categorias. São elas: comunicação, crenças e premissas, estrutura organizacional, gestão da mudança, papeis gerenciais, recrutamento, seleção e socialização, sistema de recompensas, treinamento, desenvolvimento e avaliação (LEGGE, 2005). A julgar pelos assuntos tratados como políticas, não parece haver consenso na literatura. Para os fins deste estudo foi adotada a visão de Wright e Boswell (2002), para quem políticas diferem de práticas de gestão de pessoas, embora ambas estejam relacionadas. Essa diferença e essa relação foram explicadas anteriormente na última página da seção 2.2 - Gestão Estratégica de Pessoas.

As práticas de gestão de pessoas, por sua vez, atuam como estímulos a determinadas ações e padrões de comportamento esperados. Elas também orientam os estilos de atuação dos gestores em sua relação com aqueles que nela trabalham (FISCHER, 2002). Elas podem ser definidas em função dos processos de gestão de pessoas, que segundo Fischer (2002), são cursos de ação previamente determinados que não podem ultrapassar os limites dos princípios de gestão e visam alcançar os objetivos traçados, orientados por políticas específicas.

A contribuição da gestão estratégica de pessoas para inovação tem sido retratada sob a perspectiva de práticas inovativas de gestão de recursos humanos (AGARWALA, 2003; SOM, 2003; TANNEMBAUM; DUPUEE-BRUNO, 1994), denotando uma abordagem processual. Também foi identificada foi a contribuição de práticas de gestão de pessoas para estratégia orientada para inovação (COOKE; SAINI, 2010). As cinco práticas analisadas foram: 1) democracia e justiça; 2) recompensas com base em desempenho; 3) bem-estar psicológico; 4) gestão de talentos; e 5) alinhamento entre estratégia de gestão 
de pessoas e estratégia do negócio. As duas práticas que se sobressaíram quando confrontadas com o problema de pesquisa desta tese foram as duas últimas citadas. Uma importante constatação da pesquisa realizada por Cooke e Saini (2010) para este estudo foi que a efetividade na gestão de talentos pode ajudar na retenção de profissionais considerados valiosos sob a perspectiva do processo de inovação.

Sendo assim, foram considerados os seguintes elementos para integrar a característica PPGP: recrutamento, seleção, treinamento, desenvolvimento, avaliação, remuneração, gestão de carreira, bem como gestão de talentos. É importante frisar que esses assuntos foram selecionados considerando o problema de pesquisa e a literatura consultada, conforme o quadro-síntese que será apresentado na seção 2.4 - Consolidação da Fundamentação Teórica.

\section{Outros Antecedentes de Capacidade de Inovação}

Os antecedentes de capacidade de inovação que se relacionaram apenas indiretamente com gestão estratégica de pessoas de acordo com a literatura estudada foram denominados: ambiente e condições favoráveis, estrutura organizacional, práticas e mecanismos de gestão. Embora tenham auxiliado no processo de construção do modelo conceitual da pesquisa (seção 3.2 - Modelo Conceitual e Variáveis), esses três antecedentes não foram objeto da pesquisa empírica realizada nesta tese.

\subsection{Consolidação da Fundamentação Teórica}

Neste capítulo de fundamentação teórica foi identificada a existência de um hiato entre o que se entende por gestão estratégica de pessoas e pela sua aplicação no contexto da inovação.

Apesar da importância do fenômeno - contribuição da gestão estratégica de pessoas para a capacidade de inovação - as lacunas teóricas e oportunidades de investigação indicam que se trata de um fenômeno embrionário. As poucas publicações existentes enfatizam 
fragmentos da gestão estratégica de pessoas no contexto da inovação, revelando um retrato vago e impreciso sobre o fenômeno.

As literaturas de gestão estratégica de pessoas e de gestão da inovação, que serviram de referência para a elaboração deste capítulo, abordaram assuntos semelhantes, porém sob enfoques distintos. Diante da dificuldade de comparar o conteúdo de literaturas distintas, optou-se pela elaboração de um quadro-síntese em que se associou as características de gestão estratégica de pessoas com os principais autores que a retrataram no contexto da inovação.

Para consolidar o conteúdo apresentado neste capítulo serão apresentadas as definições operacionais dos termos relevantes para a pesquisa, elaboradas a partir das abordagens conceituais e teóricas apresentados anteriormente neste capítulo.

Assim, no contexto de antecedentes de capacidade de inovação, gestão estratégica de pessoas foi definida operacionalmente como um conjunto de características organizacionais, constituída por: filosofia, valores e normas; foco estratégico em inovação; liderança e gestão; e políticas e práticas de gestão de pessoas.

Capacidade de inovação foi definida operacionalmente como habilidades envolvidas: na identificação de oportunidades de melhorias visando a inovação, na assimilação de conhecimentos adquiridos em atividades de inovação, no compartilhamento de lições aprendidas em atividades de inovação, na alocação de profissionais de diferentes grupos funcionais em atividades de inovação, e na integração de diferentes grupos funcionais envolvidos no processo de inovação.

Essas duas definições operacionais serão retomadas e desdobradas em itens no capítulo seguinte, de metodologia da pesquisa. 


\subsubsection{Indicadores de Capacidade de Inovação}

No que diz respeito aos indicadores de capacidade de inovação, Yam et al (2010) propuseram sete dimensões com base em pesquisas realizadas anteriormente (YAM et al, 2004; GUAN; MA (2003) sobre inovação tecnológica. São elas: aprendizagem, P\&D, alocação de recursos, manufatura, marketing, organização e planejamento estratégico (Quadro 7). Trata-se de uma abordagem funcional, diferente das pré-existentes realizadas com base em ativos (CHRISTENSEN, 1995) e em processos (CHIESA; COUGHLAN; VOSS, 1996; BURGELMAN; MAIDIQUE, 2004). 
Quadro 7 - Dimensões de capacidade de inovação

\begin{tabular}{|l|l|}
\hline \multicolumn{1}{|c|}{ Dimensões } & \multicolumn{1}{c|}{ Descrições } \\
\hline aprendizagem & $\begin{array}{l}\text { habilidade da firma de identificar, assimilar e explorar conhecimentos do } \\
\text { ambiente }\end{array}$ \\
\hline P\&D & $\begin{array}{l}\text { habilidade da firma de integrar estratégia de P\&D, implementação de projeto, } \\
\text { gestão de portfólio de projeto e despesas com P\&D }\end{array}$ \\
\hline $\begin{array}{l}\text { alocação de } \\
\text { recursos }\end{array}$ & $\begin{array}{l}\text { habilidade de assegurar que a firma possua capital, profissionais e tecnologias } \\
\text { suficientes no processo de inovação }\end{array}$ \\
\hline manufatura & $\begin{array}{l}\text { habilidade da firma de transformar resultados de P\&D em produtos que vão ao } \\
\text { encontro das necessidades do mercado }\end{array}$ \\
\hline marketing & $\begin{array}{l}\text { habilidade da firma de divulgar e vender produtos com o entendimento das } \\
\text { necessidades dos clientes, da competitividade, dos custos, benefícios e aceitação } \\
\text { da inovação }\end{array}$ \\
\hline organização & $\begin{array}{l}\text { habilidade da firma de estabelecer mecanismos organizacionais e harmonia, } \\
\text { cultivando e adotando boas práticas gerenciais }\end{array}$ \\
\hline $\begin{array}{l}\text { planejamento } \\
\text { estratégico }\end{array}$ & $\begin{array}{l}\text { habilidade da firma de identificar forças e fraquezas internas e oportunidades } \\
\text { externas de ameaças, de formular planos de acordo com a visão e missão } \\
\text { corporativa, bem como de preparar os planos para implementação }\end{array}$ \\
\hline
\end{tabular}

FONTE: YAM et al, 2010.

O Quadro 8 revela que essas dimensões foram tratadas como habilidades de gestão, incluindo atividades-fim da empresa e tendências de inovação, corroborando o modelo conceitual de Lawson e Samson (2001), apresentado anteriormente na Figura 2. Também são consideradas as atividades-meio, como as que versam sobre alocação de recursos e organização que podem se relacionar com a gestão de pessoas de maneira mais direta.

Yam et al (2010) propuseram uma escala de capacidade de inovação e consideraram o tamanho da empresa como variável de controle em um levantamento realizado com duzentas empresas de manufatura em Hong Kong. As análises dos resultados da pesquisa empírica revelaram que os valores dos coeficientes de correlação da capacidade de aprendizagem com as demais capacidades variaram entre 0,497 para a capacidade de manufatura e 0,591 para as capacidades de marketing e organização. Tais valores de coeficientes implicam uma classificação moderada segundo HAIR Jr. et al (2005). Porém, como a escala de capacidade de inovação foi arquitetada no contexto da inovação tecnológica e alguns de seus itens podem não se aplicar ao setor industrial como um todo, ela não pôde ser utilizada integralmente nesta tese.

Desta forma, tomou-se como ponto de partida os estudos realizados por Yam et al (2004; 2010) para selecionar as capacidades de inovação utilizadas na pesquisa realizada nesta 
tese. $\mathrm{O}$ critério de seleção consistiu na aderência com a abordagem estratégica da gestão de pessoas. As cinco capacidades selecionadas foram:

- identificação de oportunidades de melhorias visando a inovação;

- assimilação de conhecimentos adquiridos em atividades de inovação;

- compartilhamento de lições aprendidas em atividades de inovação;

- alocação de profissionais de diferentes grupos funcionais em atividades de inovação;

- integração de diferentes grupos funcionais envolvidos no processo de inovação.

No capítulo de Metodologia, essas capacidades são desdobradas em indicadores para no intuito de operacionalizar a pesquisa. 


\section{METODOLOGIA DA PESQUISA}

A metodologia da pesquisa foi organizada em seis seções: natureza e método; modelo conceitual, variáveis e hipóteses; população e amostra; procedimentos; formas de análise; e considerações metodológicas, que engloba a síntese da metodologia, cuidados e limitações.

\subsection{Natureza e Método}

Este estudo se aproxima da concepção ${ }^{4}$ pós-positivista por se voltar mais para as condições antecedentes do que para ações, situações e suas consequências (CRESWELL, 2010).

As características do pós-positivismo relativas a esta tese são: determinismo, no sentido de investigar as causas ou os aspectos que influenciam os efeitos do fenômeno; reducionismo, pela intenção de reduzir as ideias a um conjunto pequeno e distinto de variáveis a serem investigadas, como as que integram a questão da pesquisa; observação e mensuração empíricas, no sentido de que o conhecimento desenvolvido sob essa concepção é baseado em observação e mensuração da realidade objetiva; supõe que as teorias precisam ser testadas ou verificadas e refinadas para que o mundo possa ser compreendido (CRESWELL, 2010).

Considerando que a ciência tem como propósito a construção de teoria (KERLINGER, 1979), entendida como a exposição sistemática das relações entre um conjunto de variáveis, foi utilizado o processo dedutivo. De acordo com Carlile e Christensen (2005) a construção de teoria envolve três passos: observação, categorização e associação visando a elaboração de constructos, tipologias e modelos, respectivamente (Figura 4).

\footnotetext{
${ }^{4}$ Por concepção entende-se um conjunto de crenças básicas que guiam a ação (GUBA, 1990).
} 
Figura 4 - O processo de construção de teoria

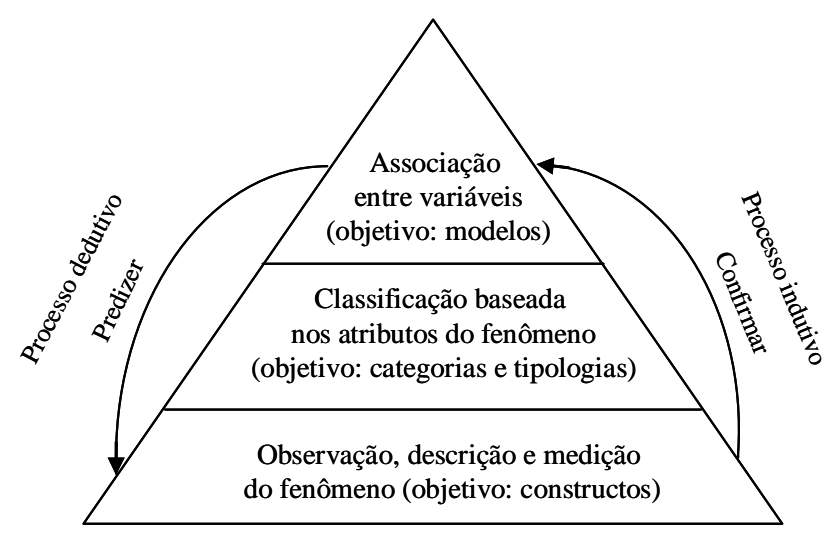

FONTE: Adaptado de CARLILE; CHRISTENSEN, 2005, p.5.

A movimentação que parte do nível inferior para o nível superior da pirâmide diz respeito ao processo indutivo de construção de teoria e o movimento no sentido oposto caracteriza o processo dedutivo. Quando alguma anomalia é encontrada na teoria, revisita-se os estágios iniciais para sua reformulação.

Sob o processo dedutivo, a contribuição da gestão estratégica de pessoas para a capacidade de inovação é um fenômeno que se situa na parte superior da Figura 4. Buscou-se verificar a existência de associação entre características de gestão estratégica de pessoas com indicadores de capacidade de inovação - ambos identificados na literatura.

O presente estudo se enquadrou em um dos propósitos de estudos descritivos: a descoberta de associações entre variáveis. Estudos descritivos são recomendados para “[...] determinar se as variáveis são independentes (ou relacionadas); caso não sejam, deve-se determinar a força ou magnitude da relação. Nenhum procedimento nos diz qual variável é a causa." (COOPER; SCHINDLER, 2011, p. 155).

Como a contribuição da gestão estratégica de pessoas para a capacidade de inovação consiste um fenômeno embrionário de acordo com a pesquisa bibliográfica realizada nesta tese, procurou-se investigar a relação de associação entre gestão estratégica de pessoas (antecedente) e capacidade de inovação (consequente), sem a pretensão de especular sobre causa e efeito dessa relação.

O problema de pesquisa apresentado no primeiro capítulo desta tese: Em que medida a gestão estratégica de pessoas pode contribuir para a capacidade de inovação no setor industrial? sugere a realização de pesquisa sob o método quantitativo. Isso implicou em fazer estimativas sobre força e direção da relação de associação entre gestão estratégica 
de pessoas (antecedente) e capacidade de inovação (consequente) a partir do modelo conceitual proposto na seção 3.2 - Modelo Conceitual e Variáveis.

Dado o exposto nesta seção, o presente estudo foi realizado sob a concepção póspositivista, com base no processo dedutivo. A julgar por suas características, o estudo foi caracterizado como de natureza descritiva, utilizando o método quantitativo (Quadro 8), com determinados procedimentos metodológicos que serão apresentados ao longo deste capítulo.

Quadro 8 - Escolhas metodológicas sob o enfoque quantitativo

\begin{tabular}{|c|c|c|c|}
\hline $\begin{array}{c}\text { Tende a ou } \\
\text { tipicamente... }\end{array}$ & $\begin{array}{l}\text { Abordagens } \\
\text { qualitativas }\end{array}$ & $\begin{array}{l}\text { Abordagens } \\
\text { quantitativas }\end{array}$ & $\begin{array}{l}\text { Abordagens de } \\
\text { métodos mistos }\end{array}$ \\
\hline $\begin{array}{l}\text { Usa essas } \\
\text { suposições } \\
\text { filosóficas }\end{array}$ & $\begin{array}{l}\text { Declarações de } \\
\text { conhecimento } \\
\text { construtivistas/ } \\
\text { reivindicatórias/ } \\
\text { participatórias }\end{array}$ & $\begin{array}{l}\text { Declarações de } \\
\text { conhecimento pós- } \\
\text { positivistas }\end{array}$ & $\begin{array}{l}\text { - Declarações de } \\
\text { conhecimento } \\
\text { pragmáticas }\end{array}$ \\
\hline $\begin{array}{l}\text { - Emprega essas } \\
\text { estratégias de } \\
\text { investigação }\end{array}$ & $\begin{array}{l}\text { Fenomenologia, } \\
\text { teoria fundamentada, } \\
\text { etnografia, estudo de } \\
\text { caso e narrativa }\end{array}$ & $\begin{array}{l}\text { - Levantamentos e } \\
\text { experimentos }\end{array}$ & $\begin{array}{l}\text { - Sequenciais, } \\
\text { concomitantes e } \\
\text { transformativas }\end{array}$ \\
\hline $\begin{array}{l}\text { - Emprega esses } \\
\text { métodos }\end{array}$ & $\begin{array}{l}\text { Questões abertas, } \\
\text { abordagens } \\
\text { emergentes, dados de } \\
\text { texto ou imagem }\end{array}$ & $\begin{array}{l}\text { Questões fechadas, } \\
\text { abordagens } \\
\text { predeterminadas, } \\
\text { dados numéricos }\end{array}$ & $\begin{array}{l}\text { Tanto questões } \\
\text { abertas quanto } \\
\text { fechadas, tanto } \\
\text { abordagens } \\
\text { emergentes quanto } \\
\text { predeterminadas, e } \\
\text { tanto dados e } \\
\text { análises } \\
\text { quantitativos } \\
\text { quanto qualitativos }\end{array}$ \\
\hline $\begin{array}{l}\text { - Usa essas } \\
\text { práticas de } \\
\text { pesquisa à } \\
\text { medida que o } \\
\text { pesquisador }\end{array}$ & 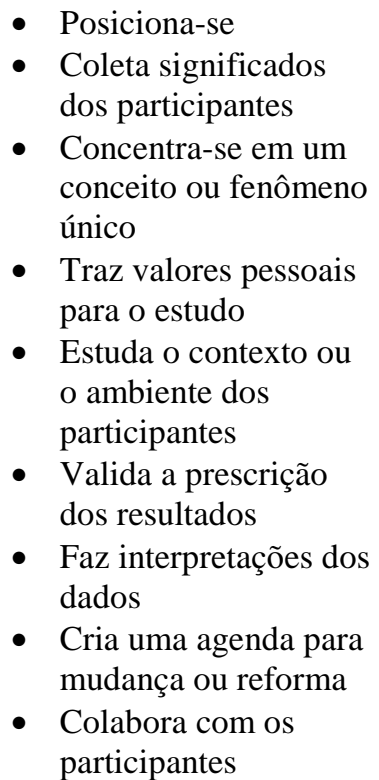 & 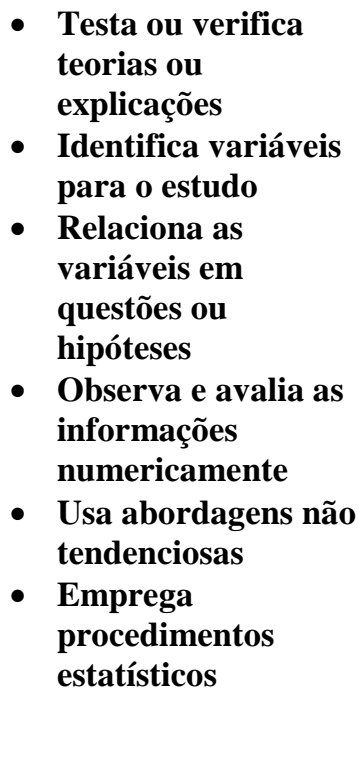 & $\begin{array}{l}\text { - } \text { Coleta tanto dados } \\
\text { quantitativos } \\
\text { quanto qualitativos } \\
\text { Desenvolve uma } \\
\text { justificativa para a } \\
\text { combinação } \\
\text { - Integra os dados de } \\
\text { diferentes estágios } \\
\text { da investigação } \\
\text { - Apresenta quadros } \\
\text { visuais dos } \\
\text { procedimentos do } \\
\text { estudo } \\
\text { Emprega as } \\
\text { práticas tanto da } \\
\text { pesquisa qualitativa } \\
\text { quanto da } \\
\text { quantitativa }\end{array}$ \\
\hline
\end{tabular}

FONTE: CRESWELL, 2010, p. 42. 


\subsection{Modelo Conceitual e Variáveis}

Partiu-se do problema de pesquisa e do referencial teórico utilizado nesta tese para construir o modelo conceitual: “[...] representação de um sistema construído para estudar algum aspecto daquele sistema ou o sistema como um todo." (COOPER; SCHINDLER, 2011, p. 60).

No lado esquerdo da Figura 5 foram inseridos os antecedentes de capacidade de inovação: características organizacionais identificadas tanto na literatura de gestão estratégica de pessoas quanto na de gestão da inovação. No lado direito consta a capacidade de inovação.

Figura 5 - Foco da pesquisa

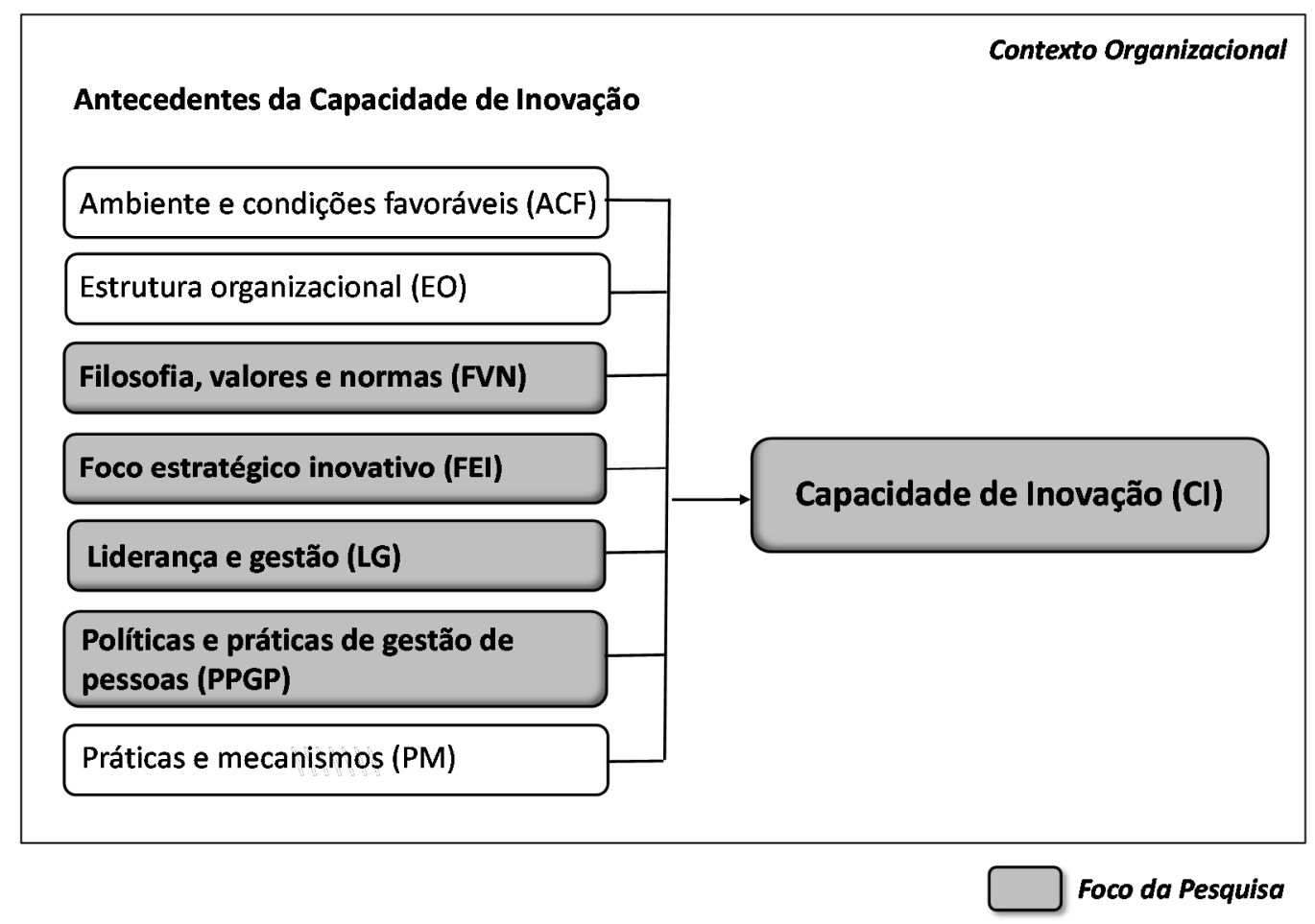

Cabe ressaltar que os quatro antecedentes de capacidade de inovação sob a perspectiva da gestão estratégica de pessoas (FVN, FEI, LG e PPGP) e a capacidade de inovação (CI) foram destacados na cor cinza para comunicar o foco da pesquisa.

Os antecedentes de capacidade de inovação sob a perspectiva da gestão estratégica de pessoas foram denominados características de gestão estratégica de pessoas para 
operacionalizar a pesquisa. Cada característica foi desdobrada em indicadores assim organizados:

- filosofia, valores e normas (FVN) - onze indicadores;

- foco estratégico em inovação (FEI) - oito indicadores;

- liderança e gestão (LG) - quinze indicadores;

- políticas e práticas de gestão de pessoas (PPGP) - nove indicadores.

Por não integrarem o escopo da pesquisa, os demais antecedentes de capacidade de inovação (ACF, EO e PM) não foram detalhados. Partiu-se do foco do estudo para definir o modelo conceitual da pesquisa e, assim, investigar a contribuição da gestão estratégica de pessoas para capacidade de inovação no setor industrial. Estipulou-se que essa contribuição seria estudada pela relação de associação entre o antecedente o consequente.

Em pesquisa, o antecedente corresponde à variável independente, o consequente à variável dependente e os fatores que possivelmente afetam a relação entre as variáveis independente e dependente constituem as variáveis intervenientes (KERLINGER, 1979; COOPER; SCHINDLER, 2011). Ressalta-se que variável pode ser entendida como um constructo, um conceito com significado específico, construído por um dado pesquisador. Ela consiste em uma propriedade que assume valores diferentes, indicando quantidade ou grau (KERLINGER, 1979).

Nesta pesquisa a variável independente Gestão Estratégica de Pessoas foi representada por quatro características organizacionais: filosofia, valores e normas (FVN); foco estratégico em inovação (FEI); liderança e gestão (LG); e políticas e práticas de gestão de pessoas (PPGP).

A variável dependente Capacidade de Inovação foi representada por cinco indicadores de gestão da inovação (YAM et al, 2004; YAM et al, 2010): habilidade de identificar oportunidades de melhorias com vistas à inovação (OM); habilidade de assimilar conhecimentos adquiridos em atividades de inovação (AC); habilidade de compartilhar lições aprendidas em atividades de inovação (LA); habilidade de alocar profissionais provenientes de diferentes grupos funcionais em atividades de inovação (AL); e habilidade de integrar diferentes grupos funcionais envolvidos no processo de inovação (GF). O critério de escolha dos cinco indicadores foi previamente apresentado na seção 
2.3.1.2 - Indicadores de Capacidade de Inovação. As variáveis independente, dependente e interveniente foram detalhadas no Apêndice 3 - Mapa das Variáveis.

Os fatores que potencialmente afetam a gestão estratégica de pessoas e/ou a gestão da inovação no ambiente organizacional interno são: setor, porte, tempo de operação no Brasil e receita operacional bruta (ARMSTRONG, 2011; SOM, 2007; BREWSTER et al, 2006; DAMANPOUR, 1992; SBRAGIA et al, 1999). A primeira variável foi desconsiderada porque a pesquisa foi realizada exclusivamente no setor industrial. As demais variáveis, por terem sido tratadas como variáveis de controle em estudos anteriores e pela potencial interferência na relação de associação estudada, foram consideradas três variáveis intervenientes: porte; tempo de operação no Brasil; e receita operacional bruta.

Com base nas variáveis anteriormente descritas foi elaborado o modelo conceitual da pesquisa.

Figura 6 - Modelo conceitual da pesquisa

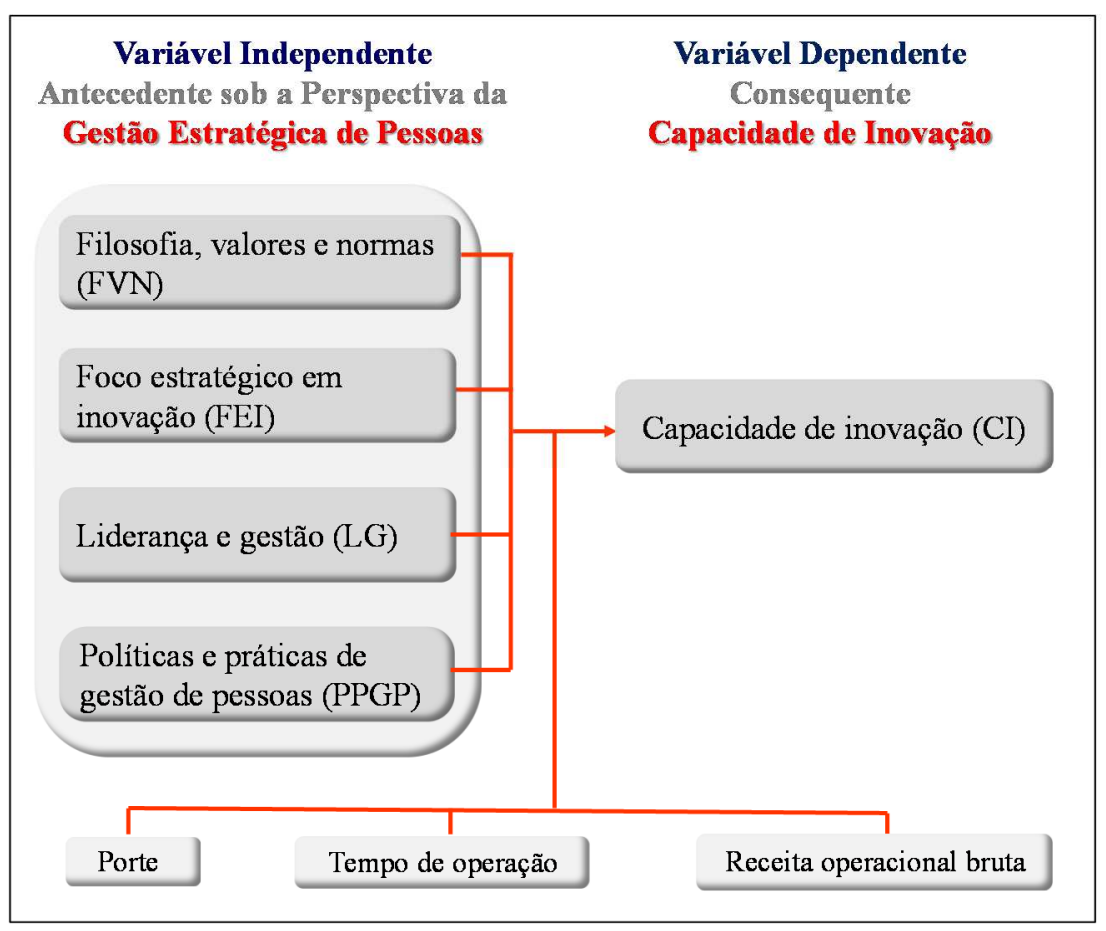

Os indicadores da variável independente gestão estratégica de pessoas que totalizaram quarenta e três foram listados no Quadro 09 acompanhados de suas fontes (Quadro 10). A variável dependente capacidade de inovação, por sua vez, foi 
desdobrada em cinco indicadores de gestão da inovação listados no Quadro 11. As variáveis intervenientes porte, receita operacional bruta e tempo de operação no Brasil foram especificadas no Quadro 12. Todos os indicadores foram desenvolvidos pela pesquisadora com base na literatura. 
Quadro 9 - Indicadores da variável independente gestão estratégica de pessoas

\begin{tabular}{|c|c|}
\hline & $\begin{array}{c}\text { Variável Independente } \\
\text { GESTÃO ESTRATÉGICA DE PESSOAS } \\
\text { Caracterís ticas e Indicadores }\end{array}$ \\
\hline \multirow{11}{*}{ FVN } & Inovar faz parte da razão de existir desta empresa. \\
\hline & A declaração de visão reforça o propósito de inovar desta empresa. \\
\hline & Inovação é um valor central desta empresa. \\
\hline & Flexibilidade é indispensável para inovação. \\
\hline & Colaboração é indispensável para inovação. \\
\hline & Comunicação ampla é indispensável para inovação. \\
\hline & Criatividade é indispensável para inovação. \\
\hline & Aprendizagemé indispensável para inovação. \\
\hline & Conhecimento é indispensável para inovação. \\
\hline & Diversidade é indispensável para inovação. \\
\hline & Diversidade é indispensável para inovação. \\
\hline \multirow{8}{*}{ FEI } & A inovação está arraigada em nosso modelo de negócio. \\
\hline & Esta empresa é mais orientada para diferenciação do que para liderança em custo. \\
\hline & Existe coerência entre a estratégia organizacional e a estratégia de inovação. \\
\hline & Esta empresa busca ser a primeira a lançar novos produtos e serviços no mercado. \\
\hline & A empresa em que trabalho se caracteriza pela orientação para o cliente. \\
\hline & A empresa em que trabalho sistematicamente divulga informações sobre inovação. \\
\hline & A empresa em que trabalho sistematicamente divulga resultados obtidos com inovação. \\
\hline & A gerência de P\&D\&I é consultada quando da tomada de decisões estratégicas. \\
\hline
\end{tabular}




\begin{tabular}{|c|c|}
\hline & $\begin{array}{l}\text { Variável Independente } \\
\text { GESTÃO ESTRATÉGICA DE PESSOAS } \\
\text { Características e Indicadores }\end{array}$ \\
\hline \multirow{15}{*}{ LG } & Os líderes de minha empresa apresentam predisposição para inovar. \\
\hline & Os líderes dis seminam o intento inovador por toda a organização de maneira efetiva. \\
\hline & Os líderes inspiram as pessoas a se engajarem em atividades de inovação. \\
\hline & Os líderes fornecem estímulo intelectual para a solução de problemas. \\
\hline & Os líderes apresentam tolerência à incerteza. \\
\hline & A líderes estimulam a interação criativa. \\
\hline & O estilo de gestão desta empresa é participativo. \\
\hline & Existe confiança no executivo que patrocina a inovação nesta empresa. \\
\hline & O executivo que patrocina a inovação na empresa as segura que os projetos recebam assistência de todos os profissionais envolvidos. \\
\hline & Existe coerência entre as orientações fornecidas pelo executivo responsável por inovação e pelos gerentes de projetos. \\
\hline & Os gerentes de projetos estimulam o desenvolvimento de competências atreladas à inovação. \\
\hline & Os gerentes de projetos encorajam a proposição de novas maneiras de fazer as coisas. \\
\hline & Riscos calculados são encarados de maneira positiva em minha empresa. \\
\hline & Aqui os erros também representam oportunidade de aprendizagem. \\
\hline & Nesta empresa entende-se que os conflitos também podem instigar a inovação. \\
\hline \multirow{9}{*}{ PPGP } & As políticas de gestão de pessoas desta empresa estão alinhadas com a estratégia corporativa. \\
\hline & As políticas de gestão de pessoas fomentam a inovação na empresa. \\
\hline & As práticas de recrutamento e seleção desta empresa contribuem para a contratação de bons profissionais de P\&D\&I. \\
\hline & Há compromisso de longo prazo com treinamento e desenvolvimento voltados para inovação. \\
\hline & O plano de carreira da empresa considera as necessidades dos profissionais de P\&D\&I. \\
\hline & A inovação é considerada no(s) método(s) de avaliação de desempenho humano. \\
\hline & O sistema de recompensas desta empresa estimula o engajamento em atividades de inovação. \\
\hline & O trabalho em equipes multifuncionais é uma prática amplamente utilizada em projetos de P\&D\&I. \\
\hline & A gestão de talentos contribui para a retenção de profissionais de P\&D\&I. \\
\hline
\end{tabular}


Quadro 10 - Fontes dos indicadores de gestão estratégica de pessoas

\begin{tabular}{|c|c|}
\hline $\begin{array}{l}\text { Características de } \\
\text { Gestão Estratégica de Pessoas }\end{array}$ & $\begin{array}{l}\text { Principais Fontes } \\
\text { Elaboração dos Indicadores }\end{array}$ \\
\hline Filosofia, valores e normas (FVN) & $\begin{array}{l}\text { Pallas et al (2013); Smith et al (2008); Martins e Terblanche (2003); Ahmed (1988); Dobni (2008); Khazanchi, } \\
\text { Lewis and Boyer (2007); Bock et al (2012); Chen, Tjosvold e Liu (2006); Schein (1988); Jamrog et al (2006); } \\
\text { Bucic e Ngo (2012); Amabile (1996); Parolin e Albuquerque (2008); Bharadwaj e Menon (2000); Roffe (1999); } \\
\text { Liao, Chang e Yueh, (2012); Aragón-Correa, García-Morales e Cordón-Pozo (2007); Tidd, Bessant e Pavitt (2008); } \\
\text { Ng (2004); Davila et al (2006); Yang e Konrad (2011); Herzog e Leker (2010); Lawson e Samson (2001); Yesil e } \\
\text { Büyükbese, 2013; Prajogo e Ahmed (2006); Isaksen e Ekwall (2010). }\end{array}$ \\
\hline Foco Estratégico em Inovação (FEI) & $\begin{array}{l}\text { Dogson, Gann e Phillips, 2014; Jamrog et al (2006); Ryan e Tipu (2013); Dobni (2008); Martins e Terblanche } \\
\text { (2003); Barney e Hesterly (2011); Porter (1989); Smith et al (2008); Pallas et al (2013); Tidd, Bessant e Pavitt } \\
\text { (2008) Lawson e Samson (2001); Akman e Yilmaz (2009); Tallman (2003). }\end{array}$ \\
\hline Liderança e Gestão (LG) & $\begin{array}{l}\text { Pallas et al (2013); Crossan e Apaydin (2009); Tsai et al (2013); Robbins, Judge e Sobral (2011); Ahmed (1998); } \\
\text { Stirpe et al (2013); Dobni (2008); Denti e Hemlin (2012); Jung, Chow e Wu (2003); Aragón-Correa, García- } \\
\text { Morales e Cordón-Pozo (2007); Dess e Picken (2000); Ryan e Tipu (2013); Smith et al (2008); Tidd, Bessant e } \\
\text { Pavitt (2008); Davila et al (2006); Jamrog et al (2006); Martins e Terblanche (2003); Schein (1988); Wang e } \\
\text { Ahmed (2004); Lawson e Samson (2001); Prajogo e Ahmed (2006), Som (2007). }\end{array}$ \\
\hline $\begin{array}{l}\text { Políticas e Práticas de Gestão de Pessoas } \\
\text { (PPGP) }\end{array}$ & $\begin{array}{l}\text { Jiménez-Jiménez e Sanz-Valle (2006); Agarwla (2003); Cooke e Saini (2010); Saá-Pérez e Díaz-Díaz (2010); } \\
\text { Leede e Looise (2005); Matthews (2002); Takeuchi (2009); Som (2007); Martins e Terblanche (2003); Tidd, } \\
\text { Bessant e Pavitt (2008); Smith et al (2008); Pallas et al (2013); Shipton et al (2006); Chandler, Keller e Lyon } \\
\text { (2000); Nybakk e Jenssen (2012); Boly et al (2014); Cavagnoli (2011); Chen e Huang (2009). }\end{array}$ \\
\hline
\end{tabular}


Quadro 11 - Indicadores da variável dependente capacidade de inovação

\begin{tabular}{|l|l|l|}
\hline \multicolumn{1}{|c|}{$\begin{array}{l}\text { Variável Dependente } \\
\text { CAPACIDADE DE INOVAÇÃO }\end{array}$} & \multicolumn{2}{c|}{ Indicadores e Fontes } \\
\hline $\begin{array}{l}\text { Identificação de oportunidades de melhorias } \\
\text { visando a inovação }\end{array}$ & $\begin{array}{l}\text { Habilidade da empresa de encorajar equipes de projetos para identificar } \\
\text { oportunidades de melhoria }\end{array}$ \\
\hline $\begin{array}{l}\text { Assimilação de conhecimentos adquiridos em } \\
\text { atividades de inovação }\end{array}$ & $\begin{array}{l}\text { Habilidade da empresa de assimilar conhecimentos adquiridos com atividades de } \\
\text { inovação }\end{array}$ \\
\hline $\begin{array}{l}\text { Compartilhamento de lições aprendidas em } \\
\text { atividades de inovação }\end{array}$ & $\begin{array}{l}\text { Habilidade da empresa de compartilhar lições aprendidas em projetos de pesquisa, } \\
\text { desenvolvimento e inovação }\end{array}$ \\
\hline $\begin{array}{l}\text { Alocação de profissionais de diferentes grupos } \\
\text { funcionais em atividades de inovação }\end{array}$ & $\begin{array}{l}\text { Habilidade da empresa de alocar profissionais provenientes de diferentes grupos } \\
\text { funcionais em atividades de inovação }\end{array}$ \\
\hline $\begin{array}{l}\text { Integração de diferentes grupos funcionais } \\
\text { envolvidos no processo de inovação }\end{array}$ & $\begin{array}{l}\text { Habilidade da empresa de integrar diferentes grupos funcionais evolvidos no } \\
\text { processo de inovação }\end{array}$ \\
\hline
\end{tabular}

Quadro 12 - Indicadores das variáveis intervenientes

\begin{tabular}{|c|c|c|}
\hline \multicolumn{3}{|c|}{ Variáveis Intervenientes } \\
\hline & Classificações & Principais fontes \\
\hline Porte & Microempresa; pequena empresa; média empresa; média-grande empresa; grande empresa ${ }^{5}$ & BNDES (2004a) \\
\hline $\begin{array}{l}\text { Tempo de operação no } \\
\text { Brasil }\end{array}$ & Anos completos & Brewster (2006) \\
\hline Receita operacional bruta & $\begin{array}{l}\text { Menor ou igual a R\$ 2,4 milhões; maior que R\$ } 2,4 \text { milhões e menor ou igual a R\$ } 16 \text { milhões; } \\
\text { maior que } \mathrm{R} \$ 16 \text { milhões e menor ou igual a } \mathrm{R} \$ 90 \text { milhões; maior que } \mathrm{R} \$ 90 \text { milhões e menor ou } \\
\text { igual a } \mathrm{R} \$ 300 \text { milhões; maior do que } \mathrm{R} \$ 300 \text { milhões }\end{array}$ & BNDES (2004a) \\
\hline
\end{tabular}

$\overline{{ }^{5} \text { Os critérios utilizados nessa classificação constam no Anexo } 3 .}$ 


\subsection{População e Amostra}

A população da pesquisa foi formada por profissionais que atuaram na gestão de projetos de P\&D\&I em organizações industriais com operações no Brasil. Partiu-se do entendimento de população como o conjunto completo de elementos sobre os quais se deseja fazer inferências (COOPER; SCHINDLER, 2011).

Um argumento que fortaleceu a escolha da população foi que para exercer a função descrita no parágrafo anterior, os profissionais também precisam coordenar esforços conjuntos, administrar expectativas, interesses, comportamentos e relacionamentos no escopo dos projetos de P\&D\&I que gerenciam. Logo, o fato de atuarem na gestão de projetos de $\mathrm{P} \& \mathrm{D} \& \mathrm{I}$ e como gestores de pessoas tornou esses profissionais um potencial alvo da pesquisa empírica.

A população serviu de base para a definição da unidade de coleta e análise de dados. Como mais de um profissional poderia exercer a função descrita na população, optou-se pela unidade de análise individual.

Foram considerados elementos da população os diretores, gerentes e líderes de projetos de P\&D\&I. No caso de empresas menores os proprietários também foram considerados. Optou-se por não utilizar nomenclaturas de cargos como referencial, posto que uma mesma função poderia ser exercida por cargos diferentes nas organizações industriais.

Da população foi selecionado um subgrupo denominado amostra. Para os fins desta pesquisa foi utilizada amostra não-probabilística obtida de maneira não aleatória. Isso significa que a probabilidade de cada elemento da população fazer parte a amostra não foi igual (FÁVERO et al, 2009). Dentre os métodos não probabilísticos existentes optouse pela amostragem por conveniência, aplicável, entre outros aspectos, quando existe participação voluntária dos respondentes.

A amostra, portanto, foi constituída por 51 profissionais que, no período em que os dados foram coletados, atuavam ou haviam atuado na gestão de projetos de P\&D\&I em organizações industriais com operações no Brasil, que concordaram em participar da pesquisa. 
Ressalta-se não ter sido possível dimensionar o tamanho da população, nem da amostra porque empresas podem ter mais de um profissional exercendo posições de gestão em P\&D\&I.

\subsection{Hipóteses}

Foram formuladas as hipóteses para a pesquisa: declarações formais de suposições não comprovadas que tentam explicar certos fatos ou fenômenos (HAIR Jr. et al, 2005) que se pretende refutar ou corroborar com base nos resultados obtidos.

As hipóteses derivaram do terceiro objetivo de investigação, que consistiu em analisar a contribuição da gestão estratégica de pessoas para a capacidade de inovação. A seguir serão enunciadas as quatro hipóteses da pesquisa.

Hipótese 1: Gestão estratégica de pessoas está associada com capacidade de inovação.

Hipótese 2: As empresas industriais de grande porte apresentam maior associação entre gestão estratégica de pessoas e capacidade de inovação.

Hipótese 3: As empresas industriais com maior receita operacional bruta apresentaram maior associação entre gestão estratégica de pessoas e capacidade de inovação.

Hipótese 4: As empresas industriais com maior tempo de operação no Brasil apresentaram maior associação entre gestão estratégica de pessoas e capacidade de inovação.

As hipóteses foram testadas empiricamente, pelos valores dos coeficientes de correlação de Spearman. Explicações complementares serão fornecidas na seção 3.6 - Plano de Análise. 


\subsection{Procedimentos}

A seguir serão apresentados os procedimentos envolvidos delineamento da pesquisa e na coleta de dados.

\subsubsection{Delineamento da Pesquisa}

Após o exame de qualificação, realizado no segundo semestre de 2013, foram incorporadas as sugestões de melhoria e feitas correções apontadas pela banca examinadora. As atividades preparatórias para a coleta de dados se concentraram no primeiro semestre de 2014 e consistiram na definição da unidade de coleta e de análise (ver seção 3.3 - População e Amostra), definição da técnica de pesquisa e desenvolvimento do instrumento de coleta de dados.

Para investigar a relação de associação entre gestão estratégica de pessoas e capacidade de inovação, optou-se pela técnica de levantamento (também denominada survey) do tipo autoadministrada, pela Internet.

Entre as vantagens da utilização de surveys eletrônicas autoadministradas no contexto dessa pesquisa, destacam-se: a rapidez na coleta de dados; e maior parcimônia possibilidade de maior cobertura geográfica sem aumento de custos (COOPER; SCHINDLER, 2011). Entre suas limitações, destacam-se: o baixo controle amostral devido à falta de conhecimento do respondente; a incerteza quanto à assertividade da lista de endereços eletrônicos; a taxa de resposta tende a ser menor que a dos meios tradicionais; aumento da dificuldade de recrutar participantes, devido ao excesso de pesquisas; dificuldade de definir o erro de não resposta (VASCONCELLOS; GUEDES, 2007), em função da falta de interação com o respondente; e risco de o e-mail convite contendo o endereço eletrônico da pesquisa seja considerado lixo eletrônico.

O levantamento foi utilizado para coletar dados primários com profissionais que atuaram na gestão de projetos de pesquisa, desenvolvimento e inovação sob o escopo corporativo de empresas industriais com operações no Brasil. 
Optou-se pelo corte transversal, que fornece um panorama ou descrição do fenômeno em determinado ponto no tempo. "Os dados são coletados em um único ponto no tempo e sintetizados estatisticamente." (HAIR Jr. et al, 2005, p. 87). O ponto no tempo correspondeu ao período em que os dados foram coletados: segundo semestre de 2014.

$\mathrm{Na}$ ausência de instrumental recente na literatura nacional e internacional que pudesse ser utilizado para investigar a relação entre gestão estratégica de pessoas e capacidade de inovação conforme apontado na seção 24 - Síntese da Fundamentação Teórica, foi necessário:

1. estabelecer definições operacionais para os conceitos de gestão estratégica de pessoas e capacidade de inovação;

2. definir as variáveis, seus respectivos indicadores e hipóteses da pesquisa;

3. construir medidas e um instrumento para coletar os dados.

As duas primeiras atividades foram realizadas anteriormente, nas seções 2.3 e 3.2. Para construir as medidas e o instrumento foram consideradas as recomendações fornecidas por García e León (2002), de revisar criticamente o problema, objetivo e hipóteses formuladas, tanto sob o ponto de vista metodológico quanto sob o ponto de vista dos conhecimentos necessários relativos ao campo de estudo.

Também foram realizadas consultas com três especialistas (professores da FEA/USP que têm como linha de pesquisa gestão de pessoas e de gestão da inovação). Eles forneceram sugestões de melhoria para o modelo conceitual e para o aprimoramento dos indicadores relativos às variáveis independente e dependente. Esse procedimento foi uma adaptação da técnica denominada por Pasquali (2010) de Consulta a Juízes, que consiste em uma análise de construto. $\mathrm{O}$ autor recomenda que "[...] os juízes devem ser peritos na área do construto, pois sua tarefa consiste em ajuizar se os itens estão se referindo ou não a um traço em questão."

A primeira versão do questionário foi submetida ao pré-teste com dois grupos de pessoas, partindo do entendimento de que cada grupo poderia fornecer contribuições sob diferentes perspectivas. Foram convidadas doze pessoas, sendo seis por grupo. O préteste foi utilizado para aprimorar o instrumento e identificar a necessidade de correções e alterações antes de sua efetiva aplicação. 
O primeiro grupo foi formado por gestores com as características descritas na população. Embora seis gestores de setores de diferentes segmentos do setor industrial tenham sido convidados, apenas dois concordaram em participar: o primeiro do setor automotivo (com Mestrado em Administração) e o segundo do setor de alimentos. As contribuições desse primeiro grupo se concentraram segunda e na terceira partes do questionário. Em resposta às contribuições recebidas, por exemplo, as questões de livre preenchimento (abertas) foram modificadas para coletar dados em faixas, principalmente as que envolveram dados financeiros das empresas.

O segundo grupo de respondentes foi formado por professores doutores em Administração formados nos últimos cinco anos pelo Programa de Pós-Graduação em Administração da Faculdade de Economia, Administração e Contabilidade da Universidade de São Paulo - PPGA FEA/USP, provenientes de áreas de concentração condizentes com esta tese: Gestão de Pessoas em Organizações e Administração Geral.

Para compor esse segundo grupo foram convidadas seis pessoas: três de Gestão de Pessoas em Organizações e três de Administração Geral (sendo duas com experiência em pesquisa quantitativa). As seis pessoas convidadas aceitaram participar do pré-teste. Dentre as contribuições fornecidas, destacaram-se: identificação das questões que demandaram ajustes na redação em função das características da população; sugestões de melhoria na redação para obter clareza e sentido, tanto no enunciado quanto nas questões; identificação de ambiguidade entre as questões, sugestão de redução de questões nas partes dois e três do questionário; sugestão de uniformização da escala das questões nas partes quatro e cinco; e mudança de ordem das questões.

Todas as pessoas que foram convidadas para participar do pré-teste receberam um $e$-mail que continha uma breve explicação sobre a pesquisa, além do questionário salvo em um arquivo do Excel. Apenas para o grupo formado por doutores em Administração foi fornecido material complementar contendo a questão de pesquisa, objetivos de investigação e modelo conceitual).

Após finalizar os ajustes, o questionário foi inserido no site de pesquisas Survey Monkey (2014). Antes de ativar o endereço eletrônico do questionário foi feito um último procedimento: a simulação de resposta. Trata-se de um mecanismo que permite preencher o questionário sem que a resposta seja computada como dado coletado. 
A pesquisadora, então, realizou três simulações e não identificou problemas na visualização do cabeçalho, instruções iniciais e enunciados de cada parte do questionário. As questões foram respondidas em formatos válidos e também em formatos não-válidos para verificar se o instrumento estava configurado adequadamente para rejeitar respostas inadequadas. Acrescenta-se que não foram identificados problemas na mudança de páginas nos sentidos de avanço e de retrocesso.

A versão final do questionário foi organizada em cinco partes. Na primeira parte foi apresentado o título e objetivo da pesquisa, informada a referência a ser utilizada nas respostas (escopo corporativo da empresa sobre a qual os dados seriam coletados) e solicitado o repasse do e-mail-convite contendo o link de acesso à pesquisa, caso o profissional abordado não possuísse as características da população.

Na segunda e terceira partes foram solicitadas informações gerais sobre a empresa e sobre o respondente, respectivamente, sem a necessidade de identificação. Para selecionar o conteúdo das questões que caracterizaram as empresas, recorreu-se à seção 2.3 - Gestão da Inovação Organizacional.

Ao final da terceira parte foi solicitado, em caráter facultativo, um e-mail que poderia ser o endereço pessoal do respondente ou de qualquer contato por ele indicado. Com essa medida, todos aqueles que tivessem respondido completa e adequadamente ao questionário teriam acesso ao relatório sintético dos resultados caso desejassem. Tanto na segunda quanto na terceira parte foram utilizadas questões abertas e de múltipla escolha.

A quarta parte versou sobre características de gestão estratégica de pessoas. Foi solicitado aos profissionais que pontuassem, segundo o nível de concordância, a alternativa que melhor descreveu a empresa em que geriram projetos de $\mathrm{P} \& \mathrm{D} \& \mathrm{I}$ no período em que os dados foram coletados. As alternativas foram expressas por números ordinais organizados em escala de sete pontos. As pontuações extremas da escala foram caracterizadas como: "1 - discordo fortemente" e "7 - concordo fortemente" para servir de referência para as respostas e minimizar a subjetividade envolvida no processo de mensuração, frisando que o propósito da pesquisa foi de quantificar e não de qualificar. 
Figura 7 - Escala para observação e mensuração das variáveis independentes

discordo

totalmente

concordo

totalmente

\begin{tabular}{|l|l|l|l|l|l|l|}
\hline 1 & 2 & 3 & 4 & 5 & 6 & 7 \\
\hline
\end{tabular}

A quinta e última parte do questionário versou sobre indicadores de capacidade de inovação. Foi solicitado aos gestores que pontuassem, segundo o nível de contribuição percebida do conjunto de afirmações apresentadas na quarta parte do questionário para cada uma das cinco frases que consistiram nos indicadores de capacidade de inovação.

Assim como na quarta parte, as alternativas foram expressas por números ordinais organizados em escala de sete pontos. As pontuações extremas da escala foram apresentadas e caracterizadas ("1 - muito baixa" e "7 - muito alta") com a mesma finalidade explicada no parágrafo anterior.

Figura 8 - Escala para observação e mensuração das variáveis dependentes

muito baixa

muito alta

\begin{tabular}{|l|l|l|l|l|l|l|}
\hline 1 & 2 & 3 & 4 & 5 & 6 & 7 \\
\hline
\end{tabular}

As escalas de medida utilizadas na versão final do questionário foram as seguintes:

- variáveis independentes: métricas em escala razão;

- $\quad$ variáveis dependentes: métricas em escala razão;

- variáveis intervenientes: não métricas em escala nominal e ordinal.

A versão final do questionário eletrônico foi inserida no Apêndice 2.

\subsubsection{Coleta de Dados}

A coleta de dados foi realizada no segundo semestre de 2014, com duração de dez semanas. Foram utilizadas fontes diretas e indiretas de respondentes. No Apêndice 1 
foram exibidos modelos de convites redigidos pela pesquisadora para coletar dados por ambas as fontes.

As fontes foram caracterizadas como diretas quando os profissionais com as características da população foram identificados e contatados pela pesquisadora; e indiretas, quando os profissionais foram identificados e abordados por instituições parceiras da pesquisa. Foram consideradas instituições parceiras as federações das indústrias de estados brasileiros e instituições de fomento à inovação que possuíam relacionamento com empresas industriais e que concordaram em apoiar formalmente a coleta de dados.

O apoio à pesquisa foi formalizado na presença de pelo menos uma evidência fornecida pela instituição: número de gestores com as características da população que receberam por e-mail um convite contendo o endereço eletrônico da pesquisa na Internet e cópia de comunicado institucional divulgando a pesquisa para as empresas industriais.

Inicialmente as federações das indústrias dos Estados das regiões sudeste e sul foram contatadas, por e-mail e telefone pela pesquisadora, com o objetivo de obter apoio na divulgação da pesquisa para seu público-alvo: profissionais com as características da população. O critério que determinou a escolha das federações foi a contribuição de seus respectivos Estados para a economia brasileira, tomando como base Produto Interno Bruto - PIB. De acordo com dados fornecidos pelo Instituto Brasileiro de Geografia e Estatística - IBGE (2012), as regiões sudeste e sul contribuíram em 2012 para 71,4\% do PIB brasileiro, conforme o Anexo 2.

Três instituições de fomento à inovação foram procuradas por terem contato com organizações industriais e pelo acesso aos indivíduos com as características da população. Acreditou-se que por serem orientadas para inovação, as instituições poderiam se interessar pela pesquisa e ajudar na divulgação.

Sendo assim, duas federações das indústrias de Estados brasileiros concordaram em apoiar formalmente a pesquisa, sendo uma da região sudeste e outra da região sul. Quanto às instituições de fomento à inovação procuradas, duas responderam à solicitação da pesquisadora e decidiram apoiar a pesquisa. Uma delas possuía representatividade nacional e a outra, estadual. 
As instituições parceiras, listadas por ordem alfabética, foram as seguintes: Agência USP de Inovação (2014); Associação Nacional de Pesquisa e Desenvolvimento das Empresas Inovadoras - ANPEI (2014); Federação da Indústria do Estado do Espírito Santo FINDES (2014); e Federação da Indústria do Estado do Paraná - FIEP (2014). No Anexo

4 consta a caracterização das empresas desses dois Estados da Federação.

\section{Quadro 13 - Breve caracterização das instituições parceiras da pesquisa}

\section{AGÊNCIA USP DE INOVAÇÃO}

- Fundada em 2003, a Agência USP de Inovação é o Núcleo de Inovação Tecnológica da USP responsável por gerir a política de inovação para promover a utilização do conhecimento científico, tecnológico e cultural produzido na universidade, em prol do desenvolvimento socioeconômico sustentável do Estado de São Paulo e do país. Dentre suas atribuições e responsabilidades, destacase o apoio aos docentes, alunos e funcionários da USP na elaboração de projetos em parceria para melhor gerenciar as relações com os setores empresariais, bem como, comunicar para a sociedade em geral o impacto e os benefícios das inovações guiadas pela ciência desenvolvida pelos pesquisadores da USP. Em parceria com o SEBRAE, atende a diversos públicos por meio do "Disque Tecnologia", sistema de atendimento via internet que constrói e disponibiliza respostas técnicas demandadas por microempresários atuantes em todos os setores industriais e de serviços.

\section{ANPEI}

- Fundada em 1984, a Anpei é uma entidade sem fins lucrativos representativa do segmento das empresas e instituições inovadoras. A entidade é constituída por empresas que investem continuamente em pesquisa, desenvolvimento e inovação, de diversos portes e setores, sendo marcante o seu caráter multissetorial. As empresas líderes das principais cadeias produtivas do Brasil integram a Associação. Também é formada por entidades do Sistema Nacional de Inovação (SNI) que dão suporte às atividades de inovação, como universidades, institutos de pesquisa públicos e privados, federações de indústria e órgãos de governo como secretarias de governo de ciência, tecnologia e inovação e fundações de amparo à pesquisa dos Estados. Há, ainda, os sócios individuais, pessoas físicas que atuam ou têm interesse nas áreas de política e gestão de inovação. A Anpei também atua na capacitação de recursos humanos para inovação por meio do programa EducAnpei.

\section{FINDES}

- Fundada em 1958, a FINDES é a entidade máxima de representação da indústria capixaba. Principal interlocutora do setor produtivo, a FINDES é composta por 31 sindicatos filiados e representa cerca de 18 mil indústrias, que são responsáveis por 38,2\% do PIB do Estado e geram mais de 241 mil postos de trabalho. As ações dessa federação contribuem para o crescimento do parque produtivo do Espírito Santo, para a formulação da política industrial do Estado, e ainda fazem a ponte entre os sindicatos filiados e outros segmentos da sociedade. Por meio dos Conselhos Temáticos Superiores, das Câmaras Setoriais, do Centro de Apoio aos Sindicatos e das Diretorias Regionais, a Findes oferece serviços nas áreas de tecnologia, comércio exterior, infraestrutura, economia, sindical, meio ambiente, jurídica e sindical. Assim, o industrial conta com toda a estrutura necessária para uma atuação destacada no seu ramo de negócio.

\section{FIEP}

- Fundada em 1944, a FIEP é a entidade de representação da indústria paranaense que coordena, protege e representa legalmente as diversas empresas do setor industrial no Estado. Como resultado da associação de sindicatos empresariais, a FIEP atua juntamente com Sesi, Senai e IEL formando o Sistema FIEP; de forma a apoiar com produtos e serviços o parque industrial do Paraná e contribuir para seu desenvolvimento dentro e fora do Brasil. Atualmente essa federação conta com 21 coordenadorias nas regiões-polo do Estado, que prestam assessoria direta aos 109 sindicatos empresariais filiados e defendem os interesses de mais de 46 mil indústrias, responsáveis por 820 mil postos de trabalho.

FONTES: Adaptado de AGÊNCIA USP DE INOVAÇÃO, 2014; ANPEI, 2014; FINDES, 2014; FIEP, 2014. 
Funcionários das quatro instituições parceiras foram informados por e-mail sobre: objetivos da pesquisa, público-alvo, endereço da pesquisa na Internet, período de coleta de dados e confidencialidade dos dados (Apêndice 1). O questionário (Apêndice 2) também foi enviado para apreciação, aprovação e documentação interna. Em contato posterior foi acordado que um convite para participação na pesquisa seria redigido e enviado pela própria pesquisadora por e-mail. Também foi acordado também que os funcionários das instituições parceiras encaminhariam o convite na íntegra ou redigiriam um novo texto com base no conteúdo fornecido pela pesquisadora para o público-alvo da pesquisa.

Uma das instituições parceiras, a ANPEI, concedeu à pesquisadora a oportunidade de expor presencialmente os objetivos e informações gerais sobre a pesquisa na edição de outubro de 2014 do Comitê Temático de Gestão da Inovação. Os comitês temáticos da ANPEI se reúnem mensalmente para debates e troca de experiências (ANPEI, 2014). Deles participam profissionais que atuam em diversos setores de atividade econômica, alguns deles com características que coincidem com as da população da pesquisa. Após o término do evento a pesquisadora enviou por e-mail o convite a um funcionário da ANPEI, que o transmitiu aos seus setenta e dois associados. A pesquisadora não teve acesso à quantidade de associados que preencheram o questionário. Tampouco soube se a breve exposição do estudo feita no Comitê tornou os associados presentes mais propensos a participarem.

O procedimento de coleta de dados foi o mesmo para as demais fontes indiretas de respondentes. A pesquisadora enviou por e-mail o convite ao ponto de contato das instituições parceiras, que o transmitiu aos seus contatos. A pesquisadora também não teve acesso à quantidade de profissionais que preencheram o questionário.

Dessa forma, todos os profissionais abordados pelas fontes indiretas que apresentaram as características da população foram convidados para participar da pesquisa. Como em nenhum momento se teve acesso à lista de contatos das instituições parceiras, foi solicitado aos pontos de contato de cada uma delas que fizessem novos contatos com os respondentes no intuito de aumentar a adesão à pesquisa.

Os pontos de contato enviaram para os mesmos profissionais que haviam sido convidados a participar da pesquisa um texto redigido pela pesquisadora. Esse texto continha um 
agradecimento àqueles que já haviam preenchido o questionário e foi reforçada a importância da pesquisa. Foi fornecido novamente o endereço eletrônico da pesquisa e solicitado aos demais que colaborassem, preenchendo o questionário e enviando suas respostas até 30 de novembro de 2014.

No que tange à coleta de dados pelas fontes diretas, os convites partiram da própria pesquisadora e foram enviados por e-mail ou pela rede profissional LinkedIn (2014) aos contatos selecionados por se enquadrarem no perfil desejado.

Foram utilizados os procedimentos de coleta de dados descritos por Vasconcellos e Guedes (2007): os respondentes inicialmente seriam informados por e-mail sobre o endereço da página do questionário na Internet; ao acessar essa página eles deveriam visualizar o questionário e responder às questões; ao final, deveriam pressionar um botão que enviaria as informações para a responsável pela pesquisa de forma anônima.

Foram realizados 1.034 contatos conforme o quadro a seguir.

Quadro 14 - Contatos efetuados por fontes de respondentes

\begin{tabular}{|l|c|}
\hline \multicolumn{1}{|c|}{ Fontes de respondentes } & Contatos efetuados \\
\hline Agência USP de Inovação & 830 \\
\hline ANPEI & 74 \\
\hline FINDES & 63 \\
\hline FIEP & 30 \\
\hline Pesquisadora & 37 \\
\hline Total & $\mathbf{1 0 3 4}$ \\
\hline
\end{tabular}

Ressalta-se que os contatos feitos pela Agência USP de Inovação foram subdivididos em 700 gestores industriais que constavam no cadastro da Agência e 130 gestores que participaram como alunos no curso de Capacitação para Gestores na Indústria, promovido pela Federação da Indústria do Estado de São Paulo - FIESP em parceria com a Agência USP de Inovação e com o Governo do Estado de São Paulo (FIESP, 2014).

Conforme exposto na seção 3.3 - População e Amostra, 51 gestores concordaram em participar da pesquisa (amostra não-probabilística por conveniência).

Observa-se no Gráfico 3 que quatro semanas após o início da coleta de dados não havia sido alcançado o número mínimo de trinta respostas para efetuar análises quantitativas, embora tenham sido efetuados 1.034 contatos com profissionais-alvo. Diante disso, foi 
necessário estender o período de coleta de dados por mais quatro semanas e intensificar o contato com as instituições parceiras da pesquisa, solicitando a elas que encaminhassem as mensagens da pesquisadora reforçando a importância da pesquisa e fornecendo benefícios aos participantes sem infringir a ética em pesquisa.

O ápice de quantidade de respostas foi obtido na semana que iniciou em 03/11/2014, que coincidiu com a adesão da Agência USP de Inovação e da ANPEI como parceiras da pesquisa na coleta de dados. Após oito semanas de coleta de dados, contando com o apoio da FINDES, havia apenas quarenta e cinco respostas na base de dados. Temendo que a eventual exclusão de respostas inadequadas ou incompletas impedisse o alcance de trinta respostas válidas, optou-se por manter os esforços na coleta de dados até a décima semana. Encerado o período de coleta de dados foram obtidas 48 respostas coletadas pela ferramenta Survey Monkey (2014).

\section{Gráfico 3 - Distribuição das respostas}

\section{Volume de respostas}

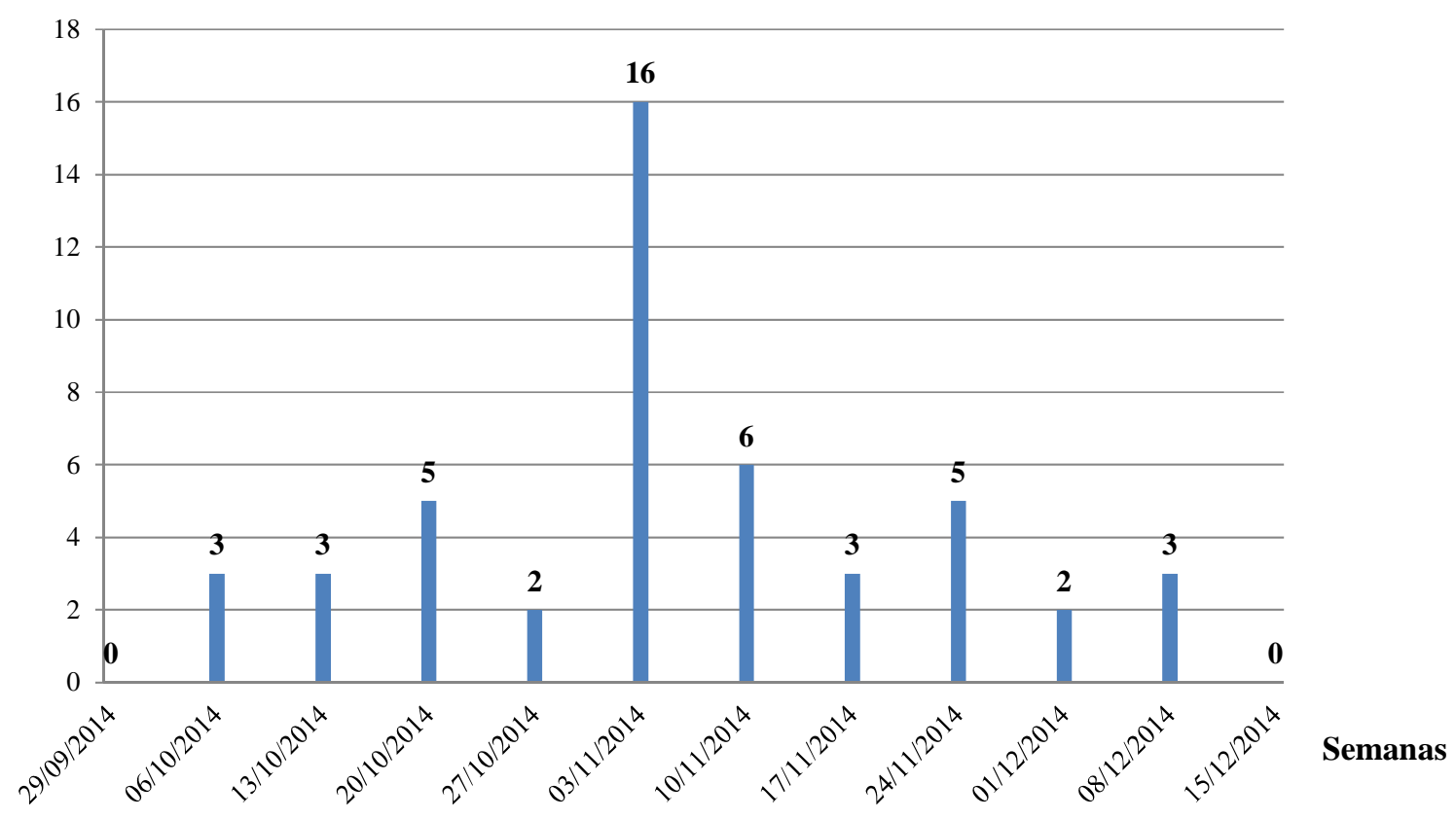




\subsection{Plano de Análise}

Foi definido um plano de análise composto de quatro etapas sequenciais. Foram apresentadas as atividades realizadas em cada etapa, acompanhadas das formas de análise.

\section{Tratamento dos dados}

Essa etapa consistiu na verificação do número total de respondentes; avaliação de cada resposta individualmente para apurar quais delas estavam incompletas (apresentaram não resposta em um ou mais itens) e efetuar sua exclusão; bem como a verificação do número total de respostas completas, que constituiria a amostra para fins de análise. Também foi verificado o tipo de distribuição dos dados coletados.

\section{Caracterização da amostra}

- No intuito de melhor caracterizar as empresas industriais tomadas como referência para participar da pesquisa, foram aplicadas técnicas estatísticas descritivas.

- Para as variáveis qualitativas (não métrica), de escala ordinal ou nominal, utilizouse de tabelas de frequência e moda. Em contrapartida, para as variáveis métricas, utilizou-se das seguintes medidas: média, mediana e desvio-padrão.

- Para caracterizar os respondentes foi utilizada análise univariada, tendo como base os princípios da estatística descritiva para representação do perfil de cada respondente.

3. Medidas de gestão estratégica de pessoas e capacidade de inovação

- Foi utilizado o valor da estatística alfa de cronbach para as variáveis que representaram o construto gestão estratégica de pessoas no contexto da inovação para verificar se cada variável representava o construto de maneira adequada. $\mathrm{O}$ alfa de cronbach serviu como medida de confiabilidade interna do instrumento.

- Visto que os indicadores que operacionalizaram as características de gestão estratégica de pessoas foram quantitativos e dispostos em escala razão, criou-se quatro índices que fossem o resultado da soma de cada uma das variáveis que representam o construto. A criação desses índices (FVN, FEI, LG, PPGP) foi utilizada para testar as duas primeiras hipóteses de investigação. 
- Nessa etapa também foi feita a análise univariada dos cinco indicadores que operacionalizam a capacidade de inovação utilizando média, mediana e desvio padrão.

- Cabe registrar que inicialmente, seria aplicada a técnica de análise multivariada de dados de análise fatorial exploratória para as medidas de gestão estratégica de pessoas. Contudo, a quantidade de respostas válidas obtidas após a coleta de dados (39 respostas) inviabilizou o uso da técnica.

4. Coeficientes de correlação de gestão estratégica de pessoas com capacidade de inovação

- Para analisar a relação entre gestão estratégica de pessoas e capacidade de inovação, foi calculada a significância estatística entre as variáveis independente e dependente. Segundo Hair Jr. et al (2005, p. 316): "Se é encontrada uma significância estatística entre as variáveis, dizemos que uma relação está presente."

- Encontrada significância estatística entre as variáveis, o passo seguinte foi de mensurar a força global da relação. Foi utilizado o coeficiente de correlação de Spearman entre os quatro índices criados e os indicadores de capacidade de inovação, com nível de confiança ( $p$-value) de 10\%, com 90\% de confiabilidade.

- Na sequência foi feita a análise dos coeficientes de correlação, avaliando a força da correlação e o seu sentido (positivamente ou negativamente correlacionados).

- A forma de análise utilizada nesta etapa foi a bivariada.

- $\quad$ Papel das variáveis que podem afetar a relação entre gestão estratégica de pessoas e capacidade de inovação no setor industrial

- Foi utilizado o coeficiente de correlação de Spearman após a segmentação dos dados com base nas variáveis intervienentes, com nível de confiança (valor p) de $10 \%$, com $90 \%$ de confiabilidade.

- A forma de análise utilizada nesta etapa foi a bivariada.

Atentou-se para os seguintes pontos levantados em obras de metodologia científica para embasar o plano de análise proposto: 
- Foram utilizados testes estatísticos não paramétricos, uma vez que não requerem que os dados apresentem distribuição normal (SIEGL; CASTELLAN Jr., 2006).

- A força da relação de associação é identificada pelo algarismo que representa o valor do coeficiente, que pode variar entre 0 e 1 . A direção da relação é identificada pelo sinal positivo ou negativo. Logo, se as variáveis covariarem no mesmo sentido, coeficiente apresentará sinal positivo e se covariarem em sentidos opostos o coeficiente apresentará sinal negativo (HAIR Jr. et al, 2005). Assim sendo, um coeficiente de correlação que se situe na faixa de $\pm 0,71$ a $\pm 0,90$ é alto ao nível de confiança estabelecido, por exemplo.

A tabela 1 consiste em uma regra prática para interpretar o valor de coeficientes de correlação, que será utilizada para analisar os resultados da pesquisa no capítulo seguinte.

Tabela 1 - Força de associação

\begin{tabular}{|ll|}
\hline Variação do coeficiente & Força de associação \\
\hline $\pm 0,91- \pm 1,00$ & Muito forte \\
$\pm 0,71- \pm 0,90$ & Alta \\
$\pm 0,41- \pm 0,70$ & Moderada \\
$\pm 0,21- \pm 0,40$ & Pequena mas definida \\
$\pm 0,01- \pm 0,20$ & Leve, quase imperceptível \\
\hline \hline
\end{tabular}

FONTE: HAIR Jr. et al, 2005, p. 312.

\subsection{Síntese e Considerações}

Com base na questão de pesquisa e nos objetivos propostos, foi investigada a relação de associação entre gestão estratégica de pessoas e capacidade de inovação no setor industrial. Sob o raciocínio dedutivo e sob a concepção pós-positivista, foi realizado um estudo exploratório-descritivo pelo método quantitativo.

A técnica de investigação utilizada foi o levantamento. $\mathrm{O}$ instrumento de coleta de dados desenvolvido para coletar os dados na pesquisa foi submetido à apreciação de especialistas em Administração e em profissionais com as características da amostra (pré- 
teste). O modelo conceitual da pesquisa, bem como as questões referentes às subvariáveis independente e dependente passaram pela avaliação de professores de Administração da FEA-USP. A amostra da pesquisa foi não probabilística por conveniência. Foram propostas hipóteses de investigação, testadas por estatística não paramétrica.

A síntese da metodologia da pesquisa é apresentada no quadro abaixo.

\section{Quadro 15 - Síntese da metodologia}

\begin{tabular}{|ll|}
\hline \multicolumn{2}{|c|}{ Metodologia da Pesquisa } \\
\hline$\bullet$ & Concepção pós-positivistas \\
\hline - & Processo dedutivo \\
\hline - & Método quantitativo \\
\hline - & Hipóteses de pesquisa: testadas empiricamente \\
\hline - & Técnica de pesquisa: levantamento (survey) \\
\hline - & Amostra: não probabilística por conveniência \\
\hline - & Instrumento de coleta de dados: questionário eletrônico de \\
& autopreenchimento hospedado em página na Internet \\
\hline - & Análise: estatística não-paramétrica \\
\hline
\end{tabular}

O alinhamento entre o problema de pesquisa com os objetivos (fins) e formas de investigação (meios) é representado no Quadro 16. 
Quadro 16 - Classificação do estudo quanto aos objetivos e formas de investigação

\begin{tabular}{|c|c|c|}
\hline Problema & Objetivos & $\begin{array}{c}\text { Formas de } \\
\text { Investigação }\end{array}$ \\
\hline 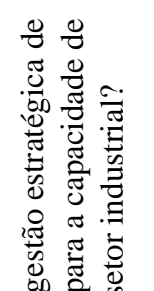 & 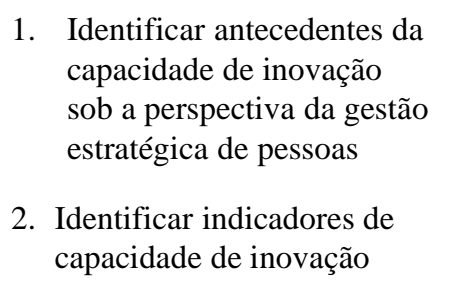 & $\begin{array}{l}\text { Pesquisa } \\
\text { bibliográfica }\end{array}$ \\
\hline 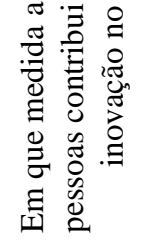 & $\begin{array}{l}\text { 3. Analisar as contribuições da } \\
\text { gestão estratégica de pessoas } \\
\text { para a capacidade de } \\
\text { inovação }\end{array}$ & $\begin{array}{l}\text { Pesquisa empírica } \\
\text { (levantamento) }\end{array}$ \\
\hline
\end{tabular}

Quadro 17 - Alinhamento entre objetivo, hipóteses e formas de análise

\begin{tabular}{|c|c|c|}
\hline Objetivo 3 & Hipóteses & $\begin{array}{c}\text { Estatística e } \\
\text { Formas de Análise }\end{array}$ \\
\hline 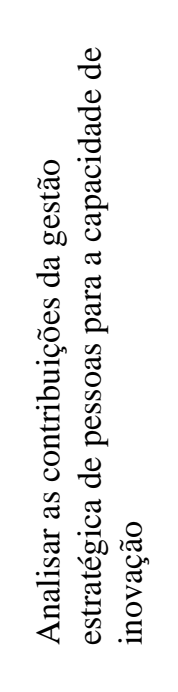 & $\begin{array}{l}\text { 1. Gestão estratégica de pessoas está } \\
\text { associada com capacidade de inovação } \\
\text { 2. As empresas industriais de grande porte } \\
\text { apresentam maior associação entre gestão } \\
\text { estratégica de pessoas e capacidade de } \\
\text { inovação. } \\
\text { 3. As empresas industriais com maior receita } \\
\text { operacional bruta apresentaram maior } \\
\text { associação entre gestão estratégica de } \\
\text { pessoas e capacidade de inovação. } \\
\text { 4. As empresas industriais com maior tempo } \\
\text { de operação no Brasil apresentaram maior } \\
\text { associação entre gestão estratégica de } \\
\text { pessoas e capacidade de inovação. }\end{array}$ & $\begin{array}{l}\text { Estatística } \\
\text { não-paramétrica } \\
\text { Análises univariada } \\
\text { e bivariada de dados }\end{array}$ \\
\hline
\end{tabular}

Após a síntese da metodologia serão citados e comentados os principais pontos que podem ter interferido no processo de observação e mensuração das variáveis.

O primeiro ponto diz respeito ao pré-teste. Há de se considerar que a efetividade do préteste depende da capacidade, interesse, empenho, condições enfrentadas pelos participantes no momento de avaliação do questionário, entre outros fatores. Trata-se de fatores sobre os quais não se teve controle. 
Aprendeu-se com essa experiência que o pré-teste consiste em uma atividade que deve ser cuidadosamente acompanhada para que seus benefícios sejam melhor aproveitados. Dada a importância dessa atividade, pretende-se realizá-la presencialmente em estudos futuros para diminuir os fatores que alegou-se não ter tido controle. Pretende-se também, em estudos com amostras maiores, realizar pré-testes mais robustos que contribuam para a validação do instrumento.

O segundo ponto diz respeito ao público-alvo da pesquisa. Para coletar dados, buscou-se profissionais que desempenharam a função descrita na população: atuar na gestão de projetos de pesquisa, desenvolvimento e inovação em organizações industriais com operações no Brasil. Tratava-se, na prática, de diretores, gerentes, líderes de projetos, entre outras posições dependendo de características das empresas industriais pesquisadas.

A ideia subjacente à escolha da população foi que a gestão de projetos, principalmente em P\&D\&I, envolve a coordenação de esforços, a gestão de relacionamentos, a administração de expectativas, forças e interesses sejam eles corporativos ou das áreas envolvidas no processo de inovação. Essas mesmas atribuições favoreceram sua elegibilidade como participantes da pesquisa sob a perspectiva de gestão de pessoas e de gestão da inovação, conforme explicado na seção 3.3 - População e Amostra.

Contudo, questiona-se se tais profissionais seriam os mais adequados para responder a questões que envolvem maior nível de abstração e que dependem do alcance da extensão em que a alta administração se empenha em comunicar o intento estratégico da empresa, tais como as que representaram filosofia, valores e normas e foco estratégico em inovação.

Como terceiro e último ponto, sustenta-se que o fenômeno da contribuição da gestão estratégica de pessoas para a capacidade de inovação foi observado por gestores, que percebem e tratam o fenômeno sob sua perspectiva. Provavelmente, essa perspectiva não representa a visão da empresa como um todo.

Acrescenta-se que a palavra percebido foi utilizada no parágrafo anterior no sentido de “[...] processo pelo qual os indivíduos organizam e interpretam suas impressões sensoriais com a finalidade de dar sentido ao seu ambiente." (ROBBINS; JUDGE; SOBRAL, 2011, p. 159). Segundo esses mesmos autores, a percepção depende de: fatores da situação, como momento de trabalho, ambiente de trabalho e ambiente social; de fatores do alvo 
(objeto) tais como novidade, tamanho, proximidade e semelhança; e de fatores do preceptor, como atitudes, personalidade, motivações, interesses, experiência e expectativas.

É provável que, para simplificar o processo de percepção, os respondentes tenham interpretado seletivamente o fenômeno da contribuição da gestão estratégica de pessoas para a capacidade de inovação a partir dos fatores mencionados, interferindo, portanto, na objetividade da observação e mensuração.

Tendo apresentado a metodologia e feitas as considerações que condicionaram a condução da pesquisa, partir-se-á para apresentação dos dados e discussão dos resultados. 


\section{APRESENTAÇÃO DOS DADOS E DISCUSSÃO DOS RESULTADOS}

Os dados coletados foram tratados e analisados por intermédio do software Statistical Package for the Social Sciences - SPSS, versão 19, de acordo com o plano descrito no capítulo de Metodologia da Pesquisa (seção 3.6 - Plano de Análise).

\subsection{Tratamento dos Dados}

Antes de aplicar qualquer tipo de tratamento estatístico na base de dados da pesquisa, foi realizada uma avaliação previa das 48 respostas para identificar qualquer tipo de inconsistência ou dados faltantes (missing data). Constatou-se que nove respostas estavam incompletas.

Considerando que nessas nove respostas mais do que 50\% das questões não haviam sido preenchidas e que as respostas ausentes foram cruciais para os objetivos desta investigação, optou-se por sua exclusão da base dados. Sendo assim, a amostra desta investigação foi reduzida para trinta e nove respostas. Como todas elas estavam completas e foram adequadamente preenchidas, considerou-se trinta e nove o tamanho de amostra para fins de análise $(n=39)$.

A partir do delineamento da amostra, o passo seguinte consistiu em verificar a confiabilidade das escalas das características que representaram as características de gestão estratégica de pessoas (filosofia, valores e normas; foco estratégico em inovação; liderança e gestão; e políticas e práticas de gestão de pessoas) por meio da estatística do alfa de cronbach.

O coeficiente de alfa de cronbach é uma estatística utilizada para medir a consistência interna de cada dimensão considerando o modelo da pesquisa e é representado pela correlação entre os itens que constituem determinado construto (CHURCHILL, 1998). Para medir a consistência interna do construto no modelo, recomenda-se obter um valor de alfa de cronbach superior a 0,6 (HAIR Jr. et al, 2009), de modo que: quanto maior for a correlação entre os itens que constituem um determinado construto, maior será a 
confiabilidade da escala. O construto mencionado pelos autores consistiu nas quatro características de gestão estratégica de pessoas citadas no parágrafo anterior.

O Quadro 18 oferece uma orientação sobre como interpretar o coeficiente do alfa de cronbach.

Quadro 18 - Interpretação do coeficiente de alfa de cronbach

\begin{tabular}{|c|c|}
\hline Variação do coeficiente de Alfa de Cronbach & Intensidade da Associação \\
\hline$<0,6$ & Baixa \\
\hline $0,6 \mathrm{a}<0,7$ & Moderada \\
\hline $0,7 \mathrm{a}<0,8$ & Boa \\
\hline $0,8 \mathrm{a}<0,9$ & Muito Boa \\
\hline 0,9 & Excelente \\
\hline
\end{tabular}

Fonte: Hair Jr et al. (2005).

A partir desses fundamentos aplicou-se o ferramental do alfa de cronbach nos dados coletados, cujos resultados são apresentados na Tabela 2. A análise da referida tabela demonstrou uma alta confiabilidade da escala utilizada neste estudo, uma vez que todos os construtos analisados apresentaram valores de alfa de cronbach superior a 0,8 , permitindo classificar a intensidade da associação como "Muito Boa" e "Excelente".

Tabela 2 - Resultados do coeficiente de alfa de cronbach

\begin{tabular}{|l|c|}
\hline Construtos & Valor \\
\hline Filosofia, valores e normas & 0,873 \\
\hline Foco estratégico em inovação & 0,836 \\
\hline Liderança e Gestão & 0,959 \\
\hline Políticas e práticas de gestão de pessoas & 0,892 \\
\hline Capacidade de inovação & 0,888 \\
\hline
\end{tabular}


Após a avaliação da confiabilidade da escala utilizada nesta investigação, a etapa seguinte consistiu em um diagnóstico do tipo de distribuição que os dados coletados empiricamente apresentaram. Neste sentido, optou-se por avaliar se os dados possuíam distribuição normal (Apêndice 4), pois a não apresentação de uma distribuição normal com 39 respostas inviabilizaria a aplicação de algumas ferramentas estatísticas. Procedeuse, então, à aplicação do teste de Kolmogorov-Smirnov .

De acordo com Fávero et al (2009) o teste de Kolmogorov-Smirnov (K-S) consiste em um teste de aderência que compara a distribuição de frequência acumulada de um conjunto de valores observados da amostra com uma distribuição esperada ou teórica. Em outras palavras, o objetivo do teste é determinar se uma amostra de tamanho superior a trinta observações é proveniente de uma distribuição normal.

Neste teste, a variável é normal quando não rejeitamos a hipótese nula. A premissa do teste, portanto, foi a seguinte:

$\mathrm{H}_{0}$ : A variável possui distribuição normal;

$\mathrm{H}_{1}$ : A variável não possui distribuição normal.

Os resultados do teste demonstraram que os dados da amostra utilizada para fins de análise não possuíam distribuição normal, inviabilizando, portanto, a utilização de qualquer ferramental de estatística paramétrica. Por esse motivo, optou-se pela aplicação de ferramental estatístico não paramétrico para analisar os dados coletados.

\subsection{Caracterização da Amostra}

O primeiro tratamento estatístico realizado teve por objetivo estabelecer o perfil das organizações tomadas como referências nas respostas e dos profissionais participantes da pesquisa. As principais questões utilizadas para caracterizar amostra serão apresentadas a seguir, com base nos procedimentos estatísticos utilizados. 


\subsubsection{Caracterização das Empresas}

No intuito de melhor caracterizar as empresas nas quais os participantes desta pesquisa atuaram, utilizou-se do ferramental da estatística descritiva. A definição das técnicas que seriam utilizadas se baseou no tipo de variável. Logo, para as variáveis qualitativas de escala nominal ou ordinal, utilizou-se de tabelas de frequência (percentual) e moda. Em contrapartida, a distribuição e a caracterização dos dados quantitativos se deram por meio das seguintes medidas: média, mediana e desvio-padrão.

Na Tabela 3, nota-se que mais da metade dos profissionais participantes da pesquisa atuaram em empresas de capital privado nacional no período em que os dados foram coletados. Portanto, houve predominância de empresas industriais brasileiras.

Tabela 3 - Origem do capital

\begin{tabular}{|l|c|c|}
\hline \multicolumn{3}{|c|}{ Origem do Capital } \\
\hline & Frequência & Percentual \\
\hline privado nacional & 24 & $61,5 \%$ \\
\hline multinacional & 11 & $28,2 \%$ \\
\hline estatal & 4 & $10,3 \%$ \\
\hline Total & 39 & $100,0 \%$ \\
\hline
\end{tabular}

Houve predominância de empresas com receita operacional bruta superior a $\mathrm{R} \$ 300$ milhões. As dezessete empresas dessa faixa representaram um percentual de 43,6. O critério utilizado para a definição das cinco faixas de receita operacional bruta foi obtido em publicação do BNDES (2014a).

Tabela 4 - Receita operacional bruta (R\$/ano)

\begin{tabular}{|l|c|c|}
\hline \multicolumn{3}{|c|}{ Receita Operacional Bruta (R\$/ano) } \\
\hline & Frequência & Percentual \\
\hline menor ou igual a R\$ 2,4 milhões & 4 & $10,3 \%$ \\
\hline maior que R\$ 2,4 milhões e menor ou igual a R\$ 16 milhões & 5 & $12,8 \%$ \\
\hline maior que R\$ 16 milhões e menor ou igual a R\$ 90 milhões & 7 & $17,9 \%$ \\
\hline maior que R\$ 90 milhões e menor ou igual a R\$ 300 milhões & 6 & $15,4 \%$ \\
\hline maior que R\$ 300 milhões & 17 & $43,6 \%$ \\
\hline Total & 39 & $100,0 \%$ \\
\hline
\end{tabular}


O critério utilizado para dividir a receita operacional bruta em faixas foi análogo ao do porte, conforme o Anexo 3. Diante disso, embora fosse esperado que a quantidade de empresas enquadradas na faixa de receita superior a $\mathrm{R} \$ 300$ milhões se mantivesse na categoria de grande empresa na classificação por porte, isso não ocorreu. Logo, é possível que tenha havido subjetividade na classificação da empresa quanto ao porte das empresas.

Tabela 5 - Porte das empresas

\begin{tabular}{|l|c|c|}
\hline \multicolumn{3}{|c|}{ Porte das Empresas } \\
\hline microempresa & Frequência & Percentual \\
\hline pequena empresa & 4 & $10,3 \%$ \\
\hline média empresa & 3 & $7,7 \%$ \\
\hline média-grande empresa & 3 & $7,7 \%$ \\
\hline grande empresa & 11 & $28,2 \%$ \\
\hline Total & 18 & $46,2 \%$ \\
\hline
\end{tabular}

O primeiro tipo de inovação organizacional retratado na fundamentação teórica se referiu à concentração de esforços das atividades inovadoras, que podiam estar tanto dentro das empresas (inovação predominantemente fechada), quanto na relação supra empresas (inovação predominantemente aberta).

A constatação de que vinte e cinco empresas em um total de trinta e nove se voltaram para a inovação fechada, respondendo por $64,1 \%$ das respostas obtidas, sugere que a gestão estratégica de pessoas em organizações do setor industrial no Brasil predomina no nível de agregação micro e estratégico, conforme a classificação de Boxall, Purcell e Wright (2007). Para esses autores, o nível micro se volta para os desdobramentos de políticas de gestão de pessoas em processos e práticas. O nível estratégico, por sua vez, se concentra nas estratégias e políticas de gestão de pessoas adotadas pelas unidades de negócio ou organizações. Esses dois níveis dizem respeito à gestão de pessoas em nível organizacional.

Catorze respostas $(35,9 \%)$ apontaram para a inovação predominantemente aberta. Não se trata de um baixo percentual, considerando a complexidade e os desafios envolvidos em inovar para além das fronteiras da organização. Esse contexto demanda que a gestão de 
pessoas acompanhe o negócio, atuando inclusive na interação entre empresas parceiras. Essa atuação corresponde ao nível de agregação internacional da gestão de pessoas, que apesar de ser relevante, esteve fora do escopo deste estudo.

Tabela 6 - Tipo de inovação praticada 2

\begin{tabular}{|l|c|c|}
\hline \multicolumn{3}{|c|}{ Tipo de inovação praticada 2 } \\
\hline & Frequência & Percentual \\
\hline predominantemente fechada & 25 & $64,1 \%$ \\
\hline predominantemente aberta & 14 & $35,9 \%$ \\
\hline Total & 39 & $100,0 \%$ \\
\hline
\end{tabular}

As respostas mostraram que as empresas do setor industrial participantes da pesquisa atuam em atividades de inovação que visam melhorias contínuas e pontuais (20 respostas, representando 51,3\%). Observou-se que houve um relativo equilíbrio de respostas quando comparado com as empresas que alegaram praticar os dois tipos de inovação (18 respostas representando 46,2\%). Diante disso, supõe-se que boa parte das empresas consideradas também está engajada em inovações que representam rupturas.

Tabela 7 - Tipo de inovação praticada 3

\begin{tabular}{|l|c|c|}
\hline \multicolumn{3}{|c|}{ Tipo de inovação praticada 3 } \\
\hline & Frequência & Percentual \\
\hline incremental & 20 & $51,3 \%$ \\
\hline radical & 1 & $2,6 \%$ \\
\hline ambas & 18 & $46,2 \%$ \\
\hline Total & 39 & $100,0 \%$ \\
\hline
\end{tabular}

Embora em quase todos os respondentes tenham identificado a prática da inovação do tipo incremental e radical nas empresas industriais (tabela acima), paradoxalmente, quase a metade desses mesmos respondentes afirmaram que não se pratica inovação organizacional.

Tabela 8 - Inovação organizacional

\begin{tabular}{|l|c|c|}
\hline \multicolumn{3}{|c|}{ Esta empresa pratica inovação organizacional } \\
\hline & Frequência & Percentual \\
\hline Sim & 20 & $51,3 \%$ \\
\hline Não & 19 & $48,7 \%$ \\
\hline Total & 39 & $100 \%$ \\
\hline
\end{tabular}


A seguir serão caracterizadas as variáveis quantitativas caracterizadoras das empresas por medidas de tendência central: média, mediana e moda.

Verifica-se que embora o valor médio das respostas fornecidas para tempo de operação no Brasil na amostra tenha sido de 45 anos, quando organizadas em ordem crescente as respostas levaram a 42,7 anos como medida de posição central dos dados. É possível que tenham sido fornecidas mais respostas com número inferior a 45 anos do que com número superior a 45 anos. A medida de variabilidade dos dados em relação à média foi de 27,4 anos, indicando uma substancial dispersão.

Tabela 9 - Tempo de operação no Brasil (anos completos)

\begin{tabular}{|l|r|}
\hline \multicolumn{2}{|c|}{ Tempo de Operação no Brasil (anos completos) } \\
\hline Média & 42,7 \\
\hline Mediana & 45,0 \\
\hline Desvio Padrão & 27,4 \\
\hline
\end{tabular}

O valor médio do número de funcionários das empresas utilizadas como referência para as respostas pesquisa foi de 2.619. Ao organizar os dados em ordem crescente, identificou-se 1.519 como o número de funcionários que dividiu a amostra ao meio. Constatou-se uma expressiva variabilidade dos dados em relação à média que, neste caso, foi de 3.816 funcionários. Esse número sinalizou a heterogeneidade da amostra, o que dificultou o estabelecimento de comparações nas seções seguintes deste capítulo.

Tabela 10 - Número de funcionários da empresa

\begin{tabular}{|l|c|}
\hline \multicolumn{2}{|c|}{ Número de funcionários da empresa } \\
\hline Média & 2619,9 \\
\hline Mediana & 1529,0 \\
\hline Desvio Padrão & 3816,8 \\
\hline
\end{tabular}

No que tange ao número de funcionários alocados em atividades de P\&D\&I, observouse na amostra o valor médio de 104. Considerando que a mediana foi substancialmente mais baixa, de 20 funcionários, supõe-se que a grande maioria dos respondentes possui mais de vinte funcionários alocados em P\&D\&I. 
Tabela 11- Número de funcionários alocados em P\&D\&I (estimativa)

\begin{tabular}{|c|c|}
\hline Número de funcionários alocados em P\&D\&I (estimativa) \\
\hline Média & 104,8 \\
\hline Mediana & 20,0 \\
\hline Desvio Padrão & 163,3 \\
\hline
\end{tabular}

Dos funcionários alocados em atividades de P\&D\&I, cuja média foi de 104 funcionários de acordo com a tabela anterior, 48 em média, foram contabilizados como tendo formação superior como nível educacional máximo. O valor da mediana foi de 18 , indicando que uma considerável parte dos funcionários alocados em P\&D\&I possui pós-graduação stricto-sensu.

Tabela 12 - Número total de graduados, mestres e doutores alocados em P\&D\&I (estimativa)

$\left.\begin{array}{|l|c|}\hline \multicolumn{2}{|c|}{\text { Número total de graduados, mestres e doutores alocados em P\&D\&I }} \\ \text { (estimativa) }\end{array}\right)$

\subsubsection{Caracterização dos Respondentes}

Assim como na caracterização das empresas, o delineamento do perfil dos respondentes foi realizado por estatística descritiva. Para os dados de natureza qualitativa, foram utilizadas tabelas de frequência (percentual) e moda. Para as variáveis quantitativas utilizou-se das medidas de tendência central: média e mediana, e o desvio-padrão, como medida de dispersão. A seguir serão apresentados os dados obtidos nas tabelas de frequência de 13 a 16.

Quanto ao perfil dos respondentes, vinte e sete são do sexo masculino, respondendo por mais da metade da amostra $(69,2 \%)$. 
Tabela 13 - Sexo

\begin{tabular}{|l|c|c|}
\hline \multicolumn{3}{|c|}{ Sexo } \\
\hline & Frequência & Percentual \\
\hline masculino & 27 & $69,2 \%$ \\
\hline feminino & 12 & $30,8 \%$ \\
\hline total & 39 & $100,0 \%$ \\
\hline
\end{tabular}

Notou-se a concentração de respondentes situados nas faixas etárias de 31 a 40 anos e de 41 a 50 anos que, juntas, responderam por vinte e sete respostas $(69,3 \%)$.

Tabela 14 - Faixa etária (anos completos)

\begin{tabular}{|l|c|c|}
\hline \multicolumn{3}{|c|}{ Faixa etária (anos completos) } \\
\hline & Frequência & Percentual \\
\hline 21 a 30 & 5 & $12,8 \%$ \\
\hline 31 a 40 & 15 & $38,5 \%$ \\
\hline 41 a 50 & 12 & $30,8 \%$ \\
\hline 51 a 60 & 6 & $15,4 \%$ \\
\hline mais de 61 & 1 & $2,6 \%$ \\
\hline Total & 39 & $100,0 \%$ \\
\hline
\end{tabular}

Três respondentes possuíam apenas ensino superior completo. Dos trinta e seis que cursaram Pós-Graduação, vinte e um optou por cursos Lato Sensu - o que correspondeu a mais da metade da amostra $(53,8 \%)$.

Tabela 15 - Formação acadêmica (nível máximo obtido)

\begin{tabular}{|l|c|c|}
\hline \multicolumn{3}{|c|}{ Formação acadêmica (nível máximo obtido) } \\
\hline & Frequência & Percentual \\
\hline Ensino superior & 3 & $7,7 \%$ \\
\hline MBA/Especialização/Extensão & 21 & $53,8 \%$ \\
\hline Mestrado & 11 & $28,2 \%$ \\
\hline Doutorado & 4 & $10,3 \%$ \\
\hline Total & 39 & $100,0 \%$ \\
\hline
\end{tabular}


Houve predominância de respondentes oriundos dos Estados do Paraná $(35,9 \%)$ e de São Paulo $(33,3 \%)$, seguido por Espírito Santo $(17,9 \%)$. É possível que a maior adesão dos respondentes nesses estados tenha sido resultado das parceiras para coleta de dados realizadas nesses Estados.

Tabela 16 - Estado onde trabalha

\begin{tabular}{|l|c|c|}
\hline \multicolumn{3}{|c|}{ Estado onde trabalha } \\
\hline Estado & Frequência & Percentual \\
\hline ES & 7 & $17,9 \%$ \\
\hline PR & 14 & $35,9 \%$ \\
\hline RJ & 4 & $10,3 \%$ \\
\hline RS & 1 & $2,6 \%$ \\
\hline SP & 13 & $33,3 \%$ \\
\hline Total & 39 & $100,0 \%$ \\
\hline
\end{tabular}

O tipo de pesquisa envolvida nos projetos em que os profissionais participantes do levantamento gerenciaram foram, em sua maioria, pesquisa aplicada, que compreenderam 21 respostas - mais da metade da amostra 53,8\%.

Sob o ponto de vista da literatura, a quantidade de respostas sobre pesquisa básica vai ao encontro dos fundamentos de inovação organizacional. A pesquisa básica pode resultar em novas descobertas ou conhecimentos passíveis de serem aplicados em projetos futuros de P\&D\&I, contribuindo indiretamente para a inovação.

Tabela 17 - Classificação dos projetos que gerencia quanto ao tipo de pesquisa envolvida

\begin{tabular}{|l|c|c|}
\hline \multicolumn{3}{|c|}{ Classificação dos projetos que gerencia quanto ao tipo de pesquisa } \\
envolvida
\end{tabular}


No que diz respeito ao tempo de experiência em P\&D\&I, observou-se na amostra o valor médio de 8 anos. Considerando que a mediana foi inferior a 5 anos, presume-se que a maioria dos respondentes tem pouca senioridade em P\&D\&I.

Tabela 18 - Tempo de experiência profissional nesta empresa em P\&D\&I (anos completos)

\begin{tabular}{|l|c|}
\hline \multicolumn{2}{|c|}{$\begin{array}{c}\text { Tempo de experiência profissional nesta empresa em } \\
\text { P\&D/inovação (anos completos) }\end{array}$} \\
\hline Média & 8,2 \\
\hline Mediana & 5,0 \\
\hline Desvio Padrão & 8,0 \\
\hline $1^{\circ}$ percentil & 3,0 \\
\hline
\end{tabular}

Foi identificado um valor expressivo para a média de número de funcionários sob a responsabilidade dos profissionais que participaram da pesquisa. Esse número, de 19 funcionários, sugere que um único gestor gerencia mais de uma equipe de projetos em sua empresa ou que ele gerencia projetos abrangentes, envolvendo em sua maioria, grandes equipes.

Para efeitos da gestão estratégica de pessoas, trata-se de uma interessante constatação na medida em que revela a adequação dos respondentes adequados para responder as perguntas da quarta parte do questionário, sobre características de gestão estratégica de pessoas.

Tabela 19 - Número de funcionários sob sua responsabilidade

\begin{tabular}{|l|c|}
\hline \multicolumn{2}{|c|}{ Número de funcionários sob sua responsabilidade } \\
\hline Média & 19,0 \\
\hline Mediana & 4,0 \\
\hline Desvio Padrão & 43,9 \\
\hline
\end{tabular}

No questionário foram coletadas informações sobre coerência entre estratégia da empresa e estratégia de inovação e sobre crenças, valores e normas das empresas. Trata-se de assuntos que podem não ser plenamente compreendidos pelos participantes, representando uma potencial limitação da pesquisa. 


\subsection{Análise Descritiva das Variáveis}

Nesta seção foram feitas as análises das variáveis independente, dependente e intervenientes com base nas trinta e nove respostas obtidas. Após as análises de cada variável foram inseridas as tabelas contendo frequências e medidas descritivas para melhor compreensão.

\subsubsection{Análise da Variável Independente Gestão Estratégica de Pessoas}

Perante a complexidade inerente de representar a gestão estratégica de pessoas, foi necessário representa-la pelas seguintes características organizacionais: Filosofia, Valores e Normas (FVN); Foco Estratégico em Inovação (FEI); Liderança e Gestão (LG); e Políticas e Práticas de Gestão de Pessoas (PPGP). Cada uma dessas características foi representada por quarenta e três indicadores, conforme a Tabela 20.

Tabela 20 - Operacionalização da variável independente

\begin{tabular}{|l|c|}
\hline Características de Gestão Estratégica de Pessoas & Quantidade de Indicadores \\
\hline Filosofia, valores e normas & 11 \\
\hline Foco estratégico em inovação & 8 \\
\hline Liderança e Gestão & 15 \\
\hline Políticas e práticas de gestão de pessoas & 9 \\
\hline Total & $\mathbf{4 3}$ \\
\hline
\end{tabular}

De acordo com a descrição previamente realizada no capítulo de Metodologia da Pesquisa, os dados coletados sobre as quatro características organizacionais de gestão estratégica de pessoas foram de natureza quantitativa, representados por pontuações que variaram de 1 a 7, indicando o nível de concordância do respondente para cada um dos indicadores redigidos em formato de assertivas.

Como os dados sobre as características de gestão estratégica de pessoas foram coletados em escala razão, optou-se pela criação de um índice que fosse o resultado da soma de cada um dos indicadores pertinentes a cada característica de gestão estratégica de pessoas. Por exemplo, por meio da Tabela 20 sabe-se que a característica FVN possui 11 
indicadores. Considerando que cada uma das respostas teve um valor mínimo atribuído igual a 1 e máximo igual a 7, hipoteticamente, o indicador de FVN teve um valor mínimo de 11 (para um respondente que atribuiu 1 a todas as variáveis de FVN) e máximo de 77 (para um respondente que atribuiu 7 a todas as variáveis de FVN).

A Tabela 21 mostra o resultado da soma destas variáveis para cada uma das características de Gestão Estratégica de Pessoas, representando os valores máximos e mínimos obtidos, a partir da amostra desta pesquisa.

Tabela 21 - Índice da soma das variáveis de cada característica de gestão estratégica de pessoas

\begin{tabular}{|l|c|c|}
\hline \multicolumn{1}{|c|}{ Características de Gestão Estratégica de Pessoas } & Mínimo & Máximo \\
\hline Filosofia, Valores e Normas (Soma) & 28 & 77 \\
\hline Foco Estratégico em Inovação (Soma) & 18 & 54 \\
\hline Liderança e Gestão (Soma) & 37 & 105 \\
\hline Políticas e Práticas de Gestão de Pessoas (Soma) & 18 & 61 \\
\hline
\end{tabular}

A partir dos dados da Tabela 21, notou-se que, em virtude das diferentes quantidades de indicadores que representam cada característica, os índices apresentaram variações substanciais, dificultando o estabelecimento de comparações. Em resposta a essa peculiaridade, optou-se por realizar uma padronização dos índices. Convém ressaltar que a padronização não implicou em mudanças na distribuição da variável, uma vez que a padronização apenas translada os valores das variáveis originais em um determinado valor estipulado (FÁVERO et al, 2009).

Segundo Fávero et al (2009) existem diversos métodos para padronização, sendo o Método Range 0 a 1 o mais adequado para esta pesquisa, já que o objetivo da padronização era fazer com que os índices das características de gestão estratégica de pessoas fossem apresentados em uma escala similar. A aplicação desse método fez com que a variável padronizada apresentasse valores que variem de 0 a 1. 
O cálculo empreendido nesse tipo de padronização foi expresso pela seguinte fórmula:

$$
\text { Z = (Xi - Mínimo)/(Máximo - Mínimo) }
$$

$\mathrm{Na}$ qual Z representa a variável padronizada, o Xi representa o valor da variável antes da padronização e "Mínimo" e "Máximo" representam, respectivamente, os valores mínimo e máxima de uma determinada variável. A Tabela 22 representa sinteticamente os índices de gestão estratégica de pessoas obtidos após o processo de padronização.

Tabela 22 - Índice da soma das variáveis que representaram características de gestão estratégica de pessoas

\begin{tabular}{|c|c|c|}
\hline Características de Gestão Estratégica de Pessoas & Mínimo & Máximo \\
\hline Filosofia, Valores e Normas (padrão) & 0 & 1 \\
\hline Foco Estratégico em Inovação (padrão) & 0 & 1 \\
\hline Liderança e Gestão (padrão) & 0 & 1 \\
\hline Políticas e Práticas de Gestão de Pessoas (padrão) & 0 & 1 \\
\hline
\end{tabular}

Visto que os dados de todos os índices - independentemente da quantidade de variáveis que representaram a gestão estratégica de pessoas foram somados para sua composição e se enquadraram em valores entre 0 e 1 , foi possível ter uma visão comparativa entre tais índices.

Tabela 23 - Estatística descritiva dos índices de gestão estratégica de pessoas

\begin{tabular}{|l|r|r|r|r|}
\hline & $\begin{array}{c}\text { Índice de } \\
\text { Filosofia, } \\
\text { Valores e } \\
\text { Normas }\end{array}$ & $\begin{array}{c}\text { Índice de } \\
\text { Foco } \\
\text { Estratégico } \\
\text { em Inovação }\end{array}$ & $\begin{array}{c}\text { Índice de } \\
\text { Liderança e } \\
\text { Gestão }\end{array}$ & $\begin{array}{c}\text { Índice de Políticas e } \\
\text { Práticas de Gestão de } \\
\text { Pessoas }\end{array}$ \\
\hline $\mathrm{N}$ & 39 & 39 & 39 & 39 \\
Valid & 0 & 0 & 0 & 0 \\
Média &, 6536 &, 4751 &, 4468 &, 4162 \\
Mediana &, 6735 &, 5000 &, 3971 &, 3721 \\
Desvio-Padrão &, 21453 &, 25313 &, 26282 &, 25719 \\
Mínimo &, 00 &, 00 &, 00 &, 00 \\
Máximo & 1,00 & 1,00 & 1,00 & 1,00 \\
\hline
\end{tabular}


Assim, no intervalo de 0 a 1, a característica de gestão estratégica de pessoas que apresentou maior média e mediana foi FVN. O desvio padrão também foi o menor, denotando pouca variabilidade das respostas em relação à média.

Após explicar os procedimentos que visaram a operacionalização, procedeu-se à análise da variável gestão estratégica de pessoas. Com base nas respostas obtidas, verificou-se que a característica FVN retratou as empresas em que os respondentes atuaram. A tabela 24 mostrou que as pontuações 5 a 7 concentraram o maior percentual de respostas.

A inovação como um valor central da empresa recebeu maior incidência de pontuação 5 $(20,5 \%)$, seguida da pontuação $7(17,9 \%)$ e da pontuação $6(15,4 \%)$. Esse resultado representa uma oportunidade para a gestão estratégica de pessoas, no sentido de comunicar melhor a estratégia (COUTINHO; KALLÁS, 2005), inclusive a inovação como um valor central da empresa.

Foi interessante constatar que a pontuação 7 predominou nos indicadores sobre valores organizacionais específicos, envolvidos com inovação: flexibilidade, colaboração, comunicação, criatividade, aprendizagem, conhecimento e diversidade. É possível tais esses valores não tenham ajudado a discriminar a contribuição da característica FVN para capacidade de inovação.

Acrescenta-se que colaboração para inovação foi o indicador que concentrou mais respostas $(71,8 \%)$ na pontuação máxima, 7. Esse resultado vai ao encontro das características de projetos de P\&D\&I, que segundo a literatura envolve trabalhos em equipes multifuncionais e reforça a importância na gestão das relações humanas no contexto da inovação.

Constatou-se que a característica FEI retratou parcialmente as empresas, já que os maiores percentuais de respostas se concentraram nas pontuações 4 e 5 (Tabela 25). A questão sobre existência de coerência entre a estratégia organizacional e a de inovação se destacou pelo maior percentual de respostas $(30,8 \%)$ na pontuação 4. Esse resultado aponta para a necessidade de maior alinhamento interno (LEPAK; SHAW, 2008) entre as estratégias do negócio e a de inovação: uma condição necessária para que a gestão estratégica de pessoas contribuir para a capacidade de inovação. Constatou-se também 
que a orientação para o cliente foi o indicador que obteve maior média nas respostas, respondendo por 5,08 na escala de 1 a 7 .

Observou-se que a média das respostas para a característica LG oscilou no intervalo de 4,2 a 5,1 conforme a Tabela 26, denotando que o papel da liderança da empresa e dos gestores precisa ser mais atuante caso a inovação seja realmente um propósito nessas organizações. Sob a perspectiva da gestão estratégica de pessoas, os líderes precisam estimular a inovação na empresa, adotar um estilo de gestão propício a inovação, como o participativo e valorizar condutas que contribuam para a criação de um ambiente favorável à inovação.

Ainda sobre a característica LG, o indicador que obteve maior média nas respostas foi o que se referiu à confiança no executivo que patrocina inovação na empresa. Esse resultado foi considerado valioso, posto que uma das consequências da confiança, na visão de Robbins, Judge e Sobral (2011) é o encorajamento para assumir riscos, um comportamento associado à inovação (MARTINS; TERBLANCHE, 2003; PALLAS et al, 2013; SMITH et al, 2008; TIDD; BESSANT; PAVITT, 2008).

A característica PPGP foi a que apresentou médias mais baixas de pontuações, variando entre 3,3 e 4,7. Ela também se destacou pelo maior percentual de respostas na pontuação 5, expressando um nível substancial de concordância dos respondentes em relação às questões (itens do questionário) sobre políticas e práticas de gestão de pessoas nas empresas industriais. Acrescenta-se que dois indicadores se destacaram pela maior média nas respostas (ambos com média 4,7): alinhamento de políticas de gestão de pessoas da empresa com a estratégia corporativa e trabalho em equipes multifuncionais como uma prática amplamente utilizada em projetos de $\mathrm{P} \& \mathrm{D} \& \mathrm{I}$.

De maneira geral, os resultados revelaram que existe oportunidade de melhoria em todas as características analisadas. É importante frisar que os resultados retrataram as percepções de gestores de projetos de $P \& D \& I$ sobre organizações industriais que não necessariamente se destacam pela excelência na gestão estratégica de pessoas.

As tabelas 24 a 27, comentadas em parágrafos anteriores, serão exibidas na sequência. 
Tabela 24 - Filosofia, valores e normas (percentual e medidas descritivas)

\begin{tabular}{|c|c|c|c|c|c|c|c|c|c|c|c|}
\hline \multicolumn{12}{|c|}{ Filosofia, Valores e Normas (percentual e medidas descritivas) } \\
\hline & 1 & 2 & 3 & 4 & 5 & 6 & 7 & Média & Mediana & Moda & $\begin{array}{l}\text { Desvio- } \\
\text { Padrão }\end{array}$ \\
\hline Inovar faz parte da razão de exisitr desta empresa & $5,1 \%$ & $7,7 \%$ & $10,3 \%$ & $17,9 \%$ & $23,1 \%$ & $15,4 \%$ & $20,5 \%$ & 4,7 & 5,0 & 5,0 & 1,8 \\
\hline $\begin{array}{l}\text { A declaração de visão reforça o propósito de inovar desta } \\
\text { empresa }\end{array}$ & $0,0 \%$ & $12,8 \%$ & $12,8 \%$ & $10,3 \%$ & $25,6 \%$ & $15,4 \%$ & $23,1 \%$ & 4,9 & 5,0 & 5,0 & 1,7 \\
\hline Inovação é um valor central desta empresa & $2,6 \%$ & $17,9 \%$ & $10,3 \%$ & $15,4 \%$ & $20,5 \%$ & $15,4 \%$ & $17,9 \%$ & 4,5 & 5,0 & 5,0 & 1,8 \\
\hline Flexibilidade é indispensável para inovação & $0,0 \%$ & $5,1 \%$ & $0,0 \%$ & $7,7 \%$ & $15,4 \%$ & $15,4 \%$ & $56,4 \%$ & 6,1 & 7,0 & 7,0 & 1,4 \\
\hline Colaboração é indispensável para inovação & $0,0 \%$ & $0,0 \%$ & $2,6 \%$ & $7,7 \%$ & $0,0 \%$ & $17,9 \%$ & $71,8 \%$ & 6,5 & 7,0 & 7,0 & 1,0 \\
\hline Comunicação ampla é indispensável para inovação & $0,0 \%$ & $2,6 \%$ & $2,6 \%$ & $7,7 \%$ & $15,4 \%$ & $28,2 \%$ & $43,6 \%$ & 5,9 & 6,0 & 7,0 & 1,3 \\
\hline Criatividade é indispensável para inovação & $0,0 \%$ & $2,6 \%$ & $0,0 \%$ & $12,8 \%$ & $17,9 \%$ & $20,5 \%$ & $46,2 \%$ & 5,9 & 6,0 & 7,0 & 1,3 \\
\hline Aprendizagem é indispensável para inovação & $0,0 \%$ & $2,6 \%$ & $0,0 \%$ & $15,4 \%$ & $15,4 \%$ & $23,1 \%$ & $43,6 \%$ & 5,9 & 6,0 & 7,0 & 1,3 \\
\hline Conhecimento é indispensável para inovação & $0,0 \%$ & $2,6 \%$ & $2,6 \%$ & $10,3 \%$ & $10,3 \%$ & $17,9 \%$ & $56,4 \%$ & 6,1 & 7,0 & 7,0 & 1,3 \\
\hline Diversidade é indispensável para inovação & $0,0 \%$ & $2,6 \%$ & $0,0 \%$ & $23,1 \%$ & $25,6 \%$ & $17,9 \%$ & $30,8 \%$ & 5,5 & 5,0 & 7,0 & 1,3 \\
\hline $\begin{array}{l}\text { As normas orientam adequadamente o propósito de } \\
\text { inovar }\end{array}$ & $2,6 \%$ & $15,4 \%$ & $20,5 \%$ & $17,9 \%$ & $28,2 \%$ & $10,3 \%$ & $5,1 \%$ & 4,1 & 4,0 & 5,0 & 1,5 \\
\hline
\end{tabular}


Tabela 25 - Foco estratégico em inovação (percentual e medidas descritivas)

\begin{tabular}{|c|c|c|c|c|c|c|c|c|c|c|c|}
\hline \multicolumn{12}{|c|}{ Foco Estratégico Inovativo (percentual e medidads descritivas) } \\
\hline & 1 & 2 & 3 & 4 & 5 & 6 & 7 & Média & Mediana & Moda & $\begin{array}{l}\text { Desvio- } \\
\text { Padrão }\end{array}$ \\
\hline A inovação está arraigada em nosso modelo de negócio & $7,7 \%$ & $12,8 \%$ & $15,4 \%$ & $20,5 \%$ & $23,1 \%$ & $15,4 \%$ & $5,1 \%$ & 4,05 & 4,00 & 5,00 & 1,65 \\
\hline $\begin{array}{l}\text { Esta empresa é mais orientada para diferenciação do que } \\
\text { para liderança em custo }\end{array}$ & $5,1 \%$ & $10,3 \%$ & $12,8 \%$ & $23,1 \%$ & $17,9 \%$ & $15,4 \%$ & $15,4 \%$ & 4,46 & 4,00 & 4,00 & 1,74 \\
\hline $\begin{array}{l}\text { Existe coerência entre a estratégia organizacional e a } \\
\text { estratégia de inovação }\end{array}$ & $0,0 \%$ & $12,8 \%$ & $17,9 \%$ & $30,8 \%$ & $23,1 \%$ & $7,7 \%$ & $7,7 \%$ & 4,18 & 4,00 & 4,00 & 1,39 \\
\hline $\begin{array}{l}\text { Esta empresa busca ser a primeira a lançar novos } \\
\text { produtos e serviços no mercado }\end{array}$ & $15,4 \%$ & $10,3 \%$ & $23,1 \%$ & $10,3 \%$ & $23,1 \%$ & $12,8 \%$ & $5,1 \%$ & 3,74 & 4,00 & 3,00 & 1,80 \\
\hline $\begin{array}{l}\text { A empresa em que trabalho se caracteriza pela } \\
\text { orientação para o cliente }\end{array}$ & $2,6 \%$ & $2,6 \%$ & $7,7 \%$ & $15,4 \%$ & $30,8 \%$ & $25,6 \%$ & $15,4 \%$ & 5,08 & 5,00 & 5,00 & 1,42 \\
\hline $\begin{array}{l}\text { A empresa em que trabalho sistematicamente divulga } \\
\text { informações sobre inovação }\end{array}$ & $7,7 \%$ & $7,7 \%$ & $12,8 \%$ & $15,4 \%$ & $20,5 \%$ & $20,5 \%$ & $15,4 \%$ & 4,56 & 5,00 & 5,00 & 1,82 \\
\hline $\begin{array}{l}\text { A empresa em que trabalho sistematicamente divulga } \\
\text { resultados obtidos com inovação }\end{array}$ & $10,3 \%$ & $12,8 \%$ & $7,7 \%$ & $12,8 \%$ & $25,6 \%$ & $20,5 \%$ & $10,3 \%$ & 4,33 & 5,00 & 5,00 & 1,87 \\
\hline $\begin{array}{l}\text { A gerência de P\&D\&I é consultada quando da tomada } \\
\text { de decisões estratégicas }\end{array}$ & $2,6 \%$ & $7,7 \%$ & $10,3 \%$ & $25,6 \%$ & $17,9 \%$ & $23,1 \%$ & $12,8 \%$ & 4,69 & 5,00 & 4,00 & 1,58 \\
\hline
\end{tabular}


Tabela 26 - Liderança e gestão (percentual e medidas descritivas)

\begin{tabular}{|c|c|c|c|c|c|c|c|c|c|c|c|}
\hline \multicolumn{12}{|c|}{ Liderança e Gestão (Percentual e medidas descritivas) } \\
\hline & 1 & 2 & 3 & 4 & 5 & 6 & 7 & Média & Mediana & Moda & $\begin{array}{l}\text { Desvio- } \\
\text { Padrão }\end{array}$ \\
\hline $\begin{array}{l}\text { Os líderes de minha empresa apresentam predisposição } \\
\text { para inovar }\end{array}$ & $0,0 \%$ & $10,3 \%$ & $12,8 \%$ & $20,5 \%$ & $28,2 \%$ & $7,7 \%$ & $20,5 \%$ & 4,7 & 5,0 & 5,0 & 1,6 \\
\hline $\begin{array}{l}\text { Os líderes disseminam o intento de inovar por toda a } \\
\text { organização de maneira efetiva }\end{array}$ & $0,0 \%$ & $12,8 \%$ & $25,6 \%$ & $17,9 \%$ & $25,6 \%$ & $12,8 \%$ & $5,1 \%$ & 4,2 & 4,0 & 3,0 & 1,4 \\
\hline $\begin{array}{l}\text { Os líderes inspiram as pessoas a se engajarem em } \\
\text { atividades de inovação }\end{array}$ & $0,0 \%$ & $7,7 \%$ & $28,2 \%$ & $17,9 \%$ & $23,1 \%$ & $12,8 \%$ & $10,3 \%$ & 4,4 & 4,0 & 3,0 & 1,5 \\
\hline $\begin{array}{l}\text { Os líderes fornecem estímulo intelectual para a solução } \\
\text { de problemas }\end{array}$ & $0,0 \%$ & $10,3 \%$ & $17,9 \%$ & $33,3 \%$ & $5,1 \%$ & $25,6 \%$ & $7,7 \%$ & 4,4 & 4,0 & 4,0 & 1,5 \\
\hline Os líderes apresentam tolerência à incerteza & $7,7 \%$ & $15,4 \%$ & $20,5 \%$ & $7,7 \%$ & $17,9 \%$ & $20,5 \%$ & $10,3 \%$ & 4,2 & 4,0 & 3,0 & 1,9 \\
\hline Os líderes estimulam a interação criativa & $2,6 \%$ & $5,1 \%$ & $30,8 \%$ & $17,9 \%$ & $23,1 \%$ & $10,3 \%$ & $10,3 \%$ & 4,3 & 4,0 & 3,0 & 1,5 \\
\hline O estilo de gestão desta empresa é participativo & $7,7 \%$ & $7,7 \%$ & $15,4 \%$ & $28,2 \%$ & $15,4 \%$ & $15,4 \%$ & $10,3 \%$ & 4,2 & 4,0 & 4,0 & 1,7 \\
\hline $\begin{array}{l}\text { Existe confiança no executivo que patrocina a inovação } \\
\text { nesta empresa }\end{array}$ & $0,0 \%$ & $5,1 \%$ & $7,7 \%$ & $20,5 \%$ & $25,6 \%$ & $23,1 \%$ & $17,9 \%$ & 5,1 & 5,0 & 5,0 & 1,4 \\
\hline $\begin{array}{l}\text { O executivo que patrocina a inovação na empresa } \\
\text { assegura que os projetos recebam assistência de todos os } \\
\text { profissionais envolvidos }\end{array}$ & $0,0 \%$ & $2,6 \%$ & $12,8 \%$ & $33,3 \%$ & $17,9 \%$ & $15,4 \%$ & $17,9 \%$ & 4,8 & 5,0 & 4,0 & 1,4 \\
\hline $\begin{array}{l}\text { Existe coerência entre as orientações fornecidas pelo } \\
\text { executivo responsável por inovação e pelos gerentes de } \\
\text { projetos }\end{array}$ & $0,0 \%$ & $2,6 \%$ & $15,4 \%$ & $33,3 \%$ & $20,5 \%$ & $17,9 \%$ & $10,3 \%$ & 4,7 & 4,0 & 4,0 & 1,3 \\
\hline $\begin{array}{l}\text { Os gerentes de projetos estimulam o desenvolvimento de } \\
\text { competências atreladas à inovação }\end{array}$ & $0,0 \%$ & $2,6 \%$ & $17,9 \%$ & $33,3 \%$ & $17,9 \%$ & $17,9 \%$ & $10,3 \%$ & 4,6 & 4,0 & 4,0 & 1,3 \\
\hline $\begin{array}{l}\text { Os gerentes de projetos encorajam a proposição de } \\
\text { novas maneiras de fazer as coisas }\end{array}$ & $0,0 \%$ & $5,1 \%$ & $20,5 \%$ & $28,2 \%$ & $20,5 \%$ & $15,4 \%$ & $10,3 \%$ & 4,5 & 4,0 & 4,0 & 1,4 \\
\hline $\begin{array}{l}\text { Riscos calculados são encarados de maneira positiva em } \\
\text { minha empresa. }\end{array}$ & $2,6 \%$ & $2,6 \%$ & $25,6 \%$ & $20,5 \%$ & $25,6 \%$ & $5,1 \%$ & $17,9 \%$ & 4,5 & 4,0 & 3,0 & 1,6 \\
\hline $\begin{array}{l}\text { Aqui os erros também representam oportunidade de } \\
\text { aprendizagem }\end{array}$ & $2,6 \%$ & $7,7 \%$ & $17,9 \%$ & $15,4 \%$ & $30,8 \%$ & $15,4 \%$ & $10,3 \%$ & 4,5 & 5,0 & 5,0 & 1,5 \\
\hline $\begin{array}{l}\text { Nesta empresa entende-se que os conflitos também } \\
\text { podem instigar a inovação }\end{array}$ & $0,0 \%$ & $5,1 \%$ & $20,5 \%$ & $35,9 \%$ & $20,5 \%$ & $7,7 \%$ & $10,3 \%$ & 4,4 & 4,0 & 4,0 & 1,3 \\
\hline
\end{tabular}


Tabela 27 - Políticas e práticas de gestão de pessoas (percentual e medidas descritivas)

\begin{tabular}{|l|c|c|c|c|c|c|c|c|c|c|c|}
\hline \multicolumn{7}{|c|}{ Políticas e Práticas de Gestão de Pessoas (percentual e medidas descritivas) } \\
\hline & $\mathbf{1}$ & $\mathbf{2}$ & $\mathbf{3}$ & $\mathbf{4}$ & $\mathbf{5}$ & $\mathbf{6}$ & $\mathbf{7}$ & Média & Mediana & $\begin{array}{c}\text { Moda } \\
\text { Desvio- } \\
\text { Padrão }\end{array}$ \\
\hline $\begin{array}{l}\text { As políticas de gestão de pessoas desta empresa } \\
\text { estão alinhadas com a estratégia corporativa }\end{array}$ & $0,0 \%$ & $7,7 \%$ & $15,4 \%$ & $12,8 \%$ & $33,3 \%$ & $20,5 \%$ & $10,3 \%$ & 4,7 & 5,0 & 5,0 & 1,4 \\
\hline $\begin{array}{l}\text { As políticas de gestão de pessoas fomentam a } \\
\text { inovação na empresa }\end{array}$ & $5,1 \%$ & $17,9 \%$ & $23,1 \%$ & $17,9 \%$ & $23,1 \%$ & $7,7 \%$ & $5,1 \%$ & 3,8 & 4,0 & 3,0 & 1,6 \\
\hline $\begin{array}{l}\text { As práticas de recrutamento e seleção desta } \\
\text { empresa contribuem para a contração de bons } \\
\text { profissionais de P\&D\&I }\end{array}$ & $5,1 \%$ & $20,5 \%$ & $15,4 \%$ & $15,4 \%$ & $23,1 \%$ & $15,4 \%$ & $5,1 \%$ & 4,0 & 4,0 & 5,0 & 1,7 \\
\hline $\begin{array}{l}\text { Há compromisso de longo prazo com } \\
\text { treinamento e desenvolvimento voltados para } \\
\text { inovação }\end{array}$ & $0,0 \%$ & $15,4 \%$ & $20,5 \%$ & $25,6 \%$ & $12,8 \%$ & $15,4 \%$ & $10,3 \%$ & 4,2 & 4,0 & 4,0 & 1,6 \\
\hline $\begin{array}{l}\text { O plano de carreira da empresa considera as } \\
\text { necessidades dos profissionais de P\&D\&I }\end{array}$ & $12,8 \%$ & $20,5 \%$ & $12,8 \%$ & $15,4 \%$ & $20,5 \%$ & $12,8 \%$ & $5,1 \%$ & 3,7 & 4,0 & 2,0 & 1,8 \\
\hline $\begin{array}{l}\text { A inovação é considerada no(s) método(s) de } \\
\text { avaliação de desempenho humano }\end{array}$ & $7,7 \%$ & $12,8 \%$ & $25,6 \%$ & $10,3 \%$ & $20,5 \%$ & $12,8 \%$ & $10,3 \%$ & 4,0 & 4,0 & 3,0 & 1,8 \\
\hline $\begin{array}{l}\text { O sistema de recompensas desta empresa } \\
\text { estimula o engajamento dos funcionários em } \\
\text { atividades de inovação }\end{array}$ & $17,9 \%$ & $25,6 \%$ & $17,9 \%$ & $15,4 \%$ & $5,1 \%$ & $10,3 \%$ & $7,7 \%$ & 3,3 & 3,0 & 2,0 & 1,9 \\
\hline $\begin{array}{l}\text { O trabalho em equipes multifuncionais é uma } \\
\text { prática amplamente utilizada em projetos P\&D\&I }\end{array}$ & $2,6 \%$ & $10,3 \%$ & $10,3 \%$ & $15,4 \%$ & $30,8 \%$ & $17,9 \%$ & $12,8 \%$ & 4,7 & 5,0 & 5,0 & 1,6 \\
\hline $\begin{array}{l}\text { A gestão de talentos contribui para a retenção de } \\
\text { profissionais de P\&D\&I }\end{array}$ & $10,3 \%$ & $25,6 \%$ & $17,9 \%$ & $15,4 \%$ & $17,9 \%$ & $5,1 \%$ & $7,7 \%$ & 3,5 & 3,0 & 2,0 & 1,7 \\
\hline
\end{tabular}




\subsubsection{Análise da Variável Dependente Capacidade de Inovação}

De acordo com a definição operacional apresentada na seção 2.4 - Consolidação da Fundamentação Teórica, capacidade de inovação foi representado por um conjunto de cinco variáveis quantitativas que podem ser visualizadas no Quadro 19.

\section{Quadro 19 - Operacionalização da variável dependente}

Indicadores de Capacidade de Inovação

Habilidade da empresa de identificar oportunidades de melhoria com vistas à inovação

Habilidade da empresa de assimilar conhecimentos adquiridos em projetos de P\&D\&I

Habilidade da empresa de compartilhar lições aprendidas em projetos de P\&D\&I

Habilidade da empresa de alocar profissionais provenientes de diferentes grupos funcionais no processo de inovação

Habilidade da empresa de integrar diferentes grupos funcionais envolvidos no processo de inovação

A seguir será analisada a extensão em que os indicadores de Gestão Estratégica de Pessoas, como um todo, estimularam cada um dos indicadores de Capacidade de Inovação nas empresas sob a perspectiva dos respondentes.

Todos os cinco indicadores (Tabela 28) revelaram um moderado estímulo da gestão estratégica de pessoas na capacidade de inovação, apresentando médias que variaram no intervalo entre 4,1 e 4,4. As particularidades serão analisadas nos parágrafos seguintes.

Quanto à habilidade da empresa de identificar oportunidades de melhorias com vistas a inovação, as pontuações 4 e 5 foram atribuídas em 51,2\% das respostas. Não foram atribuídas pontuações 1 e a pontuação 7 foi atribuída para 5,1\% das respostas. A partir das respostas fornecidas na visão dos gestores é possível inferir que a gestão estratégica de pessoas estimula as empresas a identificarem melhorias visando a inovação.

Quanto à habilidade da empresa de assimilar conhecimentos adquiridos em projetos de $\underline{P \& D \& I}$, as pontuações 4 e 5 foram atribuídas em 53,8\% das respostas. Foram observados baixos percentuais de pontuações 1 e 2 , respectivamente $2,6 \%$ e $5,1 \%$, indicando que boa parte das pontuações foram médias e altas. Essa indicação foi respaldada pela moda de 5.0 .

Quanto à habilidade da empresa de compartilhar lições aprendidas em projetos de $\underline{P \& D \& I}$, também foi identificado o estímulo da gestão estratégica de pessoas, uma vez 
que as pontuações 4 e 5 responderam por quase a metade das respostas, com 48,7\%. Esse foi o indicador de capacidade de inovação que apresentou maior variação em relação às médias das respostas, apresentando o desvio padrão de 1,5.

A gestão estratégica de pessoas parece estimular a habilidade da empresa de alocar profissionais provenientes de diferentes grupos funcionais no processo de inovação, a julgar pela elevada quantidade de pontuações 3, 4 e 5. Como cada uma dessas pontuações representou $25,6 \%$ das respostas, quando consideradas coletivamente elas responderam por $76,8 \%$ das respostas.

Quanto à habilidade da empresa de integrar diferentes grupos funcionais envolvidos no processo de inovação, as pontuações 4 e 5 foram atribuídas para 53,8\% das respostas. Não foi atribuída pontuação 1 e a pontuação 7 concentrou apenas 2,6\% das respostas, indicando que essa habilidade da empresa é estimulada pela gestão estratégica de pessoas em menor ou maior grau.

Os resultados analisados até então reforçaram a importância e a necessidade de gerir pessoas sob a abordagem estratégica, já que suas características, tratadas neste estudo como FVN, FEI, LG e PPGP estimularam moderadamente a capacidade de inovação nas organizações pesquisadas, sob a percepção dos respondentes. Os resultados também revelaram que existe oportunidade de melhoria desse estímulo para todos os indicadores de capacidade de inovação utilizados neste estudo. A seguir será exibida a Tabela 8, comentada anteriormente nesta seção. 
Tabela 28 - Capacidade de inovação (percentual e medidas descritivas)

\begin{tabular}{|c|c|c|c|c|c|c|c|c|c|c|c|}
\hline \multicolumn{12}{|c|}{ Capacidade de Inovação (Percentual e medidas descritivas) } \\
\hline & 1 & 2 & 3 & 4 & 5 & 6 & 7 & Média & Mediana & Moda & $\begin{array}{l}\text { Desvio- } \\
\text { Padrão }\end{array}$ \\
\hline $\begin{array}{l}\text { Habilidade da empresa de identificar } \\
\text { oportunidades de melhoria com vistas à inovação }\end{array}$ & $0,0 \%$ & $10,3 \%$ & $20,5 \%$ & $25,6 \%$ & $25,6 \%$ & $12,8 \%$ & $5,1 \%$ & 4,3 & 4,0 & 4,0 & 1,4 \\
\hline $\begin{array}{l}\text { Habilidade da empresa de assimilar } \\
\text { conhecimentos adquiridos em projetos de } \\
\text { P\&D\&I }\end{array}$ & $2,6 \%$ & $5,1 \%$ & $17,9 \%$ & $25,6 \%$ & $28,2 \%$ & $10,3 \%$ & $10,3 \%$ & 4,4 & 4,0 & 5,0 & 1,4 \\
\hline $\begin{array}{l}\text { Habilidade da empresa de compartilhar lições } \\
\text { aprendidas em projetos de P\&D\&I }\end{array}$ & $2,6 \%$ & $12,8 \%$ & $17,9 \%$ & $23,1 \%$ & $25,6 \%$ & $10,3 \%$ & $7,7 \%$ & 4,2 & 4,0 & 5,0 & 1,5 \\
\hline $\begin{array}{l}\text { Habilidade da empresa de alocar profissionais } \\
\text { provenientes de diferentes grupos funcionais no } \\
\text { processo de inovação }\end{array}$ & $2,6 \%$ & $7,7 \%$ & $25,6 \%$ & $25,6 \%$ & $25,6 \%$ & $10,3 \%$ & $2,6 \%$ & 4,1 & 4,0 & 3,0 & 1,3 \\
\hline $\begin{array}{l}\text { Habilidade da empresa de integrar diferentes } \\
\text { grupos funcionais envolvidos no processo de } \\
\text { inovação }\end{array}$ & $0,0 \%$ & $12,8 \%$ & $20,5 \%$ & $33,3 \%$ & $15,4 \%$ & $15,4 \%$ & $2,6 \%$ & 4,1 & 4,0 & 4,0 & 1,3 \\
\hline
\end{tabular}




\subsubsection{Análise das Variáveis Intervenientes}

Para analisar as variáveis intervenientes (porte, receita operacional bruta e tempo de operação no Brasil) foram utilizadas tabelas de frequência e percentual visando compreender a distribuição das respostas.

Embora se tenha partido da classificação fornecida pelo IBGE (2014), de cinco faixas para as variáveis porte e receita operacional bruta, essas faixas foram fundidas em três para efeitos de simplificação e melhor representação das respostas.

A maior parte dos respondentes classificaram as empresas como médias e grandes respectivamente 14 e 18 respostas. Juntas, elas responderam por 32 observações no total de 39 , o que correspondeu ao percentual de $82,1 \%$.

Tabela 29 - Porte das empresas

\begin{tabular}{|l|c|c|}
\hline \multicolumn{3}{|c|}{ Porte (Percentual) } \\
\hline & Frequência & Percentual \\
\hline Micro e Pequenas Empresas & 7 & $17,9 \%$ \\
\hline Média Empresa & 14 & $35,9 \%$ \\
\hline Grande Empresa & 18 & $46,2 \%$ \\
\hline Total & 39 & $100,0 \%$ \\
\hline
\end{tabular}

No que tange à receita operacional bruta, a maior parte dos respondentes atribuiu às empresas a classificação "acima de $\mathrm{R}$ \$ 16 milhões e menor ou igual a R 3300 milhões" e “acima de R \$ 300 milhões", respectivamente 13 e 17 respostas. Juntas, elas responderam por 30 observações no total de 39 , o que correspondeu ao percentual de $76,9 \%$.

Tabela 30 - Receita operacional bruta das empresas

\begin{tabular}{|l|c|c|}
\hline \multicolumn{3}{|c|}{ Receita Operacional Bruta (Percentual) } \\
\hline & Frequência & Percentual \\
\hline Até R\$ 16 milhões & 9 & $23,1 \%$ \\
\hline $\begin{array}{l}\text { Acima de R\$ 16 milhões e maior ou } \\
\text { igual a R\$ 300 milhões }\end{array}$ & 13 & $33,3 \%$ \\
\hline Acima de R\$ 300 milhões & 17 & $43,6 \%$ \\
\hline Total & 39 & $100,0 \%$ \\
\hline
\end{tabular}


A variável tempo de operação bruta no Brasil foi distribuída de maneira uniforme e crescente nas três primeiras faixas. A faixa "abaixo de 12 anos" apresentou 10 respostas, a faixa de "12 a 45 anos", 11 respostas e a faixa "de 46 a 70 anos", 12 observações. Essas respostas totalizaram 33 entre as 39 possíveis. A faixa de "acima de 70 anos" agregou apenas 6 respostas.

Tabela 31 - Tempo de operação das empresas no Brasil

\begin{tabular}{|l|c|c|}
\hline \multicolumn{3}{|c|}{ Faixa de Tempo de Operação no Brasil (Percentual) } \\
\hline & Frequência & Percentual \\
\hline Abaixo de 12 anos & 10 & $25,6 \%$ \\
\hline de 12 a 45 anos & 11 & $28,2 \%$ \\
\hline de 46 a 70 anos & 12 & $30,8 \%$ \\
\hline Acima de 70 anos & 6 & $15,4 \%$ \\
\hline Total & 39 & $100,0 \%$ \\
\hline
\end{tabular}

\subsection{Análise da Relação entre Gestão Estratégica de Pessoas e Capacidade de Inovação}

O foco desta seção recaiu em avaliar a relação de associação entre a Gestão Estratégica de Pessoas e a Capacidade de Inovação nas empresas do setor industrial pesquisadas sob a perspectiva dos profissionais com as características da população que participaram da pesquisa. A fim de averiguar a existência dessa relação e sua natureza, utilizou o ferramental da Correlação de Spearman.

Realizou-se o cálculo dos coeficientes de correlação de Spearman entre cada um dos índices padronizados da gestão estratégica de pessoas junto as cinco variáveis de capacidade de inovação. O coeficiente de correlação de Spearman varia de -1 a 1, onde quanto mais próximo de zero, menor será a força da associação entre a gestão estratégica de pessoas e a capacidade de inovação.

A partir do teste de Correlação de Spearman foram analisados apenas os coeficientes estatisticamente significantes para interpretação do fenômeno explorado nesta 
investigação (com valores menores ou iguais a 0,41). $\mathrm{O}$ teste permitiu verificar a existência de uma relação entre tais variáveis e a força da associação que segundo Hair Jr. et al (2009) que pode variar de muito forte a leve.

O teste de correlação de Spearman foi realizado com nível de significância de 10\% (nível de confiabilidade de 90\%). Convém ressaltar que embora seja comum assumir um nível de significância de 5\%, optou-se por assumir nível de significância maior, em virtude da amostra com poucas repostas $(n=39)$. Nesse contexto foram analisadas as correlações estatisticamente significantes e o valor de seu índice, permitindo identificar o grau de intensidade das correlações.

As premissas do teste de Correlação de Spearman foram:

H0: rho = zero;

H1: rho $\neq$ zero;

sendo rho o índice de correlação.

Foi gerada uma matriz que confrontou os índices de gestão estratégica de pessoas com os indicadores de capacidade de inovação, no intuito de identificar as correlações estatisticamente significantes a 10\% (Tabela 32). 
Tabela 32 - Correlação de Spearman entre "Gestão Estratégica de Pessoas" e "Capacidade de Inovação"

\begin{tabular}{|c|c|c|c|c|c|c|c|}
\hline \multicolumn{8}{|c|}{ Correlação de Spearman entre "Gestão Estratégica de Pessoas" e "Capacidade de Inovação" } \\
\hline & & & $\begin{array}{l}\text { Habilidade da } \\
\text { empresa de } \\
\text { identificar } \\
\text { oportunidades } \\
\text { de melhoria } \\
\text { com vistas à } \\
\text { inovação }\end{array}$ & $\begin{array}{c}\text { Habilidade da } \\
\text { empresa de } \\
\text { assimilar } \\
\text { conhecimentos } \\
\text { adquiridos em } \\
\text { projetos de } \\
\text { P\&D\&l }\end{array}$ & $\begin{array}{c}\text { Habilidade da } \\
\text { empresa de } \\
\text { compartilhar } \\
\text { lições } \\
\text { aprendidas em } \\
\text { projetos de } \\
\text { P\&D\&l }\end{array}$ & $\begin{array}{c}\text { Habilidade da } \\
\text { empresa de alocar } \\
\text { profissionais } \\
\text { provenientes de } \\
\text { diferentes grupos } \\
\text { funcionais no } \\
\text { processo de } \\
\text { inovação }\end{array}$ & $\begin{array}{c}\text { Habilidade } \\
\text { da empresa } \\
\text { de integrar } \\
\text { diferentes } \\
\text { grupos } \\
\text { funcionais } \\
\text { envolvidos } \\
\text { no processo } \\
\text { de inovação }\end{array}$ \\
\hline \multirow{12}{*}{$\begin{array}{l}\text { Spearman } \\
\text { 's rho }\end{array}$} & \multirow{3}{*}{$\begin{array}{c}\text { Indice de Filosofia, Valores e } \\
\text { Normas (FVN) }\end{array}$} & Correlation Coefficient & $0,358^{\star}$ & $0,413^{\star}$ & ,282 & ,259 & $0,408^{*}$ \\
\hline & & Sig. (2-tailed) &, 025 & ,009 & ,082 & ,112 & 010 \\
\hline & & $\mathrm{N}$ & 39 & 39 & 39 & 39 & 39 \\
\hline & \multirow{3}{*}{$\begin{array}{c}\text { Indice de Foco Estratégico } \\
\text { Inovativo (FEI) }\end{array}$} & Correlation Coefficient & $0,515^{\star}$ & $0,648^{\star}$ & $0,567^{\star}$ & $0,336^{*}$ & $0,533^{*}$ \\
\hline & & Sig. (2-tailed) &, 001 &, 000 &, 000 & ,036 & 000 \\
\hline & & $\mathrm{N}$ & 39 & 39 & 39 & 39 & 39 \\
\hline & \multirow{3}{*}{$\begin{array}{l}\text { Indice de Liderança e Gestão } \\
\text { (LG) }\end{array}$} & Correlation Coefficient & $0,512^{\star}$ & $0,768^{*}$ & $0,536^{*}$ & $0,387^{*}$ & $0,581^{*}$ \\
\hline & & Sig. (2-tailed) & 001 &, 000 &, 000 &, 015 &, 000 \\
\hline & & $\mathrm{N}$ & 39 & 39 & 39 & 39 & 39 \\
\hline & \multirow{3}{*}{$\begin{array}{l}\text { Indice de Políticas e Práticas } \\
\text { de Gestão de Pessoas (PPGP) }\end{array}$} & Correlation Coefficient & $0,639^{*}$ & $0,6301^{*}$ & $0,558^{*}$ & $0,543^{*}$ & $0,565^{\star}$ \\
\hline & & Sig. (2-tailed) &, 000 &, 000 &, 000 &, 000 &, 000 \\
\hline & & $\mathrm{N}$ & 39 & 39 & 39 & 39 & 39 \\
\hline
\end{tabular}


Resgatou-se a Tabela 1, apresentada na seção 3.6 - Plano de Análise para interpretar os resultados exibidos na matriz.

A análise preliminar da matriz revelou que todas as correlações foram positivas e superiores a 0,21 indicando que a gestão estratégica de pessoas estimulou, em menor ou maior grau, a capacidade de inovação das empresas do setor industrial pesquisadas, sob a perspectiva dos respondentes.

O passo seguinte consistiu em verificar se as relações foram estatisticamente significantes ao nível de $10 \%$. Constatou-se que:

- a habilidade da empresa de identificar oportunidades de melhoria com vistas a inovação foi moderadamente associada aos índices FEI, LG e PPGP;

- a habilidade da empresa de assimilar conhecimentos adquiridos em projetos de P\&D\&I foi moderadamente associada aos índices FVN, FEI e PPGP e altamente associada ao índice LG;

- a habilidade da empresa de compartilhar lições aprendidas em projetos de P\&D\&I foi moderadamente associada aos índices FEI, LG e PPGP;

- a habilidade da empresa de alocar profissionais provenientes de diferentes grupos funcionais no processo de inovação foi moderadamente ao índice PPGP; e

- a habilidade da empresa de integrar diferentes grupos funcionais envolvidos no processo de inovação foi moderadamente associada aos quatro índices: FVN, FEI, LG e PPGP.

Essas evidências permitiram confirmar a Hipótese 1, de que gestão estratégica de pessoas está positivamente associada com capacidade de inovação apesar da variabilidade dos valores de correlação. Os três indicadores de capacidade de inovação que apresentaram baixa correlação com FVN emergiram como pontos de atenção que serão retomados no capítulo de Considerações Finais.

Complementarmente, foram feitas matrizes de correlação específicas, que detalharam a relação entre cada indicador de gestão estratégica de pessoas agrupados em FVN, FEI LG e PPGP com cada indicador de capacidade de inovação. As matrizes foram inseridas no Apêndice 4. 


\subsubsection{Análise do Papel das Variáveis Intervenientes na Relação entre Gestão Estratégica de Pessoas e Capacidade de Inovação}

Na última etapa da análise foi avaliado o impacto das seguintes variáveis mediadoras: porte; receita operacional bruta e tempo de operação no Brasil. As referidas análises foram realizadas da seguinte forma: realizou-se o cálculo de correlação de Spearman entre os indicadores de gestão estratégica de pessoas (FVN, FEI, LG e PPGP) e capacidade de inovação, segmentando essas análises para cada uma das faixas das variáveis intervenientes.

As variáveis porte e receita operacional bruta foram inicialmente compostas por cinco faixas cada uma delas. Todavia, visto que algumas eram compostas por poucas observações (entre 2 e 3), dificultando a obtenção de correlações significativas, optou-se pela unificação, conforme demonstrado no Quadro 20.

Quadro 20 - Caracterização das variáveis intervenientes

\begin{tabular}{|c|c|c|c|}
\hline $\begin{array}{l}\text { Porte (categorias } \\
\text { iniciais) }\end{array}$ & $\begin{array}{l}\text { Porte (novas } \\
\text { categorias) }\end{array}$ & $\begin{array}{c}\text { Receita Operacional } \\
\text { Bruta (categorias } \\
\text { iniciais) }\end{array}$ & $\begin{array}{c}\text { Receita Operacional } \\
\text { Bruta (novas } \\
\text { categorias) }\end{array}$ \\
\hline Microempresa & \multirow[b]{2}{*}{$\begin{array}{c}\text { Micro e Pequenas } \\
\text { Empresas }\end{array}$} & $\begin{array}{l}\text { Menor ou igual a } \mathrm{R} \$ 2,4 \\
\text { milhões }\end{array}$ & \multirow[b]{2}{*}{ Até R\$16 Milhões } \\
\hline Pequena Empresa & & $\begin{array}{l}\text { Maior que } \mathrm{R} \$ 2,4 \\
\text { milhões e menor ou } \\
\text { igual a } \mathrm{R} \$ 16 \text { milhões }\end{array}$ & \\
\hline Média empresa & & $\begin{array}{l}\text { Maior que } \mathrm{R} \$ 16 \\
\text { milhões e menor ou } \\
\text { igual a } \mathrm{R} \$ 90 \text { milhões }\end{array}$ & \multirow{2}{*}{$\begin{array}{l}\text { Acima de } \mathrm{R} \$ 16 \text { milhões } \\
\text { e menor ou igual a } \\
\mathrm{R} \$ 300 \text { milhões }\end{array}$} \\
\hline Média-grande empresa & Média Empresa & $\begin{array}{l}\text { Maior que } \mathrm{R} \$ 90 \\
\text { milhões e menor ou } \\
\text { igual a } \mathrm{R} \$ 300 \text { milhões }\end{array}$ & \\
\hline Grande Empresa & Grande Empresa & Maior que 300 milhões & $\begin{array}{lll}\text { Acima } & \text { de } & \text { R\$300 } \\
\text { milhões } & & \\
\end{array}$ \\
\hline
\end{tabular}

No Quadro 20 é possível verificar uma redução de cinco para três faixas para as análises das variáveis intervenientes. Sendo assim, foram realizados os cálculos da correlação de Spearman entre gestão estratégica de pessoas (utilizando os quatro índices: FVN, FEI, LG e PPGP) e a capacidade de inovação por faixa de variável interveniente.

A variável tempo de operação no Brasil originalmente era um dado quantitativo (métrico). Todavia, para que se pudesse empreender o cálculo da correlação de Spearman (similar 
ao porte e receita operacional bruta), optou-se por transformá-la em uma variável intervalar. Possibilitando, assim, analisar a associação da Gestão Estratégica de Pessoas e Capacidade de Inovação em cada uma das diferentes faixas de tempo de operação no Brasil.

$\mathrm{O}$ critério utilizado para criar tais faixas de tempo se baseou na medida dos quartis. $\mathrm{O}$ quartil consiste de uma medida de posição que divide um conjunto de dados - dispostos em ordem crescente - em quatro partes ou dimensões (FÁVERO et al 2009). Dessa forma, por meio do cálculo dos quartis, criaram-se as seguintes faixas de tempo para a variável “Tempo de Operação no Brasil”, conforme ilustra o Quadro 21.

Quadro 21 - Faixas de tempo de operação no Brasil

\begin{tabular}{|c|c|}
\hline \multirow{2}{*}{\begin{tabular}{|} 
Tempo de Operação no Brasil \\
(Faixas)
\end{tabular}} & Abaixo de 12 anos \\
\cline { 2 - 2 } & De 12 a 45 anos \\
\cline { 2 - 2 } & De 46 a 70 anos \\
\cline { 2 - 2 } & Acima de 70 anos \\
\hline
\end{tabular}

Em seguida realizou-se o cálculo da correlação de Spearman entre os indicadores de Gestão Estratégica de Pessoas e Capacidade de Inovação, em cada das quatro faixas de tempo indicadas no Quadro 21, permitindo, assim avaliar se a faixa de tempo de operação no Brasil influiu de alguma forma na associação entre a gestão estratégica de pessoas e capacidade de inovação.

\subsubsection{Análise da Relação entre Gestão Estratégica de Pessoas e Capacidade de Inovação por Porte das Empresas Industriais}

Foi analisada a relação de associação por correlação de Spearman tomando como base as três faixas de porte das empresas. As principais constatações serão apresentadas nos parágrafos subsequentes, seguidas das matrizes de correlação.

A presença de correlações levemente negativas na faixa de micro e pequenas empresas (Tabela 33) sugere que a gestão estratégica de pessoas não está contribuindo para a capacidade de inovação e corrobora a visão de Brewster (2006), para quem a função de gestão de pessoas é sensível ao tamanho da empresa. Indaga-se também se em micro e 
pequenas empresas existem condições e necessidade de haver gestão estratégica de pessoas.

As médias e grandes empresas, por outro lado, não apresentaram correlações negativas. As médias empresas se destacaram em três indicadores (habilidade da empresa de assimilar conhecimentos adquiridos em projetos de P\&D\&I; habilidade da empresa de compartilhar lições aprendidas em projetos de P\&D\&I e habilidade da empresa de integrar diferentes grupos funcionais envolvidos no processo de inovação), que estiveram moderadamente e altamente correlacionados com os quatro índices (Tabela 34). É possível que, por se tratarem de empresas de médio porte, a gestão de pessoas esteja mais próxima do negócio e consiga aturar com foco nas demandas dos gestores de P\&D\&I.

A tendência de aumento no valor das correlações não foi confirmada para as grandes empresas. Os valores das correlações em FVN (Tabela 35) foram, em sua maioria, "leves, quase imperceptíveis" segundo Hair Jr. et al (2009, p. 312). Diante disso, indaga-se: as médias empresas estão comunicando suas crenças, pressupostos, valores e normas aos gestores de P\&D\&I? Até que ponto a alta gestão fornece abertura para que seus gestores funcionais compreendam as diretrizes estratégicas a ponto de desdobrá-las em seus campos de atuação?

A seguir serão exibidas as tabelas 33 a 35, explicadas nos parágrafos anteriores. 
Tabela 33 - Correlação entre "Gestão Estratégica de Pessoas" e "Capacidade de Inovação" (Micro e Pequenas Empresas)

\begin{tabular}{|c|c|c|c|c|c|c|c|}
\hline \multicolumn{8}{|c|}{ Correlação entre "Gestão Estratégica de Pessoas" e "Capacidade de Inovação" (Micro e Pequenas Empresas) } \\
\hline & & & $\begin{array}{c}\text { Habilidade } \\
\text { da empresa } \\
\text { de identificar } \\
\text { oportunidad } \\
\text { es de } \\
\text { melhoria } \\
\text { com vistas à } \\
\text { inovação }\end{array}$ & $\begin{array}{c}\text { Habilidade } \\
\text { da empresa } \\
\text { de assimilar } \\
\text { conheciment } \\
\text { os adquiridos } \\
\text { em } \\
\text { projetos de } \\
P \& D \& I\end{array}$ & $\begin{array}{c}\text { Habilidade da } \\
\text { empresa de } \\
\text { compartilhar } \\
\text { lições } \\
\text { aprendidas } \\
\text { em projetos } \\
\text { de } P \& D \& I\end{array}$ & $\begin{array}{c}\text { Habilidade da } \\
\text { empresa de alocar } \\
\text { profissionais } \\
\text { provenientes de } \\
\text { diferentes grupos } \\
\text { funcionais no } \\
\text { processo de } \\
\text { inovação }\end{array}$ & $\begin{array}{l}\text { Habilidade da } \\
\text { empresa de } \\
\text { integrar diferentes } \\
\text { grupos funcionais } \\
\text { envolvidos no } \\
\text { processo de } \\
\text { inovação }\end{array}$ \\
\hline $\begin{array}{l}\text { Spearman } \\
\text { 's rho }\end{array}$ & $\begin{array}{l}\text { Indice de Filosofia, } \\
\text { Valores e Normas (FVN) }\end{array}$ & $\begin{array}{l}\text { Correlation } \\
\text { Coefficient }\end{array}$ & ,430 &,- 039 & , 150 & ,385 &, 561 \\
\hline & & Sig. (2-tailed) &, 335 & ,933 & ,749 & ,393 &, 190 \\
\hline & & $\mathrm{N}$ & 7 & 7 & 7 & 7 & 7 \\
\hline & \begin{tabular}{|l} 
Indice do Foco \\
Estratégico e Inovador
\end{tabular} & $\begin{array}{l}\text { Correlation } \\
\text { Coefficient }\end{array}$ & ,318 &,- 197 & ,112 & , 147 & ,337 \\
\hline & & Sig. (2-tailed) & ,487 & ,672 & 811 & ,753 & $\overline{, 460}$ \\
\hline & & $\mathrm{N}$ & 7 & 7 & 7 & 7 & 7 \\
\hline & $\begin{array}{l}\text { Indice de Liderança e } \\
\text { Gestão }\end{array}$ & $\begin{array}{l}\text { Correlation } \\
\text { Coefficient }\end{array}$ & ,636 & $0,768^{*}$ & $0,730^{\star \star \star}$ & $0,698^{\star \star}$ & ,617 \\
\hline & & Sig. (2-tailed) &, 125 & ,044 & ,063 & ,081 &, 740 \\
\hline & & $\mathrm{N}$ & 7 & 7 & 7 & 7 & 7 \\
\hline & $\begin{array}{l}\text { Indice de Políticas e } \\
\text { Práticas de Gestão de }\end{array}$ & $\begin{array}{l}\text { Correlation } \\
\text { Coefficient }\end{array}$ &, 524 & ,374 & ,487 & ,624 & $0,805^{\star}$ \\
\hline & & Sig. (2-tailed) & 227 & ,408 & ,268 & , 134 & ,029 \\
\hline & & $\mathrm{N}$ & 7 & 7 & 7 & 7 & 7 \\
\hline
\end{tabular}


Tabela 34- Correlação entre "Gestão Estratégica de Pessoas" e "Capacidade de Inovação " (Médias Empresas)

\begin{tabular}{|c|c|c|c|c|c|c|c|}
\hline \multicolumn{8}{|c|}{ Correlação entre "Gestão Estratégica de Pessoas" e "Capacidade de Inovação" (Médias Empresas) } \\
\hline & & & $\begin{array}{c}\text { Habilidade } \\
\text { da empresa } \\
\text { de identificar } \\
\text { oportunidad } \\
\text { es de } \\
\text { melhoria } \\
\text { com vistas à } \\
\text { inovação }\end{array}$ & $\begin{array}{c}\text { Habilidade } \\
\text { da empresa } \\
\text { de assimilar } \\
\text { conheciment } \\
\text { os adquiridos } \\
\text { em } \\
\text { projetos de } \\
\text { P\&D\&I }\end{array}$ & $\begin{array}{c}\text { Habilidade da } \\
\text { empresa de } \\
\text { compartilhar } \\
\text { lições } \\
\text { aprendidas } \\
\text { em projetos } \\
\text { de P\&D\&I }\end{array}$ & $\begin{array}{l}\text { Habilidade da } \\
\text { empresa de alocar } \\
\text { profissionais } \\
\text { provenientes de } \\
\text { diferentes grupos } \\
\text { funcionais no } \\
\text { processo de } \\
\text { inovação }\end{array}$ & $\begin{array}{l}\text { Habilidade da } \\
\text { empresa de } \\
\text { integrar diferentes } \\
\text { grupos funcionais } \\
\text { envolvidos no } \\
\text { processo de } \\
\text { inovação }\end{array}$ \\
\hline \multirow[t]{12}{*}{$\begin{array}{l}\text { Spearman } \\
\text { 's rho }\end{array}$} & \multirow[t]{3}{*}{$\begin{array}{l}\text { Indice de Filosofia, } \\
\text { Valores e Normas (FVN) }\end{array}$} & $\begin{array}{l}\text { Correlation } \\
\text { Coefficient }\end{array}$ & ,446 & $0,506^{\star \star}$ & $0,619^{\star}$ & $0,487^{\star \star}$ & $0,642^{*}$ \\
\hline & & Sig. (2-tailed) &, 1110 & ,065 & ,018 &, 077 & $\overline{013}$ \\
\hline & & $\mathrm{N}$ & 14 & 14 & 14 & 14 & 14 \\
\hline & \multirow[t]{3}{*}{$\begin{array}{l}\text { Indice do Foco } \\
\text { Estratégico e Inovador }\end{array}$} & $\begin{array}{l}\text { Correlation } \\
\text { Coefficient }\end{array}$ & ,363 & $0,812^{\star}$ & $0,766^{\star}$ & $0,267^{*}$ & $0,739^{*}$ \\
\hline & & Sig. (2-tailed) & ,203 &, 000 & ,001 & ,357 &, 003 \\
\hline & & $\bar{N}$ & 14 & 14 & 14 & 14 & 14 \\
\hline & \multirow[t]{3}{*}{$\begin{array}{l}\text { Indice de Liderança e } \\
\text { Gestão }\end{array}$} & $\begin{array}{l}\text { Correlation } \\
\text { Coefficient }\end{array}$ & $0,522^{\star \star}$ & $0,893^{\star}$ & $0,734^{\star}$ & ,338 & $0,660^{*}$ \\
\hline & & Sig. (2-tailed) & ,055 & ,000 & ,003 & ,237 & ,010 \\
\hline & & $\bar{N}$ & 14 & 14 & 14 & 14 & 14 \\
\hline & \multirow[t]{3}{*}{$\begin{array}{l}\text { Indice de Políticas e } \\
\text { Práticas de Gestão de }\end{array}$} & $\begin{array}{l}\text { Correlation } \\
\text { Coefficient }\end{array}$ & ,438 & $0,680^{*}$ & $0,736^{*}$ & $0,580^{*}$ & $0,592^{\star}$ \\
\hline & & Sig. (2-tailed) & ,117 & ,007 & ,003 &, 030 & ,026 \\
\hline & & $\mathrm{N}$ & 14 & 14 & 14 & 14 & 14 \\
\hline
\end{tabular}


Tabela 35 - Correlação entre "Gestão Estratégica de Pessoas" e "Capacidade de Inovação" (Grande Empresas)

\begin{tabular}{|c|c|c|c|c|c|c|c|}
\hline \multicolumn{8}{|c|}{ Correlação entre "Gestão Estratégica de Pessoas" e "Capacidade de Inovação" (Grande Empresas) } \\
\hline & & & $\begin{array}{c}\text { Habilidade } \\
\text { da empresa } \\
\text { de identificar } \\
\text { oportunidad } \\
\text { es de } \\
\text { melhoria } \\
\text { com vistas à } \\
\text { inovação }\end{array}$ & $\begin{array}{c}\text { Habilidade } \\
\text { da empresa } \\
\text { de assimilar } \\
\text { conheciment } \\
\text { os adquiridos } \\
\text { em } \\
\text { projetos de } \\
\text { P\&D\&I }\end{array}$ & $\begin{array}{c}\text { Habilidade da } \\
\text { empresa de } \\
\text { compartilhar } \\
\text { lições } \\
\text { aprendidas } \\
\text { em projetos } \\
\text { de } P \& D \& I\end{array}$ & $\begin{array}{c}\text { Habilidade da } \\
\text { empresa de alocar } \\
\text { profissionais } \\
\text { provenientes de } \\
\text { diferentes grupos } \\
\text { funcionais no } \\
\text { processo de } \\
\text { inovação }\end{array}$ & $\begin{array}{l}\text { Habilidade da } \\
\text { empresa de } \\
\text { integrar diferentes } \\
\text { grupos funcionais } \\
\text { envolvidos no } \\
\text { processo de } \\
\text { inovação }\end{array}$ \\
\hline \multirow[t]{12}{*}{$\begin{array}{l}\text { Spearman } \\
\text { 's rho }\end{array}$} & \multirow[t]{3}{*}{$\begin{array}{l}\text { Indice de Filosofia, } \\
\text { Valores e Normas (FVN) }\end{array}$} & $\begin{array}{l}\text { Correlation } \\
\text { Coefficient }\end{array}$ & ,124 & ,365 & ,138 & ,011 & $\overline{166}$ \\
\hline & & Sig. (2-tailed) & ,625 & ,137 & ,585 & ,966 &, 511 \\
\hline & & $\mathrm{N}$ & 18 & 18 & 18 & 18 & 18 \\
\hline & \multirow[t]{3}{*}{\begin{tabular}{|l|} 
Inndice do Foco \\
Estratégico e Inovador
\end{tabular}} & \begin{tabular}{|l} 
Correlation \\
Coefficient
\end{tabular} & $0,659^{*}$ & $0,701^{*}$ & $0,575^{\star}$ & $0,531^{\star}$ & $0,46^{* *}$ \\
\hline & & Sig. (2-tailed) &, 003 & ,001 &, 013 &, 023 &, 055 \\
\hline & & $\bar{N}$ & 18 & 18 & 18 & 18 & 18 \\
\hline & \multirow[t]{3}{*}{$\begin{array}{l}\text { Indice de Liderança e } \\
\text { Gestão }\end{array}$} & $\begin{array}{l}\text { Correlation } \\
\text { Coefficient }\end{array}$ & ,373 & $\overline{0,794^{\star}}$ & $0,439^{\star \star}$ & ,236 & $0,466^{\star \star}$ \\
\hline & & Sig. (2-tailed) & ,127 & ,000 &, 069 & ,346 & ,051 \\
\hline & & $\mathrm{N}$ & 18 & 18 & 18 & 18 & 18 \\
\hline & \multirow[t]{3}{*}{$\begin{array}{l}\text { Indice de Políticas e } \\
\text { Práticas de Gestão de }\end{array}$} & $\begin{array}{l}\text { Correlation } \\
\text { Coefficient }\end{array}$ & $0,684^{\star}$ & $0,661^{*}$ & $0,401^{\star *}$ & ,343 & ,391 \\
\hline & & Sig. (2-tailed) &, 002 & ,003 & ,099 & , 164 & ,109 \\
\hline & & $\mathrm{N}$ & 18 & 18 & 18 & 18 & 18 \\
\hline
\end{tabular}


Conforme as três matrizes de correlação exibidas anteriormente, a segmentação da amostra por porte resultou em subamostras de tamanhos inferiores a 30. Temendo que isso prejudicasse a análise das correlações, foi acrescentado o teste de comparação de médias de KruskalWallis.

Tabela 36 - Teste de Kruskal-Wallis: "Gestão Estratégica de Pessoas" e "Porte"

\begin{tabular}{|c|c|c|c|c|}
\hline \multicolumn{5}{|c|}{ Teste de Kruskall-Wallis (Porte) } \\
\hline & Porte & $\mathbf{N}$ & Média dos Pontos & Nível de Significância \\
\hline \multirow[t]{3}{*}{ Filosofia, Valores e Normas } & Micro e Pequenas Empresas & 7 & 16,86 & \multirow{3}{*}{$0,047 *$} \\
\hline & Média Empresa & 14 & 15,36 & \\
\hline & Grande Empresa & 18 & 24,83 & \\
\hline \multirow[t]{3}{*}{ Foco Estratégico em Inovação } & Micro e Pequenas Empresas & 7 & 17,36 & \multirow{3}{*}{0,165} \\
\hline & Média Empresa & 14 & 16,54 & \\
\hline & Grande Empresa & 18 & 23,72 & \\
\hline \multirow[t]{3}{*}{ Liderança e Gestão } & Micro e Pequenas Empresas & 7 & 18,86 & \multirow{3}{*}{0,731} \\
\hline & Micro e Pequenas Empresas & 14 & 18,57 & \\
\hline & Micro e Pequenas Empresas & 18 & 21,56 & \\
\hline \multirow{3}{*}{ Políticas e Práticas de Gestão de Pessoas } & Micro e Pequenas Empresas & 7 & 18,00 & \multirow{3}{*}{0,399} \\
\hline & Micro e Pequenas Empresas & 14 & 17,57 & \\
\hline & Micro e Pequenas Empresas & 18 & 22,67 & \\
\hline
\end{tabular}

A segmentação por porte de empresa revelou que apenas a característica FVN foi estatisticamente significante a 5\%. Esse resultado precisa ser interpretado com parcimônia, pois nem sempre a significância estatística implica significância prática.

De maneira geral, porte não foi discriminante na relação de associação. Sendo assim, refuta-se a hipótese 2, segundo a qual as empresas industriais de grande porte apresentam maior associação entre gestão estratégica de pessoas e capacidade de inovação. 


\subsubsection{Análise da Relação entre Gestão Estratégica de Pessoas e Capacidade de Inovação por Receita Operacional Bruta das Empresas Industriais}

$\mathrm{Na}$ faixa de receita operacional bruta de "até $\mathrm{R} \$ 16$ milhões", destacaram-se as correlações leves e baixas, além de terem sido identificadas correlações negativas (Tabela 36). Na faixa "acima de $\mathrm{R} \$ 16$ milhões e menor ou igual a $\mathrm{R} \$ 300$ milhões", houve considerável aumento dos valores das correlações, com um destaque positivo para o indicador de "habilidade da empresa de assimilar conhecimentos adquiridos em projetos de P\&D\&I", que apresentou correlações altas para todos os índices de gestão estratégica de pessoas (Tabela 37).

Apenas não foi possível afirmar que o padrão se manteve na faixa seguinte, de "acima de R \$ 300 milhões", pois o indicador FVN apresentou um valor baixo de correlação (Tabela $38)$. 
Tabela 37 - Correlação entre "Gestão Estratégica de Pessoas" e "Capacidade de Inovação" (Receita Operacional Bruta de até R\$16 milhões)

\begin{tabular}{|c|c|c|c|c|c|c|c|}
\hline \multicolumn{8}{|c|}{ Correlação entre "Gestão Estratégica de Pessoas" e "Capacidade de Inovação" (Receita Operacional Bruta de até R\$16 milhões) } \\
\hline & & & $\begin{array}{l}\text { Habilidade da } \\
\text { empresa de } \\
\text { identificar } \\
\text { oportunidades de } \\
\text { melhoria com } \\
\text { vistas à inovação }\end{array}$ & $\begin{array}{l}\text { Habilidade da } \\
\text { empresa de } \\
\text { assimilar } \\
\text { conhecimentos } \\
\text { adquiridos em } \\
\text { projetos de } P \& D \& I\end{array}$ & \begin{tabular}{|c|} 
Habilidade da \\
empresa de \\
compartilhar \\
lições aprendidas \\
em projetos de \\
P\&D\&l \\
\end{tabular} & \begin{tabular}{|c|} 
Habilidade da empresa \\
de alocar profissionais \\
provenientes de \\
diferentes grupos \\
funcionais no processo \\
de inovação
\end{tabular} & $\begin{array}{c}\text { Habilidade da } \\
\text { empresa de integrar } \\
\text { diferentes grupos } \\
\text { funcionais envolvidos } \\
\text { no processo de } \\
\text { inovação }\end{array}$ \\
\hline \multirow[t]{12}{*}{ Spearman's rho } & \multirow[t]{3}{*}{$\begin{array}{l}\text { Indice de Filosofia, Valores } \\
\text { e Normas (FVN) }\end{array}$} & $\begin{array}{l}\begin{array}{l}\text { Correlation } \\
\text { Coefficient }\end{array} \\
\end{array}$ &, 329 &,- 119 &, 100 & ,111 & ,387 \\
\hline & & Sig. (2-tailed) & ,387 & ,761 & ,797 & ,776 & ,303 \\
\hline & & $\bar{N}$ & 9 & 9 & 9 & 9 & \\
\hline & \multirow[t]{3}{*}{$\begin{array}{l}\text { Indice do Foco Estratégico e } \\
\text { Inovador }\end{array}$} & \begin{tabular}{|l|} 
Correlation \\
Coefficient
\end{tabular} &,- 065 & ,206 & ,536 &,- 146 & ,259 \\
\hline & & Sig. (2-tailed) & ,868 & ,594 & ,137 &, 708 &, 500 \\
\hline & & $\mathrm{N}$ & 9 & 9 & 9 & 9 & 9 \\
\hline & \multirow[t]{3}{*}{$\begin{array}{l}\text { Indice de Liderança e } \\
\text { Gestão }\end{array}$} & $\begin{array}{l}\text { Correlation } \\
\text { Coefficient }\end{array}$ & ,165 & $0,587^{\star *}$ & ,477 & ,459 & ,389 \\
\hline & & Sig. (2-tailed) & 671 & ,097 & ,195 & 214 & ,301 \\
\hline & & $\mathrm{N}$ & 9 & 9 & 9 & 9 & \\
\hline & \multirow{3}{*}{\begin{tabular}{|l} 
Indice de Políticas e \\
Práticas de Gestão de \\
Pessoas
\end{tabular}} & \begin{tabular}{|l|} 
Correlation \\
Coefficient
\end{tabular} &, 546 & ,064 & ,137 & $0,624^{\star *}$ & $0,645^{\star \star}$ \\
\hline & & Sig. (2-tailed) & ,128 &, 870 & ,725 & ,072 & ,060 \\
\hline & & $\mathrm{N}$ & 9 & 9 & 9 & & \\
\hline
\end{tabular}


Tabela 38 - Correlação entre "Gestão Estratégica de Pessoas" e "Capacidade de Inovação" (Receita Operacional Bruta de acima de R $\$ 16$ milhões e menor ou igual a $\mathbf{R} \$ 300$ milhões)

\begin{tabular}{|c|c|c|c|c|c|c|c|}
\hline & & & $\begin{array}{l}\text { Habilidade da } \\
\text { empresa de } \\
\text { identificar } \\
\text { oportunidades de } \\
\text { melhoria com } \\
\text { vistas à inovação }\end{array}$ & \begin{tabular}{|} 
Habilidade da \\
empresa de \\
assimilar \\
conhecimentos \\
adquiridos em \\
projetos de P\&D\&I
\end{tabular} & $\begin{array}{l}\text { Habilidade da } \\
\text { empresa de } \\
\text { compartilhar } \\
\text { lições aprendidas } \\
\text { em projetos de } \\
\text { P\&D\&l } \\
\end{array}$ & $\begin{array}{c}\text { Habilidade da empresa } \\
\text { de alocar profissionais } \\
\text { provenientes de } \\
\text { diferentes grupos } \\
\text { funcionais no processo } \\
\text { de inovação }\end{array}$ & $\begin{array}{c}\text { Habilidade da } \\
\text { empresa de integrar } \\
\text { diferentes grupos } \\
\text { funcionais envolvidos } \\
\text { no processo de } \\
\text { inovação } \\
\end{array}$ \\
\hline \multirow[t]{12}{*}{ Spearman's rho } & \multirow[t]{3}{*}{$\begin{array}{l}\text { Indice de Filosofia, Valores } \\
\text { e Normas (FVN) }\end{array}$} & $\begin{array}{l}\text { Correlation } \\
\text { Coefficient }\end{array}$ & ,448 & $0,639^{*}$ & $0,486^{\star *}$ & ,425 & $0,489^{\star *}$ \\
\hline & & Sig. (2-tailed) &, 125 & ,019 & ,092 & , 148 & ,090 \\
\hline & & $\mathrm{N}$ & 13 & 13 & 13 & 13 & 13 \\
\hline & \multirow[t]{3}{*}{$\begin{array}{l}\text { Indice do Foco Estratégico e } \\
\text { Inovador }\end{array}$} & $\begin{array}{l}\text { Correlation } \\
\text { Coefficient }\end{array}$ & $0,501^{\star \star}$ & $0,703^{\star}$ & $0,591^{*}$ & ,398 & $0,56^{*}$ \\
\hline & & Sig. (2-tailed) & ,081 & ,007 & ,033 & ,178 & ,047 \\
\hline & & $\mathrm{N}$ & 13 & 13 & 13 & 13 & 13 \\
\hline & \multirow[t]{3}{*}{$\begin{array}{l}\text { Indice de Liderança e } \\
\text { Gestão }\end{array}$} & $\begin{array}{l}\text { Correlation } \\
\text { Coefficient }\end{array}$ & $0,782^{\star}$ & $0,856^{*}$ & ,360 & ,390 & $0,571^{*}$ \\
\hline & & Sig. (2-tailed) & ,002 & ,000 & 227 & , 188 & ,041 \\
\hline & & $\mathrm{N}$ & 13 & 13 & 13 & 13 & 13 \\
\hline & \multirow{3}{*}{$\begin{array}{l}\text { Indice de Políticas e } \\
\text { Práticas de Gestão de } \\
\text { Pessoas }\end{array}$} & $\begin{array}{l}\text { Correlation } \\
\text { Coefficient }\end{array}$ & $0,656^{*}$ & $0,645^{\star}$ & $0,546^{\star \star}$ & ,459 & $0,551^{\star \star}$ \\
\hline & & Sig. (2-tailed) & ,015 & ,017 & ,054 & ,115 & ,051 \\
\hline & & $\mathrm{N}$ & 13 & 13 & 13 & 13 & 13 \\
\hline
\end{tabular}


Tabela 39 - Correlação entre "Gestão Estratégica de Pessoas" e "Capacidade de Inovação" (Receita Operacional Bruta acima de R\$300 milhões)

\begin{tabular}{|c|c|c|c|c|c|c|c|}
\hline \multicolumn{8}{|c|}{ Correlação entre "Gestão Estratégica de Pessoas" e "Capacidade de Inovação" (Receita Operacional Bruta acima de R\$300 milhões) } \\
\hline & & & $\begin{array}{c}\text { Habilidade da } \\
\text { empresa de } \\
\text { identificar } \\
\text { oportunidades de } \\
\text { melhoria com } \\
\text { vistas à inovação }\end{array}$ & $\begin{array}{l}\text { Habilidade da } \\
\text { empresa de } \\
\text { assimilar } \\
\text { conhecimentos } \\
\text { adquiridos em } \\
\text { projetos de P\&D\&l }\end{array}$ & $\begin{array}{l}\text { Habilidade da } \\
\text { empresa de } \\
\text { compartilhar } \\
\text { lições aprendidas } \\
\text { em projetos de } \\
\text { P\&D\&l }\end{array}$ & $\begin{array}{c}\text { Habilidade da empresa } \\
\text { de alocar profissionais } \\
\text { provenientes de } \\
\text { diferentes grupos } \\
\text { funcionais no processo } \\
\text { de inovação }\end{array}$ & $\begin{array}{c}\text { Habilidade da } \\
\text { empresa de integrar } \\
\text { diferentes grupos } \\
\text { funcionais envolvidos } \\
\text { no processo de } \\
\text { inovação }\end{array}$ \\
\hline \multirow[t]{12}{*}{ Spearman's rho } & \multirow[t]{3}{*}{$\begin{array}{l}\text { Indice de Filosofia, Valores } \\
\text { e Normas (FVN) }\end{array}$} & $\begin{array}{l}\text { Correlation } \\
\text { Coefficient }\end{array}$ & ,260 & ,359 & ,234 & ,237 & ,387 \\
\hline & & \begin{tabular}{|l} 
Sig. (2-tailed) \\
(ailed
\end{tabular} & ,313 & ,157 & ,365 & ,361 &, 125 \\
\hline & & $N$ & 17 & 17 & 17 & 17 & 17 \\
\hline & \multirow[t]{3}{*}{$\begin{array}{l}\text { Indice do Foco Estratégico e } \\
\text { Inovador }\end{array}$} & \begin{tabular}{|l|} 
Correlation \\
Coefficient
\end{tabular} & $0,713^{*}$ & $0,762^{*}$ & $0,604^{*}$ &, 410 & $0,544^{*}$ \\
\hline & & Sig. (2-tailed) & ,001 &, 000 &, 010 &, 102 & ,024 \\
\hline & & $\bar{N}$ & 17 & 17 & 17 & 17 & 17 \\
\hline & \multirow[t]{3}{*}{$\begin{array}{l}\text { Indice de Liderança e } \\
\text { Gestão }\end{array}$} & $\begin{array}{l}\text { Correlation } \\
\text { Coefficient }\end{array}$ & ,326 & $0,706^{*}$ & $0,625^{\star}$ & ,325 & $0,556^{*}$ \\
\hline & & Sig. (2-tailed) & 202 & 002 & ,007 & ,204 & 021 \\
\hline & & $\bar{N}$ & 17 & 17 & 17 & 17 & 17 \\
\hline & \multirow{3}{*}{$\begin{array}{l}\text { Indice de Políticas e } \\
\text { Práticas de Gestão de } \\
\text { Pessoas }\end{array}$} & \begin{tabular}{|l|} 
Correlation \\
Coefficient
\end{tabular} & $0,58^{*}$ & $0,643^{*}$ & $0,444^{\star \star}$ & $0,489^{*}$ & $\overline{0,444^{\star \star}}$ \\
\hline & & Sig. (2-tailed) & ,015 &, 005 &, 075 &, 046 &, 074 \\
\hline & & $\mathrm{N}$ & 17 & 17 & 17 & 17 & 17 \\
\hline
\end{tabular}

Conforme as três matrizes de correlação exibidas anteriormente, a segmentação da amostra por receita operacional bruta resultou em subamostras de tamanhos inferiores a 30. Temendo que isso prejudicasse a análise das correlações, foi acrescentado o teste de comparação de médias de Kruskal-Wallis. 
Tabela 40 - Teste de Kruskal-Wallis: "Gestão Estratégica de Pessoas" e "Receita Operacional Bruta"

\begin{tabular}{|c|c|c|c|c|}
\hline \multicolumn{5}{|c|}{ Teste de Kruskall-Wallis (Receita Ope racional Líquida) } \\
\hline & Receita Operacional Bruta & $\mathbf{N}$ & Média dos Pontos & Nível de Significância \\
\hline \multirow[t]{3}{*}{ Filosofia, Valores e Normas } & Até R\$16 Milhões & 9 & 17,22 & \multirow{3}{*}{0,701} \\
\hline & $\begin{array}{l}\text { Acima de } \mathrm{R} \$ 16 \text { milhões e } \\
\text { menor ou igual a } \mathrm{R} \$ 300 \\
\text { milhões }\end{array}$ & 13 & 21,12 & \\
\hline & Acima de $\mathrm{R} \$ 300$ milhões & 17 & 20,62 & \\
\hline \multirow[t]{3}{*}{ Foco Estratégico em Inovação } & Até $\mathrm{R} \$ 16$ Milhões & 9 & 19,22 & \multirow{3}{*}{0,549} \\
\hline & $\begin{array}{l}\text { Acima de } \mathrm{R} \$ 16 \text { milhões e } \\
\text { menor ou igual a } \mathrm{R} \$ 300 \\
\text { milhões }\end{array}$ & 13 & 17,69 & \\
\hline & Acima de $\mathrm{R} \$ 300$ milhões & 17 & 22,18 & \\
\hline \multirow[t]{3}{*}{ Liderança e Gestão } & Até R\$16 Milhões & 9 & 22,78 & \multirow{3}{*}{0,614} \\
\hline & $\begin{array}{l}\text { Acima de } \mathrm{R} \$ 16 \text { milhões e } \\
\text { menor ou igual a } \mathrm{R} \$ 300 \\
\text { milhões }\end{array}$ & 13 & 20,42 & \\
\hline & Acima de $\mathrm{R} \$ 300$ milhões & 17 & 18,21 & \\
\hline \multirow[t]{3}{*}{ Políticas e Práticas de Gestão de Pessoas } & Até $\mathrm{R} \$ 16$ Milhões & 9 & 19,39 & \multirow{3}{*}{0,674} \\
\hline & $\begin{array}{l}\text { Acima de } \mathrm{R} \$ 16 \text { milhões e } \\
\text { menor ou igual a } \mathrm{R} \$ 300 \\
\text { milhões }\end{array}$ & 13 & 18,12 & \\
\hline & Acima de $\mathrm{R} \$ 300$ milhões & 17 & 21,76 & \\
\hline
\end{tabular}


Como nenhuma característica de gestão estratégica de pessoas apresentou significativa diferença no que tange às médias das subamostras, receita operacional bruta não pôde ser considerada uma variável interveniente discriminante na relação de associação investigada.

Logo, refuta-se a hipótese 3 , segundo a qual as empresas industriais com maior receita operacional bruta apresentaram maior associação entre gestão estratégica de pessoas e capacidade de inovação.

\subsubsection{Análise da Relação entre Gestão Estratégica de Pessoas e Capacidade de Inovação sob a Perspectiva do Tempo de Operação no Brasil das Empresas Industriais}

Não foi identificado um padrão, nem uma tendência nas matrizes de correlação elaboradas para a variável tempo de operação no Brasil, a julgar pelas Tabelas 41, 42, 43 e 44. 
Tabela 41 - Correlação entre "Gestão Estratégica de Pessoas" e "Capacidade de Inovação" (Tempo de Operação no Brasil inferior a 12 anos)

\begin{tabular}{|c|c|c|c|c|c|c|c|}
\hline \multicolumn{8}{|c|}{ Correlação entre "Gestão Estratégica de Pessoas" e "Capacidade de Inovação" (Tempo de Operação no Brasil menor de 12 anos) } \\
\hline & & & $\begin{array}{l}\text { Habilidade da } \\
\text { empresa de } \\
\text { identificar } \\
\text { oportunidades } \\
\text { de melhoria } \\
\text { com vistas à } \\
\text { inovação }\end{array}$ & $\begin{array}{l}\text { Habilidade da } \\
\text { empresa de } \\
\text { assimilar } \\
\text { conhecimentos } \\
\text { adquiridos em } \\
\text { projetos de } \\
\text { P\&D\&I }\end{array}$ & $\begin{array}{l}\text { Habilidade da } \\
\text { empresa de } \\
\text { compartilhar } \\
\text { lições } \\
\text { aprendidas } \\
\text { em projetos } \\
\text { de P\&D\&l }\end{array}$ & $\begin{array}{c}\text { Habilidade da } \\
\text { empresa de alocar } \\
\text { profissionais } \\
\text { provenientes de } \\
\text { diferentes grupos } \\
\text { funcionais no } \\
\text { processo de inovação }\end{array}$ & $\begin{array}{c}\text { Habilidade da } \\
\text { empresa de integrar } \\
\text { diferentes grupos } \\
\text { funcionais } \\
\text { envolvidos no } \\
\text { processo de } \\
\text { inovação }\end{array}$ \\
\hline \multirow[t]{12}{*}{$\begin{array}{l}\text { Spearman } \\
\text { 's rho }\end{array}$} & \multirow{3}{*}{$\begin{array}{l}\text { Indice de Filosofia, } \\
\text { Valores e Normas } \\
\text { (FVN) }\end{array}$} & \begin{tabular}{|l|} 
Correlation \\
Coefficient
\end{tabular} &,- 063 & ,208 & ,321 & ,245 &, 515 \\
\hline & & Sig. (2-tailed) &, 864 &, 565 & ,366 & ,494 &, 128 \\
\hline & & $\mathrm{N}$ & 10 & 10 & 10 & 10 & 10 \\
\hline & \multirow[t]{3}{*}{$\begin{array}{l}\text { Indice do Foco } \\
\text { Estratégico e Inovador }\end{array}$} & \begin{tabular}{|l|} 
Correlation \\
Coefficient
\end{tabular} &,- 232 & ,455 & ,529 & ,202 & ,446 \\
\hline & & Sig. (2-tailed) & .519 & , 187 & ,116 & .576 & , 196 \\
\hline & & $\mathrm{N}$ & 10 & 10 & 10 & 10 & 10 \\
\hline & \multirow[t]{3}{*}{$\begin{array}{l}\text { Indice de Liderança e } \\
\text { Gestão }\end{array}$} & \begin{tabular}{|l|} 
Correlation \\
Coefficient
\end{tabular} & ,381 & $0,717^{\star}$ & $0,667^{\star}$ & $0,831^{\star}$ & $0,890^{*}$ \\
\hline & & Sig. (2-tailed) & ,277 & ,019 &, 035 &, 003 &, 001 \\
\hline & & $\mathbf{N}$ & 10 & 10 & 10 & 10 & 10 \\
\hline & \multirow{3}{*}{$\begin{array}{l}\text { Indice de Políticas e } \\
\text { Práticas de Gestão de } \\
\text { Pessoas }\end{array}$} & $\begin{array}{l}\text { Correlation } \\
\text { Coefficient } \\
\end{array}$ & ,361 & ,511 & ,390 & $0,663^{*}$ & $0,791^{*}$ \\
\hline & & Sig. (2-tailed) &, 306 & ,131 & ,265 & ,037 & ,006 \\
\hline & & $\bar{N}$ & 10 & 10 & 10 & 10 & 10 \\
\hline
\end{tabular}


Tabela 42 - Correlação entre "Gestão Estratégica de Pessoas" e "Capacidade de Inovação" (Tempo de Operação no Brasil: De 12 anos a 45 anos)

\begin{tabular}{|c|c|c|c|c|c|c|c|}
\hline \multicolumn{8}{|c|}{ Correlação entre "Gestão Estratégica de Pessoas" e "Capacidade de Inovação" (Tempo de Operação no Brasil: De 12 anos a 45 anos) } \\
\hline & & & $\begin{array}{c}\text { Habilidade da } \\
\text { empresa de } \\
\text { identificar } \\
\text { oportunidades } \\
\text { de melhoria } \\
\text { com vistas à } \\
\text { inovação }\end{array}$ & $\begin{array}{l}\text { Habilidade da } \\
\text { empresa de } \\
\text { assimilar } \\
\text { conhecimentos } \\
\text { adquiridos em } \\
\text { projetos de } \\
\text { P\&D\&I }\end{array}$ & \begin{tabular}{|} 
Habilidade da \\
empresa de \\
compartilhar \\
lições \\
aprendidas \\
em projetos \\
de P\&D\&l
\end{tabular} & $\begin{array}{c}\text { Habilidade da } \\
\text { empresa de alocar } \\
\text { profissionais } \\
\text { provenientes de } \\
\text { diferentes grupos } \\
\text { funcionais no } \\
\text { processo de inovação }\end{array}$ & $\begin{array}{c}\text { Habilidade da } \\
\text { empresa de integrar } \\
\text { diferentes grupos } \\
\text { funcionais } \\
\text { envolvidos no } \\
\text { processo de } \\
\text { inovação }\end{array}$ \\
\hline \multirow[t]{12}{*}{\begin{tabular}{|l|} 
Spearman \\
's rho
\end{tabular}} & \multirow{3}{*}{$\begin{array}{l}\text { Indice de Filosofia, } \\
\text { Valores e Normas } \\
(F V N)\end{array}$} & $\begin{array}{l}\text { Correlation } \\
\text { Coefficient }\end{array}$ & ,349 & $0,554^{\star \star}$ & $0,672^{*}$ & ,358 & ,395 \\
\hline & & Sig. (2-tailed) & 292 & ,077 & ,024 & 279 & ,230 \\
\hline & & $\bar{N}$ & 11 & 11 & 11 & 11 & 11 \\
\hline & \multirow[t]{3}{*}{$\begin{array}{l}\text { Indice do Foco } \\
\text { Estratégico e Inovador }\end{array}$} & $\begin{array}{l}\text { Correlation } \\
\text { Coefficient }\end{array}$ & $0,627^{\star}$ & $0,769^{*}$ & $0,591^{\star \star}$ & ,187 & $0,584^{\star \star}$ \\
\hline & & Sig. (2-tailed) & ,039 & ,006 & ,056 & ,583 & 059 \\
\hline & & $\bar{N}$ & 11 & 11 & 11 & 11 & 11 \\
\hline & \multirow[t]{3}{*}{$\begin{array}{l}\text { Indice de Liderança e } \\
\text { Gestão }\end{array}$} & $\begin{array}{l}\text { Correlation } \\
\text { Coefficient }\end{array}$ & ,486 & $0,678^{*}$ & $0,593^{\star \star}$ & ,296 & ,465 \\
\hline & & Sig. (2-tailed) & ,129 & ,022 & ,054 & $\begin{array}{ll}, 377 \\
37\end{array}$ & ,149 \\
\hline & & $\bar{N}$ & 11 & 11 & 11 & 11 & 11 \\
\hline & \multirow{3}{*}{$\begin{array}{l}\text { Indice de Políticas e } \\
\text { Práticas de Gestão de } \\
\text { Pessoas }\end{array}$} & $\begin{array}{l}\text { Correlation } \\
\text { Coefficient }\end{array}$ & $0,589^{\star \star}$ & $0,689^{*}$ & $0,705^{\star}$ & ,428 & ,408 \\
\hline & & Sig. (2-tailed) & ,057 & ,019 & ,015 & ,189 & ,212 \\
\hline & & $\bar{N}$ & 11 & 11 & 11 & 11 & 11 \\
\hline
\end{tabular}


Tabela 43 - Correlação entre "Gestão Estratégica de Pessoas" e "Capacidade de Inovação" (Tempo de Operação no Brasil: De 46 a 70 anos)

\begin{tabular}{|c|c|c|c|c|c|c|c|}
\hline \multicolumn{8}{|c|}{ Correlação entre "Gestão Estratégica de Pessoas" e "Capacidade de Inovação" (Tempo de Operação no Brasil: De 46 a 70 anos) } \\
\hline & & & $\begin{array}{l}\text { Habilidade da } \\
\text { empresa de } \\
\text { identificar } \\
\text { oportunidades } \\
\text { de melhoria } \\
\text { com vistas à } \\
\text { inovação }\end{array}$ & $\begin{array}{l}\text { Habilidade da } \\
\text { empresa de } \\
\text { assimilar } \\
\text { conhecimentos } \\
\text { adquiridos em } \\
\text { projetos de } \\
\text { P\&D\&I }\end{array}$ & \begin{tabular}{|l|} 
Habilidade da \\
empresa de \\
compartilhar \\
$\quad$ lições \\
aprendidas \\
em projetos \\
de P\&D\&l
\end{tabular} & $\begin{array}{c}\text { Habilidade da } \\
\text { empresa de alocar } \\
\text { profissionais } \\
\text { provenientes de } \\
\text { diferentes grupos } \\
\text { funcionais no } \\
\text { processo de inovação }\end{array}$ & $\begin{array}{l}\text { Habilidade da } \\
\text { empresa de integrar } \\
\text { diferentes grupos } \\
\text { funcionais } \\
\text { envolvidos no } \\
\text { processo de } \\
\text { inovação }\end{array}$ \\
\hline \multirow[t]{12}{*}{$\begin{array}{l}\text { Spearman } \\
\text { 's rho }\end{array}$} & \multirow{3}{*}{$\begin{array}{l}\text { Indice de Filosofia, } \\
\text { Valores e Normas } \\
(\text { FVN })\end{array}$} & $\begin{array}{l}\text { Correlation } \\
\text { Coefficient }\end{array}$ & ,346 & ,266 & ,093 &,- 168 & ,161 \\
\hline & & Sig. (2-tailed) & ,270 & ,403 & ,774 & ,601 & ,616 \\
\hline & & $\bar{N}$ & 12 & 12 & 12 & 12 & 12 \\
\hline & \multirow[t]{3}{*}{$\begin{array}{l}\text { Indice do Foco } \\
\text { Estratégico e Inovador }\end{array}$} & $\begin{array}{l}\text { Correlation } \\
\text { Coefficient }\end{array}$ & $0,628^{*}$ & $0,688^{*}$ & $0,546^{* *}$ & 390 & ,438 \\
\hline & & Sig. (2-tailed) & 029 & ,013 & ,066 & 211 &, 154 \\
\hline & & $\bar{N}$ & 12 & 12 & 12 & 12 & 12 \\
\hline & \multirow[t]{3}{*}{$\begin{array}{l}\text { Indice de Liderança e } \\
\text { Gestão }\end{array}$} & \begin{tabular}{|l|} 
Correlation \\
Coefficient
\end{tabular} & $0,51^{\star \star}$ & $0,865^{*}$ & $0,612^{*}$ & ,200 & $0,513^{\star \star}$ \\
\hline & & Sig. (2-tailed) & ,091 & ,000 & ,034 & ,534 & ,088 \\
\hline & & $\bar{N}$ & 12 & 12 & 12 & 12 & 12 \\
\hline & \multirow{3}{*}{$\begin{array}{l}\text { Indice de Políticas e } \\
\text { Práticas de Gestão de } \\
\text { Pessoas }\end{array}$} & \begin{tabular}{|l} 
Correlation \\
Coefficient
\end{tabular} & $0,673^{\star}$ & $0,768^{*}$ & $0,513^{\star \star}$ & ,314 &, 376 \\
\hline & & Sig. (2-tailed) & ,016 & ,004 & ,088 & ,320 & ,229 \\
\hline & & $\bar{N}$ & 12 & 12 & 12 & 12 & 12 \\
\hline
\end{tabular}


Tabela 44 - Correlação entre "Gestão Estratégica de Pessoas" e "Capacidade de Inovação" (Tempo de Operação no Brasil: Acima de 70 anos)

\begin{tabular}{|c|c|c|c|c|c|c|c|}
\hline \multicolumn{8}{|c|}{ Correlação entre "Gestão Estratégica de Pessoas" e "Capacidade de Inovação" (Tempo de Operação no Brasil: Acima de 70 anos) } \\
\hline & & & $\begin{array}{l}\text { Habilidade da } \\
\text { empresa de } \\
\text { identificar } \\
\text { oportunidades } \\
\text { de melhoria } \\
\text { com vistas à } \\
\text { inovação }\end{array}$ & $\begin{array}{l}\text { Habilidade da } \\
\text { empresa de } \\
\text { assimilar } \\
\text { conhecimentos } \\
\text { adquiridos em } \\
\text { projetos de } \\
\text { P\&D\&I }\end{array}$ & $\begin{array}{l}\text { Habilidade da } \\
\text { empresa de } \\
\text { compartilhar } \\
\text { lições } \\
\text { aprendidas } \\
\text { em projetos } \\
\text { de P\&D\&l }\end{array}$ & $\begin{array}{c}\text { Habilidade da } \\
\text { empresa de alocar } \\
\text { profissionais } \\
\text { provenientes de } \\
\text { diferentes grupos } \\
\text { funcionais no } \\
\text { processo de inovação }\end{array}$ & $\begin{array}{c}\text { Habilidade da } \\
\text { empresa de integrar } \\
\text { diferentes grupos } \\
\text { funcionais } \\
\text { envolvidos no } \\
\text { processo de } \\
\text { inovação }\end{array}$ \\
\hline \multirow[t]{12}{*}{$\begin{array}{l}\text { Spearman } \\
\text { 's rho }\end{array}$} & \multirow{3}{*}{$\begin{array}{l}\text { Indice de Filosofia, } \\
\text { Valores e Normas } \\
(\text { FVN) }\end{array}$} & $\begin{array}{l}\begin{array}{l}\text { Correlation } \\
\text { Coefficient }\end{array} \\
\end{array}$ & $0,802^{\star \star}$ & ,580 &,- 058 & ,516 & ,439 \\
\hline & & Sig. (2-tailed) & ,055 & ,228 & ,913 & ,295 & ,383 \\
\hline & & $\mathrm{N}$ & 6 & 6 & 6 & 6 & 6 \\
\hline & \multirow[t]{3}{*}{$\begin{array}{l}\text { Indice do Foco } \\
\text { Estratégico e Inovador }\end{array}$} & \begin{tabular}{|l|} 
Correlation \\
Coefficient
\end{tabular} & $0,814^{*}$ &, 529 & ,471 & ,647 & ,600 \\
\hline & & Sig. (2-tailed) & ,049 & ,280 & ,346 & ,165 & ,208 \\
\hline & & $\mathrm{N}$ & 6 & 6 & 6 & 6 & 6 \\
\hline & \multirow[t]{3}{*}{$\begin{array}{l}\text { Indice de Liderança e } \\
\text { Gestão }\end{array}$} & \begin{tabular}{|l|} 
Correlation \\
Coefficient
\end{tabular} & $0,802^{\star *}$ &, 725 &,- 203 & ,395 & ,270 \\
\hline & & Sig. (2-tailed) & ,055 & ,103 &, 700 &, 439 & ,604 \\
\hline & & $\bar{N}$ & $\overline{6}$ & 6 & $\overline{6}$ & $\overline{6}$ & 6 \\
\hline & \multirow{3}{*}{$\begin{array}{l}\text { Indice de Políticas e } \\
\text { Práticas de Gestão de } \\
\text { Pessoas }\end{array}$} & $\begin{array}{l}\text { Correlation } \\
\text { Coefficient }\end{array}$ & ,626 &, 353 & ,603 & ,462 & ,600 \\
\hline & & Sig. (2-tailed) & ,183 & ,493 & 205 &, 356 & 208 \\
\hline & & $\mathrm{N}$ & 6 & 6 & 6 & 6 & 6 \\
\hline
\end{tabular}


Conforme as quatro matrizes de correlação exibidas anteriormente, a segmentação da amostra por tempo de operação no Brasil resultou em subamostras de tamanhos inferiores a 30. Temendo que isso prejudicasse a análise das correlações, foi acrescentado o teste de comparação de médias de Kruskal-Wallis.

Tabela 45 - Teste de Kruskal-Wallis: "Gestão Estratégica de Pessoas" e "Tempo de Operação no Brasil"

\begin{tabular}{|c|c|c|c|c|}
\hline \multicolumn{5}{|c|}{ Teste de Kruskall-Wallis (Tempo de Operação no Brasil) } \\
\hline & Tempo de Operação no Brasil & $\mathbf{N}$ & Média dos pontos & Nível de significância \\
\hline \multirow[t]{4}{*}{ Filosofia, Valores e Normas } & Abaixo de 12 anos & 10 & 11,45 & \multirow{4}{*}{$\mathbf{0 , 0 0 8 *}$} \\
\hline & de 12 a 45 ans & 11 & 17,41 & \\
\hline & de 46 a 70 anos & 12 & 25,71 & \\
\hline & Acima de 70 anos & 6 & 27,58 & \\
\hline \multirow[t]{4}{*}{ Foco Estratégico em Inovação } & Abaixo de 12 anos & 10 & 14,05 & \multirow{4}{*}{0,181} \\
\hline & de 12 a 45 ans & 11 & 20,18 & \\
\hline & de 46 a 70 anos & 12 & 21,58 & \\
\hline & Acima de 70 anos & 6 & 26,42 & \\
\hline \multirow[t]{4}{*}{ Liderança e Gestão } & Abaixo de 12 anos & 10 & 18,70 & \multirow{4}{*}{0,403} \\
\hline & de 12 a 45 ans & 11 & 17,50 & \\
\hline & de 46 a 70 anos & 12 & 19,88 & \\
\hline & Acima de 70 anos & 6 & 27,00 & \\
\hline \multirow[t]{4}{*}{ Políticas e Práticas de Gestão de Pessoas } & Abaixo de 12 anos & 10 & 15,40 & \multirow{4}{*}{0,341} \\
\hline & de 12 a 45 ans & 11 & 21,09 & \\
\hline & de 46 a 70 anos & 12 & 19,88 & \\
\hline & Acima de 70 anos & 6 & 25,92 & \\
\hline
\end{tabular}


A segmentação por tempo de operação no Brasil revelou que apenas a característica FVN foi estatisticamente significante a $5 \%$. De maneira geral,

Como tempo de operação no Brasil não foi discriminante na relação de associação investigada, refuta-se a hipótese 4, segundo a qual as empresas industriais com maior tempo de operação no Brasil apresentaram maior associação entre gestão estratégica de pessoas e capacidade de inovação.

\subsection{Síntese Analítica}

A gestão estratégica de pessoas foi considerada neste estudo como antecedente da capacidade de inovação. Essa escolha, que norteou tanto a pesquisa bibliográfica quanto o design metodológico da pesquisa empírica, confirmou a tendência de expansão dessa linha de pesquisa, abordando temas relevantes para o negócio (LENGNICK-HALL, et al, 2009) como a inovação.

A importância deste estudo se tornou mais nítida no confronto com outras publicações que, tanto em âmbito nacional quanto internacional, têm priorizado pesquisas voltadas para os elementos componentes da gestão estratégica de pessoas (COOKE; SAINI, 2010; MARTÍN-ALCÁZAR; ROMERO-FERNÁNDEZ; SÁNCHEZ-GARDEY, 2007).

Este estudo fortaleceu o argumento que as contribuições estratégicas de gestão estratégica de pessoas dependem não apenas do alinhamento interno e externo da gestão de pessoas (LENGNICK-HALL, et al, 2009), como também de mais clareza sobre o contexto (inovação organizacional) e o objeto dessas contribuições (capacidade de inovação). Esse argumento vai ao encontro do segundo objetivo da gestão estratégica de pessoas, que inclui o desenvolvimento e implementação de políticas e programas práticos de gestão de pessoas para promover um senso de direção em um ambiente turbulento (ARMSTRONG, 2011; BOXALL; PURCELL, 2003).

Os resultados obtidos na pesquisa empírica instigaram a pesquisadora a retomar pontos e questionamentos levantados nos capítulos iniciais que não foram respondidos ao longo desta tese. Um importante ponto é o argumento de Lawson e Samson (2001), que capacidade de inovação não deve ser tratada isoladamente por ser composta por processos 
e práticas da empresa que atuam como um mecanismo-chave de estímulo, mensuração e reforço da inovação.

Os resultados da pesquisa, realizada com profissionais que atuam ou atuaram em empresas do setor industrial, a gestão estratégica de pessoas atuou como estímulo à inovação, sob o enfoque da capacidade de inovação. Os profissionais de P\&D\&I que participaram da pesquisa identificaram o papel de políticas e práticas de gestão de pessoas como mecanismos de comunicação e reforço do intento organizacional de inovar.

A questão da mensuração foi apresentada no problema de pesquisa - Em que medida a gestão estratégica de pessoas pode contribuir para a capacidade de inovação no setor industrial? Embora os resultados tenham apontado para: "em que medida", entende-se que eles podem instigar a realização de novas pesquisas, que se voltem para a investigação de "como" cada característica - isolada ou conjuntamente - pode contribuir para a capacidade de inovação.

Outro ponto a ser resgatado é a premissa exibida na seção 2.1 - Definição da SituaçãoProblema), proferida por Martín-Alcázar, Romero-Fernández e Sánchez-Gardney (2007, p. 644): “A premissa de que existe uma positiva e significativa relação entre gestão do fator humano e desempenho organizacional é um argumento básico para a Gestão Estratégica de Pessoas."

No contexto da inovação tal premissa se torna vulnerável. Ao examinar os modelos conceituais propostos por Lawson e Samson (2001) e por Prajogo e Ahmed (2006), constata-se que capacidade de inovação é antecedida por características de gestão de pessoas e, ao mesmo tempo, sucedido por medidas de desempenho de inovação e de desempenho da firma. Dado o exposto, sustenta-se que a afirmação sobre gestão do fator humano e desempenho organizacional não pode ser generalizada a ponto de ser tratada como premissa.

Por fim, o processo de reflexão levou a pesquisadora a se posicionar criticamente quanto aos conceitos de gestão estratégica de pessoas - alguns deles abordados na fundamentação teórica desta tese - que a simplificam e a circunscrevem às estratégias, políticas e práticas de $\mathrm{RH}$, dentre outros elementos. Se por um lado simplifica-se o conceito visando torná-lo mais tangível, por outro, corre-se o risco de reducionismo. Sendo assim, nesta tese a abrangência e complexidade da gestão estratégica de pessoas 
no contexto da inovação foi representada na definição operacional e no modelo conceitual da pesquisa, no intuito de fornecer contribuições teóricas e práticas para a Administração. 


\section{CONSIDERAÇÕES FINAIS}

Este capítulo versa sobre as principais constatações da pesquisa e considerações sobre o estudo como um todo, concentrando-se em suas limitações, contribuições, sugestões de continuidade da pesquisa e proposição de novos estudos em termos correlatos.

\subsection{Síntese do Estudo}

Este estudo teve por objetivos: identificar antecedentes da capacidade de inovação sob a perspectiva da gestão estratégica de pessoas; identificar indicadores de capacidade de inovação; e analisar as contribuições da gestão estratégica de pessoas para a capacidade de inovação.

A pesquisa bibliográfica revelou a existência de quatro características organizacionais que atuam como antecedentes de capacidade de inovação sob a perspectiva da gestão estratégica de pessoas. Com base nessas características, estabeleceu-se um conceito multidimensional que englobou: filosofia, valores e normas; foco estratégico em inovação; liderança e gestão; e políticas e práticas de gestão de pessoas. Tais características foram desdobradas em quarenta e três indicadores.

Por pesquisa bibliográfica também foram identificados e selecionados os indicadores de capacidade organizacional para os propósitos deste estudo. Foram eles: habilidade da empresa de encorajar equipes de projetos para identificar oportunidades de melhoria; habilidade da empresa de assimilar conhecimentos adquiridos com atividades de inovação; habilidade da empresa de compartilhar lições aprendidas em projetos de pesquisa, desenvolvimento e inovação; habilidade da empresa de alocar profissionais provenientes de diferentes grupos funcionais em atividades de inovação; e habilidade da empresa de integrar diferentes grupos funcionais evolvidos no processo de inovação.

As quatro características que representaram o conceito de gestão estratégica de pessoas no contexto da inovação foram desdobradas em quarenta e três indicadores. De maneira análoga, o conceito de capacidade de inovação foi utilizado como ponto de partida efetuar seu desdobramento em cinco indicadores de gestão. Diante disso, foi possível investigar 
as contribuições de gestão estratégica de pessoas para a capacidade de inovação e verificar, por meio da correlação positiva entre elas, que ambas estavam associadas.

Os resultados da pesquisa empírica revelaram características de gestão estratégica de pessoas que estiveram (moderada ou altamente correlacionadas) com os indicadores de capacidade de inovação. As características foram: foco estratégico em inovação, liderança e gestão e políticas e práticas de gestão de pessoas. A única característica que esteve pouco associada com os indicadores de capacidade de inovação foi filosofia, valores e normas. Como o fenômeno da contribuição da gestão estratégica de pessoas para a capacidade de inovação tem sido pouco estudado - a julgar pela pesquisa bibliográfica aqui realizada - os resultados da pesquisa empírica podem ser tratados, por si só, como uma importante contribuição.

Os resultados da pesquisa empírica reforçaram o argumento de que a gestão estratégica de pessoas contribui para a inovação, já que a maioria de seus índices estiveram associados à capacidade de inovação sob a perspectiva dos profissionais que responderam ao levantamento, no âmbito de empresas do setor industrial. É importante frisar que os resultados se restringiram ao presente estudo. Logo, não podem ser generalizados para a população.

Conforme o capítulo de Apresentação dos Dados e Discussão de Resultados, apenas a hipótese geral do estudo (hipótese 1) foi confirmada: gestão estratégica de pessoas está associada com capacidade de inovação. É possível inferir, com base no estudo aqui realizado, que a gestão estratégica de pessoas participa da gestão da inovação organizacional, ao fomentar a capacidade de inovação nas empresas industriais pesquisadas.

Constatou-se que a contribuição da gestão estratégica de pessoas para a capacidade de inovação consiste em um fenômeno ainda em construção. As poucas publicações existentes enfatizam fragmentos da gestão estratégica de pessoas no contexto da inovação, revelando um retrato vago e impreciso sobre o fenômeno. 


\subsection{Contribuições do Estudo}

Este estudo apresentou uma contribuição teórica original para a Administração, posto que nas literaturas de gestão de pessoas e de gestão de inovação não foram identificados modelos conceituais que estudassem as contribuições idiossincráticas de gestão estratégica de pessoas para capacidade de inovação. Ele se destacou pela proposição de um modelo conceitual que desdobrou a gestão estratégica de pessoas em quatro amplas características organizacionais que antecedem a capacidade de inovação, passíveis de mensuração por meio de índices padronizados.

Embora o estudo das contribuições estratégicas exclusivamente com base em estratégias, políticas e práticas de gestão de pessoas seja tão relevante quanto necessária, defende-se a ideia que ela seja traduz apenas parcialmente as possíveis contribuições para o negócio.

Longe de afirmar que este estudo tenha traduzido todas as possíveis contribuições, afirmase que ele ampliou o campo de visão acerca das contribuições estratégicas da gestão de pessoas, atendo-se à capacidade de inovação. Dessa forma, além dos dois objetivos de gestão estratégica enunciados por Armstrong (2011) de alinhamento externo e interno, focou-se também na sua integração com o negócio - um propósito de grande relevância e uma resposta às alegações feitas desde a década de 1990 de que a gestão de pessoas deveria atuar como parceira do negócio.

Sob o prisma dos profissionais que atuam de P\&D\&I que também são responsáveis pela gestão de indivíduos e de equipes, contribuiu-se com maior clareza sobre os fatores que precisam ser levados em conta na tomada de decisões que visem ao fomento da capacidade de inovação nas empresas. Por outro lado, sob o prisma dos profissionais que atuam na função de gestão de pessoas ou de recursos humanos em organizações do setor industrial, os resultados lançam luz sobre novos focos de atenção e novas perspectivas para a proposição de programas e de projetos integrados, bem como para a adequação de políticas e práticas de gestão às estratégias do negócio e de inovação. 


\subsection{Limitações da Pesquisa}

O estudo de um fenômeno recente, complexo e pouco investigado como a contribuição da gestão estratégica de pessoas para a capacidade de inovação torna oportuna a identificação de contribuições. Contudo, para tornar o estudo factível, foram feitas escolhas metodológicas que podem ter restringido sua plena compreensão. Tendo isso em vista, serão discutidas as principais limitações da pesquisa.

Há de se considerar que os elementos com as características da população foram selecionados em função de sua disponibilidade e interesse em participar da pesquisa. Isso significa que a amostra não teve aleatoriedade. Os resultados se restringiram à pesquisa realizada para os fins desta tese, não podendo ser generalizados para a população.

Outra importante limitação foi o não preenchimento do campo de segmento da indústria (BNDES, 2014b) por todos os respondentes, o que inviabilizou tratá-la como variável de controle.

Quanto às fontes indiretas de respondentes, não foi possível assegurar que as instituições parceiras da pesquisa tenham pré-selecionado entre seus contatos exclusivamente os gestores que trabalhavam em empresas industriais. Dessa forma, não se pôde assegurar a precisão da amostra utilizada na pesquisa.

Houve um significativo percentual de respostas incompletas (23\%) conforme apresentado no capítulo 4. Considerando o anonimato do respondente e da empresa, a pesquisadora ficou impossibilitada de entender o motivo das respostas incompletas. Após a exclusão das respostas incompletas, que totalizaram nove, obteve-se a amostra para fins de análise que totalizou trinta e nove respostas: um número insuficiente para cogitar a aplicação de técnicas de análises de dados mais robustas, como as do tipo multivariada, que demanda um alto número de respostas (HAIR JR. et al, 2009). Acrescenta-se que foram feitos mil e trinta e seis contatos e o retorno foi de quarenta e oito $(5 \%)$.

A adesão à pesquisa pode ter sido influenciada por alguns pontos levantados na seção final da metodologia, tais como o grande número de questões do instrumento de coleta de dados. A quantidade de questões, principalmente na segunda e terceira parte do questionário, podem ter tornado seu preenchimento exaustivo. Essa evidência se torna mais clara ao constatar que três entre as nove pessoas que forneceram respostas 
incompletas interromperam o preenchimento na metade do questionário - ou seja, antes de iniciar a quarta parte, sobre características de gestão estratégica de pessoas.

Embora tenha sido feita uma substancial redução da quantidade de questões como recomendação fornecida no pré-teste, essa redução se concentrou nas questões sobre a variável independente. Em estudos futuros, sugere-se reduzir as questões iniciais sobre caracterização da empresa e do respondente, atendo-se somente àquelas que estiverem diretamente relacionadas com o problema de pesquisa.

Ainda no que tange ao instrumento de coleta de dados, foram utilizados indicadores de capacidade de inovação desenvolvidos no contexto da inovação tecnológica - que não foi objeto deste estudo. Trata-se de uma limitação da pesquisa e, ao mesmo tempo, uma oportunidade para que outros pesquisadores desenvolvam indicadores que considerem as particularidades do setor industrial.

Quanto à coleta de dados, as respostas obtidas no levantamento foram fornecidas sob a perspectiva de profissionais, portanto, pessoas. Esse ponto suscitou duas reflexões. A primeira foi que, no processo de observação e mensuração das variáveis, são feitos julgamentos de valor que são intrínsecos da natureza humana apesar de terem sido tomados os cuidados metodológicos recomendados nas obras de metodologia consultadas. Logo, não estão isentos de subjetividade. A segunda foi que nenhuma escolha, por si só, está isenta de restrições porque a perspectiva do público-alvo desta pesquisa - e de qualquer outro público que tivesse sido selecionado para definir a população - não necessariamente refletem o entendimento da empresa como um todo.

Cabe também mencionar a falta de controle sobre as condições sob as quais que os profissionais responderam às questões. Eles podem ter passado por fatores situacionais ou temporários como: cansaço, aborrecimento, ansiedade e distrações. Até mesmo fome, impaciência ou variações de humor podem ter comprometido a capacidade de responder acurada e completamente às questões, comprometendo a qualidade das respostas.

Salienta-se que o acesso aos profissionais com as características da população não representou isoladamente uma limitação, posto que mil e trinta e seis contatos foram efetuados com a colaboração das instituições parceiras. A limitação na coleta de dados foi a ausência de patrocinadores da pesquisa, que em estudos futuros poderão ser 
entidades setoriais e executivos das empresas participantes, por exemplo, considerando a unidade de coleta e análise organizacional.

Por se tratar de um fenômeno recente e pouco investigado, é possível que tenha havido falta de informação previa sobre o tema, aspecto que poderá ser tratado com os patrocinadores da pesquisa antes de iniciar a coleta de dados. O ponto que se deseja reforçar é que, ao delimitar um segmento no setor industrial, surgirá a possibilidade de efetuar outros tipos de parcerias, que além das que apoiaram a coleta de dados no presente estudo.

Acredita-se que ao alinhar expectativas, propósitos e necessidades com executivos de entidades setoriais e executivos responsáveis pela gestão de inovação nas empresas pesquisadas poderá contribuir com a sensibilização e estímulo dos profissionais que atuam na gestão de projetos de $P \& D \& I$ a se comprometerem com a pesquisa e preencherem os questionários em maior número e fornecerem respostas fidedignas.

\subsection{Sugestões de Continuidade da Pesquisa}

Os resultados apontaram para: "em que a gestão estratégica de pessoas contribuiu para a capacidade de inovação". Contudo, tais resultados podem instigar a realização de novas pesquisas, que se voltem para a investigação de "como cada característica contribuiu para a capacidade de inovação", ou ainda, "por que a característica representada por filosofia, valores e normas pouco contribuiu para a capacidade de inovação".

Uma agenda de pesquisas futuras passa pelo aprofundamento do estudo das características de gestão estratégica de pessoas no intuito de validar uma escala de gestão estratégica de pessoas no contexto da inovação. Essa agenda também passa pela continuidade da pesquisa envolvendo múltiplos níveis de análise, em resposta aos

questionamentos feitos na análise dos resultados: Estaria a gestão de pessoas nas empresas pesquisadas alinhando suas políticas de gestão de pessoas com a estratégia de inovação? Até que ponto as políticas e práticas de gestão de pessoas nessas empresas estão integradas com a estratégia da empresa e de inovação? 
A pesquisa com múltiplos níveis de análise poderia considerar os executivos da empresa, suas principais lideranças em $\mathrm{P} \& \mathrm{D} \& \mathrm{I}$, bem como os profissionais estudados na pesquisa, que gerenciam projetos em P\&D\&I. Outros questionamentos, além dos que já foram mencionados, poderão nortear futuras investigações: Até que ponto a alta gestão fornece abertura para que seus gestores funcionais compreendam as diretrizes estratégicas incluindo filosofia, valores e normas a ponto de desdobrá-las em seus campos de atuação? Até que ponto essa pouca ou não compreensão afeta a atuação da liderança e dos gestores de P\&D\&I?

No que diz respeito à realização de estudos futuros com amostras maiores, recomenda-se replicar a pesquisa em um segmento do setor industrial que se destaque pela excelência tanto da gestão de pessoas quanto da inovação organizacional. Ao focar a pesquisa em um único segmento, obter-se-ia uma amostra mais homogênea, favorecendo mais análises estatísticas robustas. Além disso, seria possível incluir no modelo conceitual variáveis condicionantes da relação de associação entre as mesmas variáveis dependentes e independentes no segmento escolhido.

Os resultados obtidos poderão, então, ser submetidos à técnica qualitativa de grupo focal com dois grupos de participantes. O primeiro grupo seria composto por profissionais que participaram da fase quantitativa, de levantamento. Na sequência, tanto os resultados da fase quantitativa, quanto os principais pontos discutidos pelo primeiro grupo focal seriam apresentados ao segundo grupo, constituído por profissionais responsáveis pela função de gestão de pessoas nas mesmas organizações investigadas.

A técnica qualitativa de grupo focal seria acrescentada, portanto, para enriquecer a interpretação dos resultados, enfatizando os pontos que se destacaram positiva e negativamente. Acrescenta-se que a consideração de dois grupos (profissionais que atuam na gestão de projetos de $\mathrm{P} \& D \& I$ e profissionais responsáveis pela função de gestão de pessoas nas empresas industriais do segmento escolhido) contribua para a validade.

O maior tamanho de amostra permitirá a utilização de procedimentos que confiram diversas formas de validade de construto e de conteúdo. Possivelmente permitirá também a utilização de formas de análises mais robustas, como as que envolvem técnicas de análise multivariada de dados. Nesse contexto, serão fornecidas três maneiras de conduzir pesquisas futuras. 
A primeira forma seria dar continuidade à coleta de dados feita nesta pesquisa para aplicar uma técnica multivariada de dependência: a regressão logística. A técnica seria utilizada para avaliar os efeitos conjuntos da variável independente sobre a variável dependente e, em outras palavras, para fazer previsões acerca da variável dependente a partir da manipulação da variável independente.

No contexto deste estudo, consistiria na análise do efeito conjunto das características que compõem a gestão estratégica de pessoas no contexto dos antecedentes de capacidade de inovação a partir da análise da interrelação simultânea entre os as características de gestão estratégica de pessoas e suas implicações para capacidade de inovação. Para atender aos requisitos da técnica, seria necessário apenas criar um índice de capacidade de inovação, classificado em escala não-métrica nominal. A variável dependente binária, consistiria, por exemplo, em "maior capacidade de inovação" e "menor capacidade de inovação". O resultado esperado, seria a identificação das características de gestão estratégica de pessoas que diferenciam as empresas do segmento investigado em relação à capacidade de inovação.

A segunda forma, que independe da primeira, seria de aplicar a análise fatorial exploratória focando em uma característica de gestão estratégica de pessoas por vez. A análise fatorial exploratória é uma técnica de interdependência que pode ser utilizada para analisar interrelações entre um grande número de variáveis e explicar essas variáveis em termos de suas dimensões inerentes comuns: os fatores. A técnica teria por objetivo "[...] condensar a informação contida em várias variáveis estatísticas (fatores) com uma perda mínima de informação." (HAIR JR. et al, 2009, p. 33). Observa-se que os dados desta pesquisa foram coletados em escala razão, facilitando a aplicação da técnica. A partir dos resultados obtidos com as análises fatoriais, espera-se obter uma escala de gestão estratégica de pessoas para inovação mais precisa e enxuta.

A terceira forma, derivada da segunda, consiste em aplicar a técnica de modelagem de equações estruturais, centrando-se nos conjuntos de características de gestão estratégica de pessoas que efetivamente representarem os antecedentes da capacidade de inovar. A pesquisa contribuiria com a proposição de um modelo estrutural (HAIR Jr. et al, 2009), que expressaria as relações entre essas características que representam os antecedentes da capacidade de inovação. Pelo modelo seriam identificadas as relações de independência 
e de dependência entre as características, de modo que uma mesma variável pode ser dependente em uma relação e independente em outra relação.

\subsection{Sugestões de Novos Estudos em Temas Correlatos}

Por fim, para finalizar este capítulo serão sugeridos novos estudos no tema Gestão Estratégica de Pessoas para Inovação, que emergiram da pesquisa bibliográfica e empírica realizadas para neste estudo.

A primeira sugestão derivou dos resultados obtidos na pesquisa empírica. Visto que o conjunto de características organizacionais que apresentou maior valor no coeficiente de correlação com capacidade de inovação foi liderança e gestão, estudos futuros podem se concentrar no comprometimento da liderança com a inovação.

A segunda sugestão derivou da pesquisa bibliográfica, a partir da qual se obteve filosofia, valores e normas como um conjunto de características da gestão estratégica de pessoas que antecedeu a capacidade de inovação. Conforme explicação fornecida no capítulo de fundamentação teórica, filosofia, valores e normas integram a cultura organizacional, porém existem outros elementos que não fizeram parte do escopo deste estudo.

Como tanto a cultura organizacional quanto a gestão da inovação são assuntos complexos, recomenda-se que futuros estudos focalizem exclusivamente a relação entre elas. $O$ futuro estudo teria como propósito investigar quais elementos da cultura organizacional podem estimular a capacidade de inovação em determinado contexto setorial por meio de estudo de múltiplos casos. Esse estudo pode representar mais um passo rumo à compreensão de outro fenômeno correlato: a cultura de inovação.

A terceira sugestão tem a finalidade de aprofundar o estudo do tópico colaboração, que integrou a característica de gestão estratégica de pessoas de filosofia, valores e normas. Trata-se, especificamente, da colaboração no contexto da inovação: um assunto que pode ser abordado sob a perspectiva da gestão estratégica de pessoas e tem sido objeto de investigação em pesquisas sobre gestão da inovação. A importância de pesquisas sobre o tema decorre, dentre outros aspectos, da possibilidade de que a colaboração não 
represente apenas um valor (como foi tratado na pesquisa empírica realizada neste estudo), como também como uma prática que pode interferir na capacidade de inovação.

A quarta sugestão consiste em um estudo da possível influência da capacidade de inovação no desempenho inovador de empresas de determinado setor em que a inovação seja uma condição necessária para manter sua competitividade e assegurar sua sobrevivência. Esse estudo poderia se concentrar na análise dos fatores determinantes da capacidade de inovação - incluindo os que dizem respeito à gestão estratégica de pessoas - e em medidas desempenho inovador obtidas na literatura.

A quinta e última sugestão consiste na realização de estudos futuros sobre configurações estratégicas orientadas para inovação, tais como a configuração de criação de capacidades que, de acordo com Tallman (2003) predomina em organizações inovadoras (conforme seção 2.1 - Capacidade Organizacional). Verificar se e como a gestão estratégica de pessoas facilita a implementação de configurações estratégicas orientadas para inovação seria mais um passo rumo à compreensão do papel e do potencial da gestão estratégica de pessoas.

Espera-se que as contribuições fornecidas neste estudo, as limitações e oportunidades de continuidade da pesquisa, bem como as sugestões de novos estudos em assuntos correlatos aos que foram aqui tratados, fomente a construção de uma agenda de pesquisas futuras em gestão estratégica de pessoas para inovação. 


\section{REFERÊNCIAS}

AGARWALA, T. Innovative human resource practices organizational commitment: an empirical investigation. The International Journal of Human Resource Management. v. 14, n. 2, March 2003.

AGÊNCIA USP DE INOVAÇÃO. Disponível em: 〈http://inovacao.usp.br/>. Acesso em: 18/09/2014.

AHMED, P. K. Culture and climate for innovation. European Journal of Innovation Management. v. 1, n. 1, p. 30-43, 1998.

AKMAN, G.; YILMASZ, C. Innovative capability, innovation strategy and Market orientation: an empirical analysis in Turkish software industry. International Journal of Innovation Management. v.12, n. 1, p. 69-111, March 2008.

ALBUQUERQUE, L. G. A gestão estratégica de pessoas. In: FLEURY, M. T. L. (Org.). As pessoas na organização. São Paulo: Gente: 2002.

ALBUQUERQUE, L. G. Estratégias de recursos humanos e competitividade. In: VIEIrA, M. M. F.; OLIVEIRA, L. M. B. (Orgs.). Administração Contemporânea. São Paulo: Atlas, 1999.

AlbuQuerque, L. G. A. Papal estratégico de Recursos Humanos. São Paulo, 1987. Tese (Livre Docência em Administração) - Programa de Pós-Graduação em Administração, Departamento de Administração, Faculdade de Economia, Administração e Contabilidade da Universidade de São Paulo.

ALLEN, M. R.; WRIGHT, P. Strategic management and HRM. In: BOXALL, P.; PURCELL, J. (Eds.). Oxford Handbook of Human Resource Management. Oxford: Oxford University Press, p. 88-107, 2007.

AMABILE, T. M. Creativity and innovation in organizations. Background note. HBS case collection. Disponível em: <http://www.hbs.edu/faculty/Pages/item.aspx?num=13672> Acesso em: 04/08/2014.

AMIT, R.; SCHOEMAKER, P. J. H. Strategic assets and organizational rent. Strategic Management Journal. v. 14, s/n, p. 33-46, 1993.

ARAGÓN-CORREA, J. A.; GARCÍA-MORALES, V. J.; CORDÓN-POZO, E. Leadership and organizational learning's role on innovation and performance: Lessons from Spain. Industrial Marketing Management. v. 36, s/n, p. 349-359, 2007.

ARMSTRONG, M. Armstrong's handbook of human resource management. $5^{\text {th }}$ ed. London: Kogan Page, 2011.

ASSOCIAÇÃO NACIONAL DE PESQUISA E DESENVOLVIMENTO DAS EMPRESAS INOVADORAS - ANPEI. Disponível em: < http://www.anpei.org.br/web/anpei/home>. Acesso em: 17/10/2014. 
BANCO NACIONAL DE DESENVOLVIMENTO ECONÔMICO E SOCIAL BNDES. Porte da Empresa. Disponível em: <http://www.bndes.gov.br/SiteBNDES/bndes/bndes_pt/Institucional/Apoio_Financeiro/ porte.html>. Acesso em: 07/05/2014. 2014a.

. Setores de atividade. Disponível em: <http://www.bndes.gov.br/SiteBNDES/bndes/bndes_pt/Institucional/Apoio_Financeiro/ porte.html>. Acesso em: 20/09/2014. 2014b.

BARNEY, J. B. Firm resources and the theory of competitive advantage. Journal of Management. v. 17, p. 99-120, 1991.

BARNEY, J. B.; HESTERLY, W. S. Administração estratégica e vantagem competitiva. São Paulo: Pearson Prentice Hall, 2011.

BARNEY. J. B.; KETCHEN Jr., D. J.; WRIGHT, M. The future of resource-based theory: revitalization or decline? Journal of Management. v. 37, n. 5, September 2011.

BARNEY. J. B.; WRIGHT, P. M. On becoming a strategic partner: the role of human resource in gaining competitive advantage. Human Resource Management. v. 37, n. 1, p. 31-46, 1998.

BHARADWAJ, S.; MENON, A. Making innovation happen in organizations: individual creativity mechanisms, organizational creativity mechanisms or both? Journal of Product Innovation Management. v. 17, n. 6, p. 424-434, November 2000.

BOCK, A. J.; OPSAHL, T.; GEORGE, G.; GANN, D. M. The Effects of Culture and Structure on Strategic Flexibility during Business Model Innovation. Journal of Management Studies. v. 49, n. 2, March 2012.

BOLY, V.; MOREL, L.; ASSIELOU, N. G.; CAMARGO, M. Evaluating innovative processes in french firms: methodological proposition for firm innovation capacity evaluation. Research Policy. v. 43, p. 608- 622, 2014.

BOXALL, P.; PURCELL, J. Strategy and human resource management. Basingstoke: Palgrave Macmillan, 2003.

BOXALL, P.; PURCELL, J.; WRIGHT, P. M. Human resource management: scope, analysis and significance. In: BOXALL, P.; PURCELL, J.; WRIGHT, P. M. (Eds.). The Oxford handbook of human resource management. Oxford: Oxford University Press, p. 1-16, 2007.

BREWSTER, C.; WOOD, G.; BROOKES, M.; OMMEREN, J. V. What determines the size of the HR Function? A cross national analysis. Human Resource Management. v. 45, n. 1, p. 3-21, Spring 2006.

BUCIC, T.; NGO, L. V. Examining drivers of collaborative inbound open innovation: empirical evidence from Australian firms. International Journal of Innovation Management. v. 16, n. 4, p, 1-24, August 2012. 
BURGELMAN, R. A.; MAIDIQUE, M. A. Strategic management of technology and innovation. New York: McGraw-Hill, 2004.

CARLILE, P. R.; CHRISTENSEN, C. M. The cycles of theory building in management research. Harvard Business School Working Knowledge. February, 2005. Disponível em: < http://hbswk.hbs.edu/item/5422.html>. Acesso em: 06/11/2013.

CAVAGNOLI, D. A conceptual framework for innovation: an application to human resources management in Australia. Innovation Management, Policy \& Practice. v. 13, n. 1, p. 111-245, April 2011.

CHANDLER, G. M.; KELLER, C.; LYON, D. W. Unraveling the determinants and consequences of an innovation-supportive organizational culture. Enterpreneurship Theory and Practice - ET\&P. p. 59-76, Fall 2000.

CHEN, C.; HUANG, H. Strategic human resource practices and innovation performance: the mediating role of knowledge management capacity. Journal of Business Research. v. 62, s/n, p. 104-114, 2009.

CHEN, G.; TJOSVOLD, D.; LIU, C. Cooperative goals, leader people and productivity values: their contribution to top management teams in China. Journal of Management Studies. v. 43, n. 5, p. 1177-1200, July 2006.

CHIESA, V.; COUGHLAN, P.; VOSS, C.A. Development of a technical innovation audit. Journal of Product Innovation Management. v. 13, s/n, p. 105-136, 1996.

CHRISTENSEN, J. F. Asset profiles for technological innovation. Research Policy. v. 24, s/n. p. 727-745, 1995.

CHURCHILL, G. Marketing research: Methodological foundations. 3.ed. New York: The Dryden Press, 1998.

COOKE. F. L.; SAINI, D. S. (How) does the RH strategy support an innovation orientated business strategy? An investigation of institutional context and organizational practices in indian firms. Human Resource Management. v. 49, n. 2, p. 377-400, May-June 2010.

COOPER, D. R.; SCHINDLER, P. S. Métodos de pesquisa em administração. 10. ed. Porto Alegre: Bookman, 2011.

COORDENAÇÃO DE APERFEIÇOAMENTO DE PESSOAL DE NÍVEL SUPERIOR - CAPES. Disponível em: 〈http://www.capes.gov.br/>. Acesso em 2012.

COUTINHO, A. R.; KALLÁS, D. (Org.). Gestão estratégica: experiências e lições de empresas brasileiras. Rio de Janeiro: Campus Elsevier, 2005.

CRESWELL, J. W. Projeto de pesquisa: métodos qualitativo, qualitativo e misto. 3. ed. Porto Alegre: Artmed, 2010.

CROSSAN, M. A.; APAYDIN, M. A multi-dimensional framework of organizational innovation: a systematic review of the literatures. Journal of Management Studies. v. 47, n. 6, p. 1155-1191, September 2010. 
DAMANPOUR, F. Organizational size and innovation. Organization Studies. v. 13, p. 375-402, 1992.

DAMANPOUR, F.; ARAVIND, D. Managerial Innovations: conceptions, processes, and antecedents. Management and Organization Review. v. 8, n. 2, p. 423-454, July 2012.

DELGADO-VERDE, M.; CASTRO, G. M.; NÁVAS-LÓPEZ, J. E. Organizational knowledge assets and innovation capability: evidence from Spanish manufacturing firms. Journal of Intellectual Capital. v. 12, n. 1, p. 5-19, 2011.

DENTI, L.; HEMLIN, S. Leadership and innovation in organizations: a systematic review of factors that mediate or moderate the relationship. International Journal of Innovation Management. v. 16, n. 3, p. 1-20, June 2012.

DESS, G. G.; PICKEN, J. C. Changing roles: leadership in the 21 st century. Organizational Dynamics. v. 28, n. 3, p. 18-33, 2000.

DÍAZ-DÍAZ, N. L.; SAÁ-PÉREZ, P. Novelty of innovation and the effect of existing and recently hired $R \& D$ human resources. Innovation: management, policy \& practice. $v$. 14, n. 1, p. 74-89, March 2012.

DOBNI, C. B. Measuring innovation culture in organizations: the development of a generalized innovation culture construct using exploratory factor analysis. European Journal of Innovation Management. v. 11, n. 4, p. 539-559, 2008.

DOGSON, M.; GANN, D. M.; PHILLIPS, N. (Eds.). The Oxford handbook of innovation management. Oxford: Oxford University Press, 2014.

DUTTA, S.; LANVIN, B. (Eds.). The global innovation index: the local dynamics of innovation. Geneva: Cornell University, INSEAD, WIPO, 2013.

DUTTA, S.; LANVIN, B. WUNSCH-VINCENT, S. (Eds.). The global innovation index: the human factor in innovation. Geneva: Johnson Cornell University, INSEAD, WIPO, 2014.

DUTTA, S.; NARASIMHAN, O.; RAJIV, S. Conceptualizing and measuring capabilities: methodology and empirical implications. Strategic Management Journal. v. 26, n. 3, p. 277-285, 2005.

EBSCO. EBSCOhost - Academic Search Premier. Disponível em: < https://www.ebscohost.com/academic> Acesso em: 2011 a 2014.

EUROSTAT. Eurostat yearbook 2012: Europe in figures. Luxembourg: Publications office of the European Union, 2012. Disponível em: http://ec.europa.eu/eurostat. Acesso em: 24/07/2013.

EUROSTAT. Eurostat yearbook 2004: the statistical guide to Europe. Luxembourg: Office for official publications of the European Communities, 2004. Disponível em: http://epp.eurostat.ec.europa.eu/portal/page/portal/product_details/publication?p_produc t code=KS-CD-04-001 Acesso em: 05/11/2012. 
FAGERBERG, J. Innovation: a guide to the literature. In: FAGERGERG, J. MOWERY, D. C.; NELSON, R. R. (Eds.). The Oxford handbook of innovation. Oxford: Oxford University Press, p. 01-26, 2006.

FÁVERO, L. F.; BELFIORE, P.; SILVA, F. L.; CHAN, B. L. Análise de dados: modelagem multivariada para tomada de decisões. São Paulo: Campus, 2009.

FEDERAÇÃO DA INDÚSTRIA DO ESTADO DO ESPÍRITO SANTO - FINDES. Disponível em: <http://www.sistemafindes.org.br/index.php/a-findes/institucional>. Acesso em: 11/11/2014.

FEDERAÇÃO DA INDÚSTRIA DO ESTADO DO PARANÁ - FIEP. Disponível em: <http://www.fiepr.org.br/conheca-1-97-188404.shtml>. Acesso em: 30/06/2014.

FEDERAÇÃO DA INDÚSTRIA DO ESTADO DE SÃO PAULO - FIESP. Capacitação para gestores na indústria. Disponível em: <http://www.fiesp.com.br/inovacaotecnologica/gestao-da-inovacao $>$. Acesso em: 04/06/2014.

FISCHER, A. L. Um resgate conceitual e histórico dos modelos de gestão de pessoas. In: FLEURY, M. T. L. (Org.). As pessoas na organização. São Paulo: Gente: 2002.

FISCHMANN, A. A. Implementação de estratégias: identificação e análise de problemas. São Paulo, 1987. Tese (Livre Docência em Administração) - Programa de Pós-Graduação em Administração, Departamento de Administração, Faculdade de Economia, Administração e Contabilidade da Universidade de São Paulo.

FIUZA, G. D.; NUNES, I.; MENDES, N. M. D. ; FERREIRA, L. A. ; MELO, B. B. Políticas de gestão de pessoas: cenário dos estudos publicados nos periódicos da área de administração. In: XXXIV Encontro da ANPAD - EnANPAD 2010. Anais do XXXIV EnANPAD. Rio de Janeiro: ANPAD, 2010.

FORSMAN, H.; Innovation capacity and innovation development in small enterprises. A comparison between the manufacturing and service factors. Research Policy. v. 40, s/n, p. 739-750, 2011.

FRISHAMMAR, J.; KURKKIO, M.; ABRAHAMSSON, L.; LICHTENTHALER, U. Antecedents and consequences of firms' process innovation capability: a literature review and a conceptual framework. IEEE Transactions on Engineering Management. v. 59, n. 4, p. 519-529, November 2012.

GANNON, J. M.; DOHERTY, L.; HOPE, A. The role of strategic groups in understanding strategic human resource management. Personal Review. v. 41, n. 2, p. 513-546, 2012.

GARCÍA, F.; LEÓN, A. El cuestionario: una propuesta para su diseño. Investigación Social. v. IV, n. 14, p. 45-54, 2002.

GUAN, J.; MA, N. Innovative capability and export performance of Chinese firms. Technovation. v. 23, s/n, p. 737-747, 2003.

GUBA, E. G. (Ed.). The paradigm dialog. Newbury Park, CA: Sage, 1990. 
GUEST, D. E. Human resource management and industrial relations. Journal of Management Studies. v. 24, n. 5, p. 503-521, 1987.

HAIR Jr. J. F.; BABIN, B.; MONEY, A. H. ; SAMOUEL, P. Fundamentos de métodos de pesquisa em administração. Porto Alegre: Bookman, 2005.

HAIR Jr. J. F.; BLACK, W. C.; BABIN, B. J.; ANDERSON, R. E.; TATHAM, R. L. Análise multivariada de dados. 6. ed. Porto Alegre: Bookman, 2009.

HART, V. H.; MILSTEIN, M. B. Creating sustainable value. Academy of Management Executive. v. 17, n. 2, p. 56-69, 2003.

HERZOG, P.; LEKER, J. Open and closed innovation: different innovation cultures for different strategies. International Journal of Technology Management. v. 52, n. 3/4, p. 322-343, 2010.

HULT, G. T. M.; HURLEY, R. F.; KNIGHT, G. A. Innovativeness: its antecedents and impact on business performance. Industrial Marketing Management. v. 33, s/n, p. 429-438, 2004.

INSTITUTO BRASILEIRO DE GEOGRAFIA E ESTATÍSTICA - IGBE. Estados@ Disponível em: <http://www.ibge.gov.br/estadosat/>. Acesso em: 2014.

. Pesquisa industrial de inovação tecnológica 2003 - PINTEC 2003. Rio de

Janeiro: $\quad 2005 . \quad$ Disponível em: <http://www.ibge.gov.br/home/estatistica/economia/industria/pintec/2003/default.shtm> . Acesso em: 06/09/2011.

ISI WEB OF KNOWLEWDGE. Web of Science. Principal coleção do Web of Science. v.5.16. Social Sciences Citation Index (SSCI). Disponível em: < http://apps.webofknowledge.com/WOS_GeneralSearch_input.do?product=WOS\&searc

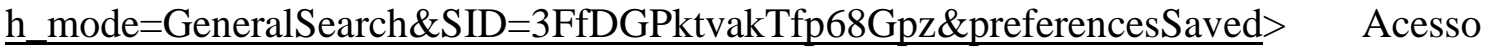
em: 02/01/2015.

ISAKSEN, S. G.; EKVALL, G. Managing for innovation: the two faces of tension in creative climates. Creativity and Innovation Management. v. 19, n. 2, p. 73-88, 2010.

JAMROG, J.; VICKERS, M.; BEAR, D.; Building and sustaining a culture that supports innovation. Human Resource Planning, v. 29, n. 13, p. 9-19, 2006.

JIMÉNEZ-JIMÉNEZ, D.; SANZ-VALLE, R. Innovation and human resource management fit: an empirical study. International Journal of Manpower. v. 26, n. 4, p. 364-398, 2005.

JOHNSON, G.; SCHOLES, K.; WHITTINGTON, R. Explorando a estratégia corporativa: texto e casos. Porto Alegre: Bookman, 2007.

JOURNAL CITATION REPORTS - JCR. Disponível em: <http://adminapps.webofknowledge.com/JCR/JCR>. Acesso em 2012. 
JUNG, D. I.; CHOW, C.; WU, A. The role of transformational leadership in enhancing organizational innovation: hypotheses and some preliminary findings. The Leadership Quarterly. v. 14, s/n, p. 525-544, 2003.

KERLINGER, F. N. Metodologia da pesquisa em ciências sociais: um tratamento conceitual. São Paulo: EPU, 5ª reimpressão, 1979.

KHAZANCHI, S.; LEWIS, M. W.; BOYER, K. K. Innovation-supportive culture: the impact of organizational values on process innovation. Journal of Operations Management. v. 25, n. 4, p. 871-884, June 2004.

KIRNER, E.; KINKEL, S.; JAEGER, A. Innovation paths and the innovation performance of low-technology firms - an empirical analysis of the German industry. Research Policy. v. 38, s/n, p. 447-458, 2009.

LAWSON, B.; SAMSON, D. Developing innovation capability in organizations: a dynamic capabilities approach. International Journal of Innovation Management. v. 5, n. 3, p. 377-400, september, 2001.

LEEDE, J. D.; LOOISE, J. K. Innovation and HRM: towards an integrated framework. Creativity and Innovation Management. v. 14, n. 2, p. 108-117, 2005.

LEGGE, K. Human resource management: rhetorics and realities. Basingstoke: Palgrave Macmillan, 1995.

LEGGE, K. Human resource management: rhetorics and realities. Anniversary edition. Basingstoke: Palgrave Macmillan, 2005.

LENGNICK-HALL, M. L.; LENGNICK-HALL, C. A.; ANDRADE, L. S.; DRAKE, B. Strategic human resource management: the evolution of the field. Human Resource Management Review. v. 19, n. 2, p. 64-85, June 2009.

LEPAK, D. P.; SHAW, J. D. Strategic HRM in North America: looking to the future. The International Journal of Human Resource Management. v. 19, n. 8, p. 14861499, August 2008.

LIAO, S.; CHANG, W.; HU, D.; YUEH, Y. Relationships among organizational culture, knowledge acquisition, organizational learning, and organizational innovation in Taiwan's banking and insurance industries. The International Journal of Human Resource Management. v. 23, n. 1, p. 52-70, January 2012.

LINKEDIN. Disponível em: 〈https://br.linkedin.com/nhome/>. Acesso em: 2014.

MARTÍN-ALCÁZAR; ROMERO-FERNÁNDEZ, P. M.; SÁNCHEZ-GARDEY, G. Strategic human resource management: the universalistic, contingent, configurational and contextual perspectives. The International Journal of Human Resource Management. v. 16, n. 5, p. 633-659, February 2007.

MARTINS, E. C.; TERBLANCHE, F. Building organisational culture that stimulates creativity and innovation. European Journal of Innovation Management. v. 6, n. 1, p. 64-74, 2003. 
MASCARENHAS, A. O. Gestão estratégica de pessoas. São Paulo: Cengage Learning, 2008.

MATTHEWS, J. Innovation in Australian small and medium enterprises: contributions form strategic human resource management. Asia Pacific Journal of Human Resources. v. 40, n. 2, p. 193-204, 2002.

MEDEIROS, C. A. F. Comprometimento organizacional: um estudo de suas relações com características organizacionais e desempenho nas empresas hoteleiras. São Paulo, 2003. Tese (Doutorado em Administração) - Programa de Pós-Graduação em Administração, Departamento de Administração, Faculdade de Economia, Administração e Contabilidade da Universidade de São Paulo.

MINISTÉRIO DA CIÊNCIA, TECNOLOGIA E INOVAÇÃO - MCTI, 2013. Lei de inovação. Disponível em: 〈http://www.mct.gov.br/index.php/content/view/8477.html> Acesso em: 28/04/2013.

MINTZBERG, H.; AHLSTRAND, B.; LAMPEL, J. O processo da estratégia: conceitos, contextos e casos selecionados. Porto Alegre: Bookman, 2007.

NEELY, A.; FILIPPINI, R.; FORZA, C.; VINELLI, A.; HII, J. A framework for analyzing business performance, firm innovation and related contextual factor: perceptions of managers and policy makers in two European regions. Integrated Manufacturing Systems. v. 12, n. 2, p. 114-124, 2001.

NELSON, R.; WINTER, S. An evolutionary theory of economic change. Cambridge: Harvard University Press, 1982.

NG, P. T. The learning organization and the innovative organisation. Human Systems Management. v. 23, s/n, p. 93-100, 2004.

NYBAKK, E.; JENSSEN, J. I. Innovation strategy, working climate, and financial performance in traditional manufacturing firms: an empirical analysis. International Journal of innovation management. v. 16, n. 2, p.1-30, April 2012.

ORGANISATION FOR ECONOMIC CO-OPEERATION AND DEVELOPMENT OECD. Manual de Oslo. 3. ed., 1997. Disponível em: 〈http://www.mct.gov.br/upd_blob/0026/26032.pdf>. Acesso em: 22/06/2012.

. Frascati Manual: proposed standard practices for survey of resarch and experimental development. The measurement of scientific and technical activities series. Paris: 1981.

OKE, A.; WALUMBWA, F. O.; MYERS, A. Innovation strategy, human resource policy and firms' revenue growth: the roles of environmental uncertainty and innovation performance. Decision Sciences. v. 43, n. 2, p. 273-302, April 2012.

OXFORD. Oxford advanced learner's dictionary. Disponível em: http://www.oxfordlearnersdictionaries.com/definition/english/2015. Acesso em: 12.01.2015. 
PALLAS, F.; BÖCKERMANN, F.; GOETZ, O.; TECKLENBURG, K. Investigating organisational innovativeness: developing a multidimensional formative measure. International Journal of Innovation Management. v. 17, N. 4, p. 1-41, August 2013.

PAPACONSTANTINOU, G. Technology and industrial performance. The OECD Observer. v. 204. February/March, p. 6-10, 1997.

PAROLIN, S. R. H.; ALBUQUEREQUE, L. G. A gestão estratégica de pessoas para a inovação: o caso do Laboratório Herbarium. In: XXXII EnANPAD - Encontro da ANPAD. Rio de Janeiro: Anais do XXXII EnANPAD, 2008.

PASQUALI, L. Testes referentes a construto: teoria e modelo de construção. In: PASQUALI, L. Instrumentos psicológicos: manual prático de elaboração. Porto Alegre: Artmed, p. 165-198, 2010.

PENROSE, E. T. A teoria do crescimento da firma. Campinas: Unicamp, 2006.

PORTER, M. E. Vantagem competitiva. Rio de Janeiro: Campus, 1989.

PRAJOGO, D. I.; AHMED, P. K. Relationships between innovation stimulus, innovation capacity, and innovation performance. R\&D Management. v. 36, n, 5, p. 499-515, November 2006.

PRAHALAD, C. K.; HAMEL, G. A competência essencial da corporação. In: ULRICH, D. (Org.). Recursos humanos estratégicos: novas perspectivas para os profissionais de RH. São Paulo: Futura, 2000.

QUISHIDA, A.; ALBUQUERQUE, L. G. A produção acadêmica internacional sobre gestão estratégica de pessoas para inovação. In: XXXVIII EnANPAD - Encontro da ANPAD. Rio de Janeiro: Anais do XXXVIII EnANPAD, 2014.

QUISHIDA, A.; ANDRADE, S. M. A produção nacional e internacional sobre gestão estratégica de recursos humanos de 2001 a 2011. XVII SEMEAD - Seminários em Administração da FEA/USP. São Paulo: Anais do XVII SEMEAD, 2014.

RITALA, P.; ARMILA, L.; BLOMQVIST, K. Innovation orchestration capability defining the organizational and individual level determinants. International Journal of Innovation Management. v. 13, n. 4, p.569-591, Dec. 2009.

ROBBINS, S. P.; JUDGE, T. A.; SOBRAL, F. Comportamento organizacional: teoria e prática no contexto brasileiro. 14. ed. São Paulo: Pearson, 2011.

ROFFE, I. Innovation and creativity in organisations: a review of the implications for training and development. Journal of European Industrial Training. v. 23, n. 4-5, p. 224-237, 1999.

ROEHLING, M. V.; BOSWELL, W. R.; CALIGURI, P.; FELDMAN, D.; GRAHAM, M. E.; GUTHRIE, J. P.; MORISHIMA, M.; TRANSKY, J. W. The future of HR management: needs and directions. Human Resource Management. v. 44, n. 2, p 206216, Summer 2005.

ROKEACH, M. The nature of human values. New York: The Free Press, 1973. 
RYAN, J. C.; TIPU, S. A. A. Leadership effects on innovation propensity: a two-factor full range leadership model. Journal of Business Research. v. 66, s/n, p. 2116-2129, 2013.

SAÁ-PÉREZ, P.; DÍAZ-DÍAZ, N. L. Human resource management and innovation in the Canary Islands: an ultra-peripheral region of the European Union. The International Journal of Human Resource Management. v. 21, n. 10, p. 1649-1666, August 2010.

SAÁ-PÉREZ, P.; GARCÍA-FALCÓN, J. M. A resource-based view of human resource management: an organizational capabilities development. The International Journal of Human Resource Management. v. 13, n. 1, p. 123-140, February 2011.

SBRAGIA, R.; KRUGLIANSKAS, I.; SBRAGIA, R. Los indicadores de I,D\&E em las empresas mas y menos inovadoras. Espacios, Revista Venezoelana da Gestión Tecnologica. v. 20, n. 1, 1999.

SCHEIN, E. H. Innovative cultures and organizations. Management in the 1990s. Sloan School of Management, n. 2066. Massachusetts Institute of Technology, November 1988.

SCHEIN, E. H. Organizational culture and leadership. $4^{\text {th }}$ ed. San Francisco: JosseyBass, 2010.

SCHEIN, E. H. Coming to a new awareness of organizational culture. Sloan Management Review. v. 25 n. 2, p. 3-16, Winter 1984.

SCHULER, R. S.; JACKSON, S. E. Linking competitive strategies with human resource management practices. The Academy of Management Executive. v.1, n. 3, p. 207-219, August 1987.

SCHWAB, K. (Ed.). The global competitiveness report 2013-2014. Geneva: World Economic Forum, 2013. Disponível em: 〈http://www.weforum.org/reports〉. Acesso em: 11/09/2013.

SHIPTON, H.; WEST, M. A.; DAWSON, J.; BIRDI, K.; PATTERSON, M. HRM as a predictor of innovation. Human Resource Management Journal. v. 16, n. 1, p. 3-27, 2006.

SIEGL, S.; CASTELLAN Jr., J. Estatística não-paramétrica para as ciências do comportamento. 2. ed. Porto Alegre: Bookman/Artmed, 2006.

SMITH, M.; BUSI, M.; BALL, P.; VEN DER MEER, R. Factors influencing an organization's ability to manage innovations: a structured literature review and conceptual model. International Journal of Innovation Management. v. 12, n. 4, p. 655-676, Dec 2008.

SOM, A. What drives adoption of innovative HR practices in Indian organizations? The International Journal of Human Resource Management. v. 18, n. 5, p. 808-828, 2003.

STALK Jr., G.; EVANS, P.; SCHULMAN, L. E. Competição baseada em capacidades: as novas regras da estratégia empresarial. In: ULRICH, D. (Org.). Recursos humanos estratégicos: novas perspectivas para os profissionais de RH. São Paulo: Futura, 2000. 
STIRPE, L.; TRULLEN, J.; BONACHE, J. Factors helping the HR function gain greater acceptance for its proposals and innovations: evidence from Spain. The International Journal of Human Resource Management. v. 24, n. 20, p. 3794-3811, 2013.

SURVEY MONKEY. Disponível em: <https://pt.surveymonkey.com/>. Acesso em: 28/09/2014.

TAKEUCHI, N. How Japanese manufacturing firms align their human resource policies with business strategies: testing a contingency performance prediction in a Japanese context. The International Journal of Human Resource Management. v. 20, n. 1, p. 34-56, January 2009.

TALLMAN, S. Dynamic capabilities. In.: FAULKNER, D. O.; CAMPBELL, A. (Ed.). The Oxford handbook of strategy: a strategy overview and competitive strategy. Oxford: Oxford University Press, 2003.

TANNEMBAUM, S.; DUPUEE-BRUNO, L. M. The relationship between organizational and environmental factors and the use of innovative human resource practices. The International Journal of Human Resource Management. v. 19, n. 2, p. 171-202, 1994.

TEECE, D. J.; PISANO, G.; SHUEN, A. Dynamic capabilities and strategic management. Strategic Management Journal. v. 18, n. 2, p. 509-533, 1997.

TIDD, J.; BESSANT, J.; PAVITT, K. Gestão da inovação. 3. ed. Porto Alegre: Bookman, 2008.

TSAI, Y.; JOE, S.; DING, C. G.; LIN, C. Modeling technological innovation performance and its determinants: an aspect of buyer-seller social capital. Technological Forecasting \& Social Change. v. 80, p. 1211-1221, 2013.

ULRICH, D. Os campeões de recursos humanos: inovando para obter os melhores resultados. São Paulo: Futura, 1998.

ULRICH, D.; LAKE, D. Organizational capability: competing from the inside out. New York: John Wiley \& Sons, 1990.

VALLADARES, P. S. D.; BRITO, L. A. L.; VASCONCELLOS, M. A. Determinantes da Capacidade de Inovação: Análise Estrutural de um Modelo Integrador. In: XXXVI Encontro da Anpad - ENANPAD 2012. Anais do XXXVI ENANPAD. Rio de Janeiro: Anpad, 2012.

VASCONCELLOS-GUEDES, L.; VASCONCELLOS, E.; GUEDES, L. F. A.; DEBOM, $\mathrm{R}$. The presence of an innovative culture across the Company and differences among functional areas. 2012 Academy of Management Annual Meeting, 2012.

VASCONCELLOS, L.; GUEDES, L. F. A. Esurveys: vantagens e limitações dos questionários eletrônicos via internet no contexto da pesquisa científica. In: X SEMEAD: Seminários em Administração FEA/USP. São Paulo. Anais do X SEMEAD. São Paulo, 2007. 
WANG, C. L.; AHMED, P. The development and validation of the organizational innovativeness construct using confirmatory factor analysis. European Journal of Innovation Management. v. 7, n. 4, p. 303-313, 2004.

WRIGHT, P. M.; BOSWELL, W. R. Desegregating HRM: a review and synthesis of micro and macro human resource management research. Journal of Management. v. 28, n. 3, p. 247-276, 2002.

WRIGHT, P. M.; McMAHAN, G. C. Theoretical perspectives for strategic human resource management. Journal of Management. v. 18, n. 2, p. 295-320, 1992.

YAM, R. C. M.; GUAN, J. C.; PUN, K. F.; TANG, E. P. Y. An audit of technological innovation capabilities in Chinese firms: some empirical findings in Beijing, China. Research Policy. v. 33, p. 1123-1140, 2004.

YAM, R. C. M.; LO, W.; TANG, E. P. Y.; LAU, A. K. W. Technological innovation capabilities and firm performance. World Academy of Science, Engineering and Technology, v. 42, s/n, p. 1009-1017, 2010.

YANG, Y.; KONRAD, A. M. Diversity and organizational innovation: the role of employee involvement. Journal of Organizational Behavior. v. 32, s/n, p. 1062-1083, 2011.

YESIL, S.; BÜYÜKBESE, T. Exploring the link between knowledge sharing enablers, innovation capability and innovative performance. International Journal of Innovation Management. v. 17, n. 4, p. 1-20, August 2013.

ZHANG, J. A.; GARRETT-JONES, S.; SZETO, R. Innovation capability and market performance: the moderating effect of industry dynamism. International Journal of Innovation Management. v. 17, n. 2, p. 1-35, April 2013. 


\title{
APÊNDICES
}

\section{Apêndice 1 - Modelo de e-mail convite para participação na pesquisa}

\author{
Federações da Indústria dos Estados, Agências e Associações
}

Prezado nome do gestor,

Considerando o histórico de fomento à inovação do (sigla da Federação, Agência ou Associação), gostaria de solicitar seu apoio na divulgação da pesquisa de doutorado que estou conduzindo pela Faculdade de Economia, Administração e Contabilidade da Universidade de São Paulo (FEA/USP).

O objetivo da pesquisa é identificar em que medida a gestão estratégica de pessoas, composta por um conjunto de características organizacionais, contribui para a capacidade de inovação em organizações industriais que possuem operações no Brasil.

Peço a gentileza de encaminhar o link de acesso ao questionário eletrônico para os gestores responsáveis pela condução de projetos em pesquisa, desenvolvimento e inovação, independentemente da função e cargo exercidos: https://pt.surveymonkey.com/s/XJNQJ5S. Caso o respondente se depare com a mensagem de "erro de página", solicito que acesse o link por outro navegador. A pesquisa estará disponível até 30 de novembro.

Respondentes e empresas não deverão se identificar. Peço apenas, em caráter facultativo, um e-mail (endereço pessoal do respondente ou de qualquer contato por ele indicado). Dessa forma, todos que tiverem respondido completa e adequadamente o questionário serão agraciados com o relatório sintético dos resultados.

Será assegurada a confidencialidade dos dados coletados, que serão tratados e analisados de maneira agregada em âmbito nacional. Os resultados serão utilizados exclusivamente para fins acadêmicos.

Estarei à disposição para esclarecer eventuais dúvidas sobre a pesquisa.

Atenciosamente,

Alessandra Quishida

Doutoranda em Administração

Faculdade de Economia, Administração e Contabilidade

Universidade de São Paulo

quishida@usp.br 


\title{
Apêndice 2 - Questionário
}

\section{Capacidade de Inovação sob a Perspectiva da Gestão Estratégica de Pessoas}

\section{Introdução}

Prezado(a) gestor(a),

Este questionário faz parte de uma pesquisa que visa verificar em que medida a gestão estratégica de pessoas, composta por um conjunto de características organizacionais, contribui para a capacidade de inovação na indústria.

Favor responder as questões no escopo corporativo da empresa em que trabalha, utilizando as operações no Brasil como base para as respostas.

Favor encaminhar o e-mail recebido caso não seja responsável pela condução de projetos de pesquisa, desenvolvimento e inovação (P\&D\&I) ou caso a empresa em que trabalha não possua operações no Brasil.

Diante de mensagem de erro de página recomendamos que acesse o link da pesquisa por outro navegador.

Muito obrigada por sua participação!

\author{
Alessandra Quishida \\ Doutoranda em Administração \\ Faculdade de Economia, Administração e Contabilidade \\ Universidade de São Paulo \\ quishida@usp.br
}


II. Informações Gerais

Selecione a alternativa mais adequada e complete o campo quando solicitado.

Sobre a empresa:

*1. Tempo de operação no Brasil (anos completos)

*2. Setor de atividade

$\square$ indústria

$\square$ serviços

Especifique o setor de atividade escolhido

*3. Origem do capital

$\square$ privado nacional

$\square$ multinacional

$\square$ estatal

*4. Receita operacional bruta (R\$/ano)

$\square$ menor ou igual a $\mathrm{R} \$ 2,4$ milhões

$\square$ maior que $\mathrm{R} \$ 2,4$ milhões e menor ou igual a $\mathrm{R} \$ 16$ milhões

$\square$ maior que $\mathrm{R} \$ 16$ milhões e menor ou igual a $\mathrm{R} \$ 90$ milhões

$\square$ maior que $\mathrm{R} \$ 90$ milhões e menor ou igual a $\mathrm{R} \$ 300$ milhões

$\square$ maior que $\mathrm{R} \$ 300$ milhões

*5. Porte

$\square$ microempresa

$\square$ pequena empresa

$\square$ média empresa

$\square$ média-grande empresa

$\square$ grande empresa

*6. Número de funcionários da empresa

*7. Número de funcionários alocados em P\&D\&I (estimativa) 
*8. Número total de graduados, mestres e doutores alocados em P\&D\&I (estimativa)

*9. Tipo de inovação praticada 1

$\square$ predominantemente de produto

$\square$ predominantemente de processo

*10. Tipo de inovação praticada 2

$\square$ predominantemente fechada

$\square$ predominantemente aberta

*11. Tipo de inovação praticada 3

$\square$ incremental

$\square$ radical

$\square$ ambas

*12. Esta empresa pratica inovação organizacional (novo método organizacional que

consiste em uma nova prática de negócio, organização do trabalho ou relações internas)?

$\square \operatorname{sim}$

$\square$ não

III. Informações gerais

Selecione a alternativa mais adequada e complete o campo quando solicitado.

Sobre o(a) respondente:

*13. Sexo

$\square$ masculino

$\square$ feminino

*14. Faixa etária (anos)

$\square 21$ a 30

$\square 31$ a 40

$\square 41$ a 50 
$\square 51$ a 60
$\square$ mais de 61

*15. Formação acadêmica (nível máximo obtido)

$\square$ Ensino médio

$\square$ Ensino superior

$\square$ MBA/Especialização/Extensão

$\square$ Mestrado

$\square$ Doutorado

$\square$ Outro (especifique)

*16. Tempo de experiência profissional nesta empresa em P\&D/inovação (anos completos)

*17. Estado em que trabalha
$\square \mathrm{ES}$
$\square \mathrm{MG}$
$\square \mathrm{PR}$
$\square \mathrm{RJ}$
$\square \mathrm{RS}$
$\square \mathrm{SC}$
$\square \mathrm{SP}$
$\square$ Outro (especifique utilizando a sigla do Estado)

*18. Classificação dos projetos que gerencia quanto ao tipo de pesquisa envolvida
$\square$ básica
$\square$ aplicada
$\square$ ambas

19. Número de funcionários sob sua responsabilidade

20. Caso queira receber o relatório sintético da pesquisa ou tenha interesse em participar do workshop de apresentação dos resultados, favor informar seu email pessoal no campo abaixo. Serão considerados os e-mails referentes aos questionários que tiverem sido respondidos completa e adequadamente. 


\section{IV - Características de Gestão Estratégica de Pessoas}

Selecione a alternativa que melhor descreve a empresa em que trabalha, utilizando a escala que varia entre: 1 - discordo fortemente e 7 - concordo fortemente.

*21. Inovar faz parte da razão de existir desta empresa.

*22. A declaração de visão reforça o propósito de inovar desta empresa.

*23. Inovação é um valor central desta empresa.

*24. Flexibilidade é indispensável para inovação.

*25. Colaboração é indispensável para inovação.

*26. Comunicação ampla é indispensável para inovação.

*27. Criatividade é indispensável para inovação.

*28. Aprendizagem é indispensável para inovação.

*29. Conhecimento é indispensável para inovação.

*30. Diversidade é indispensável para inovação.

*31. As normas orientam adequadamente o propósito de inovar.

*32. A inovação está arraigada em nosso modelo de negócio.

*33. Esta empresa é mais orientada para diferenciação do que para liderança em custo.

*34. Existe coerência entre a estratégia organizacional e a estratégia de inovação.

*35. Esta empresa busca ser a primeira a lançar novos produtos e serviços no mercado.

*36. A empresa em que trabalho se caracteriza pela orientação para o cliente.

*37. A empresa em que trabalho sistematicamente divulga informações sobre inovação.

*38. A empresa em que trabalho sistematicamente divulga resultados obtidos com inovação

*39. A gerência de P\&D\&I é consultada quando da tomada de decisões estratégicas.

*40. Os líderes de minha empresa apresentam predisposição para inovar.

*41. Os líderes disseminam o intento de inovar por toda a organização de maneira efetiva.

*42. Os líderes inspiram as pessoas a se engajarem em atividades de inovação.

*43. Os líderes fornecem estímulo intelectual para a solução de problemas.

*44. Os líderes apresentam tolerância à incerteza.

*45. Os líderes estimulam a interação criativa. 
*46. O estilo de gestão desta empresa é participativo.

*47. Existe confiança no executivo que patrocina a inovação nesta empresa.

*48. O executivo que patrocina a inovação na empresa assegura que os projetos recebam

assistência de todos os profissionais envolvidos.

*49. Existe coerência entre as orientações fornecidas pelo executivo responsável por inovação

e pelos gerentes de projetos.

*50. Os gerentes de projetos estimulam o desenvolvimento de competências atreladas à inovação.

*51. Os gerentes de projetos encorajam a proposição de novas maneiras de fazer as coisas.

*52. Riscos calculados são encarados de maneira positiva em minha empresa.

*53. Aqui os erros também representam oportunidade de aprendizagem.

*54. Nesta empresa entende-se que os conflitos também podem instigar a inovação.

*55. As políticas de gestão de pessoas desta empresa estão alinhadas com a estratégia corporativa.

*56. As políticas de gestão de pessoas fomentam a inovação na empresa.

*57. As práticas de recrutamento e seleção desta empresa contribuem para a contratação de bons profissionais de P\&D\&I.

*58. Há compromisso de longo prazo com treinamento e desenvolvimento voltados para inovação.

*59. O plano de carreira da empresa considera as necessidades dos profissionais de P\&D\&I.

*60. A inovação é considerada no(s) método(s) de avaliação de desempenho humano.

*61. O sistema de recompensas desta empresa estimula o engajamento dos funcionários em

atividades de inovação.

*62. O trabalho em equipes multifuncionais é uma prática amplamente utilizada em projetos

de P\&D\&I.

*63. A gestão de talentos contribui para a retenção de profissionais de P\&D\&I.

Subvariáveis redigidas pela pesquisadora com base nos autores citados no referencial teórico. 
V - Capacidade de Inovação

Classifique o nível de contribuição do conjunto de afirmações apresentadas na parte 4 do questionário (questões 21 a 63) para cada uma das frases abaixo.

Selecione a alternativa mais adequada utilizando a escala que varia entre: 1 - muito baixa e 7 - muito alta.

*64. Habilidade da empresa de identificar oportunidades de melhoria com vistas à inovação $\square$

*65. Habilidade da empresa de assimilar conhecimentos adquiridos em projetos de P\&D\&I $\square$

*66. Habilidade da empresa compartilhar lições aprendidas em projetos de P\&D\&I $\square$

*67. Habilidade da empresa de alocar profissionais provenientes de diferentes grupos funcionais no processo de inovação

*68. Habilidade da empresa de integrar diferentes grupos funcionais envolvidos no processo de inovação $\square$ 


\section{Apêndice 3 - Mapa das Variáveis}

Caracterização das Variáveis

Caracterização das Empresas (caracterização da amostra)

\begin{tabular}{|c|c|c|c|}
\hline Código & Rótulo (Label) da Variável & Tipo de Variável & Tipo de Escala \\
\hline $\mathrm{q} 0001$ & Tempo de operação no Brasil (anos completos) & Quantitativa (métrica) & Razão \\
\hline $\mathrm{q} 0002$ & Setor de atividade & Qualitativa (não métrica) & Nominal \\
\hline $\mathrm{q0003}$ & Origem do capital & Qualitativa (não métrica) & Nominal \\
\hline $\mathrm{q} 0004$ & Receita operacional bruta (R\$/ano) & Qualitativa (não métrica) & Ordinal \\
\hline q0005 & Porte & Qualitativa (não métrica) & Ordinal \\
\hline q0006 & Número de funcionários da empresa & Quantitativa (métrica) & Razão \\
\hline $\mathrm{q0007}$ & Número de funcionários alocados em P\&D\&I (estimativa) & Quantitativa (métrica) & Razão \\
\hline q0008 & Número total de graduados, mestres e doutores alocados em P\&D\&I (estimativa) & Quantitativa (métrica) & Razão \\
\hline q0009 & Tipo de inovação praticada 1 & Qualitativa (não métrica) & Nominal \\
\hline q0010 & Tipo de inovação praticada 2 & Qualitativa (não métrica) & Nominal \\
\hline q0011 & Tipo de inovação praticada 3 & Qualitativa (não métrica) & Nominal \\
\hline $\mathrm{q0012}$ & Esta empresa pratica inovação organizacional ? & Qualitativa (não métrica) & Nominal (dicotômica) \\
\hline
\end{tabular}

Caracterização dos Entrevistados (caracterização da amostra)

q0013 Sexo

q0014 Faixa etária (anos)

q0015 Formação acadêmica (nível máximo obtido)

q0016 Tempo de experiência profissional nesta empresa em P\&D/inovação (anos completos)

q0017 Estado em que trabalha

q0018 Classificação dos projetos que gerencia quanto ao tipo de pesquisa envolvida

q0019 Número de funcionários sob sua responsabilidade

Qualitativa (não métrica)

Qualitativa (não métrica)

Qualitativa (não métrica)

Quantitativa (métrica)

Qualitativa (não métrica)

Qualitativa (não métrica)

Quantitativa (métrica) 
Construto FVN

q0021 Inovar faz parte da razão de exisitr desta empresa.

q0022 A declaração de visão reforça o propósito de inovar desta empresa.

q0023 Inovação é um valor central desta empresa.

q0024 Flexibilidade é indispensável para inovação.

q0025 Colaboração é indispensável para inovação.

q0026 Comunicação ampla é indispensável para inovação.

q0027 Criatividade é indispensável para inovação.

q0028 Aprendizagem é indispensável para inovação.

q0029 Conhecimento é indispensável para inovação.

q0030 Diversidade é indispensável para inovação.

q0031 1 As normas orientam adequadamente o propósito de inovar.

Quantitativa (métrica) $\quad$ Razão

Quantitativa (métrica)

Quantitativa (métrica)

Quantitativa (métrica)

Quantitativa (métrica)

Quantitativa (métrica)

Quantitativa (métrica)

Quantitativa (métrica)

Quantitativa (métrica)

Quantitativa (métrica)

Quantitativa (métrica)

Razão

Razão

Razão

Razão

Razão

Razão

Razão

Razão

Razão

Razão

\section{Construto FEI}

q0032 A inovação está arraigada em nosso modelo de negócio.

q0033 Esta empresa é mais orientada para diferenciação do que para liderança em custo.

q0034 Existe coerência entre a estratégia organizacional e a estratégia de inovação.

q0035 Esta empresa busca ser a primeira a lançar novos produtos e serviços no mercado.

q0036 A empresa em que trabalho se caracteriza pela orientação para o cliente.

q0037 A empresa em que trabal ho sistematicamente divulga informações sobre inovação.

q0038 A empresa em que trabalho sistematicamente divulga resultados obtidos com inovação.

q0039 A gerência de P\&D\&l é consultada quando da tomada de decisões estratégicas.
Quantitativa (métrica)

Quantitativa (métrica)

Quantitativa (métrica)

Quantitativa (métrica)

Quantitativa (métrica)

Quantitativa (métrica)

Quantitativa (métrica)

Razão

Razão

Razão

Razão

Razão

Razão

Razão
Quantitativa (métrica) 
q0040 Os líderes de minha empresa apresentam predisposição para inovar.

Construto LG

q0041 Os líderes disseminam o intento de inovar por toda a organização de maneira efetiva.

q0042 Os líderes inspiram as pessoas a se engajarem em atividades de inovação.

q0043 Os líderes fornecem estímulo intelectual para a solução de problemas.

q0044 Os líderes apresentam tolerência à incerteza.

q0045 Os líderes estimulam a interação criativa.

q0046 O estilo de gestão desta empresa é participativo.

q0047 Existe confiança no executivo que patrocina a inovação nesta empresa.

q0048 O executivo que patrocina a inovação na empresa assegura que os projetos recebam assistência de todos os profissionais envolvidos.

q0049 Existe coerência entre as orientações fornecidas pelo executivo responsável por inovação e pelos gerentes de projetos.

q0050 0 Os gerentes de projetos estimulam o desenvolvimento de competências atreladas à inovação.

q0051 Os gerentes de projetos encorajam a proposição de novas maneiras de fazer as coisas.

q0052 Riscos calculados são encarados de maneira positiva em minha empresa.

q0053 Aqui os erros também representam oportunidade de aprendizagem.

q0054 Nesta empresa entende-se que os conflitos também podem instigar a inovação.

Quantitativa (métrica) Quantitativa (métrica) Quantitativa (métrica) Quantitativa (métrica) Quantitativa (métrica) Quantitativa (métrica) Quantitativa (métrica) Quantitativa (métrica) Quantitativa (métrica) Quantitativa (métrica) Quantitativa (métrica) Quantitativa (métrica) Quantitativa (métrica) Quantitativa (métrica) Quantitativa (métrica)

\begin{tabular}{|l|l|}
\hline Razão \\
\hline Razão \\
\hline Razão \\
\hline Razão \\
\hline Razão \\
\hline Razão \\
\hline Razão \\
\hline Razão \\
\hline Razão \\
\hline Razão \\
\hline Razão \\
\hline Razão \\
\hline Razão \\
\hline Razão \\
\hline Razão \\
\hline
\end{tabular}

\section{Construto PPGP}

q0055 1 As políticas de gestão de pessoas desta empresa estão alinhadas com a estratégia corporativa.

q0056 1 As políticas de gestão de pessoas fomentam a inovação na empresa.

q0057 As práticas de recrutamento e seleção desta empresa contribuem para a contratação de bons profissionais de P\&D\&I.

q0058 Há compromisso de longo prazo com treinamento e desenvolvimento voltados para inovação.

q0059 O plano de carreira da empresa considera as necessidades dos profissionais de P\&D\&I.

q0060 A inovação é considerada no(s) método(s) de avaliação de desempenho humano.

q0061 O sistema de recompensas desta empresa estimula o engajamento dos funcionários em atividades de inovação.

q0062 O trabalho em equipes multifuncionais é uma prática amplamente utilizada em projetos P\&D\&l.

q0063 A gestão de talentos contribui para a retenção de profissionais de P\&D\&I.

\section{Variáveis Dependentes}

q0064 Habilidade da empresa de identificar oportunidades de melhoria com vistas à inovação

q0065 Habilidade da empresa de assimilar conhecimentos adquiridos em projetos de P\&D\&I

q0066 Habilidade da empresa de compartilhar lições aprendidas em projetos de P\&D\&I

q0067 Habilidade da empresa de alocar profissionais provenientes de diferentes grupos funcionais no processo de inovação

q0068 Habilidade da empresa de integrar diferentes grupos funcionais envolvidos no processo de inovação

\begin{tabular}{|l|l|}
\hline Quantitativa (métrica) & Razão \\
\hline Quantitativa (métrica) & Razão \\
\hline Quantitativa (métrica) & Razão \\
\hline Quantitativa (métrica) & Razão \\
\hline Quantitativa (métrica) & Razão \\
\hline Quantitativa (métrica) & Razão \\
\hline Quantitativa (métrica) & Razão \\
\hline Quantitativa (métrica) & Razão \\
\hline Quantitativa (métrica) & Razão \\
\hline
\end{tabular}

Quantitativa (métrica) Quantitativa (métrica)

Quantitativa (métrica)

Quantitativa (métrica)

Quantitativa (métrica)
Razão

Razão

Razão

Razão

Razão 
Apêndice 4 - Testes de Normalidade

Variáveis Caracterizadoras - Empresa e Respondentes

\begin{tabular}{|c|c|c|c|c|c|c|}
\hline \multicolumn{7}{|c|}{ Teste de Normalidade } \\
\hline & \multicolumn{3}{|c|}{ Kolmogorov-Smirnov } & \multicolumn{3}{|c|}{ Shapiro-Wilk } \\
\hline & Statistic & $\mathrm{df}$ & Sig. & Statistic & df & Sig. \\
\hline $\begin{array}{l}\text { Tempo de operação no } \\
\text { Brasil (anos completos) }\end{array}$ & ,206 & 39 & ,000 & ,866 & 39 & ,000 \\
\hline Setor de atividade & ,450 & 39 & ,000 & ,564 & 39 &, 000 \\
\hline Origem do capital & ,377 & 39 & ,000 & ,694 & 39 &, 000 \\
\hline $\begin{array}{l}\text { Receita operacional bruta } \\
\text { (R\$/ano) }\end{array}$ & ,258 & 39 & ,000 & ,820 & 39 &, 000 \\
\hline Porte & ,266 & 39 & ,000 & ,765 & 39 & ,000 \\
\hline $\begin{array}{l}\text { Número de funcionários da } \\
\text { empresa }\end{array}$ & ,282 & 39 &, 000 & ,665 & 39 &, 000 \\
\hline $\begin{array}{l}\text { Número de funcionários } \\
\text { alocados em P\&D\&I } \\
\text { (estimativa) }\end{array}$ & ,272 & 39 & ,000 & ,686 & 39 & ,000 \\
\hline \begin{tabular}{|l|} 
Número total de graduados, \\
mestres e doutores \\
alocados em P\&D\&I \\
(estimativa)
\end{tabular} & ,315 & 39 & ,000 & ,584 & 39 &, 000 \\
\hline Tipo de inovação praticada 1 & ,424 & 39 & ,000 & ,596 & 39 & 000 \\
\hline Tipo de inovação praticada 2 &, 411 & 39 & ,000 & ,608 & 39 &, 000 \\
\hline Tipo de inovação praticada 3 & \begin{tabular}{l|l}
342 \\
\end{tabular} & 39 & ,000 & ,652 & 39 &, 000 \\
\hline $\begin{array}{l}\text { Esta empresa pratica } \\
\text { inovação organizacional } \\
\text { (novo método organizacional } \\
\text { que consiste em uma nova } \\
\text { prática de negócio, } \\
\text { organização do trabalho ou } \\
\text { relações internas)? }\end{array}$ & ,345 & 39 & ,000 & ,637 & 39 &, 000 \\
\hline Sexo & ,437 & 39 & ,000 &, 581 & 39 &, 000 \\
\hline Faixa etária (anos) & ,228 & 39 &, 000 & ,902 & 39 &, 003 \\
\hline $\begin{array}{l}\text { Formação acadêmica (nível } \\
\text { máximo obtido) }\end{array}$ & ,315 & 39 & ,000 & ,832 & 39 &, 000 \\
\hline
\end{tabular}




\section{Características de GEP}

Filosofia, valores e normas (FVN)

\begin{tabular}{|c|c|c|c|c|c|c|}
\hline \multicolumn{7}{|c|}{ Teste de Normalidade } \\
\hline & \multicolumn{3}{|c|}{ Kolmogorov-Smirnov } & \multicolumn{3}{|c|}{ Shapiro-Wilk } \\
\hline & Statistic & $\mathrm{df}$ & Sig. & Statistic & $\mathrm{df}$ & Sig. \\
\hline Inovar faz parte da razão de exisitr desta empresa. & , 148 & 39 & 032 & ,925 & 39 & 012 \\
\hline $\begin{array}{l}\text { A declaração de visão reforça o propósito de } \\
\text { inovar desta empresa. }\end{array}$ & ,171 & 39 & 006 & 897 & 39 & ,002 \\
\hline Inovação é um valor central desta empresa. & ,144 & 39 & ,040 & ,919 & 39 & ,008 \\
\hline Flexibilidade é indispensável para inovação. & ,319 & 39 & ,000 & ,724 & 39 & ,000 \\
\hline Colaboração é indispensável para inovação. &, 410 & 39 &, 000 &, 564 & 39 &, 000 \\
\hline $\begin{array}{l}\text { Comunicação ampla é indispensável para } \\
\text { inovação. }\end{array}$ & ,235 & 39 & 000 & ,802 & 39 &, 000 \\
\hline Criatividade é indispensável para inovação. & ,264 & 39 &, 000 & ,806 & 39 &, 000 \\
\hline Aprendizagem é indispensável para inovação. & ,247 & 39 & 000 & ,816 & 39 &, 000 \\
\hline Conhecimento é indispensável para inovação. & ,321 & 39 & ,000 & ,735 & 39 &, 000 \\
\hline Diversidade é indispensável para inovação. & 186 & 39 & ,002 & ,874 & 39 & ,000 \\
\hline $\begin{array}{l}\text { As normas orientam adequadamente o propósito } \\
\text { de inovar. }\end{array}$ & ,172 & $\overline{39}$ &, 005 & 947 & $\overline{39}$ &, 063 \\
\hline
\end{tabular}

\section{FEI}

\begin{tabular}{|c|c|c|c|c|c|c|}
\hline \multicolumn{7}{|c|}{ Teste de Normalidade } \\
\hline & \multicolumn{3}{|c|}{ Kolmogorov-Smirnov } & \multicolumn{3}{|c|}{ Shapiro-Wilk } \\
\hline & Statistic & $\mathrm{df}$ & Sig. & Statistic & df & Sig. \\
\hline A inovação está arraigada em nosso modelo de negócio. & ,153 & 39 & ,022 & 948 & 39 & ,068 \\
\hline $\begin{array}{l}\text { Esta empresa é mais orientada para diferenciação do que } \\
\text { para liderança em custo. }\end{array}$ & ,119 & 39 & ,180 & 9,941 & 39 &, 040 \\
\hline $\begin{array}{l}\text { Existe coerência entre a estratégia organizacional e a } \\
\text { estratégia de inovação. }\end{array}$ & ,167 & 39 & ,008 & ,931 & 39 & ,020 \\
\hline $\begin{array}{l}\text { Esta empresa busca ser a primeira a lançar novos } \\
\text { produtos e serviços no mercado. }\end{array}$ & ,167 & 39 & ,008 & ,931 & 39 & 019 \\
\hline $\begin{array}{l}\text { A empresa em que trabalho se caracteriza pela orientação } \\
\text { para o cliente. }\end{array}$ & ,196 & 39 & ,001 & ,915 & 39 & ,006 \\
\hline $\begin{array}{l}\text { A empresa em que trabalho sis tematicamente divulga } \\
\text { informações sobre inovação. }\end{array}$ & ,159 & 39 & ,014 & ,925 & 39 & ,013 \\
\hline $\begin{array}{l}\text { A empresa em que trabalho sistematicamente divulga } \\
\text { resultados obtidos com inovação. }\end{array}$ & ,203 & 39 & ,000 & ,912 & 39 & ,005 \\
\hline $\begin{array}{l}\text { A gerência de P\&D\&I é consultada quando da tomada de } \\
\text { decisões estratégicas. }\end{array}$ & ,156 & 39 & ,018 & ,939 & 39 & ,034 \\
\hline
\end{tabular}


LG

\begin{tabular}{|c|c|c|c|c|c|c|}
\hline \multicolumn{7}{|c|}{ Teste de Normalidade } \\
\hline & \multicolumn{3}{|c|}{ Kolmogorov-Smirnov } & \multicolumn{3}{|c|}{ Shapiro-Wilk } \\
\hline & Statistic & df & Sig. & Statistic & df & Sig. \\
\hline Os líderes de minha empresa apresentam predisposição para inovar. & ,147 & 39 & ,032 & ,916 & 39 &, 006 \\
\hline $\begin{array}{l}\text { Os líderes disseminam o intento de inovar por toda a organização de } \\
\text { maneira efetiva. }\end{array}$ & ,176 & 39 & ,004 & ,929 & 39 &, 017 \\
\hline $\begin{array}{l}\text { Os líderes inspiram as pessoas a se engajarem em atividades de } \\
\text { inovação. }\end{array}$ & ,180 & 39 & ,003 & ,922 & 39 & ,010 \\
\hline Os líderes fornecem estímulo intelectual para a solução de problemas. & ,223 & 39 & ,000 & ,906 & 39 &, 003 \\
\hline Os líderes apresentam tolerência à incerteza. & ,167 & 39 & ,008 & ,922 & 39 &, 010 \\
\hline Os líderes estimulam a interação criativa. & ,181 & 39 & ,002 & ,934 & 39 &, 023 \\
\hline O estilo de gestão desta empresa é participativo. & ,144 & 39 & ,040 & ,946 & 39 &, 060 \\
\hline Existe confiança no executivo que patrocina a inovação nesta empresa. & ,155 & 39 & ,019 & ,925 & 39 & ,013 \\
\hline $\begin{array}{l}\text { O executivo que patrocina a inovação na empresa assegura que os } \\
\text { projetos recebam assistência de todos os profissionais envolvidos. }\end{array}$ & ,214 & 39 & ,000 & ,910 & 39 & ,004 \\
\hline \begin{tabular}{|l|} 
Existe coerência entre as orientações fornecidas pelo executivo \\
responsável por inovação e pelos gerentes de projetos.
\end{tabular} & ,208 & 39 & ,000 & ,927 & 39 & ,015 \\
\hline $\begin{array}{l}\text { Os gerentes de projetos estimulam o desenvolvimento de competências } \\
\text { atreladas à inovação. }\end{array}$ & ,217 & 39 & ,000 & ,922 & 39 & ,010 \\
\hline $\begin{array}{l}\text { Os gerentes de projetos encorajam a proposição de novas maneiras de } \\
\text { fazer as coisas. }\end{array}$ & ,182 & 39 & ,002 & ,933 & 39 & ,022 \\
\hline $\begin{array}{l}\text { Riscos calculados são encarados de maneira positiva em minha } \\
\text { empresa. }\end{array}$ & ,147 & 39 & ,032 & ,918 & 39 & ,007 \\
\hline Aqui os erros também representam oportunidade de aprendizagem. & ,188 & 39 & ,001 & ,945 & 39 &, 055 \\
\hline $\begin{array}{l}\text { Nesta empresa entende-se que os conflitos também podem instigar a } \\
\text { inovação. }\end{array}$ & ,222 & 39 & ,000 & ,914 & 39 &, 006 \\
\hline
\end{tabular}

\section{PPGP}

\begin{tabular}{|c|c|c|c|c|c|c|}
\hline \multicolumn{7}{|c|}{ Teste de Normalidade } \\
\hline & \multicolumn{3}{|c|}{ Kolmogorov-Smirnov } & \multicolumn{3}{|c|}{ Shapiro-Wilk } \\
\hline & Statistic & $d f$ & Sig. & Statistic & $\mathrm{df}$ & Sig. \\
\hline $\begin{array}{l}\text { As políticas de gestão de pessoas desta empresa estão } \\
\text { alinhadas com a estratégia corporativa. }\end{array}$ & ,212 & 39 & 000 & ,925 & 39 & ,012 \\
\hline $\begin{array}{l}\text { As políticas de gestão de pessoas fomentam a inovação na } \\
\text { empresa. }\end{array}$ & ,156 & 39 & ,017 & ,949 & 39 & ,074 \\
\hline $\begin{array}{l}\text { As práticas de recrutamento e seleção desta empresa } \\
\text { contribuem para a contratação de bons profissionais de } \\
\text { P\&D\&I. }\end{array}$ & ,165 & 39 & ,009 & ,937 & 39 &, 030 \\
\hline $\begin{array}{l}\text { Há compromisso de longo prazo com treinamento e } \\
\text { desenvolvimento voltados para inovação. }\end{array}$ & ,173 & 39 & ,005 & ,919 & 39 & ,008 \\
\hline $\begin{array}{l}\text { O plano de carreira da empresa considera as necessidades } \\
\text { dos profissionais de P\&D\&l. }\end{array}$ & ,159 & 39 & ,015 & ,931 & 39 & ,019 \\
\hline $\begin{array}{l}\text { A inovação é considerada no(s) método(s) de avaliação de } \\
\text { desempenho humano. }\end{array}$ & ,179 & 39 & ,003 & ,937 & 39 & 031 \\
\hline $\begin{array}{l}\text { O sistema de recompensas desta empresa estimula o } \\
\text { engajamento dos funcionários em atividades de inovação. }\end{array}$ & ,185 & 39 & ,002 & $\begin{array}{ll}, 896 \\
\end{array}$ & 39 & ,002 \\
\hline $\begin{array}{l}\text { O trabalho em equipes multifuncionais é uma prática } \\
\text { amplamente utilizada em projetos P\&D\&I. }\end{array}$ & ,198 & 39 & ,001 & ,932 & 39 & ,021 \\
\hline $\begin{array}{l}\text { A gestão de talentos contribui para a retenção de } \\
\text { profissionais de P\&D\&l. }\end{array}$ & 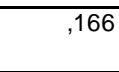 & 39 & ,008 & ,926 & 39 & 0,014 \\
\hline
\end{tabular}


CI

\begin{tabular}{|c|c|c|c|c|c|c|}
\hline \multicolumn{7}{|c|}{ Teste de Normalidade } \\
\hline & \multicolumn{3}{|c|}{ Kolmogorov-Smirnov } & \multicolumn{3}{|c|}{ Shapiro-Wilk } \\
\hline & Statistic & df & Sig. & Statistic & $\mathrm{df}$ & Sig. \\
\hline $\begin{array}{l}\text { Habilidade da empresa de identificar oportunidades de } \\
\text { melhoria com vistas à inovação }\end{array}$ & , 145 & 39 & ,038 & ,941 & 39 & ,040 \\
\hline $\begin{array}{l}\text { Habilidade da empresa de assimilar conhecimentos } \\
\text { adquiridos em projetos de P\&D\&I }\end{array}$ & ,143 & 39 & ,042 & ,949 & 39 & ,076 \\
\hline $\begin{array}{l}\text { Habilidade da empresa de compartilhar lições aprendidas } \\
\text { em projetos de P\&D\&I }\end{array}$ & ,141 & 39 & ,048 & ,953 & 39 &, 101 \\
\hline $\begin{array}{l}\text { Habilidade da empresa de alocar profissionais } \\
\text { provenientes de diferentes grupos funcionais no processo } \\
\text { de inovação }\end{array}$ & ,149 & 39 &, 029 & ,952 & 39 &, 094 \\
\hline $\begin{array}{l}\text { Habilidade da empresa de integrar diferentes grupos } \\
\text { funcionais envolvidos no processo de inovação }\end{array}$ & ,190 & 39 &, 001 & ,929 & 39 & ,017 \\
\hline
\end{tabular}




\section{Apêndice 5 - Matrizes de Correlação Adicionais}

\begin{tabular}{|c|c|c|c|c|c|c|c|}
\hline \multicolumn{8}{|c|}{ Correlação de Spearman entre "Filosofia, Valores e Normas" e "Capacidade Inovadora" } \\
\hline & & & $\begin{array}{c}\text { Habilidade da } \\
\text { empresa de } \\
\text { identificar } \\
\text { oportunidades } \\
\text { de melhoria } \\
\text { com vistas à } \\
\text { inovacăão }\end{array}$ & $\begin{array}{c}\text { Habilidade da } \\
\text { empresa de } \\
\text { assimilar } \\
\text { conhecimentos } \\
\text { adquiridos em } \\
\text { projetos de } \\
\text { P\&D\&I }\end{array}$ & $\begin{array}{c}\text { Habilidade da } \\
\text { empresa de } \\
\text { compartilhar } \\
\text { liçöes } \\
\text { aprendidas em } \\
\text { projetos de } \\
P \& D \& 1\end{array}$ & $\begin{array}{c}\text { Habilidade da } \\
\text { empresa de } \\
\text { alocar } \\
\text { profissionais } \\
\text { provenientes de } \\
\text { diferentes grupos } \\
\text { funcionais no } \\
\text { processo de } \\
\text { inovação }\end{array}$ & $\begin{array}{l}\text { Habilidade da } \\
\text { empresa de } \\
\text { integrar } \\
\text { diferentes } \\
\text { grupos } \\
\text { funcionais } \\
\text { envolvidos no } \\
\text { processo de } \\
\text { inovacaão }\end{array}$ \\
\hline \multirow{33}{*}{\begin{tabular}{|l} 
Spearmat \\
's rho
\end{tabular}} & \multirow{3}{*}{ Inovar faz parte da razão de exisitr desta empresa. } & Correlation Coefficient & $0,419^{*}$ & $0,554^{*}$ & $0,568^{*}$ & 305 & $0,54^{*}$ \\
\hline & & Sig. (2-tailed) & ,008 &, 000 & ,000 &, 059 &, 000 \\
\hline & & & 39 & 39 & 39 & 39 & \\
\hline & \multirow{3}{*}{$\begin{array}{l}\text { A declaraçäo de visão reforça o propósito de inovar desta } \\
\text { empresa. }\end{array}$} & Correlation Coefficient & $0,345^{*}$ & $0,401^{*}$ & $0,387^{*}$ & 137 & ,231 \\
\hline & & Sig. (2-tailed) & 032 & ,012 & 015 &, 405 & ,157 \\
\hline & & $\mathrm{N}$ & 39 & 39 & 39 & 39 & 39 \\
\hline & \multirow[t]{3}{*}{ Inovação é um valor central desta empresa. } & Correlation Coefficient & $0,477^{*}$ & $0,594^{*}$ & $0,444^{*}$ & $\overline{0,393^{*}}$ & $\overline{0,604^{*}}$ \\
\hline & & Sig. (2-tailed) & ,002 & ,000 & ,005 & ,013 & 000 \\
\hline & & $\mathrm{N}$ & 39 & 39 & 39 & 39 & 39 \\
\hline & \multirow[t]{3}{*}{ Flexibilidade é indispensável para inovação. } & Correlation Coefficient & ,088 & ,153 &,- 035 & ,156 & 267 \\
\hline & & Sig. (2-tailed) & ,595 & ,353 & ,832 & 343 & ,101 \\
\hline & & $\mathrm{N}$ & 39 & 39 & 39 & 39 & \\
\hline & \multirow[t]{3}{*}{ Colaboração é indispensável para inovação. } & Correlation Coefficient & , 109 & ,189 & ,070 & ,129 & ,170 \\
\hline & & Sig. (2-tailed) & ,510 & ,250 & ,672 &, 435 & ,302 \\
\hline & & $\mathrm{N}$ & 39 & 39 & 39 & 39 & 39 \\
\hline & \multirow[t]{3}{*}{ Comunicação ampla é indispensável para inovação. } & Correlation Coefficient & ,067 & ,108 & ,030 & ,084 & ,133 \\
\hline & & Sig. (2-tailed) & 687 &, 515 & 855 &, 610 & 420 \\
\hline & & $\mathrm{N}$ & 39 & 39 & 39 & 39 & \\
\hline & \multirow{3}{*}{ Criatividade é indispensável para inovação. } & Correlation Coefficient & ,203 & ,097 & ,132 & ,247 & 219 \\
\hline & & Sig. (2-tailed) & ,215 &, 558 & ,422 &, 130 & 180 \\
\hline & & $\mathrm{N}$ & 39 & 39 & 39 & 39 & 39 \\
\hline & \multirow[t]{3}{*}{ Aprendizageme é indispensável para inovação. } & Correlation Coefficient & ,092 & ,142 &,- 050 & ,039 & ,088 \\
\hline & & Sig. (2-tailed) & ,577 & ,390 & ,763 & ,814 & 596 \\
\hline & & $\mathrm{N}$ & 39 & 39 & 39 & 39 & 1 \\
\hline & \multirow[t]{3}{*}{ Conhecimento é indispensável para inovação. } & Correlation Coefficient & , 186 & ,224 & $-0,026$ & ,112 & ,150 \\
\hline & & Sig. (2-tailed) & ,257 & ,171 & ,873 & ,497 & ,361 \\
\hline & & $\mathrm{N}$ & 39 & 39 & 39 & 39 & \\
\hline & \multirow[t]{3}{*}{ Diversidade é indispensável para inovação. } & Correlation Coefficient &,- 021 & ,017 &,- 076 &,- 025 & ,043 \\
\hline & & Sig. (2-tailed) & 899 & ,919 & ,645 & ,882 & 795 \\
\hline & & $\mathrm{N}$ & 39 & 39 & 39 & 39 & 39 \\
\hline & \multirow[t]{3}{*}{ As normas orientam adequadamente o propósito de inovar. } & Correlation Coefficient & $0,441^{*}$ & ,315 & $0,34^{*}$ & $0,321^{*}$ & $0,408^{*}$ \\
\hline & & Sig. (2-tailed) & ,005 & ,051 & ,034 & ,046 & 010 \\
\hline & & $\mathrm{N}$ & 39 & 39 & 39 & 39 & 39 \\
\hline
\end{tabular}




\begin{tabular}{|c|c|c|c|c|c|c|c|}
\hline \multicolumn{8}{|c|}{ Correlação de Spearman entre "Foco Estratégico e Inovativo" e "Capacidade Inovadora" } \\
\hline & & & $\begin{array}{c}\text { Habilidade da } \\
\text { empresa de } \\
\text { identificar } \\
\text { oportunidades de } \\
\text { melhoria com } \\
\text { vistas à inovação }\end{array}$ & $\begin{array}{l}\text { Habilidade da } \\
\text { empresa de } \\
\text { assimilar } \\
\text { conhecimentos } \\
\text { adquiridos em } \\
\text { projetos de P\&D\&I }\end{array}$ & \begin{tabular}{|c|} 
Habilidade da \\
empresa de \\
compartilhar \\
lições \\
aprendidas em \\
projetos de \\
P\&D\&I
\end{tabular} & $\begin{array}{c}\text { Habilidade da } \\
\text { empresa de alocar } \\
\text { profissionais } \\
\text { provenientes de } \\
\text { diferentes grupos } \\
\text { funcionais no } \\
\text { processo de inovação }\end{array}$ & $\begin{array}{c}\text { Habilidade da } \\
\text { empresa de } \\
\text { integrar diferentes } \\
\text { grupos funcionais } \\
\text { envolvidos no } \\
\text { processo de } \\
\text { inovação }\end{array}$ \\
\hline \multirow{24}{*}{$\begin{array}{l}\text { Spearman } \\
\text { 's rho }\end{array}$} & \multirow{3}{*}{$\begin{array}{l}\text { A inovação está arraigada em nosso modelo de } \\
\text { negócio. }\end{array}$} & Correlation Coefficient & $0,461^{\star}$ & $0,466^{\star}$ & $0,498^{\star}$ & $0,373^{*}$ & $0,481^{*}$ \\
\hline & & Sig. (2-tailed) &, 003 &, 003 & ,001 & ,019 &, 002 \\
\hline & & $\bar{N}$ & 39 & 39 & 39 & 39 & 39 \\
\hline & \multirow{3}{*}{$\begin{array}{l}\text { Esta empresa é mais orientada para diferenciação } \\
\text { do que para liderança em custo. }\end{array}$} & Correlation Coefficient & $0,289^{\star \star}$ & $0,456^{*}$ & $0,479^{\star}$ & ,263 & $0,469^{*}$ \\
\hline & & Sig. (2-tailed) & 074 & 004 & ,002 & ,105 & ,003 \\
\hline & & $\mathrm{N}$ & 39 & 39 & 39 & 39 & 39 \\
\hline & \multirow{3}{*}{$\begin{array}{l}\text { Existe coerência entre a estratégia organizacional } \\
\text { e a estratégia de inovação. }\end{array}$} & Correlation Coefficient & ,416 & $0,567^{\star}$ & $0,489^{\star}$ & $0,412^{*}$ & $0,460^{*}$ \\
\hline & & Sig. (2-tailed) & ,008 & ,000 & ,002 & ,009 &, 003 \\
\hline & & $\mathrm{N}$ & 39 & 39 & 39 & 39 & 39 \\
\hline & \multirow{3}{*}{$\begin{array}{l}\text { Esta empresa busca ser a primeira a lançar novos } \\
\text { produtos e serviços no mercado. }\end{array}$} & Correlation Coefficient & $0,346^{*}$ & $0,431^{\star}$ & $0,443^{*}$ & 142 & $0,393^{*}$ \\
\hline & & Sig. (2-tailed) & ,031 &, 006 & ,005 & ,389 & 013 \\
\hline & & $\mathrm{N}$ & 39 & 39 & 39 & 39 & 39 \\
\hline & \multirow{3}{*}{$\begin{array}{l}\text { A empresa em que trabalho se caracteriza pela } \\
\text { orientação para o cliente. }\end{array}$} & Correlation Coefficient & ,195 & ,243 & ,217 & \begin{tabular}{|l|}
,- 013 \\
\end{tabular} & ,149 \\
\hline & & Sig. (2-tailed) & ,235 & ,136 & ,185 & (937 & ,364 \\
\hline & & $\bar{N}$ & 39 & 39 & 39 & 39 & 39 \\
\hline & \multirow{3}{*}{$\begin{array}{l}\text { A empresa em que trabalho sistematicamente } \\
\text { divulga informações sobre inovação. }\end{array}$} & Correlation Coefficient & $0,361^{\star}$ & $0,550^{\star}$ & $0,366^{\star}$ & $0,330^{*}$ & $0,455^{\star}$ \\
\hline & & Sig. (2-tailed) & ,024 &, 000 & ,022 & ,040 &, 004 \\
\hline & & $\mathrm{N}$ & 39 & 39 & 39 & 39 & 39 \\
\hline & \multirow{3}{*}{$\begin{array}{l}\text { A empresa em que trabalho sistematicamente } \\
\text { divulga resultados obtidos com inovação. }\end{array}$} & Correlation Coefficient & $0,418^{*}$ & $0,509^{\star}$ & $0,390^{\star}$ & $0,334^{\star}$ & $0,483^{*}$ \\
\hline & & Sig. (2-tailed) & ,008 & ,001 & ,014 & ,038 & ,002 \\
\hline & & $\mathrm{N}$ & 39 & 39 & 39 & 39 & 39 \\
\hline & \multirow{3}{*}{$\begin{array}{l}\text { A gerência de P\&D\&l é consultada quando da } \\
\text { tomada de decisóes estratégicas. }\end{array}$} & Correlation Coefficient & $0,463^{\star}$ & $0,538^{\star}$ & $0,316^{*}$ & ,265 &, 264 \\
\hline & & Sig. (2-tailed) & ,003 &, 000 & ,050 & , 103 &, 105 \\
\hline & & $\mathrm{N}$ & 39 & 39 & 39 & 39 & 39 \\
\hline
\end{tabular}




\begin{tabular}{|c|c|c|c|c|c|c|c|}
\hline \multicolumn{8}{|c|}{ Correlação de Spearman entre "Liderança e Gestäo" e "Capacidade Inovadora" } \\
\hline & & & \begin{tabular}{|c|} 
Habilidade da \\
empresa de identificar \\
oportunidades de \\
melhoria com vistas à \\
inovação \\
\end{tabular} & $\begin{array}{c}\text { Habilidade da } \\
\text { empresa de assimilar } \\
\text { conhecimentos } \\
\text { adquiridos em } \\
\text { projetos de P\&D\&I } \\
\end{array}$ & $\begin{array}{l}\text { Habilidade da } \\
\text { empresa de } \\
\text { compartihar } \\
\text { liçoses } \\
\text { aprendidas em } \\
\text { projetos de } \\
\text { P\&D\&I }\end{array}$ & $\begin{array}{l}\text { Habilidade da empresa de } \\
\text { alocar profissionais } \\
\text { provenientes de diferentes } \\
\text { grupos funcionais no } \\
\text { processo de inovação }\end{array}$ & \begin{tabular}{|c} 
Habilidade da \\
empresa de \\
integrar \\
diferentes grupos \\
funcionais \\
envolvidos no \\
processo de \\
inovação \\
\end{tabular} \\
\hline \multirow{45}{*}{$\begin{array}{l}\text { Spearman } \\
\text { 's rho }\end{array}$} & \multirow{3}{*}{$\begin{array}{l}\text { Os líderes de minha empresa apresentam } \\
\text { predisposição para inovar. }\end{array}$} & Correlation Coefficient & $0,460^{*}$ & $0,708^{*}$ & $0,568^{*}$ & $0,437^{*}$ & $0,566^{*}$ \\
\hline & & Sig. (2-tailed) & ,003 &, 000 &, 000 & 005 & 000 \\
\hline & & $\mathrm{N}$ & 39 & 39 & 39 & 39 & 39 \\
\hline & \multirow{3}{*}{$\begin{array}{l}\text { Os líderes disseminam o intento de inovar por } \\
\text { toda a organização de maneira efetiva. }\end{array}$} & Correlation Coefficient & $0,363^{*}$ & $0,598^{*}$ & $0,523^{*}$ & ,251 & $0,422^{*}$ \\
\hline & & Sig. (2-tailed) & ,023 &, 000 & ,001 & ,124 & ,007 \\
\hline & & $\mathrm{N}$ & 39 & 39 & 39 & 39 & 39 \\
\hline & \multirow{3}{*}{$\begin{array}{l}\text { Os lideres inspiram as pessoas a se engajarem } \\
\text { em atividades de inovação. }\end{array}$} & Correlation Coefficient & $0,486^{*}$ & $0,641^{*}$ & $\overline{0,447^{*}}$ & $0,352^{*}$ & $0,562^{*}$ \\
\hline & & Sig. (2-tailed) & ,002 &, 000 & 004 & ,028 &, 000 \\
\hline & & $\mathrm{N}$ & 39 & 39 & 39 & 39 & 39 \\
\hline & \multirow{3}{*}{$\begin{array}{l}\text { Os lideres fornecem estímulo intelectual para a } \\
\text { solução de problemas. }\end{array}$} & Correlation Coefficient & $0,479^{*}$ & $0,668^{*}$ & $0,478^{*}$ & $0,386^{*}$ & $0,438^{*}$ \\
\hline & & Sig. (2-tailed) & ,002 &, 000 &, 002 &, 015 &, 005 \\
\hline & & $N$ & 39 & 39 & 39 & 39 & 39 \\
\hline & \multirow[t]{3}{*}{ Os líderes apresentam tolerência à incerteza. } & \begin{tabular}{|l|} 
Correlation Coefficient \\
\end{tabular} & $0,383^{*}$ & $0,620^{*}$ & $0,429^{*}$ & $0,335^{*}$ & $0,437^{*}$ \\
\hline & & Sig. (2-tailed) & ,016 &, 000 &, 006 & ,037 &, 005 \\
\hline & & $\mathrm{N}$ & 39 & 39 & 39 & 39 & 39 \\
\hline & \multirow[t]{3}{*}{ Os lideres estimulam a interaçāo criativa. } & \begin{tabular}{|l|} 
Correlation Coefficient \\
\end{tabular} & $0,552^{*}$ & $0,636^{*}$ & $\overline{0,433^{*}}$ & $0,404^{*}$ & $\overline{0,482^{*}}$ \\
\hline & & Sig. (2-tailed) & ,000 &, 000 & ,006 & ,011 & ,002 \\
\hline & & $\mathrm{N}$ & 39 & 39 & 39 & 39 & 39 \\
\hline & \multirow[t]{3}{*}{ O estilo de gestão desta empresa é participativo. } & Correlation Coefficient & ,206 & $0,570^{*}$ & ,252 & ,160 & $0,385^{*}$ \\
\hline & & \begin{tabular}{|l|l|} 
Sig. (2-tailed) \\
\end{tabular} & 208 &, 000 &, 122 & 329 & 016 \\
\hline & & $\mathrm{N}$ & 39 & 39 & 39 & 39 & 39 \\
\hline & \multirow{3}{*}{$\begin{array}{l}\text { Existe confiança no executivo que patrocina a } \\
\text { inovação nesta empresa. }\end{array}$} & \begin{tabular}{|l|} 
Correlation Coefficient \\
\end{tabular} & $0,442^{*}$ & $0,434^{*}$ & $0,336^{*}$ & $0,462^{*}$ & $0,325^{*}$ \\
\hline & & \begin{tabular}{|l} 
Sig. (2-tailed) \\
\end{tabular} & ,005 &, 006 & 037 & 003 &, 044 \\
\hline & & $\mathrm{N}$ & 39 & 39 & 39 & 39 & 39 \\
\hline & \multirow{3}{*}{$\begin{array}{l}\text { Oexecutivo que patrocina a inovação na } \\
\text { empresa assegura que os projetos recebam } \\
\text { assistência de todos os profissionais envolvidos. }\end{array}$} & Correlation Coefficient & $0,514^{*}$ & $0,639^{*}$ & $0,348^{*}$ & $0,409^{*}$ & $0,536^{*}$ \\
\hline & & \begin{tabular}{|l} 
Sig. (2-tailed) \\
\end{tabular} & 001 & ,000 & ,030 &, 010 &, 000 \\
\hline & & $\mathrm{N}$ & 39 & 39 & 39 & 39 & 39 \\
\hline & \multirow{3}{*}{$\begin{array}{l}\begin{array}{l}\text { Existe coerência entre as orientaçōes fornecidas } \\
\text { pelo executivo responsável por inovação e pelos } \\
\text { gerentes de projetos. }\end{array} \\
\end{array}$} & Correlation Coefficient & $0,581^{*}$ & $0,512^{\star}$ & $0,416^{*}$ & $0,460^{*}$ & $0,399^{*}$ \\
\hline & & \begin{tabular}{|l} 
Sig. (2-tailed) \\
\end{tabular} & 000 & ,001 & 008 &, 003 &, 012 \\
\hline & & $\mathrm{N}$ & 39 & 39 & 39 & 39 & 39 \\
\hline & \multirow{3}{*}{\begin{tabular}{|l|}
$\begin{array}{l}\text { Os gerentes de projetos estimulam o } \\
\text { desenviolvimento de competências atreladas à } \\
\text { inovaçâa. }\end{array}$ \\
\end{tabular}} & Correlation Coefficient & $0,590^{*}$ & $0,698^{*}$ & $0,409^{*}$ & $0,453^{*}$ & $0,555^{*}$ \\
\hline & & \begin{tabular}{|l} 
Sig. (2-tailed) \\
\end{tabular} & ,000 &, 000 &, 010 & ,004 &, 000 \\
\hline & & $\mathrm{N}$ & 39 & 39 & 39 & 39 & 39 \\
\hline & \multirow{3}{*}{$\begin{array}{l}\text { Os gerentes de projetos encorajam a proposição } \\
\text { de novas maneiras de fazer as coisas. }\end{array}$} & Correlation Coefficient & $0,560^{*}$ & $0,710^{*}$ & $0,462^{*}$ & ,295 & $0,583^{*}$ \\
\hline & & \begin{tabular}{|l} 
Sig. (2-tailed) \\
\end{tabular} & ,000 &, 000 & ,003 & ,069 &, 000 \\
\hline & & $\mathrm{N}$ & 39 & 39 & 39 & 39 & 39 \\
\hline & \multirow{3}{*}{$\begin{array}{l}\text { Riscos calculados são encarados de maneira } \\
\text { positiva em minha empresa. }\end{array}$} & Correlation Coefficient & $0,346^{*}$ & $0,578^{*}$ & $0,345^{*}$ & $0,272^{*+*}$ & $0,387^{*}$ \\
\hline & & Sig. (2-tailed) & ,031 &, 000 & ,031 & 094 &, 015 \\
\hline & & $N$ & 39 & 39 & 39 & 39 & 39 \\
\hline & \multirow{3}{*}{$\begin{array}{l}\text { Aqui os erros também representam oportunidade } \\
\text { de aprendizagem. }\end{array}$} & Correlation Coefficient & $0,346^{*}$ & $0,596^{*}$ & $0,431^{*}$ & ,214 & $0,380^{*}$ \\
\hline & & \begin{tabular}{|l} 
Sig. (2-tailed) \\
\end{tabular} & ,031 & ,000 & 006 & ,192 & ,017 \\
\hline & & $\mathrm{N}$ & \begin{tabular}{l|l}
39 \\
\end{tabular} & 39 & 39 & 39 & 39 \\
\hline & \multirow{3}{*}{$\begin{array}{l}\text { Nesta empresa entende-se que os conflitos } \\
\text { também podem instigar a inovação. }\end{array}$} & Correlation Coefficient & $0,625^{*}$ & $\overline{0,634^{*}}$ & $0,411^{*}$ & $0,362^{*}$ & $0,583^{*}$ \\
\hline & & \begin{tabular}{|l} 
Sig. (2-tailed) \\
\end{tabular} & ,000 & ,000 & ,009 & ,023 &, 000 \\
\hline & & $\mathrm{N}$ & 39 & 39 & 39 & 39 & 39 \\
\hline
\end{tabular}




\begin{tabular}{|c|c|c|c|c|c|c|c|}
\hline \multicolumn{8}{|c|}{ Correlação de Spearman entre "Políticas e Práticas de Gestão de Pessoas" e "Capacidade Inovadora" } \\
\hline & & & \begin{tabular}{|c|} 
Habilidade da \\
empresa de \\
identificar \\
oportunidades de \\
melhoria com vistas \\
à inovação \\
\end{tabular} & $\begin{array}{l}\text { Habilidade da } \\
\text { empresa de } \\
\text { assimilar } \\
\text { conhecimentos } \\
\text { adquiridos em } \\
\text { projetos de P\&D\&I }\end{array}$ & \begin{tabular}{|c|} 
Habilidade da \\
empresa de \\
compartilhar \\
lições aprendidas \\
em projetos de \\
$P \& D \& I$ \\
\end{tabular} & $\begin{array}{c}\text { Habilidade da } \\
\text { empresa de alocar } \\
\text { profissionais } \\
\text { provenientes de } \\
\text { diferentes grupos } \\
\text { funcionais no } \\
\text { processo de } \\
\text { inovação }\end{array}$ & $\begin{array}{c}\text { Habilidade da } \\
\text { empresa de } \\
\text { integrar diferentes } \\
\text { grupos funcionais } \\
\text { envolvidos no } \\
\text { processo de } \\
\text { inovação }\end{array}$ \\
\hline \multirow{27}{*}{$\begin{array}{l}\text { Spearman } \\
\text { 's rho }\end{array}$} & \multirow{3}{*}{$\begin{array}{l}\text { As políticas de gestão de pessoas } \\
\text { desta empresa estão alinhadas com } \\
\text { a estratégia corporativa. }\end{array}$} & Correlation Coefficient & $0,317^{\star \star}$ & $0,473^{*}$ & $0,352^{*}$ & $0,296^{\star \star *}$ & $0,310^{\star \star}$ \\
\hline & & Sig. (2-tailed) & ,049 & 002 & ,028 & ,067 & ,055 \\
\hline & & $\mathrm{N}$ & 39 & 39 & 39 & 39 & 39 \\
\hline & \multirow{3}{*}{$\begin{array}{l}\text { As políticas de gestão de pessoas } \\
\text { fomentam a inovação na empresa. }\end{array}$} & Correlation Coefficient & $0,489^{*}$ & $0,473^{*}$ & $0,534^{\star}$ & $0,441^{*}$ & $0,379^{*}$ \\
\hline & & Sig. (2-tailed) & ,002 & ,002 & ,000 & ,005 & ,017 \\
\hline & & $\mathrm{N}$ & 39 & 39 & 39 & 39 & 39 \\
\hline & \multirow{3}{*}{$\begin{array}{l}\text { As práticas de recrutamento e } \\
\text { seleção desta empresa contribuem } \\
\text { para a contratação de bons } \\
\text { profissionais de } P \& D \& I .\end{array}$} & Correlation Coefficient & $0,398^{*}$ & $0,395^{\star}$ & $0,373^{\star}$ & $0,496^{*}$ & $0,462^{\star}$ \\
\hline & & Sig. (2-tailed) & ,012 & ,013 & ,019 & ,001 &, 003 \\
\hline & & $N$ & 39 & 39 & 39 & 39 & 39 \\
\hline & \multirow{3}{*}{$\begin{array}{l}\text { Há compromisso de longo prazo com } \\
\text { treinamento e desenvolvimento } \\
\text { voltados para inovação. }\end{array}$} & Correlation Coefficient & $0,535^{\star}$ & $0,552^{\star}$ & $0,573^{\star}$ & $0,377^{*}$ & $0,479^{*}$ \\
\hline & & Sig. (2-tailed) & ,000 & ,000 & ,000 & ,018 &, 002 \\
\hline & & $\bar{N}$ & 39 & 39 & 39 & 39 & 39 \\
\hline & \multirow{3}{*}{$\begin{array}{l}\text { O plano de carreira da empresa } \\
\text { considera as necessidades dos } \\
\text { profissionais de P\&D\&I. }\end{array}$} & Correlation Coefficient & $0,438^{*}$ & $0,422^{*}$ & $0,351^{\star}$ & $0,367^{*}$ & $0,416^{*}$ \\
\hline & & Sig. (2-tailed) & ,005 & ,007 & ,028 & ,022 & ,008 \\
\hline & & $\bar{N}$ & 39 & 39 & 39 & 39 & 39 \\
\hline & \multirow{3}{*}{$\begin{array}{l}\text { A inovação é considerada no(s) } \\
\text { método(s) de avaliação de } \\
\text { desempenho humano. }\end{array}$} & Correlation Coefficient & $0,593^{*}$ & $0,455^{*}$ & $0,301^{\star \star}$ & $0,397^{\star}$ & $0,507^{*}$ \\
\hline & & Sig. (2-tailed) & , 000 & ,004 & ,063 & 012 & ,001 \\
\hline & & $\mathrm{N}$ & 39 & 39 & 39 & 39 & 39 \\
\hline & \multirow{3}{*}{$\begin{array}{l}\text { O sistema de recompensas desta } \\
\text { empresa estimula o engajamento dos } \\
\text { funcionários em atividades de } \\
\text { inovação. }\end{array}$} & Correlation Coefficient & $0,522^{*}$ & $0,551^{*}$ & $0,513^{*}$ & $0,458^{*}$ & $0,463^{*}$ \\
\hline & & Sig. (2-tailed) & ,001 &, 000 & ,001 & ,003 &, 003 \\
\hline & & $\bar{N}$ & 39 & 39 & 39 & 39 & 39 \\
\hline & \multirow{3}{*}{$\begin{array}{l}\text { O trabalho em equipes } \\
\text { multifuncionais é uma prática } \\
\text { amplamente utilizada em projetos de } \\
\text { P\&D\&l. }\end{array}$} & Correlation Coefficient & $0,462^{*}$ & $0,426^{*}$ & $0,364^{*}$ & $0,406^{*}$ & $0,456^{*}$ \\
\hline & & Sig. (2-tailed) & ,003 & ,007 & ,023 & ,010 &, 004 \\
\hline & & $\bar{N}$ & 39 & 39 & 39 & 39 & 39 \\
\hline & \multirow{3}{*}{$\begin{array}{l}\text { A gestão de talentos contribui para a } \\
\text { retenção de profissionais de } P \& D \& I .\end{array}$} & Correlation Coefficient & $0,515^{*}$ & $0,362^{*}$ & $0,392^{*}$ & $0,419^{\star}$ & $0,314^{\star \star}$ \\
\hline & & Sig. (2-tailed) & ,001 & ,023 & ,013 & ,008 & ,051 \\
\hline & & $\mathrm{N}$ & 39 & 39 & 39 & 39 & 39 \\
\hline
\end{tabular}


ANEXOS

Anexo 1 - Produto Interno Bruto e Participação das Grandes Regiões e Unidades da Federação

\begin{tabular}{|c|c|c|}
\hline \multirow{2}{*}{$\begin{array}{c}\text { Grandes Regiões e } \\
\text { Unidades da Federação }\end{array}$} & \multicolumn{2}{|c|}{ Produto Interno Bruto } \\
\hline & Valor corrente (1 $000000 \mathrm{R} \$)$ & Participação (\%) \\
\hline Brasil & 4392094 & 100,0 \\
\hline Norte & 231.383 & 5,3 \\
\hline Rondônia & 29.362 & 0,7 \\
\hline Acre & 9.629 & 0,2 \\
\hline Amazonas & 64.120 & 1,5 \\
\hline Roraima & 7.314 & 0,2 \\
\hline Pará & 91.009 & 2,1 \\
\hline Amapá & 10.420 & 0,2 \\
\hline Tocantins & 19.530 & 0,4 \\
\hline Nordeste & 595.382 & 13,6 \\
\hline Maranhão & 58.820 & 1,3 \\
\hline Piauí & 25.721 & 0,6 \\
\hline Ceará & 90.132 & 2,1 \\
\hline Rio Grande do Norte & 39.544 & 0,9 \\
\hline Paraíba & 38.731 & 0,9 \\
\hline Pernambuco & 117.340 & 2,7 \\
\hline Alagoas & 29.545 & 0,7 \\
\hline Sergipe & 27.823 & 0,6 \\
\hline Bahia & 167.727 & 3,8 \\
\hline Sudeste & 2.424.005 & 55,2 \\
\hline Minas Gerais & 403.551 & 9,2 \\
\hline Espírito Santo & 107.329 & 2,4 \\
\hline Rio de Janeiro & 504.221 & 11,5 \\
\hline São Paulo & 1.408 .904 & 32,1 \\
\hline Sul & 710.860 & 16,2 \\
\hline Paraná & 255.927 & 5,8 \\
\hline Santa Catarina & 177.276 & 4,0 \\
\hline Rio Grande do Sul & 277.658 & 6,3 \\
\hline Centro-Oeste 4304639,8 & 430.463 & 9,8 \\
\hline Mato Grosso do Sul & 54.471 & 1,2 \\
\hline Mato Grosso & 80.830 & 1,8 \\
\hline Goiás & 123.926 & 2,8 \\
\hline Distrito Federal & 171.236 & 3,9 \\
\hline
\end{tabular}

Fonte: IBGE, em parceria com os Órgãos Estaduais de Estatística, Secretarias Estaduais de Governo e Superintendência da Zona Franca de Manaus - SUFRAMA.

FONTE: IBGE, 2014. 


\section{Anexo 2 - Critério para Classificação das Empresas por Porte, com Base na Receita}

\section{Operacional Bruta}

\begin{tabular}{|c|c|}
\hline Porte & Receita operacional bruta anual \\
\hline Microempresa & Menor ou igual a $\mathrm{R} \$ 2,4$ milhões \\
\hline Pequena empresa & $\begin{array}{l}\text { Maior que R\$ } 2,4 \text { milhões e menor ou igual a } \mathrm{R} \$ \\
16 \text { milhões }\end{array}$ \\
\hline Média empresa & $\begin{array}{l}\text { Maior que R\$ } 16 \text { milhões e menor ou igual a R\$ } \\
90 \text { milhões }\end{array}$ \\
\hline Média-grande empresa & $\begin{array}{l}\text { Maior que R } \$ 90 \text { milhões e menor ou igual a R\$ } \\
300 \text { milhões }\end{array}$ \\
\hline Grande empresa & Maior que R\$ 300 milhões \\
\hline
\end{tabular}

Entende-se por receita operacional bruta anual a receita auferida no ano-calendário com:

- $\quad$ o produto da venda de bens e serviços nas operações de conta própria;

- o preço dos serviços prestados; e

- o resultado nas operações em conta alheia, não incluídas as vendas canceladas e os descontos incondicionais concedidos.

FONTE: BNDES, 2014a. 


\section{Anexo 3 - Caracterização de Empresas Industriais dos Estados do Paraná e Espírito Santo}

Empresas industriais participantes da Pesquisa de Inovação 2011.

\section{Paraná}

Número de empresas do universo da pesquisa

\subsection{8}

Número de empresas inovadoras em produto ou processo no período 2009-2011

Taxa de inovação de produto ou processo no período 2009-2011

Número de empresas inovadoras em produto no período 2009-2011

Taxa de inovação de produto no período 2009-2011

Número de empresas inovadoras em processo

Taxa de inovação de processo no período 2009-2011

Número de empresas que tiveram dispêndio com Pesquisa e Desenvolvimento internos em 2011

Taxa de incidência de empresas que tiveram dispêndio em Pesquisa e Desenvolvimento internos

Dispêndio em inovação em 2011

Relação entre dispêndio em inovação e receita líquida de vendas em 2011

Dispêndio em Pesquisa e Desenvolvimento internos em 2011

Relação entre dispêndio em Pesquisa e Desenvolvimento internos e receita líquida de vendas em 2011

Pessoal ocupado nas empresas que tiveram dispêndio em Pesquisa e Desenvolvimento internos em 2011

4,3

empresas

$\%$

\section{R\$} $\%$

0,52

1000 R\$

$\%$

pessoas 


\section{Espírito Santo}

Número de empresas do universo da pesquisa

Número de empresas inovadoras em produto ou processo no período 2009-2011

641

Taxa de inovação de produto ou processo no período 2009-2011

Número de empresas inovadoras em produto no período 2009-2011

Taxa de inovação de produto no período 2009-2011

307

Número de empresas inovadoras em processo

13,2

Taxa de inovação de processo no período 2009-2011

509

21,9

Número de empresas que tiveram dispêndio com Pesquisa e Desenvolvimento internos em 2011

Taxa de incidência de empresas que tiveram dispêndio em Pesquisa e Desenvolvimento internos

Dispêndio em inovação em 2011

Relação entre dispêndio em inovação e receita líquida de vendas em 2011

1,82

Dispêndio em Pesquisa e Desenvolvimento internos em 2011

Relação entre dispêndio em Pesquisa e Desenvolvimento internos e receita líquida de vendas em 2011

0,22

Pessoal ocupado nas empresas que tiveram dispêndio em Pesquisa e Desenvolvimento internos em 2011

\section{$\%$}

empresas $\%$

empresas

$\%$

$1000 \mathrm{R} \$$

$\%$

1000 R\$ $\%$

pessoas

Fonte: IBGE, 2014. 